

\section{BRICS Education}

Volume 2

\section{Critical Issues in South African Education}

Illumination from international comparative perspectives from the BRICS countries 


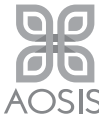

Published by AOSIS Books, an imprint of AOSIS Publishing.

\section{AOSIS Publishing}

15 Oxford Street, Durbanville 7550, Cape Town, South Africa

Postnet Suite \#110, Private Bag X19, Durbanville 7551, South Africa

Tel: +27 219752602

Website: https://www.aosis.co.za

Copyright (c) Charl C. Wolhuter (ed.). Licensee: AOSIS (Pty) Ltd

The moral right of the authors has been asserted.

Cover image: Original design created with the use of free image. Free images used: https:// pixabay.com/vectors/south-africa-flag-national-flag-162425/, https://pixabay.com/ vectors/russia-flag-national-flag-nation-162400/, https://pixabay.com/vectors/brazil-flagcountry-symbol-green-305531/, https://pixabay.com/vectors/india-flag-indian-nationalcountry-26828/, https://pixabay.com/vectors/china-people-s-republic-of-china-162389/ is released under Pixabay License, and https://www.pexels.com/photo/atlas-close-up-darkdirty-592753/ used under the Pexels Licence.

Published in 2020

Impression: 1

ISBN: 978-1-928523-61-1 (print)

ISBN: 978-1-928523-62-8 (epub)

ISBN: 978-1-928523-63-5 (pdf)

DOI: https://doi.org/10.4102/aosis.2020.BK207

How to cite this work: Wolhuter, C.C. (ed.), 2020, 'Critical Issues in South African Education: Illumination from international comparative perspectives from the BRICS countries', in BRICS Education Volume 2, pp. i-376, AOSIS, Cape Town.

BRICS Education

ISSN: 2709-3654

Series Editors: Z.L. de Beer \& E.L. Niemczyk

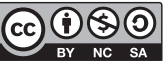

Printed and bound in South Africa.

Listed in OAPEN (http://www.oapen.org), DOAB (http://www.doabooks.org/) and indexed by Google Scholar. Some rights reserved.

This is an open access publication. Except where otherwise noted, this work is distributed under the terms of a Creative Commons Attribution-NonCommercial-ShareAlike 4.0 International license (CC BY-NC-SA 4.0), a copy of which is available at https:// creativecommons.org/licenses/by-nc-sa/4.0/. Enquiries outside the terms of the Creative Commons licence should be sent to the Rights Department, AOSIS, at the above address or to publishing@aosis.co.za

The publisher accepts no responsibility for any statement made or opinion expressed in this publication. Consequently, the publishers and copyright holder will not be liable for any loss or damage sustained by any reader as a result of his or her action upon any statement or opinion in this work. Links by third-party websites are provided by AOSIS in good faith and for information only. AOSIS disclaims any responsibility for the materials contained in any third-party website referenced in this work.

Every effort has been made to protect the interest of copyright holders. Should any infringement have occurred inadvertently, the publisher apologises and undertakes to amend the omission in the event of a reprint. 


\title{
BRICS Education
}

Volume 2

\section{Critical Issues in South African Education}

Illumination from international comparative perspectives from the BRICS countries

\author{
Editor
}

Charl C. Wolhuter

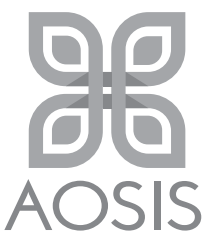




\title{
Social Sciences, Humanities, Education and Business Management domain editorial board at AOSIS
}

\author{
Commissioning Editor \\ Andries G. van Aarde, MA, DD, PhD, D Litt, South Africa
}

\section{Board Members}

Jan Botha, Professor, Centre for Research on Evaluation, Science and Technology, Stellenbosch University, Stellenbosch, South Africa

Joan Hambidge, Deputy Dean, Faculty of Humanities, University of Cape Town, Cape Town, South Africa; Professor, School of Languages and Literatures, University of Cape Town, Cape Town, South Africa

Sakari Häkkinen, Dean, The Diocese of Kuopio, Finland

Glenna Jackson, Associate Editor, Professor Chair, Department of Religion and Philosophy, Otterbein University, Westerville, OH, USA

Gregory C. Jenkins, Dean-Elect, St George's College, Jerusalem, Israel

Reina-Marie Loader, Director and Filmmaker, Cinéma Humain, Vienna, Austria

Babita Marthur-Helm, Senior Lecturer, Organisational Transformation and Development; Managing Diversity Gender Empowerment, University of Stellenbosch Business School, Stellenbosch, South Africa

Christopher Mbazira, Professor of Law and Coordinator of the Public Interest Law Clinic, Makerere University, Kampala, Uganda

Piet Naudé, Professor, Ethics related to Politics, Economics and Business, University of Stellenbosch Business School, Stellenbosch, South Africa; Director, University of Stellenbosch Business School, Stellenbosch, South Africa

Charles Neill, Professor, Department of Business Administration, The British University in Egypt, El Sherouk, Cairo Governorate, Egypt

Cornelia Pop, Full Professor, Department of Business, Faculty of Business, Babes-Bolyai University, Cluj-Napoca, Romania

Michael Schratz, Professor, Institute of Teacher Education and School Research, University of Innsbruck, Innsbruck, Austria; Dean, School of Education, University of Innsbruck, Innsbruck, Austria Johann Tempelhoff, Extraordinary Professor, South African Water History Archival Repository (SAWHAR), Faculty of Humanities, North-West University, Potchefstroom, South Africa Anthony Turton, Professor, Centre for Environmental Management, University of the Free State, Bloemfontein, South Africa; Director, Touch Stone Resources, University of the Free State, Bloemfontein, South Africa

Willie L. van der Merwe, Professor and Chair, Philosophy of Religion, Apologetics and Encyclopaedia of Theology, Stellenbosch University, Stellenbosch, South Africa; Professor Extraordinary, Vrije Universiteit Amsterdam, Amsterdam, The Netherlands

Christi van der Westhuizen, Associate Professor, Department of Sociology, Faculty of Humanities, University of Pretoria, Pretoria, South Africa

Joke van Saane, Professor, Amsterdam Center for the Study of Lived Religion, Vrije Universiteit Amsterdam, Amsterdam, The Netherlands

Paul van Tongeren, Professor, Department Philosophy, Radboud University, Nijmegen, The Netherlands

Robert G. Varady, Deputy Director and Research Professor, Environmental Policy, Udall Center for Studies in Public Policy, The University of Arizona, Tucson, AZ, USA

Anné H. Verhoef, Associate Editor, Professor, Faculty of Arts, School of Philosophy, NorthWest University, Potchefstroom, South Africa

Xiao Yun Zheng, Professor and Assistant President, Yunnan Academy of Social Sciences (YASS); Director, International Center for Ecological Culture Studies (ICECS-YASS),

Yunnan Academy of Social Sciences, Kunming City, China

\section{Peer review declaration}

The publisher (AOSIS) endorses the South African 'National Scholarly Book Publishers Forum Best Practice for Peer Review of Scholarly Books.' The manuscript was subjected to rigorous two-step peer review prior to publication, with the identities of the reviewers not revealed to the author(s). The reviewers were independent of the publisher and/or authors in question. The reviewers commented positively on the scholarly merits of the manuscript and recommended that the manuscript be published. Where the reviewers recommended revision and/or improvements to the manuscript, the authors responded adequately to such recommendations. 


\section{Research Justification}

The main thesis of this book is that, given that South African education faces major challenges, the BRICS (Brazil, Russia, India, China and South Africa) constellation of states offers - thus far overlooked - a valuable tertium comparationis, a source of international comparative perspectives, to inform the domestic scholarly discourse on education. Hitherto, the public as well as the scholarly discourse on education issues in South Africa have tended to be inwardlooking. As far as international perspectives were brought in, these have concentrated on models from the Global North (the introduction of OutcomesBased Education, developed in the Global North, where it had had its trial runs before being brought to South Africa, being an example), or recently from the countries who came out tops in the international Programme for International Student Assessment (PISA) test series, such as Finland. Both the Global North education systems and those of nations coming out tops in the PISA test series are inappropriate to serve as a comparative yardstick and example for South Africa, for the simple reason of too large contextual differences which these countries have with South Africa, a point explained thoroughly in this book. Up to now South-South comparisons in comparative and international education research have been few and far between, and comparisons between education issues in South Africa and other nations of the Global South have been virtually absent. The BRICS grouping represents a towering bloc of nations within the Global South, which has caught the interest of political leaders in South Africa. This book first investigates the national contexts and development of education in the BRICS countries, arguing that this grouping represents a valuable yet overlooked field for illuminating South African education issues with international perspectives. The book comprises chapters arguing for and illustrating this thesis from a variety of angles. Common to all chapters is that authors used the comparative method in education, that is, comparing the national education system in their education societal context interrelationships of the BRICS countries. The chapters focus on a number of critical issues in South African education, including the issue of the language of learning and teaching, the alignment of the world of education with the world of work, early childhood education and the development of world-class universities. Regarding the last one, for example, China has been the terrain of the most intensive national projects of establishing world-class universities, with Project 985, Project 211 and the 'Double First Class University' project. The chapters demonstrate what South Africa, in approaching her education issues, can learn from the experience of the BRICS countries. Motivating and illustrating the value of intra-BRICS education comparisons for South Africa, the book contains original research. The similarity report of an iThenticate analysis confirms that the work contains no plagiarism. This volume is a scholarly publication aiming at scholars of Education, arguing the case of international comparative studies within the BRICS grouping as a promising approach to do research on issues of education in South Africa.

Charl C. Wolhuter, Department of Comparative and International Education, Faculty of Educational Sciences, North-West University, Potchefstroom, South Africa. 



\section{Contents}

Abbreviations, Figures and Tables Appearing in the Text

xix

List of Abbreviations

List of Figures

$x x i i$

List of Tables

$x x i i$

Notes on Contributors

XXV

Chapter 1: Critical issues in South African education

Charl C. Wolhuter

Abstract

Introduction

Theoretical framework

South African education: Assessment of a system

Quantitative dimension

Quality

Equality

Contextual imperatives

The South African higher education system

Conclusion

Chapter 2: The significance of the BRICS countries as international datum line and data bank for South African education

Charl C. Wolhuter

Abstract

Introduction

The problematique and scope involved in comparison of education policy, praxis and scholarship 
The problematique in finding a comparative data bank suitable for use by South African scholars of education

The weight of the BRICS countries in the world

Societal contexts

Geography

Demography

Sociocultural situation $\quad 43$

Economy $\quad 44$

Politics $\quad 44$

Religion and life and world philosophy $\quad 45$

Education in the BRICS countries 46

Brazil 46

$\begin{array}{ll}\text { Russia } & 48\end{array}$

India $\quad 49$

China 51

BRICS organisation $\quad 52$

BRICS as supranational taxon in scholarship 53

A broader taxon of 'emerging countries'? 55

Conclusion 56

Chapter 3: Early childhood education: Benefitting from the BRICS experience by a new front of education development in South Africa

Benita Taylor, Marinda Neethling \& Juliana Seleti

Abstract $\quad 60$

Introduction $\quad 61$

Overview of early childhood development 64

Early childhood education in

China $\quad 65$

Historical and socio-economic background 65

Early childhood education's legal framework: China 66

Early childhood education practitioner training 69

$\begin{array}{ll}\text { Curriculum } & 70\end{array}$ 
Quality of early childhood education services in China 71 Early childhood education in India

Historical and socio-economic background 75

Early childhood education's legal framework: India 75

Early childhood education practitioner training 79

Curriculum

Early childhood education in Brazil

Historical and socio-economic background

Early childhood education's legal framework

Early childhood education practitioner training

Quality of early childhood education services

Historical and socio-economic background

Early childhood education's legal framework:

South Africa

Early childhood education practitioner training

Quality of early childhood education services in South Africa

Curriculum

Comparing early childhood education in China, India, Brazil and South Africa

\section{Chapter 4: Language of learning and teaching in South Africa and India: A comparative study}

\section{Santhakumar \& Charl C. Wolhuter}

Abstract

Introduction

Research methodology

The linguistic diversity of South Africa

Language as a medium of education in South Africa

Historical evolution of formal education in South Africa 
The language of learning and teaching in Indian education: Changes driven by historical, political, social and economic reasons

The language of learning and teaching and the history of education in India

Limited focus on mass education during initial decades after independence and its impact on the medium of instruction

Expansion of schooling in certain states focused on regional languages

Many other languages and mother tongues neglected 126

Higher education continued with English medium

Higher education informally in regional languages

Nature of employment in India and its role in the medium of instruction

Losing interest in schooling in regional languages and the growth of demand for English medium

Conclusion: India's struggle with the medium of instruction

Conclusion

Chapter 5: Aligning education with employment:

Lessons from vocational education in India and

South Africa

Artwell Marimo, Hennie J. Steyn \& Ewelina K. Niemczyk

Abstract

Introduction

The nature of vocational education $\quad 142$

Defining vocational education $\quad 142$

Key features of vocational education 143

Aims of vocational education 143

Governance of vocational education $\quad 144$

Quality assurance $\quad 144$

Funding vocational education $\quad 145$

Curriculum for vocational education 146 
Stakeholders in vocational education

Role of teaching personnel

Role of training institutions

Role of industry

Role of government

Provision of vocational education

Basic vocational education

Secondary vocational education

Post-secondary vocational education

The informal sector as a training provider

Delivery methods for vocational education

Challenges to vocational education

Vocational education in India

Aims of vocational education

Provisioning

Governance

Curriculum

Funding

Stakeholders in vocational education

Central government

Teachers and trainers

Quality assurance

Challenges

Limited capacity

Awareness

Placement-linked challenges

Quality of training

Mobility concerns

Basic infrastructure challenge

High levels of unemployment

Complexity of the system

Achievements

Achieving scale

Boosting quality 
Vocational education in South Africa Introduction

Aims of vocational education

Governance

Funding vocational education

Quality assurance

Stakeholders

Provision of vocational education

Curriculum

Challenges

Curriculum challenges

Overlapping qualifications

Lack of institution-industry partnership

Lack of coherence at post-school stage

Weak infrastructure

Hybrid classes

Negative perceptions

Lack of trained staff

Skills gap and unemployment

Achievements

Establishment of the department of higher

education and training

Creation of agencies for skills development

Strategic partnership between Sector Education and Training Authority and institutions

Comparison

Aims

Governance

Curriculum

Quality assurance

Funding

Stakeholders

Challenges

Achievements 
Chapter 6: Providing for the unique educational needs of minority groups: Lessons from the BRICS countries

Hennie J. Steyn \& Z.L. (Louw) De Beer

Abstract

Introduction

International guidelines of education for minorities

Defining minority groups

A minority group can be identified by its religion

Culture as an identifier of a minority group

Ethnicity as an identifier of a minority group

The internationally recognised rights of minority groups

The International Covenant on Civil

and Political Rights (1966)

The Charter of Paris for a New Europe

Implications of international instruments for

minority rights

The internationally recognised educational rights of minority groups

The Convention against discrimination in

education as adopted by the UNESCO, 1960

The United Nations Convention on the Rights of

the Child, 1990

Implications of the two conventions regarding the educational rights of minorities

The expectations of minority groups from the education system

The recognition of educational rights of minorities:

The consequences

Recognising minority educational rights in the member states of BRICS

Introduction

Education to minorities in South Africa: Frameworks, practices and challenges

The Constitution of the Republic of South Africa

(Act No. 108 of 1996)

The South African Schools Act (Act No. 84 of 1996) 
Language in education policy 197

South African languages, religions and culture 197

Education to minorities in Russia: Practices and challenges

The Russian Constitution 198

Language and cultural legislation 199

Russian language, religions and culture 199

Education to minorities in India: Practices and challenges 200

The Constitution of the Republic of India 200

India's Ministry of Minority Affairs 201

Indian prime minister's new 15-point programme

for the welfare of minorities 201

Indian languages, religions and culture 203

Education to minorities in China: Practices and challenges

Policy provisions 205

Administration of education 206

Sufficient funding as the keystone for successful education to minorities 206

The role of school system in minority education $\quad 207$

Findings regarding education to minorities in China 208 Education to minorities in Brazil: Practices and challenges

Brazilian legislation $\quad 209$

Brazilian languages, religions and culture 210

Conclusion

\section{Chapter 7: Models of trilingual education in China and the relevance thereof for South Africa}

Charl C. Wolhuter

Abstract

The pivotal importance of language of learning and teaching in any educational project 
The language situation in South Africa and what can be learned from India

China: Societal context

Education in China

Traditional Chinese education

China under western influence

Period of Marxism and Sovietisation of education from 1949

Post-1979 modernisation

Hong Kong

Language in education in China

Policy

Model 1: The accretive or additive model

Model 2: The balanced model

Model 3: The transitional model

Model 4: The depreciative or subtractive model

Universities

Hong Kong

Comparison

Conclusion

Chapter 8: Violence and education in the BRICS countries: A comparative study

Johan Botha \& Oliver Gore

Abstract

Introduction

Approach to the literature review

Results from literature on violence in South Africa

Causes of school violence in South Africa

Attempts to prevent violence in South Africa

Evidence from Brazil, Russia, India and China on school violence

Brazilian schools

Russian schools 
Indian schools

Chinese schools 261

Lessons from the above review 263

Conclusion 265

Chapter 9: The objectives of the BRICS organisation in correlation with the objectives of the Organisation for Economic Cooperation and Development

Deon Vos \& Z.L. (Louw) De Beer

Abstract

Introduction $\quad 268$

$\begin{array}{ll}\text { Methodology } & 270\end{array}$

$\begin{array}{ll}\text { The history of BRICS } & 270\end{array}$

BRIC Summit 1: Yekaterinburg, Russia, June 2009

BRIC Summit 2: Brasília, Brazil, April $2010 \quad 273$

Category 1: Shared vision on global governance $\quad 273$

Category 2: International and financial business $\quad 274$

Category 3: International trade $\quad 274$

Category 4: Agriculture $\quad 274$

Category 5: Poverty relief $\quad 274$

Category 6: Energy 274

Category 7: Climate change 275

Category 8: Terrorism 275

Category 9: Cooperation 275

BRICS Summit 3: Sanya, China, April 2011

BRICS Summit 4: New Delhi, India, March 2012

BRICS Summit 5: Durban, South Africa, March $2013 \quad 276$

BRICS Summit 6: Fortaleza, Brazil, July 2014

BRICS Summit 7: Ufa, Russia, July 2015

BRICS Summit 8: Benaulim (Goa), India, October $2016 \quad 277$

BRICS Summit 9: Xiamen, China, September $2017 \quad 278$

BRICS Summit 10: Johannesburg, South Africa, July 2018280

The objectives of the Organisation for Economic

Cooperation and Development 
The Organisation for Economic Cooperation and Development explains its existence in the policy-making sphere by answering the 'who, where,

what and how questions'

The Organisation for Economic Cooperation and

Development education and skills

The educational aims of the BRICS member states

regarding socio-economic development

BRICS educational aims

Higher education

Technical vocational education

General education

Instruction strategy procedures

The status of socio-economic trends in the BRICS

member states

Brazil

Russia

India

China

South Africa

Possible best practices regarding the development

of the socio-economic status in the BRICS member states

Brazil

Russia

India

China

South Africa

The BRICS economy synopsis 2020 and COVID-19

Chapter 10: The creation of world-class universities in China as an object lesson for South Africa

Charl C. Wolhuter

Abstract

Introduction 
The pivotal place of university in the 21st-century society 308 What is a university? 308

The beginnings of the university 308

The long, unimpressive history of universities in the society

The take-off since the mid-20th century 309

The global higher education revolution 310

The nascent knowledge society and the fourth industrial revolution

The purpose or mission of a university 312

World-class university $\quad 315$

Higher education in China $\quad 317$

China's quest to build world-class universities 320

The South African higher education sector and the ideal

of a world-class university

Conclusion

\section{References}




\section{Abbreviations, Figures and Tables Appearing in the Text}

\section{List of Abbreviations}

AICTE All India Council for Technical Education

ANC African National Congress

ARP Agricultural Research Plan

ARWU Academic Ranking of World Universities

BRIC Brazil, Russia, India, and China

BRICS Brazil, Russia, India, China, and South Africa

CAP Changing Academic Profession

CAPS Curriculum Assessment Policy Statements

CCCCP Central Committee of Chinese Communist Party

CCIT Comprehensive Convention on International Terrorism

CIBSA China, India, Brazil and South Africa

CPLS Collaboration Problem-solving Skills

CRA Contingent Reserve Arrangement

CTS Craftsmen Training Scheme

CWUR Centre for the World University Rankings

DBE Department of Basic Education

DGE\&T Directorate General of Employment and Training

DHET Department of Higher Education and Training

DoE Department of Education

EC Early Childhood

ECA Extra-curricular Activities

ECCD Early Childhood Care and Development

ECCE Early Childhood Care and Education 
ECD Early Childhood Development

ECE Early Childhood Education

ECEC Early Childhood Education and Care

ECED Early Childhood Education Development

EFA Education for All

ERIC Education Resources Information Centre

EU European Union

FET Further Education and Training

FOCAC Forum on China-Africa Cooperation

GDP Gross Domestic Product

$\mathrm{HEl} \quad$ Higher Education Institution

HKDSE Hong Kong Diploma of Secondary Education Examination

ICDS Integrated Child Development Services

ICT Information and Communications Technology

IMF International Monetary Fund

IT Information Technology

ITES Information Technology-enabled Services

MAEF Maulana Azad Education Foundation

MEC Member of the Executive Council

MES Modular Employable Skills

$\mathrm{MSCl} \quad$ Morgan Stanley Capital International

MSDE Ministry of Skills Development and Entrepreneurship

MWCD Ministry of Women and Child Development

NCF National Curriculum Framework

NCS National Curriculum Statements

NCV National Certificate (Vocational)

NCTE National Council Teacher Education

NDB New Development Bank

NGO Non-governmental Organisation

NIWC National Interim Working Committee

NPA National Plan of Action

NPE National Policy on Education 


\begin{tabular}{|c|c|}
\hline NQF & National Qualification Framework \\
\hline NSDA & National Skills Development Agency \\
\hline NSDC & National Skills Development Council \\
\hline NSQF & National Skills Qualifications Framework \\
\hline OECD & $\begin{array}{l}\text { Organisation for Economic Cooperation and } \\
\text { Development }\end{array}$ \\
\hline PIM & Primeira Infância Melhor \\
\hline PISA & Programme for International Student Assessment \\
\hline QCTO & Quality Council for Trades and Occupations \\
\hline QS & Quacquarelli Symonds \\
\hline R\&D & Research and Development \\
\hline RMSA & Rashtriya Madhyamik Shiksha Abhiyan \\
\hline RSA & Republic of South Africa \\
\hline SAAECE & $\begin{array}{l}\text { South African Association for Early Childhood } \\
\text { Education }\end{array}$ \\
\hline SABER & Systems Approach for Better Education Results \\
\hline SACECD & $\begin{array}{l}\text { South African Congress for Early Childhood } \\
\text { Development }\end{array}$ \\
\hline SAQA & South African Qualifications Authority \\
\hline SASA & South African School Act \\
\hline SDG & Sustainable Development Goal \\
\hline SES & Selected Educational Statistics \\
\hline SETA & Sector Education and Training Authority \\
\hline SGB & School Governing Body \\
\hline SONA & State of the Nation Address \\
\hline TB & Tuberculosis \\
\hline THES & Times Higher Education Supplement \\
\hline TIMS & $\begin{array}{l}\text { Trends in International Mathematics and Science } \\
\text { Study }\end{array}$ \\
\hline TIMSS & Trends in International Mathematics and Science Study \\
\hline TVET & Technical Vocational Education and Training \\
\hline UN & United Nations \\
\hline UNESCO & $\begin{array}{l}\text { United Nations Educational, Scientific and Cultural } \\
\text { Organization }\end{array}$ \\
\hline
\end{tabular}




$\begin{array}{ll}\text { UNICEF } & \text { United Nations Children's Fund } \\ \text { USSR } & \text { Union of Soviet Socialist Republics } \\ \text { VE } & \text { Vocational Education } \\ \text { WEFFI } & \text { Worldwide Educating for the Future Index } \\ \text { WTO } & \text { World Trade Organization }\end{array}$

\section{List of Figures}

Figure 3.1: Terminologies, names and acronyms used for child development.

Figure 3.2: Early childhood education legal framework in China.

Figure 3.3: Early childhood education's legal framework in India.

Figure 3.4: Early childhood education legal framework in South Africa.

Figure 9.1: BRICS and its global presence.

Figure 9.2: Cooperation between the BRICS member states. 279

\section{List of Tables}

Table 1.1: Unemployment levels in South Africa for segments of the population according to education level and age group.

Table 1.2: Growth of global higher education enrolments and enrolment ratios since 1990.

Table 1.3: Enrolment progress in higher education in South Africa, 1994-2016.

Table 1.4: Enrolment equalisation in higher education in South Africa, 1994-2016.

Table 2.1: The demography of the BRICS countries.

Table 2.2: The economic power of the BRICS countries.

Table 2.3: The economic growth rates of the BRICS countries. 44 Table 3.1: Policy changes in early child education in Brazil. 
Table 3.3: Comparing early childhood education in China, India, Brazil and South Africa.

Table 8.1: A synopsis of violence in South Africa compared to Brazil, Russia, India and China for children in 2015.

Table 9.1: Average socio-economic indicators.

Table 10.1: Student composition in South African public universities as per population group. 



\section{Notes on Contributors}

\section{Johan Botha}

Subject Group Comparative and International Education, Education and Human Rights in Diversity Research Unit, Faculty of Education, North-West University,

Potchefstroom, South Africa

Email: johan.botha@nwu.ac.za

ORCID: https://orcid.org/0000-0002-1811-0908

\section{Z.L. (Louw) De Beer}

Subject Group Comparative and International Education, Education and Human Rights in Diversity Research Unit, Faculty of Education, North-West University,

Potchefstroom, South Africa

Email: louw.debeer@nwu.ac.za

ORCID: https://orcid.org/0000-0002-9682-2441

\section{Oliver Gore}

Subject Group Comparative and International Education, Education and Human Rights in Diversity Research Unit, Faculty of Education, North-West University,

Potchefstroom, South Africa

Email: 34759824@nwu.ac.za

ORCID: https://orcid.org/0000-0002-1475-4175

\section{Artwell Marimo}

Faculty of Mechanical Technology Teaching, Applied Technology High School, Abu Dhabi, United Arab Emirates

Email: amarimo@yahoo.com

ORCID: https://orcid.org/0000-0002-9413-2746

\section{Marinda Neethling}

School of Psycho-Social Education,

Faculty of Education, North-West University,

Potchefstroom, South Africa

Email: marinda.neethling@nwu.ac.za

ORCID: https://orcid.org/0000-0002-4548-426X

\section{Ewelina K. Niemczyk}

Subject Group Comparative and International Education, Education and Human Rights in Diversity Research Unit, Faculty of Education, North-West University, Potchefstroom, South Africa

Email: ewelina.niemczyk@nwu.ac.za

ORCID: https://orcid.org/0000-0002-9381-5449 


\section{Santhakumar}

School of Development,

Azim Premji University,

Bangalore, India

Email: santhakumar@apu.edu.in

ORCID: https://orcid.org/0000-0002-7449-9962

\section{Hennie J. Steyn}

Subject Group Comparative and International Education,

Education and Human Rights in Diversity Research Unit,

Faculty of Education, North-West University,

Potchefstroom, South Africa

Email: hennie.steyn@nwu.ac.za

ORCID: http://orcid.org/0000-0002-7596-8361

\section{Benita Taylor}

Early Childhood Development and Education, School of Languages,

Faculty of Education, North-West University,

Potchefstroom, South Africa

Email: 13096613@nwu.ac.za

ORCID: https://orcid.org/0000-0002-8600-8593

\section{Deon Vos}

Subject Group Comparative and International Education, Education and Human Rights in Diversity Research Unit, Faculty of Education, North-West University,

Potchefstroom, South Africa

Email: deon.vos@nwu.ac.za

ORCID: https://orcid.org/0000-0003-2287-8810

\section{Charl C. Wolhuter}

Subject Group Comparative and International Education, Education and Human Rights in Diversity Research Unit, Faculty of Education, North-West University, Potchefstroom, South Africa

Email: charl.wolhuter@nwu.ac.za

ORCID: https://orcid.org/0000-0003-4602-7113

\section{Juliana Seleti}

School of Psycho-Social Education,

Faculty of Education, North-West University,

Potchefstroom, South Africa

Email: jseleti@yahoo.com

ORCID: https://orcid.org/Oooo-0001-7375-5437 


\section{Chapter 1}

\section{Critical issues in South African education}

Charl C. Wolhuter Subject Group Comparative and International Education, Education and Human Rights in Diversity Research Unit, Faculty of Education, North-West University, Potchefstroom, South Africa

\section{Abstract}

This chapter uses the two models of Wolhuter (2014b) and Wolhuter and Van der Walt (2018) to analyse and identify the weak places in the South African education system at primary and secondary levels, and the analysis of Wolhuter (2012) for identifying critical shortcomings at the level of higher education in South Africa. The model for the assessment of a national education project revolves around three dimensions of education, namely, the quantitative dimension, education quality and equality in education; whilst the latter is built on the roles or functions of a university in society, namely, teaching and learning at the cutting edge of science, service, innovation, preservation

How to cite: Wolhuter, C.C., 2020, 'Critical issues in South African education', in C.C. Wolhuter (ed.), Critical Issues in South African Education: Illumination from international comparative perspectives from the BRICS countries (BRICS Education Volume 2), pp. 1-28, AOSIS, Cape Town. https://doi.org/10.4102/aosis.2020.BK207.01 
and development of culture and societal critique. It is concluded that the most critical problems in South African education relate to the issue of language of learning and teaching, accommodation of diversity, early childhood education, having education in tandem with the world of work, and, at the level of higher education, securing the establishment and maintenance of worldclass universities. The chapter concludes with suggesting the international comparative method, and the Brazilian, Russian, Indian, China, South African countries as tertium comparationis for the illumination of these critical issues, thus setting a prospectus for the remainder of the book of which this chapter is the opening chapter.

Keywords: BRICS countries; Comparative and international education; Culture and education; Diversity and education; Education and employment; Education quality; Language and education; World-class universities.

\section{Introduction}

Education in South Africa is given a tall order (i.e. being looked onto as a means of individual social mobility, expected to entrench democracy, create a society of equal opportunities and entrench a culture of human rights, cf. Wolhuter 2015) and a huge portion of public and private funds is allocated to education (20\% of the government budget in South Africa is allocated to education, compared to the global figure of 16\%) (Mupunga 2019:28), but at the same time it is widely condemned to be a failure, being in the intensive care unit (cf. Wolhuter 2014b). To illustrate the last point, the wasteful high attrition rate in South African education could be mentioned: Of every 100 learners entering grade 1, 60 write matric, 37 pass the matriculation examination, 14 pass with university admission granted, 12 enter university, 6 eventually finish a degree and 4 finish in 6 years with a degree (CHE 2017). The objective of this chapter is firstly to identify the problems or challenges in South African education. 
Borrowing, or better learning from other education, has long been a method employed to improve education systems (Li 2017; ed. Steiner-Khamsi 2004). In Chapter 2, the suitability of Brazil, Russia, India, China and South Africa (BRICS nations) as a comparative reference point and supply store of education ideas, policies and practices for South Africa to borrow or import or learn from is argued. The remainder of the chapters in the book then zooms into a selection of challenges in South African education, and illuminate these by means of the education experience of one or more of the other BRICS countries. The second objective of this chapter is therefore to serve as a prelude to the remainder of the book.

The chapter commences with the construction of a theoretical framework to be used to assess the South African education system and to identify weak parts thereof. Subsequently, firstly the South African primary and secondary education system, and then the South African higher education system are assessed using this framework. From this, in the conclusion, weak parts of the South African school and higher education system are identified.

\section{Theoretical framework}

A theoretical framework to survey and to assess the South African education system is built up from three blocks. Firstly, the model for assessing education systems developed by Wolhuter (2014b) and Wolhuter and Van der Walt (2018) is used. Secondly, as education systems are called into existence from societal contextual imperatives, the societal context in which the South African education system is embedded is used. Thirdly, as universities have their own specific role in an education system, these roles, as enumerated by Wolhuter (2012) are employed as a theoretical framework.

Wolhuter (2014b) constructed a framework for assessing national education projects. This framework distinguishes 
between three dimensions of a national education effort: The quantitative dimension, the qualitative dimension and the equality dimension. The quantitative dimension concerns participation in education and can be measured by means of data on enrolments and enrolment ratios.

Education quality is a difficult concept, and cannot be summarised in a simple, one line definition. A more meaningful exercise is to identify and unpack the components of education quality. Wolhuter and Van der Walt (2018) distinguish between the following components of education quality: input quality, process quality, output quality and product quality. Input quality refers to the quality of the financial investment or physical facilities of a school or education system. This component of quality is fairly easy to measure, and data of education systems are readily available. Indicators of input quality include per learner public spending and number of desks per learner. Process quality comprises the quality of teaching and learning realised in schools and in education systems. This component is more complex, more difficult to measure, and comparable data are not as widely available. Process quality can be broken up in the following: the administrative substructure, the curriculum, teacher-bound factors (training of teachers, experience of teachers, input of teachers and teaching methods), school-bound factors (leadership, school climate and organisation culture), family-bound factors (family and home environment, and parental involvement in schools) and learner-bound factors (initial situation regarding level of knowledge and development when learners enter the school, and learner input; cf. Mentz et al. 2018:158).

Output quality refers to the outcome or end result of the learning process or activity, that is, the achievement levels of learner at the end or at any point in a school or learning programme. The measurement of this is relatively easy and data are readily available, such as the matric results in South Africa, or the results of international test series, such as the Programme for International Student Assessment (PISA) or Trends in International Mathematics and Science Study (TIMSS) tests. Product quality 
related to the impact of education - or the effect it exerts - both at an individual level (i.e. the life chances of the graduate) and at a societal level. Product quality at an individual level includes the income-generating potential that a particular level or programme of education renders, and the intellectual/cognitive skills, the character cultivation and the hierarchy of values brought about by a programme of education. One common measure of product quality at an individual level is the rate of return analyses. Societal product quality (which is more difficult to measure than individual product quality) includes increased economic productivity, political returns (such as entrenching a culture of democracy) and social returns (e.g. creating respect for all humans, strengthening a culture or the role of education in promoting social mobility; cf. Kuper 2019; Montacute \& Nightingale 2019; OECD 2018).

Defining the concept of equal education and equal educational opportunities is difficult. A one line definition is difficult (cf. Wolhuter 1993:76-77). Furthermore, as Lazenby's (2016:65) opening statement in his discussion on the term states: 'There is widespread disagreement about what equality of opportunity in education requires'. However, a commonly used model is the model of Joseph Farrell (first published in 1982; republished and reworked in 2013). Farrell (1982, 2013) distinguished between four facets of equality:

- Equality of access: The statistical ratios of learners belonging to different social categories in entering the school system.

- Equality of survival: The statistical ratios of learners belonging to different social categories progressing to a specific level in the school system (e.g. the last year of secondary school).

- Equality of output: The statistical ratios of learners belonging to different social categories attaining similar or the same outcomes (e.g. performance in the matriculation examination).

- Equality of product: The statistical ratios of learners belonging to different social categories with the same educational qualifications securing the same jobs, remuneration and life opportunities. 
Whilst the three dimensions of gender, socio-economic descent and race/ethnicity (also called the 'trinity of inequality') have come to dominate both scholarly and public discourse on educational inequality (cf. Wolhuter 2019), other salient dimensions, such as regional, urban-rural and geographical inequality, on the core-periphery gradient are also extant (cf. Wolhuter 1993).

One of the basic theorems in the scholarly field of comparative and international education is that education systems do not exist in a vacuum but are created by and within particular societal contexts (Wolhuter 2020). A societal context contains the shaping forces of education systems. For analytical purposes, scholars in the field of comparative and international education distinguish between the following aspects of these societal contexts: geography, demography, social system, economy, politics, and religion and life and world philosophical systems (Bray \& Thomas 1995; Manzon 2014; Sobe \& Kowalcyk 2014; Steyn \& Wolhuter 2008).

Aspects of the geography of a particular context which impact education in the area include location (e.g. in the case of a national education system, the location of the country), the size of a country/context, the shape of the country, the topography, climate, and flora and fauna. From the side of the geographical context, the current age is an age when an ecological crisis is facing humanity, to the extent that the continual existence of the human species and even of the planet earth is at stake. For this reason, the concept or ideal of sustainable development has been formulated by the global community, concretely in the form of the Sustainable Development Goals (SDGs); and education ('Education for Sustainable Development') is looked up to as a means of ensuring that the SDGs will be attained by the target date of 2030.

Demography refers to the features and dynamics pertaining to the population in a country. These include number of people, the age profile of the population, the rate of growth, birth and 
mortality statistics, number of immigrants and emigrants, population density, geographical distribution of the population as well as population mobility. All these impact on the supply of education. With the global population now over 7 billion, and the Global South still characterised by swift population growth, education is widely looked up to as an instrument to curb fast population growth and to address the problem of overpopulation, the belief then being that higher educated people tend to have smaller families.

Turning to the social system, aspects of the social system having a bearing on education include the system of social stratification, the existence or absence of social capital and social maladies, cultural patterns and language patterns. As touched upon in the Introduction, in contemporary society, education is expected to serve as a vehicle of upward social mobility for people. Education is also expected to create social capital ('social capital' here is used with the meaning attached to it by Fukuyama (1999), namely, social capital refers to a set of common norms and values which ensure peaceful coexistence and cooperation in society).

Salient aspects of the economy that influence education are firstly, the level of economic development or affluence (which determines the amount of money available for expenditure on education), and secondly, the structure of economic activities (the percentage of the population engaged in various kinds of economic activities, such as agriculture, industry, services, etc.). The percentage of a country's labour force engaged in various economic activities affects the education system, particularly to the extent that an education system equips learners for their future occupations. In the contemporary world, education is considered to affect economic growth, and to ensure the employability of every person, that is, to eradicate unemployment.

The political system and features of a country is a further contextual factor shaping education systems. The policy of the ruling party after all determines the type of education system 
that will be chosen as well as the educational objectives and curricula in schools. The type of political system in a country affects the education setup of that country; for example, the measure of school autonomy allowed, the degree of centralised or decentralised education control or the place given to religious education in schools. In the education systems of the world today, what the political system and its principals expect from schools are to nurture a loyalty towards the state, to mould national unity and to produce a citizenry taking part in the political process.

The last set of societal contextual forces having a formative influence on education systems is religion and life and the world view. Historically, religious systems and structures saliently and concretely shaped education systems, and in many countries, this is visible even today. In Italy, the Roman Catholic Church in its organised form and formal structures still has a strong say in the formulation of education policy because of its strong position in the country. In Egypt, a fully, state-financed, Islamic religionbased education system (right up to Al-Azhar University in Cairo at the pinnacle) exists as a system parallel to the secular state education system, also because of the strong position of Islam there. The life and world view of people in a society prescribe, for example, the values that are taught to learners in schools. However, with the secularisation of societies and governments in the present day and age, the creed of human rights has stepped into the place of religions to form the pistic superstructure from which education systems are built. This entails that education is not only seen as one of the human rights but also the expectation that the education system and institutions should inculcate respect for human rights into the educands.

Finally, whilst all the these (regarding the dimensions of quantity, quality and equality), as well as the contextual imperatives, hold true for the higher education sector as much as any other level of education, the university's particular role or mission in society necessitates an additional set of requirements to be tabled in the case of universities. A university is, in terms of its lexical definition, an autonomous institution for the advan 
cement of various branches of higher learning (Wolhuter 2012). From this definition, Wolhuter (2012) enumerates the six functions of the university as follows: teaching and learning; research; service; innovation (commercially oriented); cultural preservation, transmission and development, and societal critique.

The first function, namely, that of teaching, has been visible from the first of the modern universities, in the 11th century. This teaching has always been of a dual kind, namely, a general academic schooling in foundation disciplines, and secondly, a more occupationally directed teaching. In the beginning, in the medieval universities, education was available for higher professions (these were medicine, law and the ministry), but in recent times, these have been extended to the full gamut of professions, including those in the hierarchy under the higher order professions (e.g. social workers, human resource managers or industrial chemists) and even further (Wolhuter \& Mushaandja 2015).

Whilst the rudiments of the second function, that of research, can be detected right from the medieval universities, this function came in all seriousness to the fore in 1810 with the formation of the Humboldt University in Germany. Paralleling the teaching and learning functions, this function too falls out into two. These are firstly, the basic research (nowadays often called 'blue sky' research), with the set intention of pressing forward the borders of knowledge. The second function is that of applied research, applying knowledge for the amelioration of the conditions of humanity. As in the case of teaching, these two should be seen as complementary. Knowledge applied more than often draws on knowledge generated on the basic research line by researchers who never had the eventual applications in mind (Stiglitz 2019:24-25). Furthermore, the teaching-learning and research functions of the university also exist in a symbiotic interrelationship to each other (cf. Sutherland \& Wolhuter 2002).

The service function of the university, the third function, which came to the fore in 1862 with the Land Grant Act or Morrill Act in the United States of America (USA), and the universities founded under this Act, is a rather nebulous role or function, and has 
hitherto escaped the attention of serious scholarly attention. However, Ward (2003) teased out the meaning of service as a category of functions of the university and has divided it into three sub-categories. The first is internal on-campus services, which include services to students, academic oversight, institutional governance and institutional support. The second category of functions is internal off-campus services: these are services to academic disciplines and fields that is, services to professional associations (membership committees, programme committees, etc.) or publication-related activities (e.g. serving on editorial boards or as reviewers; cf. Wolhuter \& Mushaandja 2015:4 of 12). Finally, there are external services, that is, putting their specialised knowledge to the benefit of various external parties. This can include counselling, consultancy services, short learning courses, community action-based research, community upliftment projects and participation in cultural activities and rendering assistance to governmental departments of ministries. Services can be for remuneration or not unpaid. The common characteristic amongst all service activities is that these are based on the specialised knowledge of academics.

The pragmatic (in terms of not only commercial applications but also value, for example, the military-industrial complex) innovation function of the university is visible in, for example, the number of registered patents emanating from universities. A top university on this count, Stanford University in the USA, filed 691 patents during 2011-2016 (Thomson Reuters 2019). The cultural preservation, transmission and development function is visible not only in departments of literature and language studies or anthropology but also in libraries, museums, art galleries and dictionary projects housed at universities. Finally, being an autonomous institution (not under the rule of government) and stocked with the best brain power, the university is uniquely positioned to critique society, to fulfil the role of the conscience in society, very relevant in, for example, the present day and age of the creed of human rights, as explained previously. 


\section{- South African education: Assessment of a system}

\section{Quantitative dimension}

As far as pre-primary education is concerned, it should first be mentioned that a comprehensive or complete package of early childhood education, development and support comprises a number of elements components (Berry et al. 2017):

- Maternal and child health services, including antenatal care, PMTCT, physical and mental health screening, psychosocial support and immunisation.

- Nutritional support for pregnant women, mothers and children.

- Support for primary care givers, including parenting skills and psychosocial support.

- Social services, including birth registration, access to social grants, responsive child protection services and psychosocial support.

- Stimulating early learning, including access to quality, ageappropriate early learning programmes. (n.p.)

Given the widespread poverty levels in South Africa (which are discussed in the forthcoming section on contextual forces impinging on South African education), families cannot ensure these four components, underscoring the importance of structured and formalised early childhood education. Yet, of the high number of children aged less than 6 years in South Africa - 6.6 million - 70\% are not in such structured, formal education settings (Centre for Early Childhood Development 2018). Given the powerful (even decisive) effect of the first 5 years on the rest of life (cf. Irvin, Siddiqi \& Hertgrun 2007), this underdevelopment of pre-school education is certainly the first weak link in South African education, the Achilles heel right at the base of the system. 
Turning to primary school enrolments, in terms of the South African Schools Act (Act 84 of 1996), Section 3, school attendance is mandatory for all children from the age of 7 years until the last day of the year in which the child turns 15 years of age or has completed Grade 7, whichever comes first (RSA 1996). This practically means that primary school attendance is compulsory. Accordingly, primary school enrolments in South Africa are high and have grown consistently. Primary school enrolments in South Africa have increased from 7024368 in 2010 to 7569924 in 2016 (UNESCO 2019). Whilst gross enrolment ratios stand at over $100 \%$ (because of a large number of children in primary schools above the official age; cf. UNESCO 2019), 3.23\% of primary school children are out of school (UNESCO 2019) - this translates to over 500000 children. Another problem is that although the completion rate of primary schools stands at 94.29\% (UNESCO 2019), it still means that about 60000 children who enter primary school each year drop out before they complete the primary school cycle.

Secondary school enrolments too have shown a persistent growth. These increased from 4141946 in 2000 to 5164481 in 2017 (UNESCO 2019), and whilst in the case of gross secondary school enrolment a ratio of over $100 \%$ is given by UNESCO (2019, because of overage learners), the problem of attrition becomes acute at secondary level, as explained in the Introduction. Research aimed at identifying risk factors in dropouts has been carried out in South Africa as well as internationally. This includes both cross-sectional and longitudinal studies (cf. Weybright et al. 2017). Determinants or correlates of secondary school dropouts identified are individualrelated factors (e.g. gender, race, substance use; Townsend, Flisher \& King 2007), previously failing a grade (Battin-Pearson et al. 2000), family-related factors (e.g. family composition; Ananga 2011) and social factors (e.g. poverty; Strassburg, Meny-Gibert \& Russell 2010).

\section{Quality}

Comparative research has repeatedly shown a discrepancy between the relatively high levels of education expenditure (both per student expenditure in real terms and public expenditure as 
percentage of the government budget), that is, input quality and outcome levels (e.g. cf. Wolhuter 1997a, 1998, 2011, 2014b; Wolhuter \& Van der Walt 2018). These poor outcome levels are evident in both internal assessment series (such as the Annual National Assessments tests and the annual matriculation examination) and international test exercises, where outcomes recorded are consistently at alarming levels. For example, in the last round of the TIMSS (2019), South Africa was second last of the 39 participating countries. The average score of Grade 8 South African learners in the mathematics test was 372, compared with Singapore, 621 (which came first); Russia, 538; USA, 518; Australia, 505; Turkey, 458; Egypt, 392; Botswana, 391, and Saudi Arabia (which ended last), 368. Causal factors for these low achievement levels are certainly manifold (for a systematic review of these, cf. Wolhuter \& Van der Walt 2018), but one factor highlighted here, as it forms the focus of more than one chapter in this volume, is the medium of instruction. One common factor that South Africa shares with many of the poorest performing nations is that the medium of instruction in schools is not the first language of the majority of learners. In South Africa, instructions in the mother tongue are the norm only in the first 3 years of schooling, thereafter the medium of instruction in educational institutions is English or Afrikaans. How starkly this lies at odds with the language context of South Africa is illustrated later in this chapter, when the societal context of South African education is dealt with, whereas the debilitating effect of this on education will be the focus of two subsequent chapters, and one of the themes of two subsequent chapters.

On the societal outcomes of education, that is, the product quality, South African Education scholarship, Comparative and International Education scholarship, in particular, suffers from the same shortcoming as scholarship abroad, namely, a dearth of research on this component of education (cf. Wolhuter 1994, 1997b, 2008, 2014a). However, fairly extensive data on employ ment levels for segments of the population according to education level and age group do exist, but these too show that all is not in order. These are presented in Table 1.1. 
TABLE 1.1: Unemployment levels in South Africa for segments of the population according to education level and age group.

\begin{tabular}{lcc}
\hline Highest level of education & \multicolumn{2}{c}{ Age group } \\
\cline { 2 - 3 } & $\mathbf{2 5 - 3 4}$ years & $\mathbf{3 5 - 6 4}$ years \\
\hline Total & 34.2 & 18.0 \\
Less than matric & 41.0 & 23.3 \\
Matric & 32.4 & 17.0 \\
Tertiary below degree & 25.2 & 9.4 \\
University degree & 12.9 & 4.3 \\
\hline
\end{tabular}

Source: RSA (2019a).

Whilst there is - heartingly - a consistent negative correlation between highest education achievement and rate of unemployment, equally, and this time concern-raising, there is substantially higher unemployment amongst the youth than the aggregate population at each level of education achievement. Apart from eradicating unemployment, education in South Africa is called for a tall task of societal objectives, such as creating a peaceful, non-sexist, non-racial society of equality and equal opportunity, entrenching democracy and a culture of respect for human rights, and establishing a common hierarchy of values.

\section{Equality}

All the three universal dimensions of inequality in education ethnicity/race, gender and socio-economic status - are present in South Africa too - and very rife at that - together with a host of other dimensions of inequality.

For decades up to 1994, South Africa has been known globally as the poignant example of a society of inequality, including educational inequality, along racial lines. White schools were at par with the best schools in the affluent countries of the Global North (cf. Wolhuter 1998). Schools for black people on the other hand, whilst markedly better than anywhere else in sub-Saharan Africa, were way behind white schools in terms of levels of spending, teacher qualifications, infrastructure, learning outcomes, 
attrition levels and the like (Wolhuter 1998). Whilst desegregation and equalisation have been two of the pillars of education policy in the era commencing in 1994 (cf. Wolhuter 1999), two adverse remarks regarding the outcome of that exercise have to be made at this point. Firstly, post-1994 school desegregation has been very much unidirectional. Black children from higher socioeconomic strata of society (in particular, the new rising black middle class) moved from the historically black schools to the better endowed historically white schools. The result is that the historically black schools are still virtually uniformly black, whilst all white learners in public schools are still concentrated in the historically white schools (although these schools now have a multi-racial learner composition because of the influx of black learners from more affluent families). Thus, to a substantial measure, racially segregated education has merely been changed for socio-economic segregation. Secondly, 25 years after 1994, despite the stated intentions of the government, the historically black schools are still much more poorly resourced than the historically white schools, as even the most casual observation after a drive through any South African city or town will show.

The public and scholarly discourse on gender inequality in South African society at large, and in education in particular, has been subdued by the intensity of attention given to racial inequalities, so in contrast to the research agenda internationally, domestically not much attention has been paid to gender inequalities (cf. Wolhuter 1994, 1997a, 2014a). However, this dimension of inequality in education is by no means absent. In the National Senior Certificate Examinations, male candidates got, on aggregate, $4 \%$ higher marks than female candidates (RSA 2019b). Women constitute $72.5 \%$ of all teachers in South Africa, but only $37.3 \%$ of all school principals (Skosana 2018). Insofar as South African society is (for whatever historical or current reasons) a male-dominated, patriarchic or chauvinistic society (claims frequently made in public and scholarly discourses) - examination or elaboration of this is beyond the scope of this chapter - this too is bound to impact adversely on educational participation and achievement of female learners and students. 
Educational inequalities related to socio-economic status of families are also strongly present, if muted in the discourse dominated by racial inequalities. For example, whereas some $90 \%$ of children of 4 years of age from the most affluent quintile of South African families are in structured and formal early learning programmes, the corresponding figure for the poorest quintile families is 50\% (Berry et al. 2017:35).

Globally, it was especially the volume Schooling in capitalist America: Educational reform and the contradictions of economic life (Bowles \& Gintis 1976) that defending the thesis that schools function to reproduce existing socio-economic stratification patterns in society, brought the extent of educational inequalities along the dimension of socio-economic descent to the fore. Apart from the trinity of inequality (the dimensions of gender, race and socio-economic descent), other categories of educationally marginalised children in South Africa include children of people classified as refugees, dislodged people, or illegal immigrants; children of the unemployed; dependents on social grants; the destitute; domestic workers; the poor; chronically ill people; people living from garbage; and car guards as well as street and parentless and/or guardianless children. Weybright et al.'s (2017) empirical research on South African secondary school dropout rates found that living with a father and living with a mother are $87.7 \%$ and $63.1 \%$ accurate predictors of secondary school dropouts, respectively.

\section{Contextual imperatives}

The following are compelling contextual forces impinging on education in South Africa.

The first is that South Africa is a linguistically diverse country. Manifest evidence of this is that the country has 11 official languages. None of these is the first language of an outright majority of the population. The respective percentages of first language speakers of these 11 languages in rank order are isiZulu, 22.7\%; isiXhosa, 16.0\%; Afrikaans, 13.5\%; English, 9.6\%; Sepedi, 9.1\%; Setswana, 8.0\%; 
Sesotho, 7.6\%; Xitsonga, 4.5\%; Siswati, 2.6\%; Tshivenda, 2.4\%; and isiNdebele, 2.1\% (RSA 2018). As was pointed out earlier (and this is taken up again in subsequent chapters in this book), English (with the exception of Afrikaans) becomes the language of teaching and learning from the fourth year of school, and nine of the indigenous African languages at this point cease to be used as the language of teaching and learning. This presents an immense challenge or dilemma, is detrimental to quality education and creates an impossible situation regarding the equalisation of educational opportunities.

The second salient contextual factor that impinges schools in South Africa are the extant lack of social capital in South African society and a very high number of incidents of violence in the country. For example, 52.1 people are murdered in South Africa every day - which is a murder rate of 34.1 per 100000 persons per year (Africa Check 2018). It is not hard to imagine how this culture of violence spills over into school premises, making schools unsafe and making the task of teachers to maintain discipline all the more difficult (cf. Segalo \& Rambuda 2018).

The next contextual problem flashing red lights to education, alluded to above at one point, is the alarming - and growing levels of unemployment in South Africa. The latest available statistics at the time of writing this chapter (18 August 2019) are that of the second quarter of 2019. The unemployment rate in South Africa has reached an all-time high of 29\% (RSA 2019b). In the second quarter of 2019 alone, the absolute number of unemployed people of working age in South Africa increased by 455000 (RSA 2019b). Moreover, the expanded unemployment rate (i.e. including those of working age who have given up searching for a job) has risen to 38\%, and for the first time, this number of unemployed people in South Africa topped the 10 million mark. An even more acute aspect of this problem of unemployment is the extent of NEET ('not in employment, education or training'), that is, young people aged 15-34 years who are neither employed nor in any education or training programme (i.e. they are not fulltime students at any education institution). Of the 20.4 million 
young people aged $15-34$ years, $40.3 \%$, or a staggering 8.2 million, are not in employment, education or training (RSA 2019b). On the one hand, over 16 million adult South Africans are dependent on some form of social grant for an income, and on the other hand, the small tax base makes economic growth all the more imperative. Only $10 \%$ of the population pays $86.9 \%$ of all income tax in South Africa, the next percentile a further $10.4 \%$, which means that $80 \%$ of the population contributes merely $3 \%$ of income tax to the fiscus (Fourie 2019:2). As the figures quoted under the section of education quality show, there is an inverse correlation between education achievement and unemployment. However, the rising levels of unemployment for the similar levels of education achievements amongst the younger sections of the population point to the spectre of schooled unemployment looming on the horizon. This means that getting the world of education in step with the world of work (i.e. the needs of the labour market) is urgent.

\section{The South African higher education system}

This section begins with a brief survey of the historical evolution of the South African higher education system, to comprehend the challenges history bequeathed this system in 1994, when it suddenly faced the new post-1994 contextual challenges and the compelling force of the global higher education revolution, which at that time began to gather force. The main tenets of the post1994 contextual imperatives and the global higher education revolution are outlined in turn. Finally, the achievements of South African higher education reforms and developments since 1994 are assessed and the remaining challenges identified.

Higher education in South Africa commenced rather late (cf. Carruthers 1992:59-75) when the University of Good Hope was established in 1873 (this institution became the University of Cape Town) under the auspices of the then British colonial administration. In the course of time, the following universities 
were founded: the University of South Africa (1916; eventually this university was changed into a distance education university), Stellenbosch University (1916), University of Cape Town (1916), Witwatersrand University (1922), University of Pretoria (1930), University of Natal (1949), University of the Orange Free State (1950), Rhodes University (1951), Potchefstroom University (1951), University of Port Elizabeth and the Rand Afrikaans University (1967). All these universities supplied higher education to the white segment of the population. Furthermore, they were all created on the template of Britain's university model, with its characteristic liberal academic education. During the 20th century, a second type of higher education institution (HEI) emerged, namely, the technikons (see Ogude, Netswera \& Mavundla 2003:283-299), supplying higher education of technical vocational nature. Eight technikons for white people were eventually created, that is, the Cape Technikon, Natal Technikon, Port Elizabeth Technikon, Pretoria Technikon, Vaal Triangle Technikon, Witwatersrand Technikon, Free State Technikon and Technikon RSA (the last offered distance education).

Tertiary education for black South Africans, on the other hand, began in 1916, when the South African Native College was founded at Fort Hare. This college became autonomous in 1949 and from then was known as the University of Fort Hare (see Morrow \& Gxabalashe 2000:481-497). The year 1948 is a major period in the history of South Africa. In that year, the National Party was voted into power by the white electorate. It put in place policies of rigorous de jure as well as de facto segregation ('apartheid') (a colonial society, de facto racial segregation had existed in South Africa before 1948). This segregation also entailed educational segregation (see Wolhuter, 2015). As part of this policy, HEls were created, each exclusively for students of a particular black ethnic group. Higher education institutions for exclusive use were established for both Indians (South Africans of Indian descent) and 'mixed race' (South Africans of a mixed racial descent) (see Wolhuter et al. 2018:278). 
By the end of the 1980s, the following universities existed: for black people, the University of Fort Hare, the University of Transkei, the University of Qua-Qua, the University of Bophuthatswana, the University of Zululand, Medunsa University, the University of the North, the University of Venda and Vista University; for Indians, the University of Durban-Westville; and for mixed race people, the University of the Western Cape. Also, paralleling higher education for white people, by the end of the 1980s, the following technikons existed: for black people, the Technikon Northern Transvaal, Mangosuthu Technikon and the Setlogelo Telchnikon; for mixed race people, the Peninsula Technikon; and for Indian people, the M.L. Sultan Technikon.

The policy of separate segregated education systems and universities was strongly objected by black South Africans and condemned as being of low quality and aiming to reinforce inequality and white hegemony (vide: Christie 1991:229-265; Karis \& Gerhart 1977; Nkomo (ed.) 1990; Tabata 1960; UNESCO 1972).

Resistance to black education (see inter alia De Wet \& Wolhuter 2009:359-376) took the form of countrywide uproar by black students (primary school, secondary school and university students), and this reached a zenith with the Soweto uprising in 1976. By the mid-1980s, black education was in a crisis manifested in school boycotts and lecture boycotts at universities, entangled inseparably with the broader socio-political turmoil and resistance against apartheid. In many schools, teaching and learning came to a halt and many universities were often closed, with their lectures cancelled. This was the situation of black education with the commencement of South Africa's new political order in 1994 (cf. Booyse 2011:248-268). In 1993, that is, at the end of the pre1994 dispensation, white, Indian, mixed race and black South African gross higher education enrolment ratios were, respectively, 50.4\%, 30.4\%, 9.7\% and 11.1\% (Wolhuter 1998:15).

It is clear that as the new government took control in 1994, with a new policy and creating a new socio-political dispensation, in no small part brought about by objections to the pre-1994 
education dispensation, higher education in particular, its reshaping was on the cards. However, it was not only the imperatives of the new socio-political context which impacted higher education. As South Africa, and in particular its higher education, became part of the international fold again (after boycotts isolated the country from global developments for well-nigh three decades), South African higher education also felt the force of the international higher education revolution, which at that time (1994) had begun to sweep all over the world.

Since 1990, at least six interrelated societal forces have been driving international higher education. These are demographic forces, economic growth, economic transformation, globalisation, the information and communications technology (ICT) revolution, and the neo-liberal economic revolution and democratisation. Global demographic dynamics include the population explosion, the changing age pyramid and the increasing mobility of people. (Population growth is concentrated in the Global South, which has directly affected higher education, for it has created an evergrowing demand for employment in HEls Indirectly, this has also affected, in terms of global student mobility, the HEls of the Global North.). Since 1990, the world was the scene of one of the most sustained and forceful economic growth phases in history. This spectacular rise in economic output and the resulting growing affluence put higher education within the financial reach of a growing number of people. The most advanced economies in the world were experiencing a transformation as they entered a new phase of economic development, namely, a knowledge society, which is the next phase in economic history, after the sequential stages of a hunter and gatherer economy, an agricultural economy, an industrial manufacturing economy and a service economy. The rise in knowledge societies lends new, enhanced value and relevance to higher education. As from 1990, a neo-liberal economic revolution has taken place in developed societies, from where it has rapidly spread to the countries of the erstwhile Eastern Bloc and to those of the Global South (see Schiavone 2005:1, 10). The capabilities of individuals realised by 
the information, communications and transportation technology revolutions, the demise of the once strong central nation-states and the wave of economic liberalisation have given momentum to political democratisation, also commencing in the West, which disseminated to the nations of the East and the Global South.

The key features of the resulting higher education revolution have been massification and democratisation, competition and differentiation, a shift in funding patterns and the emergence of private and corporate universities, a shift in relations between university and state and between university and industry, emerging managerialism at universities, the imperative for relevance, a new professional working atmosphere for academics, the restructuring of programmes and curricula, a new research agenda and renewal of teaching methods (cf. Wiseman \& Wolhuter 2013:9). The summative effect of population explosion, economic growth, economic transformation and democratisation has been the transformation from elite to mass higher education. The extent of this massification, which constitutes the key feature of the global higher education revolution, is manifested in enrolments and enrolment ratios, which are presented in Table 1.2.

Democratisation, constituting a key trend in the world since 1990, has made an impact on university campuses (together with the neo-liberal economic revolution, which has recasted the role of students from learners to consumers), especially with respect to students who have been empowered and gained a much stronger role in the running of universities,

TABLE 1.2: Growth of global higher education enrolments and enrolment ratios since 1990.

\begin{tabular}{lcc}
\hline Year & $\begin{array}{l}\text { Global higher education } \\
\text { enrolments (million) }\end{array}$ & $\begin{array}{l}\text { Global higher education } \\
\text { enrolment ratios (percentage) }\end{array}$ \\
\hline 1990 & 68 & 14 \\
2000 & 100 & 19 \\
2010 & 182 & 29 \\
2017 & 221 & 38 \\
\hline
\end{tabular}

Source: UNESCO (2019). 
including academic projects. However, even stronger than democratisation has been the force of neo-liberal economic revolution. This has entailed the carrying of business principles into the higher education sector. This included the profit motive, the cult of efficiency and, sadly, the performance measurement cult. The result of all this was increasing managerialism experienced by the academic professionals, distracting them seriously from their role in the unhindered, free pursuit of truth (cf. eds. Locke, Cummings \& Fisher 2011). The neo-liberal economic revolution, which has as one of its key principles the downscaling of the range of activities of the state, also had, as one of its consequences, a decline in public spending on education, higher education in particular. At the same time, in as far as the state remained the biggest single funder of higher education, it claims to bigger say in the running of universities.

Two trends - prima facie contradictory - in education in this global higher education revolution have been the differentiation of institutions/institutional missions and the golden bar of a 'world-class university', which well-nigh every university is aspiring to achieve. In what Friedman (2006) calls the contemporary 'flat world'- that is, where geographical advantage in terms of location of endowment with natural resources has been obliterated by the revolution of ICT - and in the nascent knowledge economy of today (i.e. an economy where the production and consumption of new knowledge has become its driving axis), education, the university (as the summit of national education systems) has assumed new importance. The result is that in the globally competitive world, nations are in a race to cultivate world-class universities, as evident from the frantic industry of university rankings (completely unknown as little as a generation ago).

It was not only the global higher education revolution that hit the South African higher education landscape in 1994 in full force but also the contextual imperatives emanating from the new socio-political framework. The discourse which gave momentum 
to the socio-political turmoil and the politics and the electioneering in the run-up to 1994, during 1994 and in the years after 1994 created an expectation that education in general, and higher education in particular, was scheduled for a major overhaul.

Following were the principles of this policy, the intrinsic goals of the post-1994 education system (cf. Wolhuter 1999):

- Democratisation: This was to counter the much criticised authoritarianism of pre-1994 education.

- Desegregation: This was then hold forth as the antithesis of the apartheid system collateral in the field of education, the policy of separate educational institutions and the systems for different population groups.

- Decentralisation: This too was presented as an antidote to the pre-1994 authoritarianism.

- Equal educational opportunities: As stated earlier, the inequality of pre-1994 education was a grievance foregrounded in the political mobilisation of people in the run-up to 1994.

- Multicultural education: Pre-1994 education was also deemed Eurocentric, neglecting the heritage (history and culture) of black South Africans, and multiculturalism was proffered as education creed to rectify this.

The entire education system provides a ladder of opportunities for lifelong learning for every citizen of South Africa. For this reason, a National Qualification Framework (NQF), in which every education programme should be accredited and fitted, was developed and a National Qualifications Council was established. Within the radically reconstructed society, education was given a tall order in terms of external or societal objectives as a task to pursue. These entailed the following objectives (cf. Wolhuter 2015):

- Economic objectives: These include stamping out poverty and catalysing South Africa's economic productivity and development. 
- Social objectives: These pertain to the kind of society that is being strived for, that is, a society rid of racial, gender and other forms of unfair discriminations and a society where social mobility occurs and artificial barriers in the way of people's progress have been dismantled.

- Cultural objectives: These refer to the empowerment of people so that they can participate in activities of cultural expression.

- Political goals: Empowering citizens to take part in the processes of a democratic society and nation-building, that is, building a political culture with democracy, equality, freedom, peace, justice, tolerance and stability as key features.

- Moral goals: At that time, the Department of Education released Manifesto on values, education and democracy (Department of Education 2001), explaining that the new society vision stemmed from a common value system characterised by democracy, social justice and equality. Chiming in with this, education in South Africa should promote the following values: equality, tolerance, multilingualism, openness and social honour. These values flow from the ideals of democracy, social justice, non-racism and non-sexism, human dignity (Ubuntu), an open society, accountability (responsibility), rule of law, respect and reconciliation (Department of Education 2001).

Finally, turning to an assessment of achievements since 1994 and the remaining challenges, spectacular progress has been made since 1994 in terms of enrolment growth and equalisation, as shown in Table 1.3 and Table 1.4.

TABLE 1.3: Enrolment progress in higher education in South Africa, 1994-2016.

\begin{tabular}{lcr}
\hline Population group & $\mathbf{1 9 9 4}$ & $\mathbf{2 0 1 6}$ \\
\hline Black & 212042 & 701482 \\
Mixed race & 27474 & 61963 \\
Indian & 34010 & 50450 \\
White & 221827 & 152489 \\
Unspecified & - & 9453 \\
\hline Total & $\mathbf{4 9 5} \mathbf{3 5 5}$ & $\mathbf{9 7 5} \mathbf{8 3 7}$ \\
\hline
\end{tabular}

Source: RSA (2005). 
TABLE 1.4: Enrolment equalisation in higher education in South Africa, 1994-2016.

\begin{tabular}{lccc}
\hline Population group & $\mathbf{1 9 9 4}$ & $\mathbf{2 0 1 6}$ & Percentage of total population \\
\hline Black & 42.8 & 71.9 & 79.3 \\
Mixed race & 5.5 & 6.3 & 8.9 \\
Indian & 6.9 & 5.2 & 2.5 \\
White & 44.8 & 15.6 & 8.9 \\
Unspecified & - & 1.0 & 0.5 \\
\hline Total & $\mathbf{1 0 0}$ & $\mathbf{1 0 0}$ & $\mathbf{1 0 0}$ \\
\hline
\end{tabular}

Note: Percentage of higher education enrolments per population group.

The progress in terms of enrolment has, however, not been matched by progress in the originally stated ideals of multiculturalism and inclusivity. On the one hand, multiculturalism has been eclipsed by a feverish call for decolonisation, and on the other, especially the (white) Afrikaans first language feels marginalised and even excluded at universities (cf. Giliomee 2019:317-325), mirroring concerns also present at the primary and secondary echelons of the education system (Nel 2016; cf. Rubagumya et al. 2011). Belabouring or illustrating the statement as a highly emotionally charged drive for decolonisation, a round of protests broke out at South African campuses in 2015-2016. During this unrest, damage caused to infrastructure alone amounted to at least R150 million (Tandwa 2016). Furthermore, irreparable damage was caused to the image of universities where teaching, learning and research could have taken place in an atmosphere devoid of fear (Van der Walt \& Wolhuter 2016:1018). Harm was also incurred to racial relations and tolerance and to political and economic stability (Van der Walt \& Wolhuter 2016:1018).

However, much merit the pursuit of quantitative targets and the decolonisation of universities in South Africa brought, quality had suffered under these priorities. One indicator of this is the fall in capital expenditure by universities (necessitated by a number of factors, including the fact that student fees cannot be increased 
and government funding has also not increased enough). Capital expenditure by South Africa's HEls has now been falling for two consecutive years (RSA 2019b). The country's 20 universities and six universities of technology showed a $5.4 \%$ decline in capital expenditure in 2017, compared with that in 2016, that is, dropping from R6.22 billion to R5.89bn (RSA 2019b). This is evident from the changing stature of the country in the world university rankings. Whilst there are many ranking agencies, this chapter has used the figures published by the UAE-based Centre for the World University Rankings (CWUR). Since 2012, CWUR has published its rankings of global universities using a basket of indicators covering the quality of education, alumni employment, research output and citations and without relying on surveys and university data submissions. Almost 20000 universities are assessed worldwide (i.e. all universities in the world, depending on the definition of a university), and a list of the top 2000 are published annually. South Africa's top institution in the list dropped from number 114 in 2014 to 230 in 2019 (CWUR 2019). This indicates that South Africa is falling behind in this global throat-cutting race for top universities. Analysts have pointed out this trend of South African universities with respect to other rankings too. When the 2018 Shanghai Rankings (one of the two oldest in the world and regarded as very authoritative) was published, analysis pointed out that fewer South African universities made it to the top 500 (Businesstech 2018).

\section{Conclusion}

From the survey presented in this chapter, it is evident that South African education is facing huge challenges. These challenges are so numerous that it would be very difficult to compile an exhaustive list. It will also not be possible to attain unanimity as to what are the most pressing challenges. However, because these constitute the focus of subsequent chapters in this book, the following critical issues are highlighted here: 
- dealing with (cultural and linguistic) diversity in education

- getting in tandem the world of education with the world of work

- building and securing the future of world-class universities.

This volume is built on the premise that a valuable way to approach these challenges is to cast the scholarly eye on international comparative examples of nations and education systems that have also grappled with these very same challenges, especially nations and systems comparable to South Africa, and such education systems that did succeed in successfully negotiating such challenges. In Chapter 2, the international comparative method in education is explained and justified, and the BRICS countries are presented as a datum line for suitable comparisons with South African education. In the ensuing chapters of the book, the previously highlighted critical issues of South African education are illuminated by means of the experiences of other BRICS countries. 


\section{Chapter 2}

\section{The significance of the BRICS countries as international datum line and data bank for South African education}

Charl C. Wolhuter

Subject Group Comparative and International Education, Education and Human Rights in Diversity Research Unit, Faculty of Education, North-West University,

Potchefstroom, South Africa

\section{Abstract}

One approach to improve the domestic education project is the comparative approach, that is, learning from best ideas, policies and practices of other countries. The proviso is that, for such an

How to cite: Wolhuter, C.C., 2020, 'The significance of the BRICS countries as international datum line and data bank for South African education', in C.C. Wolhuter (ed.), Critical Issues in South African Education: Illumination from international comparative perspectives from the BRICS countries (BRICS Education Volume 2), pp. 29-57, AOSIS, Cape Town. https:// doi.org/10.4102/aosis.2020.BK207.02 
exercise to take place, contextual similarities and differences between the lender country and the borrower country need to be taken into account. On the one hand, in view of the large contextual differences between these countries and South Africa, models from the Global North are not well suited for taking over by South Africa. On the other hand, the best prospects, given the dearth of data and research findings from large parts of the Global South, beckon from the BRICS constellation. These are not only in terms of geographic and growing demographic and economic weight the rising antipodes in civilisation blocks outside the west, but the formal BRICS group formation, and the immanent BRICS university, also offer the best promise for research themes and epistemologies to be developed in extra-western context. The BRICS countries showing traits, such as diversity, in the contemporary world in the extreme, means that the value of research themes explored and epistemologies developed in the BRICS countries can be of value to even modern western societies and contexts (Wolhuter \& Chigisheva 2020). This chapter surveys the BRICS societal context and education projects within the BRICS countries as tertium comparationis for South African education. Ensuing chapters then zoom in on each of the critical issues identified (in ch. 1) in South African education, offering comparative perspectives from one or more of the BRICS countries.

Keywords: Brazil; BRICS countries; China; Comparative and international education; Emerging countries; India; Russia; Tertium comparationis.

\section{Introduction}

In Chapter 1 of the volume, the South African education landscape was surveyed. Even the most cursoric look at that landscape reveals in no uncertain terms the efflorescence of an almost unlimited number of compelling problems. These problems or challenges are so urgent and pivotal for the future of not only education but also South African society (socially, politically, economically and otherwise) at large that some time 
ago the editor of the prestigious scholarly journal South African Journal of Science wrote in an editorial that the country does not have the luxury to experiment any further; it needs to adopt policies and practices that have a proven record of effectiveness in dealing with the enormous challenges facing education (Cherry 2011). This leaves the next best option, namely, to benefit from the experience of other countries. Indeed, founder of the scholarly field of sociology, Emile Durkheim, calls such comparisons between societies, learning from the experiences of other nations, as indirect experimentation (as cited by $\mathrm{Li}$ 2017). However, any such societal comparative exercise is fraught with dangers, and extreme care has to be exercised in selecting a basis or referential point for comparison. 'The problematique and scope involved in comparison of education policy, praxis and scholarship' section of this chapter unpacks the caveats involved in comparative social scholarship in order to identify the pre-conditions for such comparative exercises. Then the particular case of South African society and education is briefly surveyed in order to arrive at the set conditions of candidates for comparison with South African education. The objective of this chapter is to justify the choice of the BRICS grouping as a set of foreign education systems suitable for serving as comparative territory for South African education. The final sections of the chapter survey the societal contexts and education systems and experiences of the BRICS countries. This then together with Chapter 1 sets the frame for rest of the chapters of this book, in which critical issues in South African education are illuminated from the BRICS experience.

\section{The problematique and scope involved in comparison of education policy, praxis and scholarship}

The narrative of the book hitherto runs straight to an operation of comparison of education policy and praxis. Obviously then the scholarship offered falls within the scholarly field of comparative education. Indeed, the editor of the volume and the author of this 
chapter, as well as all contributors to all chapters, are scholars active in the field of comparative education. Yet the term 'comparative', is problematic, notwithstanding an identity giving part of the name of the field. In an enumeration of 10 crises of identity besetting the field, Wolhuter (2015) identified this as one of the crises, and in a classic essay under the title 'The problematic meaning of "comparison" in Comparative Education', comparative education doyen Epstein (1992) too explains this difficulty scholars in the field have to contend with.

The problem can be explained by referring to two broad traditions of scholarship in the field. On the one hand, there are comparativists contending that the gist of the field is to find laws pertaining to the interrelationship between education and societal contexts. The problem is that despite decades of scholarship, a body of such laws, at least in the natural science sense of irrefutable, universal laws, has not been constructed. The antipodal camp of comparativists has been described with the collective name of 'cultural relativists'. These scholars place at the centre the theorem of the field that education systems are shaped by societal contextual forces. Every education system is unique as each (national) education system in the world finds itself in a highly unique configuration of societal contextual forces. This makes for a highly nominalist take on the subject of study of the field, the kaleidoscope of education systems in the world. The problem is, taken to the extreme, if every education system with its contextual ecology in the world is sui generis, then what basis for comparison exists? The author's way out of this conundrum is explained based on his view of the object of study of comparative education. From this view, the ontologico-epistemological basis of comparison emanates, and this explanation culminates in suggesting the education project in the BRICS countries as appropriate referential point for the illumination of challenges in South African education by means of international comparative perspectives. 
On how the scholarly field of comparative education should be defined, no agreement exists (see Manzon 2011:153-183). It is commonplace to describe it as a complex field and a dynamic field, ever testing new boundaries regarding themes of research, research methods and research paradigms. A recent publication, surveying the global state and developments in the field, typify it as 'an infinite field' (eds. Wiseman \& Wolhuter, 2019).

However, the author of this chapter has defined comparative education as having a three-in-one perspective on education (Wolhuter 2018):

- an education system perspective

- a contextual perspective

- comparative perspective.

Firstly, comparative education scholars study the education system. However, the focus of study of comparative education exceeds just the narrow perimeters of the education system as such. So secondly, the education system is studied as the outcome of societal forces. These include economic, political, geographical, social, demographic, life-philosophical and religious forces. Besides studying these societal attributes as shaping forces of education systems, comparative education scholars are also interested in the societal outcomes of education with respect to society (e.g. the effect of education on the incomes of people), the social system (e.g. the effect of education on establishing a society of gender-equality) and so on. Thirdly, comparative education scholars do not study education systems in silos. Various education systems are compared in their societal interrelationships.

One of the sources of inspiration for scientific endeavour is to find uniformity in a large number of phenomena, that is, to strive at generalisations, even universal laws. And whilst education systems may have a universal structure (with invariable components and elements; see Steyn, Van der Walt \& Wolhuter 2015) and 
likewise, whilst the societal context may always be made out of an invariable set of components (see Wolhuter, Van Jaarsveld \& Challens 2018), each of these components and elements can take on one of such a large variety of possibilities, and can manifest in education systems in such a well-nigh infinite number of permutations that the attainment of singular, immutable universal laws, in the sense of laws in natural sciences, should be placed beyond the hope of the possible by scholars in the field. Whilst such an ideal is like a lodestar for the navigator out of reach, it should not distract the scholar in the field to an eternal quest for finding patterns of regularities in the interrelationships between education systems and their societal contexts, searching for regularities at ever higher levels and refining formulations of found regularities in the view of more detailed analyses of the education system-societal context interrelationships.

A helpful perspective can also be found from an etymological analysis of the term 'compare'. The word 'compare' comes from two Latin roots, namely, 'com', meaning 'with' and 'par', which can be translated as 'equal' (Online Etymological Dictionary 2019), thus implying sorting together that which is the same or equal and separating them from those that are different. Stone (1983:54) writes that the ontologico-epistemological basis for the intellectual exercise of comparison is located in the fact that with respect to any two objects in the world, there is bound to be some similarities as well as some differences. Now, if a scholar of comparative education, for example, is interested in the employment of education in stimulating economic growth (a societal effect of education, i.e. an aspect of society-education system interrelationships), he or she may begin with Harbison and Meyers' (1964) classic study calculating the correlation and doing a regression analysis between education enrolment ratios and per capita gross domestic product (GDP) in 75 countries, and finding the impressive correlation of 0.89 on aggregate level. Whilst a strong correlation was found at an aggregate level, residuals of individual cases (i.e. countries) were large. If the scholar wants to predict the chances of increased enrolment 
ratios in a particular country that would be likely to result in accelerated economic growth, he needs to turn to these residuals, paying meticulous attention to the entire societal context in each, trying to identify contaminating variables or features in each context which may hamper or boost the role of education in spurring economic growth.

From this example, the subsequent points are evident about a comparative education study:

- The study is of society-education system interrelationships.

- The study compares different education systems together, separating various systems, based on contextual and education system similarities and differences.

Just as there is always a search for similarities between various education systems and their contexts, likewise there is a place for having contextual and education system differences. With respect to the first, the term tertium comparationis was introduced in the field of comparative education by Ulich (1961) and popularised to become part of scholars' research in the field's key vocabulary by Bereday (1964). The term tertium comparationis, literary meaning in Latin 'the third comparison', refers to the attribute that two objects or phenomena that are being compared have in common. It is the reason for comparison that prompted the scholar of the comparison at work to liken one object to another in the first place (Word Finder 2019). In comparative education, this term has taken on the meaning of securing societal contextual similarities between two countries the researcher is comparing. In view of the potential contaminating role of contextual factors in affecting educational outcomes, this is a valid, even a laudable premise. But there is also a point in searching for, identifying and exploring contextual divergences, as these may well point to contextual forces having a powerful bearing on education too.

This brings the discussion to the next point, namely what is the point or significance or purpose of such an exercise of comparison in education scholarship? The significance or 
relevance of comparative studies in education is manifold, and these have been enumerated (see Wolhuter 2015). What concerns the topic of this chapter, however, are two purposes, namely, the use of comparison in education research to improve policy and to improve practice.

A long-standing rationale of comparative education has been to support and design a new education system, plan education and reform education systems (see Bray 2014:22-25; Watson 2012:32; Wiseman 2012). In rendering better an educational system or in responding to an educational issue, challenge or problem, one nation can learn from the track record of other education systems. When a country contemplates a particular educational issue or obstruction, a comparison with the learning trajectory of other nations that at some time tackled the same issue could reveal the full scope and dimensions of the issue and possible contributory causes and also serve as indication to possible ways of addressing the problem. This rationale for comparative studies in education has been given a new lease of life with the rise of mass data repositories resulting from mass international testing exercises (such as the tests of the International Association for the Evaluation of Educational Achievement and the PISA). Forestier and Crossley (2014) write, for example, that whereas historically the education system and education reforms of Hong Kong were modelled on what took place in the colonial (or later ex-colonial) metropolis of England, in recent years, with Hong Kong coming on top in the PISA tests, education policymakers in England have been taking their cue from Hong Kong.

Likewise, the worth (or potential worth) of comparative education in supporting or guiding the teacher to raise the quality of his or her teaching practice has been demonstrated in several publications (e.g. Bray 2014:19; Planel 2008). Comparative education scholarship can reconstruct the success record of lack of specific teaching methods in particular contexts. Of particular significance is the value of supporting and guiding teachers of multicultural classrooms - as Planel (2008) undoubtedly 
demonstrates in her comparative study of teaching methods in English and French classrooms. Noteworthy and instructively, research on students' expectations and experiences of comparative education courses have revealed that students too seek from these courses assistance with raising the quality of their teaching practice (Wolhuter et al. 2011).

\section{The problematique in finding a comparative data bank suitable for use by South African scholars of education}

From the argument presented in 'The problematique and scope involved in comparison of education policy, praxis and scholarship' section, it can be deduced that when South African scholars of comparative education are looking for comparative data to illuminate education issues in South Africa, they should be guided by the following criteria:

- The criterion of a tertium comparationis, as explained earlier, the fine balance of having foreign systems of education with maximum societal, contextual and educational system similarities, but also differences, so as to be able to detect effect-causing factors.

- There should be enough literature available (unless, in the exceptional case of the scholar being able to do on-site empirical research in a foreign setting).

Against this, the situation pertaining to comparative studies in education is characterised subsequently:

- The corpus of published literature in the field of comparative education consists by far mostly of single unit studies (see Wolhuter 2008). As it can still be argued that such studies build up a stock of knowledge ready to be drawn upon by comparative studies, this feature does not constitute an insurmountable problem for scholars intending to do comparative studies; in fact, it can even be regarded as an asset. 
- As far as comparisons occur, they tend to be steered by comparisons with countries regarded as leaders (educational and otherwise) in the world. For example, in Wolhuter's (2008:328-329) survey of all articles published in the first half century of the existence of the leading journal Comparative Education Review, the United States of America (USA), the erstwhile Union of Soviet Socialist Republics (USSR) and Japan stand out as comparative yardsticks being compared with any other country, no matter how different in contextual imperatives. Two books of foreign education systems have managed to break through the walls of the ivory tower of academe to reach the mass market. The first of these was Thrace's What Ivan knows that Johny doesn't (1961), a comparison between the education system of the USA and that of the USSR. This book, which appeared shortly after the launch of Sputnik in 1957, shook the USA into a selfexamination, the result of which was that education in the USA was seen as a scapegoat and the education system of the USSR was seen as superior, and a quest for knowledge of that education system took off in the USA. The second book was Sahlberg's (2010) Finnish lessons: What can the world learn from educational change in Finland? This book appeared in the wake of the interest and admiration for the education system of Finland after Finland unexpectedly came out top in the PISA tests.

- Apart from the fact that education in Finland and USSR, Russia takes or has taken place in a context widely divergent from that of South Africa, these two books are fairly uncritical appraisals of, respectively, USSR and Finland, and the contextual correlates and pre-requisites of those education systems are not even tangentially touched upon. This brings the discussion to the next problem besetting comparative studies in education; it may be in the scholarly literature or as part of policy discussion documents, namely, the inadequate factoring in of contextual similarities and differences between the countries which are compared 
(see De Wet \& Wolhuter 2007) - this despite the factoring in of contextual similarities and differences being a central article of faith in the scholarly field of comparative education, as explained earlier.

Regarding the penchant, as explained earlier, to nations and education systems of the Global North as a reference point in comparative studies, it should be cautioned that the education system and societal context of these countries are so divergent from South Africa so as to greatly reduce the value of any comparison. Two examples will suffice. Firstly, the levels of affluence of countries in the Global North make possible the kind of education system and infrastructure unattainable in South Africa. Whereas the annual per capita income in South Africa is $\$ 6560$, in the USA, Finland and the UK, the corresponding figures are, respectively, $\$ 62517$, \$45977 and $\$ 42260$ (Statistics Times 2019). Secondly, the imperative - from society, the student corps, the public discourse and political authorities - to decolonise education is absent in the countries of the Global North. Because of the differences in affluence, the learner per teacher ratio at primary school level in Western Europe and North America is 14.1, compared to 33.6 in South Africa (Wolhuter \& Van der Walt 2018). However, the developing countries, or countries in the Global South, are simply too numerously divergent (in terms of, but by no means limited to, economic wellbeing and education development): learners per student ratio in these countries range from 17 to 48 (see Wolhuter 2011). Therefore, a numerically more manageable and contextually more consonant comparative base for South Africa education is called for. It is here that the BRICS grouping comes to the fore. Scholars from a variety of scholarly fields, such as political science, economics and cultural studies, have been drawn to BRICS since it came together in an organised fashion a decade ago (Lo, Hiscock \& Edward Elgar 2014; Vadra 2017, 2018; Van Noort 2018). In subsequent sections of the chapter, the suitability of BRICS as candidature and reference point for the illumination 
of issues in South Africa by means of international comparative perspectives is investigated under the following rubrics:

- the weight of the BRICS countries in the world

- the societal context of the BRICS countries

- education development in the BRICS countries

- the BRICS organisation

- BRICS as a supernational taxonomy in scholarship

- a possible broader (i.e. BRICS plus) taxonomy in scholarship.

\section{The weight of the BRICS countries in the world}

Political geography teaches that the three factors that determine national power are geography (surface area), demography and economy (Pounds 1972). Whilst a crude generalisation, and far from being an exhaustive list of the factors constituting national power, this chapter uses this analysis to gain an estimation of the weight of the BRICS countries in the world of the early 21st century.

As the largest country in the world in terms of surface area, Russia occupies 17.1 million $\mathrm{km}^{2}$. China is the fourth biggest country in the world covering 9.6 million $\mathrm{km}^{2}$, Brazil comes fifth with 8.5 million $\mathrm{km}^{2}$ and India seventh with 3.2 million $\mathrm{km}^{2}$. South Africa covers 1.2 million $\mathrm{km}^{2}$, making it the 25th largest country in the world. Put together, the BRICS countries occupy 29.6 million $\mathrm{km}^{2}$, or $19.9 \%$ of the land mass on earth.

The demographic strength of the BRICS countries is presented in Table 2.1.

China and India are, respectively, the most populous and second most populous countries on the globe. Together, the BRICS countries have a total population of 3.118 billion, which means the BRICS countries have $40.49 \%$ of the total global population of 7.7 billion. 
TABLE 2.1: The demography of the BRICS countries.

\begin{tabular}{lccc}
\hline Country & Total population & $\begin{array}{l}\text { Rank order in the world } \\
\text { in terms of population }\end{array}$ & $\begin{array}{l}\text { Annual growth rate } \\
\text { (percentage) }\end{array}$ \\
\hline China & 1.4 billion & 1 & 0.43 \\
India & 1.3 billion & 2 & 1.02 \\
Brazil & 213 million & 6 & 0.75 \\
Russia & 146 million & 9 & 0.09 \\
South Africa & 24 million & 24 & 1.33 \\
\hline
\end{tabular}

Source: Worldometers (2019).

TABLE 2.2: The economic power of the BRICS countries.

\begin{tabular}{lccc}
\hline Country & $\begin{array}{c}\text { Gross domestic } \\
\text { product (in \$ billion) }\end{array}$ & $\begin{array}{c}\text { Gross domestic } \\
\text { product, percentage } \\
\text { of global economic } \\
\text { output }\end{array}$ & $\begin{array}{c}\text { Gross domestic } \\
\text { output, rank order in } \\
\text { the world }\end{array}$ \\
\hline China & 14172 & 16.1 & 2 \\
India & 2958 & 3.36 & 5 \\
Brazil & 1930 & 2.19 & 9 \\
Russia & 1649 & 1.87 & 12 \\
South Africa & 385 & 0.48 & 31 \\
\hline
\end{tabular}

Source: Statistics Times (2019).

Turning to economic power, the GDP of the BRICS countries and the portion thereof of the global economic output are portrayed in Table 2.2.

Together, the BRICS countries are responsible for $23 \%$ of the global economic output. Whilst considerable, it is out of sync with the demographic and geographic weight of this grouping in the world. Taken together, the BRICS countries represent (as measured by geography, demography and economy) a significant bloc in the world.

\section{- Societal contexts}

For surveying, analysing and comparing the societal contexts of the BRICS countries, the schema conventionally used in the scholarly field of comparative and international education is 
distinguishing between geography, demography, sociocultural situation, economy, political system, and religion and life and world philosophy (see Wolhuter et al. 2018).

\section{Geography}

In the preceding section dealing with the weight taken on by the BRICS countries in the world, the geographic extent of the BRICS countries was touched upon. All five countries are relatively large, although their geographical proportions vary considerably, with the largest, Russia, being almost 15 times the size of the smallest, South Africa. Further to this, the BRICS countries are geographically endowed with particular and diverse features. Brazil is located in the equatorial zone, with the world's largest river and equatorial forests; Russia is located in the steppes and ice fields, India has the monsoon climate and China and South Africa are located in temperate and semi-arid and arid latitudes. South Africa is, relative to its size, the country with the richest mineral resources in the world. India and China are notably poor in mineral resources. All five BRICS countries, however, have to negotiate their share of the global ecological crisis, although in varying degrees. In 2019, the global Earth Overshoot Day (i.e. the day in the year when the environment is used to the point where natural forces can replenish in a year) was 29 July; for the individual BRICS countries, this day was 26 April for Russia, 14 June for China, 08 July for South Africa, 31 July for Brazil and 01 August for India (India: 2018 figure) (Earth Overshoot Day 2019).

\section{Demography}

The significant numbers of people that the BRICS countries make up in the global population have been noted previously. The annual population growth rates of the BRICS countries are $0.09 \%$ for Russia, $0.43 \%$ for China, $0.75 \%$ for Brazil, 1.02\% for India and $1.33 \%$ for South Africa (Worldometers 2019). These figures mean 
that the BRICS countries' spectrum straddles the global average of $1.08 \%$ per year. Whilst still way below the African aggregate figure of $2.52 \%$, South Africa has a higher population growth rate than the other BRICS countries.

\section{Sociocultural situation}

When surveying the South African societal context in Chapter 1, the sociocultural diversity was highlighted as a very conspicuous facet, with first language used to illustrate the point. Whilst increasing diversity is (and this point is very relevant to the discourse of this chapter) a trend gathering momentum in virtually every country of the world, this feature is acutely present in the BRICS countries. Whilst 98\% of the population of Brazil speaks Portuguese as the first language, there are a myriad of Amerindian languages also spoken there. Then Brazil got a significant component of her population from Africa during the period of the trans-Atlantic slave trade. It is not widely realised that, after Nigeria, Brazil is the country in the world with the largest number of people of African descent.

The post-1990 dissolution of the USSR into a number of nation states did not result in a homogenous Russia either, as later events in, for example, Chechnya, have testified. In Russia, 35 languages used in various parts of the country are recognised officially.

The constitution of China recognises 55 ethnic minorities, although in each case the language pattern is even more complex. Further to this, a significant minority language community such as the Cantonese is not provided for in the constitutional dispensation. India's constitution recognises 22 languages.

On the other striking feature of the South African society, that of inequality, the BRICS countries show an interesting variety. Measured in terms of income disparity, the Gini Index values of the BRICS countries are as follows: South Africa, 62.5 (2nd in the world); Brazil, 49.0 (19th); China, 46.3 (29th); Russia, 41.2 (57th), 
and India, 35.2 (95th in the world) (Central Intelligence Agency 2019). The World Bank considers $40 \%$ as the threshold, higher of which signifies dangerous levels of inequality. The BRICS grouping of countries straddles this divide. Interestingly, despite the exemplary performance on the income distribution front, India is known as an extremely socially compartmentalised society, and the traditional caste system lingers on. This is a situation paralleling that of South Africa, where the effect of extreme pre1994 segregation policies is still evident. In both countries, policies of affirmative action and education are regarded as instruments to create more equalitarian societies.

\section{Economy}

The economic force which the BRICS grouping represents in the contemporary world has been explained above. The current economic growth rates of the BRICS countries are presented in Table 2.3.

With the global aggregate economic growth rate of $3.0 \%$, the BRICS countries, as they do in case of population growth, are straddling the global spectrum.

\section{Politics}

All five BRICS countries went through a phase of radical political restructuring in recent history. In South Africa, a new Constitution and dispensation was ushered in 1994. This change entailed a

TABLE 2.3: The economic growth rates of the BRICS countries.

\begin{tabular}{lc}
\hline Country & Growth rate (2018) (percentage) \\
\hline China & 6.6 \\
India & 7.0 \\
Brazil & 1.1 \\
Russia & 2.3 \\
South Africa & 0.8 \\
\hline
\end{tabular}

Source: World Bank (2019). 
constitution on the western liberal template, fortified by a Manifesto of Human Rights, widely praised as one of the most exemplary in the world. The challenge lies in the practical realisation of this manifesto as well as menacing signs of populism (mercifully thus far contained). Brazil saw not only a return to democracy from 1986 (after a spell of military rule, 1964-1986) but also (and somewhat stronger than South Africa) recent signs of rising populism amongst its rulers and electorate. India became independent in 1947 after two centuries of colonial rule, followed by a forceful embracement of neo-liberal economics since 2014 under the Modi administration. Populism has also reared its head, as is evident from the recent election results. In an about turn, in 1990, Russia embraced both democratic principles and the free market economy. However, populism and a disregard for human rights have reared its head in recent times. China has also in an about turn embraced the principles of a free market economy in 1979 but resisted any attempts to establish a dispensation based on a guarantee of human rights.

\section{Religion and life and world philosophy}

All the BRICS countries find themselves, as far as religion and life and world philosophy are concerned, at the confluence of a number of currents, some of them in conflict with each other. These currents can roughly be typified as the traditional, the historical and those brought about by the forces of the modern, globalised world. Amongst the traditional count are Confucianism in China, Roman Catholicism in Brazil, Hinduism in India, Orthodoxism in Russia and in the case of South Africa, traditional African values and culture. The historical philosophies include Maoism in China, post-colonial traces in India (cf. e.g. the position of and the penchant for the English language), communism in Russia and Christianity and vestiges of colonialism in South Africa. The 21st-century globalised world has brought with it forces of (western origin) individualism, materialism and consumerism, as well as the Creed for Human Rights, democracy 
and the neo-liberal economic revolution (which is far more than a narrow economic doctrine if it does not constitute a full blown philosophy). Reactions to these forces have also spawned a number of life and world philosophical stances, such as various strands of populism, new ethno-nationalism and post-colonial creeds or a call for decolonisation.

This is a portrait of the societal contextual kaleidoscope shaping education in the BRICS countries. Subsequently, the education panorama of the BRICS countries is surveyed.

\section{Education in the BRICS countries Brazil}

Education in Brazil, as in Latin America overall, developed slowly during the colonial era as well as during the first 150 years since the advent of independence. A massive education expansion effort was made since the mid-20th century, aiming at intrinsic goals (universal adult literacy and universal primary school attendance, and later lower and upper secondary education too as well as mass higher education participation) and extrinsic goals of economic growth and poverty reduction (Wolhuter 1995). This effort has resulted in commendable expansion of education but has also encountered its own share of problems and challenges, which affect negatively the education effort. These include rampant population growth, widespread poverty, political instability and the economic squeeze (Wolhuter 1995). Under these circumstances, education has had to contend with problems of low quality and uneven spread of resources, whilst the spectre of schooled unemployment has also reared its head (Wolhuter 1995). Given the parallels between Latin America and Africa (South Africa included), particularly in education, one published comparative study between Latin American and South African education has carried the title: 'Education in Latin America: Lessons for South Africa from a sister continent' (Wolhuter 1995). 
As could be expected from her population numbers and the historical survey, the size of Brazil's education effort is staggering. According to the latest available figures, enrolments at preprimary school, primary school, secondary school and higher education levels stand at respectively 3406796, 16118565, 23536672 and 8318089 , whilst gross enrolment ratio levels come to $37.54 \%$ for early childhood development programmes, $113.95 \%$ at primary school level, $101.54 \%$ at secondary school level and $56.49 \%$ at higher education level (UNESCO 2019) (percentages exceeding $100 \%$ can be explained by the large number of overaged learners). It was especially during the term of office of President Lula (2003-2010) and his successor, Dilma Rousseff (2011-2018), stringent efforts were made to reduce poverty in Brazil, and education was seen as an instrument towards this effort (Brock 2013:159). During 2000-2008, per student public expenditure on education at primary and secondary education levels rose by $122 \%$ (Brock 2013:159). This made possible an impressive rise in enrolments, which is evident in the figures cited earlier. Spending on education, percentage of GDP increased from $3.5 \%$ in 2000 to $5.3 \%$ in 2008 , rising to $6.2 \%$ in 2015 , well above the Organisation for Economic Cooperation and Development's (OECD) average of 5.9\% (Brock 2013:159).

The large higher education system was made possible by the substantial private sector. Two-thirds of the universities are private universities. The pattern in Brazil mirrors that of Latin America, where public universities are the highly prestigious universities, and private universities are less prestigious institutions of higher education. Under global influences, as well as part of the neo-liberal economic revolution affecting the higher education sector, Brazil introduced in 2004 'The National System of Higher Education Assessment' to evaluate and accredit both public and private universities (Pedrosa 2011).

Brazil is the ground turf where Paolo Freire developed and demonstrated his well known 'Literacy in 45 days' in the early 1960 s, and his theory of 'literacy for critical consciousness'. 


\section{Russia}

Russia went, at the same time as South Africa, that is, from the early 1990s, through a three-fold process of political democratisation, embracing the free market economy and joining the international fold or global community, a process paralleling that of South Africa. However, in the case of Russia, regression concerning both democratisation and professing human rights has somewhat tarnished the image of the country. This new societal context also created the imperative for a radical overhauling and redesigning of the country's education system, once again showing simultaneously many parallels with the South African education system. Key features of the post-1990 education dispensation were decentralisation; de-ideologisation of the curriculum; giving space to private education and religion in education; shifting the focus, as the aim of education, from USSR patriotism and international communist solidarity to (Russian) nationalism and internationalism; differentiation and diversification; and feeling the effect of economic constraints (cf. Wolhuter 1996).

Between 2002 and 2009, public expenditure on education rose from $3.7 \%$ to $4.6 \%$ of the GDP (although some of this has been cancelled out by a shrinking economy) but declining again to $3.7 \%$ in 2016 (World Bank 2019). The USSR government built up an impressive system of education from nothing after taking over the government in 1917 (see Wolhuter 1996). Enrolments rose steeply and remained high. Gross enrolment ratios in Russia at early childhood programmes, primary, secondary and higher education levels are, respectively, 57.14\%, 102.58\%, $103.38 \%$ and 81.91\% (UNESCO 2019). However, in PISA, Russian students have performed somewhat modestly and her educational institutions have been criticised for encouraging rote learning rather than critical analysis and evaluation of information (OECD 2011). Inequality in education has also increased since 1990 (Brock 2013:172). 
To zoom in on the staggering $81.91 \%$ higher education enrolment ratio, not only in terms of size but also in kind, Russia is noteworthy from a scholarly point of view as it currently displays an interesting variety of HEls. It contains both the traditional programmes offering the 5-year undergraduate specialist diploma - a relic from the Soviet times, and itself being a combination of the historically long cycles of first higher education qualifications which had characterised continental Europe before Bologna, and the Soviet vocationally oriented education programmes and institutions that embraced the Bologna process, offering 3- or 4-year Bachelor programmes. Further to this variety, besides public institutions, a variety of private HEls have mushroomed since 1990.

The USSR had drawn the interest of the comparative education scholarly fraternity in the 1960s. Writing in the early 1960s, Thut and Adams (1964:172) alleged that the volume of studies on Soviet education, during that period, exceeded that of all other national systems of education. After a surge of interest in Russian education reforms during the first few years after 2008, sadly, Russian education has diminished on the international agenda of the comparative education scholarly community (see Wolhuter 2008).

\section{India}

In terms of enrolment ratios, India represents the trend opposite to that of Russia on the BRICS spectrum. Whilst the gross primary school enrolment ratio is $112.96 \%$, gross secondary and higher education enrolment ratios stand at respectively $73.48 \%$ and 28.06\% (UNESCO 2019). During independence, adult illiteracy stood at a paltry $12 \%$. Even today, India is the country in the world with the maximum number of illiterate adults: 256 million (Wolhuter \& Barbieri 2017). 
Of the four BRICS countries other than South Africa, India is also the most poverty-stricken and has the most unequal society. The institutionalised caste system also means that social mobility is much slower than, for example, Brazil (Brock 2013:159). Nonetheless, in 2010, the Right of Children to Free and Compulsory Education Act was passed, committing the nation to free and compulsory education for children aged 6-14 years. India has also been the terrain of noteworthy projects in the pursuit of universal primary education, such as Operation Blackboard and the District Primary Education Project. Public spending on education is relatively low and has, for some time, remained around 3.8\% of the GDP (see Brock 2013:160; World Bank 2019). There is also an exodus of learners from public to private schools, a trend especially visible in learners from middle class families.

The 28 states and eight union territories of India have diverse combinations regarding culture, colonial legacy and local political orientation, as well as educational arrangements. With the Hindu religion and world view standing strong, there has been a longstanding tension between 'modernist' and 'traditionalist' approaches to development (Baxi \& Parekh 1995). This has been evident in the recent past in the differences between the Manmohan Singh government (2001-2014), practising unflinched neo-liberal economics, and the next administration of Narendra Modi, of the Bharatiya Janata Party, standing on a ticket of Hindu nationalism. The issue of English (strong because of both historical reasons - the colonial language and currently the international lingua franca in a globalised world) versus national language, Hindi, versus other (regional) first languages in education has been resolved in a variety of ways, varying from state-to-state and time-to-time.

Higher education has seen a forceful expansion in recent years. Between 2005 and 2010, 200 new universities and 3000 new colleges were established (Agarwal 2017). Over 50\% of university students in India are now in the private sector (Altbach, Reisberg \& 
Rumbley 2009). Concerns about the quality of education resulted in the formulation of an accreditation law.

\section{China}

China has developed the world's most expansive education system, at least in terms of enrolments and number of teachers. In the 2010-2011 academic year, China (which, just as the USA and the countries of Western Europe, follows the Northern Hemispheric calendar for the academic year, i.e. it begins in September and goes to June) overtook the USA by becoming the largest higher education system in the world in terms of number of students - a feat rendered even more remarkable if it is borne in mind that China had to rebuilt her university system from base after it was virtually destroyed during Mao ZeDong's Cultural Revolution of 1966-1976. Even at the level of doctoral education, China has taken the lead: in the 2016-2017 academic year, China delivered 71000 doctorates and has overtaken the USA (48 000 doctorates).

China has embraced, as Russia and India, but more forcefully so, the principles of a free market economy. However, whereas the results in Russia were chaotic and in India remarkable, it caused a miracle in China, propelling it to rival the USA as the largest economy in the world. Unlike Russia and India, China has neither embraced the creed of human rights nor even claimed to democratise (at least in the western sense of the word). As in Russia, in China post-Mao education policy has seen decentralisation as one of its hallmarks, and the private sector became a significant partner in the supply of education. The Minban or people-run institutions (which range from kindergartens to HEls) became a strong part of China's educational architecture.

The importance of early childhood education was emphasised in the National Development Plan (2010-2020). The goal of one year free and three universal years of early childhood education 
are set. This has spurred an increase in public spending in this sector. But still this education is not free. There has been a spurt of private schools at pre-primary school level. In 2016, there were 239800 kindergartens, an increase of 16100 compared to 2015 (Ryan 2019:62).

The 1986 Compulsory Education Law of the People's Republic of China has put in place the 9 years' compulsory schooling.

Higher education was characterised not only by a feverish expansion over the past 40 years (as illustrated above where enrolments were discussed) but also by an equally strong drive to produce world-class universities: projects 985 and 212 and the 'Double world-class project' became the envy of the world.

From the point of handling of diversity, Chinese education is noteworthy too. The 55 minorities acknowledged in the constitution have given rise to special education dispensations for them, such as the 17 universities in China for national minorities. However, the handling of Cantonese in education in Hong Kong, more so in Southern China, is open to criticism.

\section{BRICS organisation}

BRICS was created as a geopolitical bloc in 2009. Originally, the organisation was named BRIC and comprised Brazil, Russia, India and China, but South Africa was later invited to join, and the organisation was renamed BRICS. It was called into being as a bastion or antipode against western dominance in the international arena. BRICS's purpose is to devise multilateral solutions, to rise above the ongoing geopolitical interregnum, a situation where 'subjectivity is over-concentrated in the West at the expense of the nations of the Global South' (Kotze 2019:21). BRICS can, therefore, be regarded as a concerted effort by the vanguard of the extra-western world to increase the agency of that part of the world, in a world characterised by asymmetrical power relations, tilted in favour of the Global North. 
Being part of an organisation, which reaches to all corners of the world and is collectively geographic, demographic and economic as muscular as explained earlier in this chapter, surely presents to South Africa an opportunity (albeit hitherto a much underutilised opportunity) to maximise its policy and strategy (Kotze 2019:31). Yet, despite these promises of the BRICS organisation, South Africa associating itself with such an organisation has also drawn its share of well-argued criticism. Well known historian and commentator on South African public affairs Johnson (2015:193-220) devoted a chapter to a scathing attack on BRICS in one of his recent publications, How long will South Africa survive? The looming crisis. Johnson's criticism includes the discordance of South Africa by virtue of its constitution proclaiming to uphold and promote democratic values in contrast to Russia and China, which are in effect oneparty dictatorships. Further to this, Johnson cautions that the way in which the BRICS bank was set up (tellingly with its headquarters in Shanghai, against the express wishes of the South African government that it should have been Durban) will not favour South Africa, and in fact can easily lead South Africa to dependence on China. The fact that the 'road and belt' foreign drive of China - and the BRICS organisation being a very handy track in this exercise - will only serve China's interests and work to the detriment of others is also a point extensively argued by Frankopan (2018) in his book The new silk roads: The present and future of the world. Recently, a BBC correspondent warned against the setting up and operation of Confucius Institutes in universities throughout the world, as such institutes would serve the interests of the rulers of China, rather than promoting academic or university values (Jakhar 2019).

\section{BRICS as supranational taxon in scholarship}

Thus far, BRICS as a supranational unit has not produced a voluminous amount of scholarly literature, at least not as far as education is concerned. A search on the data web of the 
Education Resources Information Centre (ERIC) on 24 November 2019 under the keyword BRICS produced a paltry 25 sources. In comparison, the keywords EU and European Union drew, respectively, 1399 and 2194 publications. Education developments in individual BRICS countries have produced a large stock of literature, and at times the BRICS countries have made it to the top notches of the research agenda of comparative and international education scholarship; some of this have been pointed out earlier in this chapter. Wolhuter (2008) has analysed the geographical terrain of all articles published in the first 50 years in the top journal of the field and, in this process, identified the 10 most frequent countries forming the focus of research in 5-year periods and found that the BRICS countries registered as follows:

- Volumes 1-5: USSR: The most common country; South Africa: Rank order No. 5; China: Rank order No. 8

- Volumes 6-10: USSR: The most common country; South Africa: Rank order No. 9

- Volumes 11-15: USSR: The most common country; China: Rank order No. 4; India: Rank order No. 6

- Volumes 16-20: China: Rank order No. 7

- Volumes 21-25: China: Rank order No. 6

- Volumes 26-30: China: Rank order No. 2

- Volumes 31-35: China: Rank order No. 5; Brazil: Rank order No. 8

- Volumes 36-40: China: Rank order No. 5; Brazil: Rank order No. 8

- Volumes 41-45: China: Rank order No. 2; Hong Kong: Rank order No. 5; South Africa: Rank order No. 7

- Volumes 46-50: South Africa: The most common country; China: Rank order No. 3; Brazil: Rank order No. 8

It should be pointed out though that this interest in the BRICS countries as research focus has not been matched by prominence of authors hailing from these countries. In 2017, Wolhuter (2017) conducted an investigation into the author provenance of all articles published in all 219 Web of Science-indexed education journals. 
Of the total number of 18523 authors of articles, the crop of BRICS-hailing authors was small:

- Brazil: 198

- Russia: 10

- India: 48

- China: 455

- South Africa: 273

This compares very unfavourably with the USA (6616), the UK (1915), Australia (1490), the Netherlands (1688), Germany (546) and Turkey (614) (Wolhuter 2017). This discrepancy means that much of the literature on education in the BRICS countries was authored by expatriates (a situation common in social sciences, which has often been criticised by social scientists, and also by comparativists of education in particular; see Biraimah 2006) and holds a number of disadvantages, as summarised by Wolhuter (2018).

\section{A broader taxon of 'emerging countries'?}

After a survey of the BRICS countries as supranational taxon, particularly in comparative and international education, there is still the question as to the possibility of a somewhat more inclusive taxon of what is termed (especially in the business world and political discourse alike, and in both spheres has actually become fashionable to talk about) the 'emerging countries'.

There is nowhere a clinical definition, much less a commonly accepted list of emerging countries, or even a commonly set of criteria as to what makes a country an 'emerging country', but apparently the product of the following factors can make a country an 'emerging country': Geographic size, demographic weight, economic output, economic growth rate, political stability and exemplary politics. In the financial world, at least, very influential seems to be the Morgan Stanley Capital International ( $\mathrm{MSCl}$ 2019), whose $\mathrm{MSCl}$ unit trust fund of emerging countries is 
widely followed by other fund managers as a tracker or index fund. Since the inception of this fund in 1988, MSCl has varied its list of emerging countries, but at present, the following 22 countries are listed as emerging economies: Argentina, Brazil, Chile, Malaysia, Mexico, the Philippines, Thailand, Indonesia, Turkey, (South) Korea, Colombia, India, Qatar, the United Arab Emirates, Peru, Taiwan, Egypt, Saudi Arabia, South Africa, Poland, Russia, China and Hungary.

Such a taxon would create a wider datum line for South Africa than the BRICS. On individual countries, a large stock of literature surely exists on their educational efforts, although with the exception of Turkey and South Korea, once again a large part of the literature would have been authored by expatriates. As a group, these countries have never attracted much research from education scholars. An ERIC search under the descriptor 'emerging countries' yielded 21 publications (date of search: 24 November 2019).

\section{Conclusion}

The BRICS countries present a rich source of data for comparative research illuminating education issues. However, scholars using such data for comparative research with South African education, should bear the following in mind:

- The BRICS countries surely have more in common with South Africa (education as well as societal context wise) than either the developed countries, the countries of the Global North or the entire gamut of developing or southern countries. This would make comparison much more manageable and credible.

- At the same time, these BRICS countries, between them as well as within them, contain enough variety regarding education so as to make them very attractive for comparative bases for South African education. 
- The sheer weight of these countries in the world, geographically, demographically and economically, lends an aura of gravitas in any comparative exercise, where they will be used as a reference point.

Finally, whilst (in terms of economy, geography and economic output) South Africa may appear to be the odd case out in the family of the BRICS nations - and for these reasons, follow-up research looking for scope of comparative research amongst the emerging countries will be valuable - critical issues of education that South Africa is grappling with, such as early childhood education, the issue of language of education, building worldclass universities and getting in step the world of education with the world of work, all seem to be very acutely or pronouncedly present in these countries where noteworthy efforts have been made to address them. Therefore, in subsequent chapters in this volume, these issues will be unpacked and illuminated by means of international comparative perspectives from the BRICS countries. 



\section{Chapter 3}

\section{Early childhood education: Benefitting from the BRICS experience by a new front of education development in South Africa}

Early Childhood Development and Education, School of Languages,

Benita Taylor Faculty of Education, North-West University, Potchefstroom, South Africa

Marinda Neethling

School of Psycho-Social Education, Faculty of Education, North-West University, Potchefstroom, South Africa

How to cite: Taylor, B., Neethling, M. \& Seleti, J., 2020, 'Early childhood education: Benefitting from the BRICS experience by a new front of education development in South Africa', in C.C. Wolhuter (ed.), Critical Issues in South African Education: Illumination from international comparative perspectives from the BRICS countries (BRICS Education Volume 2), pp. 59-107, AOSIS, Cape Town. https://doi.org/10.4102/aosis.2020.BK207.03 
Juliana Seleti

School of Psycho-Social Education, Faculty of Education, North-West University, Potchefstroom, South Africa

\section{Abstract}

This chapter introduces Early Childhood Education (ECE) in four selected BRICS countries, China, India, Brazil and South Africa (CIBSA), excluding Russia, since it functions on a much higher level of income, has an industrialised economy, is in an advanced stage of development and was a former superpower. Of the world's population of 7.7 billion, around 3 billion are located in CIBSA. Therefore, $40 \%$ of world's population and $50 \%$ of the population in developing countries live in these selected countries. The four countries further have a considerable potential for articulating a collective voice in the world of multilateralism that can reshape rules and create policy space for other developing countries (Nayyar 2008:4,6; 2016:575-577; World Bank 2019).

As mentioned above, this chapter focuses on the historical and socio-economic background, legal frameworks, practitioners' training, ECE curriculum and quality services of ECE development in CIBSA. We further argue that ECE has been identified as the Achilles heel hampering education efforts, including pedagogy and curriculum challenges, absence of quality indicators, mechanisms of regulation and accreditation of centres and a nodal body for coordination along with widespread poverty and diversity. This chapter highlights similarities and differences, pioneer models and role players with similar encounters regarding ECE experiences in the mentioned countries and concludes with an overview pointing to the importance of investing in ECE to transform the lives of children and their families globally.

Keywords: Brazil; BRICS; China; India; South Africa. 


\section{Introduction}

More than 20 years ago, Early Childhood Education (ECE) in South Africa was identified as hampering the education efforts (Wolhuter 1998:33). Several policy and programme initiatives, as we see in this chapter, have been introduced since 2001 to address this weakness in the education system. With the timely announcement done by the South African president in his 2019 state of the nation address (SONA) regarding introduction of compulsory pre-primary education, there is an urgent need for models to act as templates for the roll out of such an ambitious project. The above-mentioned announcement aligns with Nobel Laureate James Heckman's (2012a) following statement, which provided overwhelming evidence on the need to invest in ECE:

$[T]$ he highest rate of return in early childhood development comes from investing as early as possible, from birth through to five, in disadvantaged families. Starting at the age of three or four is too late as it fails to recognize that skills beget skills in a complementary and dynamic way. Efforts should focus on the first years for the greatest efficiency and effectiveness of child development. (n.p.)

Globally, many efforts are put into developing ECE in countries such as Brazil, India, China and South Africa with the aim to pioneer models and learn from role players with similar encounters like pedagogy and curriculum challenges, absence of quality indicators, mechanisms of regulation, and accreditation of centres and relevant bodies for coordination along with widespread poverty and diversity (DBE 2015; Government of India 2018; Xiaofei, Edward \& Melhuish 2017:268-284).

Although having similar challenges, it should be noted that different countries, international and national organisations, and various notable global initiatives use different terminologies with varied emphases and nuances to define the terminologies they choose. For example, Education for All Goals (EFA Goals) use Early Childhood Education and Care (ECEC), The World Bank use Early Childhood Development (ECD), United Nations International Emergency Fund use Early Childhood Care and 
Development (ECCD) and the Organisation for Economic Cooperation and Development (OECD) uses ECEC (Kamerman 2006:8). It is thus clear that in the field of early childhood (EC), there is a plethora of terminologies used according to the importance that is being targeted in policies and programmes.

The umbrella term used to describe the human development stage from conception to the age of 8-9 years is EC. Many sectors and disciplines are involved in EC in order to meet the needs of children towards attaining holistic development in physical, social, cognitive and emotional levels (Haddad 2016:281-283). The core disciplines concerned in young children's needs for holistic development are early education, also known as early stimulation, health and wellbeing, safety and protection. In different countries, these disciplines fall under government departments or ministries of education, health, social welfare and development. Many terminologies, names and acronyms have been created from these disciplines to express the age range and their developmental needs. These terminologies include the following (Figure 3.1):

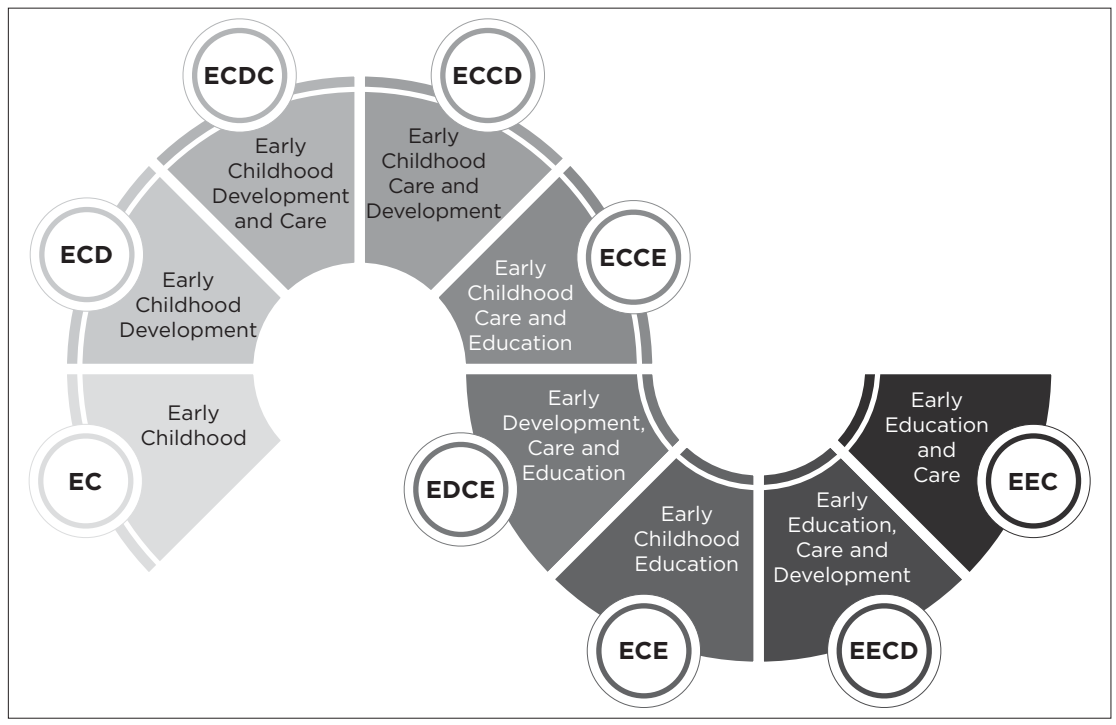

FIGURE 3.1: Terminologies, names and acronyms used for child development. 
The above-mentioned terminologies, names and acronyms include developmental needs and stages of children. For example, health, wellbeing, safety and protection are encapsulated in the term care, education and early stimulation are encapsulated in the term education, and development is a holistic and integrated term used to explain the maturational and growth processes that children go through towards achieving the physical, emotional, cognitive and social outcomes (UNESCO 2015:15-18). Kamerman (2006:1-6) explains the use of, for example, three interchangeable terms, namely development, care and education, in ECEC as significant developmental milestones of both physical care and education, necessary for preschool children. The synergistic, inter-relationship between health, protection and education is another example of interchangeable terms. More countries prefer integrated programmes where children are offered education, care and protection in a balanced approach. It should, however, be noted that ECE focuses primarily on providing preschool education to children aged 3-6 years (Zhou 2011:29).

Linked to the above-mentioned terminologies are the parallel terms used particularly for the institutions where care development and education take place. These organisations include nursery schools, preparatory schools, kindergartens, daycare or educare centres, preschools in formal schools or separate preschool centres, crèches, home-based programmes and play schools, just to mention a few. Various organisations have given a wide scope to Early Childhood Care and Education (ECCE) programmes such as part-day, full-school-day and full work-day programmes under education, wellbeing and social government assistance support, subsidised and conveyed in an assortment of courses in both general society and private areas, contingent upon the accentuation of the projects or administrations being offered alongside the focus on age category (Kamerman 2006:1-2).

In this chapter, the main emphasis is on education; however, we use different terminologies interchangeably according to the country under discussion. 


\section{Overview of early childhood development}

The understanding that ECCE has a lifelong positive impact on children and their societies is becoming a global phenomenon. Research has shown that investment in EC has far higher returns in later life (MacEwan 2013:20).

The main objective of ECD is to promote the holistic development of children through age-appropriate programmes of play-based activities and interactions that could foster appropriate developmental skills and experiences with the aim of school readiness. These programmes promoting holistic development of children include age-appropriate activities to promote social, emotional, cognitive, physical and language development (Haddad 2016:281-283).

It is essential to stress that early learning isn't academic and must be guided by the interests and the relevant developmental levels of the child, pertinent to the social settings of the child. Children who are kept from reaching their developmental ageappropriate levels and brain development because of lack of nutrition, health and stimulation, are affected in bringing about subjective, social, cognitive, physical and behavioural delays with deep-rooted outcomes. These burdened youngsters are probably going to do inadequately in education, and hence have low salaries, high fertility and, in turn, also give poor consideration and care to their own children, consequently adding to the progressing cycle and creating poverty in the family environment (Government of India 2011:44-51; MWCD 2010:4-23).

It is thus clear that to invest in young children is not simply the right thing to do from an ethical point of view but it is also a smart thing to do from an economic point of view for children, their families, communities and society at large (NCERT 2006a; cf. Vagh, Nag \& Banerij 2007:419). The availability of ECD programmes and services to support children's development 
during the early years is an integral component of an overall strategy for reducing poverty and helping children achieve their full potential in life as well as for reducing risks of morbidity and mortality (MHRD 2007-2008:25-62; MWCD 2010:4-21).

Various global initiatives are formed about the value of ECD and have driven the agenda of providing quality access to ECE provision, for example the 2000 EFA Goals. The first of these goals was the provision of access to ECEC. China, India, Brazil and South Africa are signatories to these international goals and set in place policies, models and programmes to achieve it. More recently the SDGs replaced the Millennium Development Goals (MDGs; Statistics South Africa 2015) that include ECD as goal number 4.1, and most of these countries have committed to the SDGs as they did with the MDGs.

In this chapter, the state of affairs of ECD in CIBSA is discussed and compared.

\section{Early childhood education in China}

In China, ECE includes educational approaches for young children from birth to 6 years of age. The ECE sector in China is divided into three educational settings. The first refers to nurseries with the focus on childhood care and education from birth to 3 years; the second is kindergarten that is referred to as care and education of 3 - to 6-year-old children, including the preschool classes that focus on education of 5- to 6-year-olds (Zhu 2009:51).

\section{Historical and socio-economic background}

In 1903, when the first kindergarten was opened, the care and education of young children was seen as the responsibility of families. This view started changing in the 20th century. In 1903, 
Duanfrang, governor of Hubei province in China, built the first public formal kindergarten. The kindergarten was influenced by the Japanese tradition and the first headmaster and teachers were Japanese (Xiaofei \& Melhuis 2017:270). China experienced many social and cultural changes over the years and the first formal ECE kindergarten curriculum standards were issued in 1932 and revised in 1936 by the ministry of the Republic of China. Because of political systems changing to socialist states, the Kindergarten Provincial Guidelines were drafted in 1952. These guidelines followed a teacher-centred approach to education, and guided teachers in planning and educating children in a purposeful manner. Up to the 1960s, ECE in China experienced growth, but the Chinese Cultural Revolution of 1966-1976 closed most of the teacher training schools. Since the 1980s, both policy and practice of Early Childhood Education Development (ECED) in China has undergone many challenges and economic and social changes, including the kindergarten curriculum. Being a developing country, with a population of 1.35 billion, China faces a major challenge in improving the wellbeing of its citizens. Developing ECEC is seen as improving the wellbeing of children in China. China's kindergarten expansion movement was started in 2010, which was influenced by western education theories such as Dewey, Froebel and Montessori (Yu 2017:102-103). It was proposed that the ECE curriculum would focus on Chinese tradition with western influence (1920s-1930).

\section{Early childhood education's legal framework: China}

Laws, regulations and guidelines that could affect the development of young children are referred to as a legal framework (Systems Approach for Better Education Results [SABER] 2016:11-18). In this section, laws, regulations and guidelines that guide ECE in China are investigated (Figure 3.2).

In 1932, the kindergarten curriculum standards were introduced as the first formal ECE curriculum in China. The kindergarten provincial guidelines were introduced in 1952, and in the 1980s, the kindergarten provision of ECE in China 


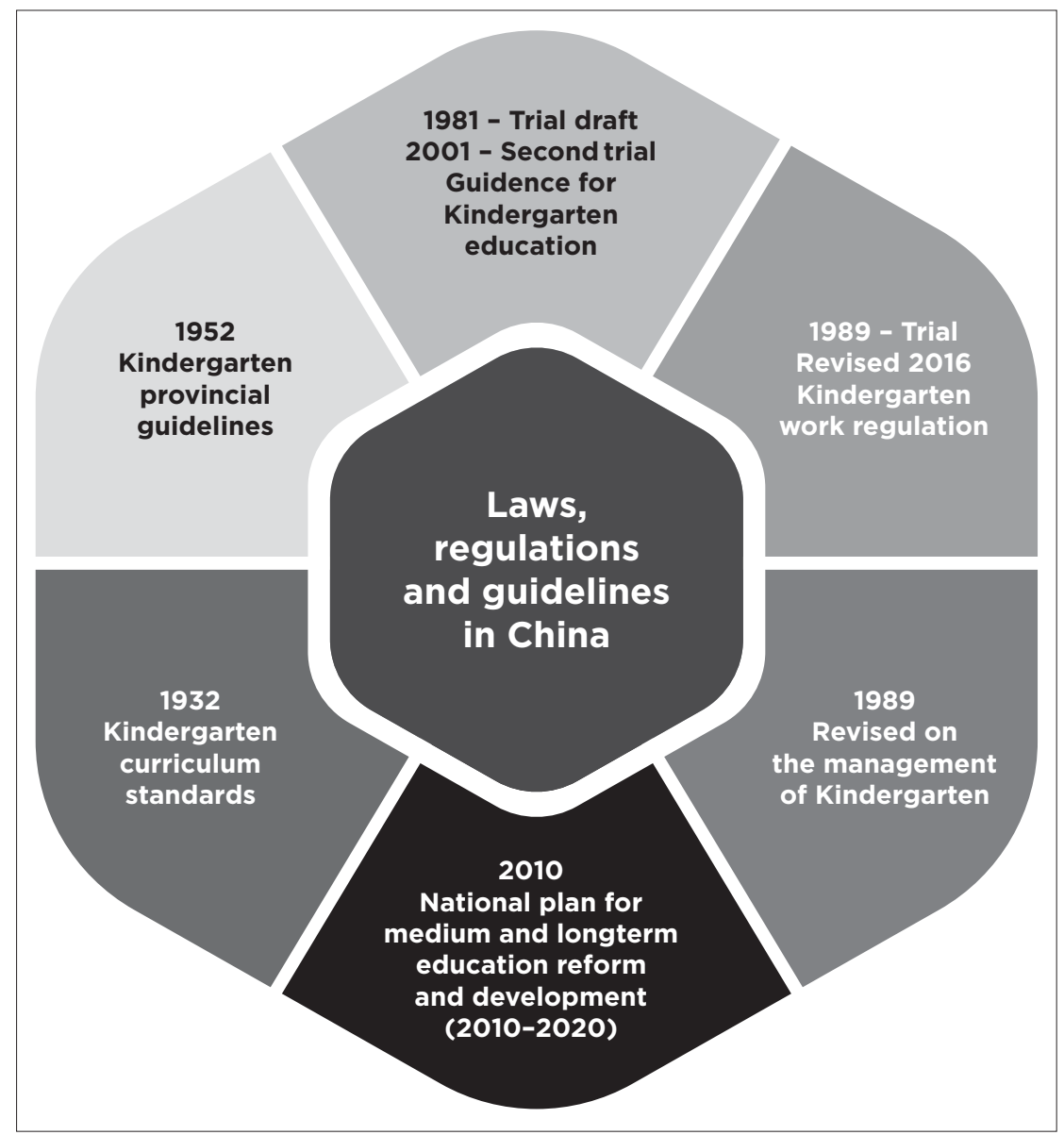

FIGURE 3.2: Early childhood education legal framework in China.

started recovering and regulations and legislations were developed. In 1981, the guidelines for kindergarten education (trial draft) was released to assist practitioners to implement all these documents in practice as earlier they had found it very difficult to implement these. In 1989, regulations on the management of kindergartens were developed and dealt with the principles of operations of kindergartens. In the same year (1989), the trial Kindergarten Work Regulation was established 
and formed the legal base for operating kindergarten services; this was replaced with a reviewed version in 1996 and again in 2016. The growth of preschool education in China over the last 13 years has been monumental, although Chinese legal framework does not directly instruct free and compulsory provisions for ECE (SABER 2016:4-9).

In 2001, the guidelines for kindergarten education went through a trial as the guidelines were now influenced by western theories and ideas (Qi \& Melhuish 2016:268-284, adopted from the Ministry of Education 1932, 1952, 1981, 1989, 1996, 2001, 2012, 2016).

These regulations (kindergarten work regulation and regulations on the management of kindergartens) formed the basis for the development of legislation of ECE (Qi \& Melhuish 2016:269). Implemented at national, regional and local levels, these documents stipulated and focused on caring and educating young children to assure that they are holistically prepared for preschool (Haddad 2016:281-283). Increasing demands for highquality and affordable services arose, creating many complaints and made headlines all over China (Qi \& Melhuish 2016:275).

In 2010, the national plans for medium- and long-term education reform and development (2010-2020) were announced by Chinese government as part of national strategies to assure concrete goals for ECE in China. These goals included improving childcare services, which also included compulsory preschool education for at least one year, including access to preschools for the majority of children for two years, and three years' accessibility of preschools in developed areas. Strengthening of early education services in rural areas was also identified as a crucial part of the strategies to improve childcare services (Qi \& Melhuish 2016:284; SABER 2016:4-9). The national plans for medium- and long-term education reform and development include an enrolment plan that provides for kindergarten enrolments of $95 \%$ for all five-year-old children with a further focus to reach $80 \%$ enrolment for four-year olds and $70 \%$ for three-year-olds by 2020 (SABER 2016:23-29). 
The document 'Issues Regarding Current Development of Early Childhood Education' was released by Chinese state council with the intention of improving the implementation of the national plans in China, during which ECE was only seen as an integral part of a person's wellbeing. Ten principles were laid out in this document to support the development of ECE, and another three-year action plan was laid out (2014-2016) by Chinese Ministry of Education (Qi \& Melhuish 2017:280; Zhou et al. 2015:29). This action plan included the following primary goals (Vong \& Li 2016):

- expanding EC programmes

- adapt programme designs and procedures

- strengthening EC management systems

- better quality EC services.

This action plan also required that local and provincial governments should increase budgets to achieve the goals set for the 2020 ECE enrolments (SABER 2016:18-19). The policy document 'Kindergarten Work Regulations' was adapted, replaced and implemented in 2016 and is seen as the most important ECD policy in China, as this manages and refers to all other policy documents, including ECE practice (Qi \& Melhuish 2017:280).

\section{Early childhood education practitioner training}

Early childhood education staff training has been a major challenge in China for decades, and hiring qualified practitioners with a degree or ECE diploma even more so (Hu et al. 2015:823). In 2012, kindergarten training programmes for teachers were launched across China. Traditionally, children aged 0-3 years were cared for at home by family members or by welfare services provided by companies of working parents.

Owing to the economic reforms of 1990, many of these services (nurseries) closed down or were transferred to private 
centres, and therefore few policies providing for childcare services (0-3 years) are available (Qi \& Melhuish 2016:280). Teachers' perceptions on challenges in ECE in rural areas of China brought to light that opportunities for professional development are very rare, as there is no funding available and practitioners are expected to pay for themselves if they are interested in professional development ( $\mathrm{Hu}$ et al. 2015:823-824). Early childhood education practitioners do not have the time and capacity for professional development as they daily work hard and for long hours by taking care of and educating children.

The practitioners are of the opinion that the status of their counterparts in rural areas is lower than of those working in grades 1-9. Rural ECE practitioners work for long hours and experience high demands in their jobs. Furthermore, salaries are poor with no benefits, such as medical aid and pension funds, and no opportunities for promotions. Early childhood education practitioners in rural areas are sometimes put in positions to care, educate and keep up to 50 children safe in the classroom, and therefore often do not let children play freely in and outdoor, for the fear of children getting hurt. Many principals of ECE centres are worried that practitioners would leave if they are afforded the opportunity of professional development, and therefore do not offer training to their staff (Hu et al. 2015:823-824).

In China, practitioners working with children aged up to 3 years are expected to have completed at least high school, whereas practitioners working with 3- to 7-year-old children are expected to have completed at least vocational ECE training (SABER 2016:1-47).

\section{Curriculum}

In 1932, the 'Kindergarten Curriculum Standards' were introduced as the first formal ECE curriculum in China. Many new curricula have been developed in China by adopting and localising different curricula, including Reggio Amelia and Montessori. The Reggio Amelia curriculum follows a student-centred constructivists 
approach to learning, and the Montessori curriculum follows an approach that guides children through ageappropriate activities and fosters self-directed learning. An example of a new curriculum which represents a localised progressive early learning childhood education approach is called the Integrated Theme-based Curriculum. However, this has been criticised by many researchers who believe in a culturally appropriate curriculum development (Zhou 2011:38).

The Chinese culture values group-oriented learning, including drilling, memorisation and discipline, rather than creativity, understanding and freedom in educational systems; therefore, the curriculum that emphasises individual needs and development has been criticised (Hu et al. 2015:817; Zhu 2009:54). Curricula should allow people to adapt their culture without changing their culture completely. Zhu (2009:56) and Hu et al. (2015:817) argue that each school or preschool should develop socially and culturally acceptable children in the specific context that it finds itself in. In a study conducted by Hu et al. (2015:825), it was found that $45 \%$ of kindergartens in China were of the opinion that freeplay is not important for children's learning and development and $36.4 \%$ offered less than $1 \mathrm{~h}$ for outdoor play per day.

\section{Quality of early childhood education services in China}

The Ministry of Education is in charge of the development of ECE, but various other multi-sectors, including health and family planning, also have responsibilities and obligations within the ECE sector, which is seen as basic education in rural and urban China. In 2009, it was reported that ECE in China was not compulsory and the government only allocated $1.3 \%-1.4 \%$ of the entire educational budget to ECE (Zhu 2009:52). Currently, 6 years of primary school and 3 years of middle school are compulsory, which amount to 9 years of compulsory education in China. The Systems Approach for Better Education Results 
(SABER) (2016) country report by World Bank group has found that the total admission to preschool education increased from $38 \%$ (2002) to 50\% in 2007 and reached a high of $67.5 \%$ in 2013. United Nations Educational, Scientific and Cultural Organization's (UNESCO) statistics reported a high of 81.6\% in 2014.

Zhou et al. (2015:1969) found a major gap in the ECE service provisions in urban and rural areas. They found a $99 \%$ enrolment rate in urban areas and only $10 \%$ in rural areas. These findings explained the reason why teachers in rural areas have been paid less. Zhou (2011:29-37) found that the ECE situation in rural zones was worse than in urban zones. Qualified teachers in rural zones were less and teacher-child ratio and the relevant centres were much worse than those in urban zones. A further noticeable difference between urban and rural areas is that children mostly attend kindergarten for the first time at the age of 5 to 6 years whereas in urban areas, children have access to ECE facilities, mostly not connected to a primary school, from the age of 2 years. The ECE programmes also differ, as in the urban areas practitioners receive various forms of support, including that from the public sector and parents have more steady incomes than in rural areas.

To provide quality ECE, it is necessary that research must be done on the challenges that are faced by practitioners. In the research conducted by $\mathrm{Hu}$ et al. (2015:817), interviews were conducted with 217 teachers whilst investigating challenges in ECE in rural China. During this investigation, the following three reasons led to the lack of ECE services:

- economical challenges

- lack of ECE priorities associated with uneducated parents

- unreliable transport.

Hu et al. (2015:816) realised that a lot of young people migrate to cities from rural areas in desperate need of finding better work opportunities. In such cases, children either migrate with the family or parents or are left behind with a caregiver, mostly an ageing grandparent, who, in turn, has also received little education and has no money to send children to a kindergarten (Hu et al. 
2015:818; Zhou et al. 2015:1970). Because people move away, there are few children left behind in rural areas to go to a kindergarten. All preschools must go through a registration and accreditation procedure for government and private ECE facilities (SABER 2016:34; Zhou et al. 2015:1970).

Kindergarten enrolment rates in China vary from area to area. In more developed areas, the enrolment rate was as high as 100\% but in rural areas as little as O\% (SABER 2016:16). In 2010, the enrolment rate in urban areas of China was above $90 \%$ and in rural areas below 50\%. According to the SABER Country Report (2016:24-25), there were approximately 2.7 million more boys aged 6 and 7 years enrolled for preschool education across China than girls in the same age group. These findings showed that access to ECE for boys are comparatively higher than for girls across China.

China is investing in ECE because this is seen as investing in the future of the country to minimise poverty through education which starts in the early years. Policies in China are focused on improving quality ECE programmes, especially in rural areas for disadvantaged children. Enrolment, class size, teacher-child ratio, facilities, availability of materials, teacher qualifications and a suitable culturally appropriate curriculum and pedagogy are seen as challenges of implementing and sustainability of quality ECE programmes (Hu et al. 2015:817). The success of quality ECE programmes depends on the support and interventions offered by the government.

Suggestions were made through the SABER Country Report (2016:1-47) and include the appointment of qualified teachers with good salaries with benefits, whether in rural or urban area, or public or private sector. Furthermore, nutritional meal plans and school health services are suggested to ensure and manage nutritional and educational barriers and common diseases at ECE sites. Educational barriers could be identified at a young age if the government assists with identification, prevention and stimulating services to children as young as three years of age, only to mention a few. Furthermore, it was suggested that the 
government could support pregnant and breastfeeding mothers as well as raise awareness for breastfeeding in China.

\section{Early childhood education in India}

According to the Ministry of Women and Child Development (MWCD) (2010:6), India has the world's largest education system with 1.52 million schools. Ministry of Women and Child Development explains ECCE in the Indian context as the care and education of children aged 6 years and below by providing for their health, nutrition and education needs through a variety of settings such as crèches, home-based parent education programmes and preschools.

Early childhood care and education in India is offered through three separate straits: firstly, the public (government), sponsored by the Integrated Child Development Services (ICDS), which mainly support disadvantaged communities, residing in rural areas known as Anganwadis (Aws) or the rural childcare centres in India. The ECD programmes address the all-round development of children by meeting their health, nutrition and educational needs. They further support pregnant and lactating mothers and adolescent girls (MHRD 2007-2008:13).

Secondly, the non-governmental organisations (NGOs) offer ECE on a small, sparsely distributed and advanced scale in the socially and economically backwards areas, providing care to communities functioning in difficult circumstances, for example migrant labourers and families and children living in marginalised rural areas.

Thirdly, the private service providers are free-charging, profitmaking initiatives aimed at children of socio-economically betteroff families (Government of India 2011:64).

Since there is no regulated system in place for the different straits, education stretches over a wide range, and some of the 
ECE centres are known as 'teaching shops', rather than education centres because little focus is given to the developmental norms of young children. This results in children not acquiring the desirable school readiness competencies when joining primary school and missing out on important education (CECED 2012a:137).

\section{Historical and socio-economic background}

The institutional history of ECE in India dates back to 1890 when the first kindergarten was started by a Scottish missionary, followed by preschool centres that opened in different parts of the country during the 1920s and 1930s by early pioneers like Gijubhai Badhekar, Tarabari Modak and Annie Besant, influenced by the work of Maria Montessori. The schools catered for either the children of the elite or the poor as a philanthropic gesture. Mahatma Gandhi, Rabindranath Tagore and Dr Zakir Hussain recognised the importance of formative years and evolved an indigenous philosophy of ECE. By the time of independence in 1947, the state took up the responsibility of child development and ECE was perceived as the first step on the educational ladder, imparted in private and voluntarily owned centres (NCERT 2006:vi).

\section{Early childhood education's legal framework: India}

ECD, Early childhood development.

In 1950, the Constitution of India enshrined the vision of welfare, protection and development of the country's children as either Fundamental Rights (justice) or Directive Principles of State Policy (directives) that promote ECD in India (See Figure 3.3). The Directive Principles, Articles 24, 39(e) and (f), 42, 45 and 47 deal with prohibiting deployment of children aged 14 years and younger (comprising around one-third of the total population of the country) in hazardous occupations, protection 
against misuse, and honest and sensible abandonment (Government of India 2018:43-45). It further deals with maternity relief; free and compulsory education and raising the level of nutrition and health of all children. In 1993, Article 45 was amended and the age groups of 0-14 and 0-6 years were split into two clear age groups, covering their educational needs and interests under two separate Articles of the constitution. Under Article 21(A), free and compulsory education to children aged

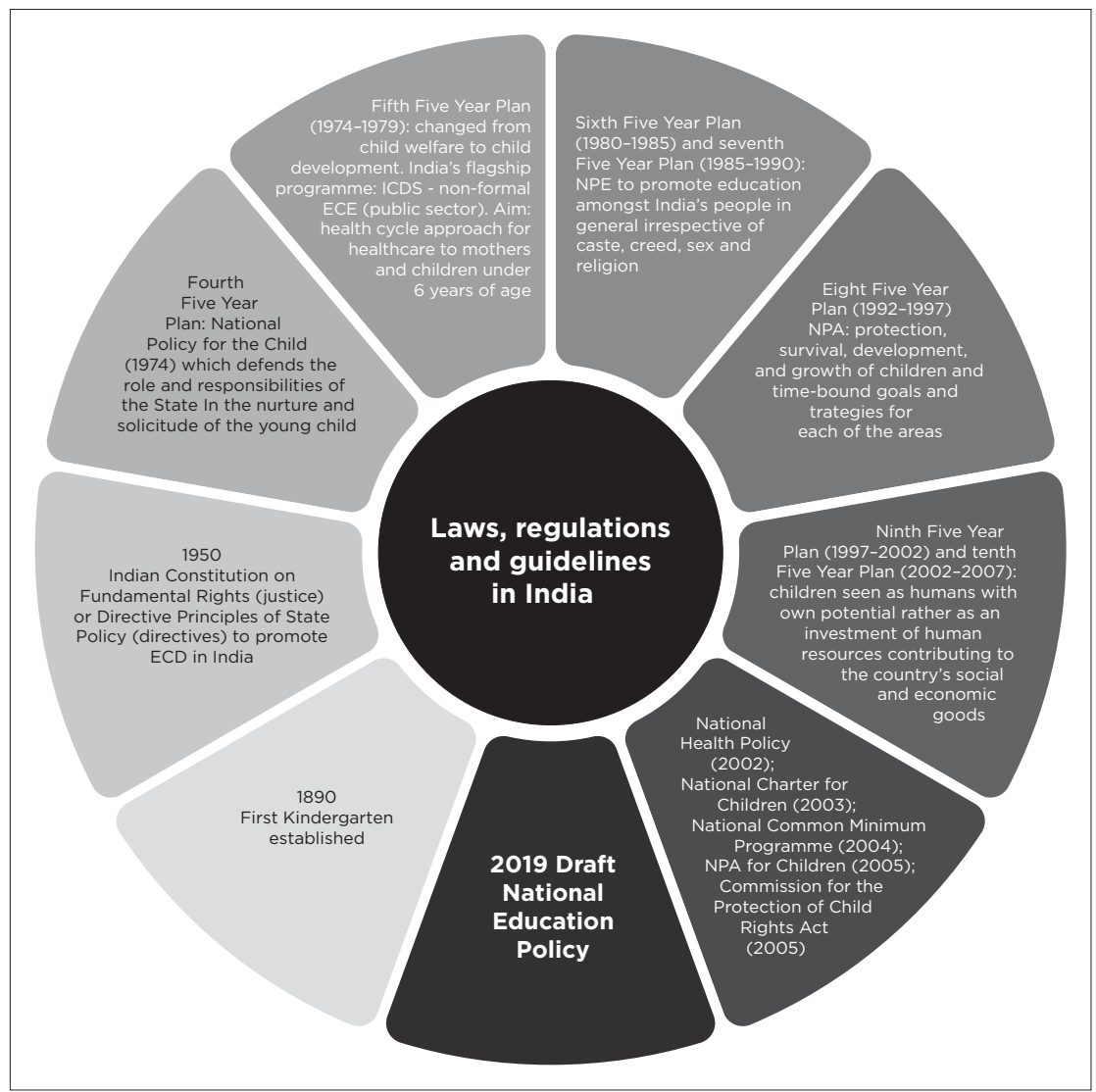

ECD, early childhood development; ECE, early childhood education; ICDS, integrated child development services; NPA, national plan of action; NPE, national policy on education.

FIGURE 3.3: Early childhood education's legal framework in India. 
6 to 14 years became their fundamental right whereas the Right of Children to Free and Compulsory Education Act (RTE 2015) under section 11 of the act that addresses ECCE, states that children aged below six years were not included, and reads:

$[W]$ ith a view to prepare children above the age of three years for elementary education and to provide early childhood care and education for all children up to the age of six years, the appropriate Government may make necessary arrangement for providing free pre-school education for such children. (p. 152)

Role players in ECD viewed the amendment with concern as it released the government from the obligation to provide ECD services for children aged below 6 years along with de-recognising the importance of formative years. In other words, the government neglected the rights of young children. Supportive laws and legislation concerning their right to life, health and equal opportunities were enacted for the protection of the rights of children aged less than 6 years. The laws further focused on the prevention of female foeticide, promotion of breastfeeding (since only $46 \%$ mothers practice exclusive breastfeeding up to 5 months), ensuring growth and development of children with disabilities and implementing child care services where women with infants and young children were employed. Daycare facilities such as crèches were directed as a constitutional provision under different labour acts, subject to achievement of certain conditions (Sharma 2008:49).

Although ECD was a focus within the national planning process of India after independence, the approach towards the planning strategies evolved from welfare to development to rights (MWCD 2007:46). The fourth Five-Year Plan (1969-1974), one of the 12 five-year plans, under Indira Gandhi, concluded in the adoption of the National Policy for the Child, which defends the role and responsibilities of the state in the nurture and solicitude of young children, stating that (Ministry of Social Welfare 1974):

It shall be policy of the state to provide adequate services to children, both before and after birth and throughout the period of growth. The state progressively increases the scope of such services so that, 
within a reasonable time, all children in the country enjoy optimum conditions for their balanced development. (p. 42)

The fifth Five-Year Plan (1974-1979) under Fakhruddin Ali Ahmed is known as a turning point in child development when the perspective changed from child welfare to child development, emphasising integration of and coordination between various services and programmes to invest in human capital as a prerequisite for the nation's economic and social development. The fifth Five-Year Plan was translated in 1975 into the Indian government's flagship programme of ICDS scheme, the largest provision for non-formal ECE in India within the public sector. Its aim was to offer a health cycle approach of healthcare for mothers and children less than 6 years of age, along with ECE and care services through an integrated way with the premise of the programme to meet ECCE needs on a holistic basis through Anganwadis. Although the ICDS brought relief in Anganwadis, two major limitations could be mentioned: firstly, it did not focus on educating parents for 'promising psychosocial stimulation' (Saracho 2019) and thus providing an encouraging milieu for child development at the household level, and secondly, it failed to reach and capitalise on the development of children from birth to 3 years of age.

During the sixth Five-Year Plan (1980-1985) under Giani Zail Singh and the seventh Five-Year Plan (1985-1990) under R. Venkataraman, the Indian government implemented the National Policy on Education (NPE) based on the Kothari Education Commission (1964-1966) to promote education amongst India's people in general. In 1992, the programme of action was implemented that aimed to establish a national system of education that gives similar quality access to all children irrespective of caste, creed, sex and religion. The policy and programme viewed ECCE as an important aspect in its approach to human resource development, and as a support programme for primary education. It advocates for play without formal teaching of three Rs (MHRD 1986:8).

During the eight Five-Year Plan (1992-1997) under Dr Shankar Dayal Sharma, the National Plan of Action (NPA), aimed at the 
protection, survival, development and growth of children, laid down specific time-bound goals and strategies for each of the areas. By the ninth Five-Year Plan (1997-2002) under K.R. Narayanan and the tenth Five-Year Plan (2002-2007) under Pratibha Devisingh Patil, the development imperative gave way to the right approach in which children were seen as humans with their own potential, rather than an investment of human resources contributing to the country's social and economic goodness. Policy frameworks followed such as the enactment of the National Health Policy (2002); adoption of the National Charter for Children (2003); announcement of the National Common Minimum Programme (2004); formulation of the NPA for Children (2005) and setting up of the Commission for the Protection of Child Rights Act (2005). Monitorable targets to assess progress in key indicators of child development, disaggregated by sex, with the aim of bridging gender gaps and improving accountability in service delivery, were set up in the sectors of health, education and nutrition. In the light of the mentioned, the rights-based declaration/convention ratified and endorsed policy and programming for ECD as an imperative. In response to the 'strong advocacy' (see UNICEF 2010; cf. Tunyogi \& Schuurman n.d.; Toolkit, Eurochild) from civil society for the inclusion of children less than 6 years of age, Article 45 was amended as follows: 'The State shall endeavor to provide ECCE for all children until they complete the age of six years' (MWCD 2012:59-60).

\section{Early childhood education practitioner training}

Training and working conditions of ECD staff are neglected in India that results in poor performance and motivation of practitioners. The practitioners are not recognised as teachers and therefore receive poor salary without career mobility. Because of the absence of government's regulatory framework in the setting of ECE centres, there is no demand for the professional training of staff, except if the centres make an effort to improve the training quality of their practitioners (Rajawat 2016:7316). 
Therefore, the majority of professional training institutes are clustered in the private sector, of which over $60 \%$ do not have recognition from the National Council Teacher Education (NCTE). Therefore, the wide variety of ECE programmes, content, methodology, gap between theory and practice, duration and eligibility training conditions. There are four training provisions. The first is a tailor-made in-service training programme for specific needs in NGOs and government sectors; the second is a pre-service training programme provided by government or private institutions through a face-to-face classes and distance mode of delivery. The private institutions often focus on profitmaking without adherence to standard curricula or duration of training. The third training is a customised 26-day training programme for the ICDS, in which 4 days are devoted to ECE education. It is thus clear that the training does not provide Anganwadi practitioners with adequate knowledge to relate and apply theory into practice (Education Promotion Society for India 2019:45-54).

The fourth training provision is the two-year university- and government-recognised Integrated Pre-primary and Primary Teacher Training course. This training is provided through faceto-face classes and distance mode of delivery, and is recognised by the NCTE, a statutory body engaged with maintaining standards in teacher education. The NCTE has laid down norms for single teacher education programme in ECE, called the Certificate in Education, with the same training, duration, rigour and eligibility criteria as the Diploma in Education, which trains teachers for grades 1 to 5. The Certificate in Education limits the range of ECD to six years of age instead of eight years, resulting in grades 1 and 2 ambiguously clustered with higher elementary grades 3-5. It is therefore debatable how much of the ECCE philosophy would permeate teaching-learning at lower primary grades (CECED 2012b; Education Promotion Society for India 2019:45-54). 


\section{Curriculum}

Various committees were formed to plan a framework on approaches, pedagogies and curriculum for education. The National Curriculum Framework (NCF) by the NCERT (2005) addresses four aspects: educational purpose, educational experience, organisation of experience and assessing the learner. These committees also foresee ECCE to stimulate a holistic improvement of the child through a developmentally suitable curriculum based on the context related to active construction of knowledge by the child. The ECCE curriculum covers three sub-stages of child development, namely: early stimulation for children less than three years of age mainly through parental involvement and education in a relatively unstructured mode; the organised centre-based play and development-oriented curriculum for three- to five-yearolds; and the school readiness curriculum which overlaps with the four- to six-year-olds and includes reading, writing and number readiness as a preparation for primary schooling starting at six years of age (Education Promotion Society for India 2019:45-54; Rajawat 2016:7317).

The vision regarding the core of ECD has not developed fundamentally at all levels, since the services of preschool children vary in terms of quality because of the absence of a nodal body to coordinate the criteria on specifying quality indicators, regulation and accreditation of ECE centres (NCERT 2006). The draft National Education Policy (Education Promotion Society for India 2019) states severe learning crises in six-year-old children enrolled in primary schools when pointing to the absence of basic literacy and numeracy skills because of the quality of ECCE and specific preschool education of ICDS. Preschool education is fundamentally seen as a downward extension of the primary education curriculum often presented by teachers with no ECCE training, giving little 
thought to ECCE as a specific sub-stage of education with a unique pedagogical method and curriculum. A further strain is the budget for education. In the financial year 2018-2019, a total budget of Rs. 79088.35 crores was allocated to the 472 million children, which is just about $3.23 \%$ of the total budget of India (Education Promotion Society for India 2019:45-54).

\section{Early childhood education in Brazil}

The constitution of Brazil defines ECE as the first stage of basic education for children from birth to six years of age. It is divided into two components: zero to three years, which is under nursery school, and four to six years, which is preschool. However, in 2009, the starting age of primary school was changed to six years, which meant that the ECE age had to reduce to zero to five years, and the constitution was amended accordingly (Mami 2013:78).

\section{Historical and socio-economic background}

Brazil is a highly complex country historically as well as socially and economically. The differences and disparities cut across urban and rural populations. Even though it runs one of the largest economies, it has some of the poorest communities in the world with a very low standard of living. Brazil is also known for its high violence in communities and homes. This situation has an impact on how children are cared for and educated in Brazil (Azevedo de Aguiar, Nascimento \& Segundo 2007:2).

Prior to 1996, ECE in Brazil was full of confusion, chaos and loose entities. There was no age specification for entrance to daycares or preschools. Children up to seven years of age were enrolled in daycares. Coordination and management involved several government entities such as departments of health, social welfare and labour, and they all provided services in a fragmented 
manner, with some services being duplicated. These entities used daycares for their pro-poor programmes. The main focus of these programmes were daycare centres, which have been in existence in Brazil for many decades. In the early 1900s, workplaces provided daycare for female employees. It was compulsory for workplaces to provide this service. That is why the departments of labour and health were involved in programmes at the daycare centres, but preschools were fully under the Ministry of Education. Philanthropies and other NGOs also played a very important role in ECE provision of pro-poor programmes (UNESCO 2007:10-12). The divide between care and ECE was very clear and the disjuncture in coordination and management of this sector became the focus of attention by the late 1900s.

Recognition of ECE started with the country's constitution in 1988 when for the first time ECE became a right for every child and a choice for every family and a duty of the state (Haddad 2016:298; Johnson 2013; UNESCO 2007:15). It's therefore a federal mandate that all Brazilian children less than 6 years of age have access to pre-elementary education (Hadad 2016:283-284). Since then, the provision of crèches for young children from birth to 3 years of age has been formally integrated into the educational sector. Historically, this sector was part of social assistance policies (UNESCO 2007:20).

\section{Early childhood education's legal framework}

Brazil's government has adopted a pro-child policy approach in the last 30 years (Johnson 2013):

The Federal Constitution of 1988 declared children to be citizens and stated all children have the right of access to education starting at birth. The 1990 Statute for children dictated children's right to education to a family or guardianship and protection from labor and from full penalties for crime. (p. 2) 
Early childhood education is a constitutional right and municipalities are responsible for its provision under the leadership of the Ministry of Education. Municipalities provide ECE autonomously. There are two main types of ECE institutions that are recognised in Brazil: firstly, daycares for children aged 0 to 3 years, and secondly, preschools for children aged 4 to 6 years (UNESCO 2007:26). In 2009, the government extended compulsory education to children aged 4 years, making basic education compulsory from 4 to 17 years. This law made it mandatory for families to send their children to school (Haddad 2016:284). Overall, Brazil's ECE policies have established a strong foundation for ECE provisioning. Table 3.1 demonstrates Brazil's ECE policy development.

TABLE 3.1: Policy changes in early child education in Brazil.

\begin{tabular}{|c|c|c|}
\hline Year & Law & Policy changes \\
\hline 1975 & $\begin{array}{l}\text { Preschool education coordinating } \\
\text { body (Coordenação de Educação } \\
\text { Pré-Escolar) }\end{array}$ & $\begin{array}{l}\text { Education of } 4-6 \text {-year-olds put under } \\
\text { responsibility of the MEC of the Federative } \\
\text { Republic of Brazil }\end{array}$ \\
\hline 1988 & Federal Constitution (Art 208.IV) & $\begin{array}{l}\text { Defined ECE (age 0-6 years) as a } \\
\text { government responsibility }\end{array}$ \\
\hline 1996 & $\begin{array}{l}\text { Law of Directives and Bases of } \\
\text { National Education }\end{array}$ & $\begin{array}{l}\text { Placed responsibility for ECE in } \\
\text { municipalities-defined ECE (age 0-6 years) } \\
\text { as part of basic education set starting age } \\
\text { for obligatory education at } 7 \text { years }\end{array}$ \\
\hline 1998 & $\begin{array}{l}\text { Fundamental Education Fund } \\
\text { (FUNDEF) }\end{array}$ & $\begin{array}{l}\text { Increased education revenue to } \\
\text { municipalities }\end{array}$ \\
\hline 2005 & Law 11.114 & Lowered obligatory starting age to 6 years \\
\hline 2006 & $\begin{array}{l}\text { National Policy for Early Child } \\
\text { Education }\end{array}$ & $\begin{array}{l}\text { Defined strategies and goals for ECE at } \\
\text { each the level of government }\end{array}$ \\
\hline 2007 & Basic Education Fund (FUNDEB) & $\begin{array}{l}\text { Provided municipalities with capitation } \\
\text { grants for ECE starting from birth }\end{array}$ \\
\hline 2009 & Constitutional Amendment 59 & Lowered obligatory starting age to 4 years \\
\hline
\end{tabular}

Source: Evans and Kosec (2012:8).

ECE, early childhood education; MEC, Member of the Executive Council. 


\section{Early childhood education practitioner training}

Brazil has over the years advanced in providing EC training opportunities to those interested in working with young children. However, there has been a major gap in preparing caregivers and teachers for young children aged zero to three years; as a result, most daycare centres employ people who are inadequately prepared to educate and take care of this age group. Previously the highest eligibility that the most preschool teachers had in Brazil was a secondary school qualification. However, this situation has changed with most teachers having a tertiary qualification for preschool teachers. Government is playing an important role in providing training opportunities for ECE teachers. The training system has a strong in-service training focus. Several programmes are provided using distance training modalities. The municipalities are also involved in providing various in-service training programmes (Haddad 2016:278-280).

Early childhood education is designed to prepare children not only for their academic lives that help them to be ready for all of life's experiences in the academic context but also in their various other contexts as individuals and members of their communities and society. They, therefore, need to be prepared holistically taking into account all their aspects of development, namely social, cognitive, physical and emotional. Another aspect that should be emphasised is language development, which in many respects is the conduit for all aspects of a child's development. Early childhood education experiences in Brazil, particularly the preschool phase, resemble the primary school phase experiences. Teacher-centred approaches with children sitting in roles are the typical settings, with children being taught rather than them directing their own learning experiences. Pedagogical practices are therefore very formal instead of them being play-based. Besides this, Brazil has a very high student-teacher ratio, which 
makes it very difficult to apply EC pedagogies and practices. All these issues affect teacher training programmes and the government with municipalities is trying to address these through in-service training programmes (Haddad 2016:281-283).

Brazil has experienced challenges with regard to coordination management and financing of the ECEC sector. Tensions have existed from as far back as 1996 relating to the department that should handle the ECEC finances.

\section{Quality of early childhood education services}

The Ministry of Education has prioritised ECE with continued expansion of access to crèches and preschools for young children (Evans \& Kosec 2012):

Fifteen years ago, less than half of Brazil's children aged four to six were enrolled in preschool, and fewer than one in twelve attended crèche. A scant one in five preschool teachers had training beyond secondary school. Now, the number of children in preschool has increased by more than fifty percent, to 75 percent of 4-5-year olds and 81 percent of 4-6-year olds; moreover, 18 percent of 0-3-year olds attend crèche, and half of pre-school teachers have post-secondary training. The School infrastructure has also improved steadily, and class sizes have declined. (p. 1)

Despite this improvement of access, there are still large numbers of young children not accessing ECE. In order to further improve access and quality in ECD, Brazil has embarked on providing certain programmes delivered through municipalities. An example of such a programme is the Primeira Infância Melhor (PIM; Better Early Childhood). This is a home-visiting programme implemented in Rio Grande do Sul, one of Brazil's states. Primeira Infância Melhor is designed for children from conception to 6 years of age, providing them with holistic development interventions relating to health and social wellbeing as well as early learning experiences based on theories of Vygotsky's cultural approach, Piaget's theory of learning, neuro-developmental evidence and attachment theory 
(Goncalves, Duku \& Junas 2019:12-13). The programme involves well-trained and highly skilled staff such as home visitors, medical and education professionals working collaboratively and in an integrated manner to deliver the PIM services. Government officials are assigned responsibilities and roles in the programme. All relevant stakeholders are trained in the PIM model.

Brazil provides various other services such as birth registration in hospitals through the National Plan for Birth Registration and various health programmes, such as vitamin A supplementation. Brazil has a national nutrition programme that covers financial support for school grants, including food programmes and petrol subsidy. However, to receive these subsidies, families need to follow specific routines related to health such as vaccinations and post-natal care. Children in more affluent parts of Brazil have access to private ECE services, which often are of good quality, whereas children in poor regions have no access at all or have inadequate services provided by municipalities. As the UNESCO (2007:20) report indicates: 'Brazil is no exception when it comes to socio-economic disparities in access to EC services. Children from poor families are less likely to participate in such services'.

In 1996, Brazil implemented a shift of responsibilities of ECE from social development to basic education. Brazil has gone through all the challenges, for example creating a viable ECEC financial system housed in basic education and aligned to its new roles and functions in early education. Through this transfer process, the social and health wellbeing needs of children were neglected to a certain extent. Haddad (2016:285) has stated that 'from the lens of an integrated approach, the transference of ECEC services to education in Brazil has meant the subordination of the social dimensions'. The education system does not consider the needs of young children, for example considering the play pedagogy and the need for a whole day programme catering for the care and protection of children whilst their parents are at work. The shift of ECEC to education in Brazil therefore brought about several challenges in the area of financial management. UNESCO (2007) has stated that: 
Although the 1996 education law gave government sector responsibility for early childhood education to the Ministry of Education, battles continue between the education sector and the social assistance sector over the management and funding of preschools and daycare centres. (p. 15)

Brazil has adopted an integrated approach to EC services as a lever for quality services for young children. In this approach, care and education are designed to be provided simultaneously to ensure holistic child development. Brazil has also recognised the development of ECD standards as a contributing factor to ensure quality of early childhood services. In 1998, the Ministry of Education developed the first curriculum framework for O- to 6-year-old children; this was the National Curricular Reference for ECE. In 1991, the National Operational Guidelines were implemented to enable the coalescence of EC care centres and preschools into the education system for quality assurance purposes. All the standards were intended to facilitate monitoring of ECCE services. Brazil has made some strides with regard to legislation and development of standards for quality purposes; however, the major challenge is in their application and practical implication. This problem has been attributed to lack of or inadequate personnel and technical capacity along with lack of planning and implementation systems (UNESCO 2007:10).

Even though there are gaps and challenges, it is clear that the situation of ECD as a whole has improved for young children in Brazil in terms of government policies in education, health protection and other areas (Evans \& Kosec 2012:14).

\section{Early childhood education in South Africa}

Since 2001, South Africa has chosen to use the term ECD for the programmes and services of young children. White Paper Five on ECE and many other government documents define ECD as 'an umbrella term which applies to the process by which children from birth to nine years grow and thrive: physically, emotionally, 
mentally, socially, spiritually and morally' (South Africa Department of Education 2001:8). It should be noted that the White Paper Five is an ECE policy development document but it outlines the government's integrated ECD approach.

\section{Historical and socio-economic background}

The history of ECD in South Africa can be traced as far back as the beginning of the 20th century with the creation of the South Africa Council for Child and Family Welfare in 1908 to care for children's health and wellbeing. Daycare centres and nursery schools were separated. Daycare centres were under the department of social welfare and nursery schools were under the provincial departments of education (DoEs). The division of these two programmes was heightened when in 1939 the South African Association for Early Childhood Education (SAAECE) was formed to take care of white nursery schools (Nel 2007:3). Apartheid did not spare ECD in its provision of racially divided services and resources. As $\mathrm{Nel}$ states: 'Unfortunately, the same ECD services and privileges were not experienced by black children'. Limits that were put on parental income placed restrictions on welfare subsidies for black children. In 1958, training courses for black teachers were restricted but were allowed to continue for white teachers (although on a small scale). By the end of 1990, lower-level teacher training courses that had been set up by the provincial education departments were phased out. The state's obvious unwillingness to invest in preschool services became increasingly evident between 1980 and 1990 (Nel 2007:3).

It is against the above historical background that in the early 1990s, the new democratic political dispensation was ushered with the formation of the South African Congress for Early Childhood Development (SACECD). The roots of SACECD stem from the role the ECD (NGO) played through advocacy and lobbying young children's rights as they saw the social injustices, particularly amongst the poor and vulnerable children in non- 
white communities. Nel (2007:5) asserts that 'The NGOs were looking for alternative ways for ECD provisioning, especially for the training of educators'. The National Interim Working Committee (NIWC) was launched in 1990 to represent ECD nationally. 'The NIWC and the South African Association for Early Childhood Education (SAAECE) eventually amalgamated in 1994 to form the current SACECD which plays both a lobbying and organisational role in South Africa through which ECD educators are represented and their provisioning is addressed' (Nel 2007:5). This was a multi-racial organisation with representatives from all the four races of South Africa, including Indian, white, black and coloured. It has provincial and national structures. The SACECD played a pivotal role in ensuring that ECD was included in the new government's political agenda through incorporation in the new policies of the DoE, social development and health. The DoE was the pioneer in driving the country's new ECD/ECE policies and establishing the first ever ECD directorate under the chief directorate responsible for curriculum.

The development and implementation of ECD in South Africa followed a pattern of stages in setting up systems, developing legal frameworks and conducting studies to understand ECD and its context.

\section{Early childhood education's legal framework: South Africa}

Since 1994, there have been many significant legal frameworks, which include laws, regulations and guidelines, developed to guide ECD in the country. Storbec and Moodley (2011:2) support this by stating that, the 'importance of the young child in South African policy has been recognised through the inclusion of ECD planning in documents relating to the national DoEs, social development and health'. It should be emphasised that ECD is a very intersectional sector in South Africa and other departments included are departments of monitoring and evaluation, local 
government, correctional services (as young children with their mothers are in prisons) and housing, just to mention a few. All these departments have their own legal frameworks which include the provision of ECD in them. These frameworks have been supported by various other processes such as conducting audits, pilots and other studies.

Most notable processes are:

- National ECD pilot of 1996, which was conducted after the development of the interim ECD policy.

- First national ECD audit in 2001.

- First ECD diagnostic review in 2012.

- Second ECD audit in 2014.

All these processes have contributed to the policy development and reforms undertaken in ECD. However, it is important to observe that despite having very good ECD legal frameworks, some of which have been implemented and created as ECD programmes and systems in the country, the challenges of equitable and quality access to ECD programmes and services still exist in South Africa. The following are the legal frameworks that have helped ECD to grow as a sector for programme and service delivery in the past 25 years (see Figure 3.4 and Table 3.2). Even though the main focus here is on the frameworks that are linked to education, a few others are mentioned to indicate that implementation of ECD does not lie solely with education. In 2010, the DoE was divided into two departments, namely the Department of Basic Education (DBE) and the department of higher education (DoE 2010:7).

\section{Early childhood education practitioner training}

South Africa has different types of training provisions for the ECD sector. There are different institutions, structures and systems that support the training programmes. The NGO training organisations known as the ECD resource training 


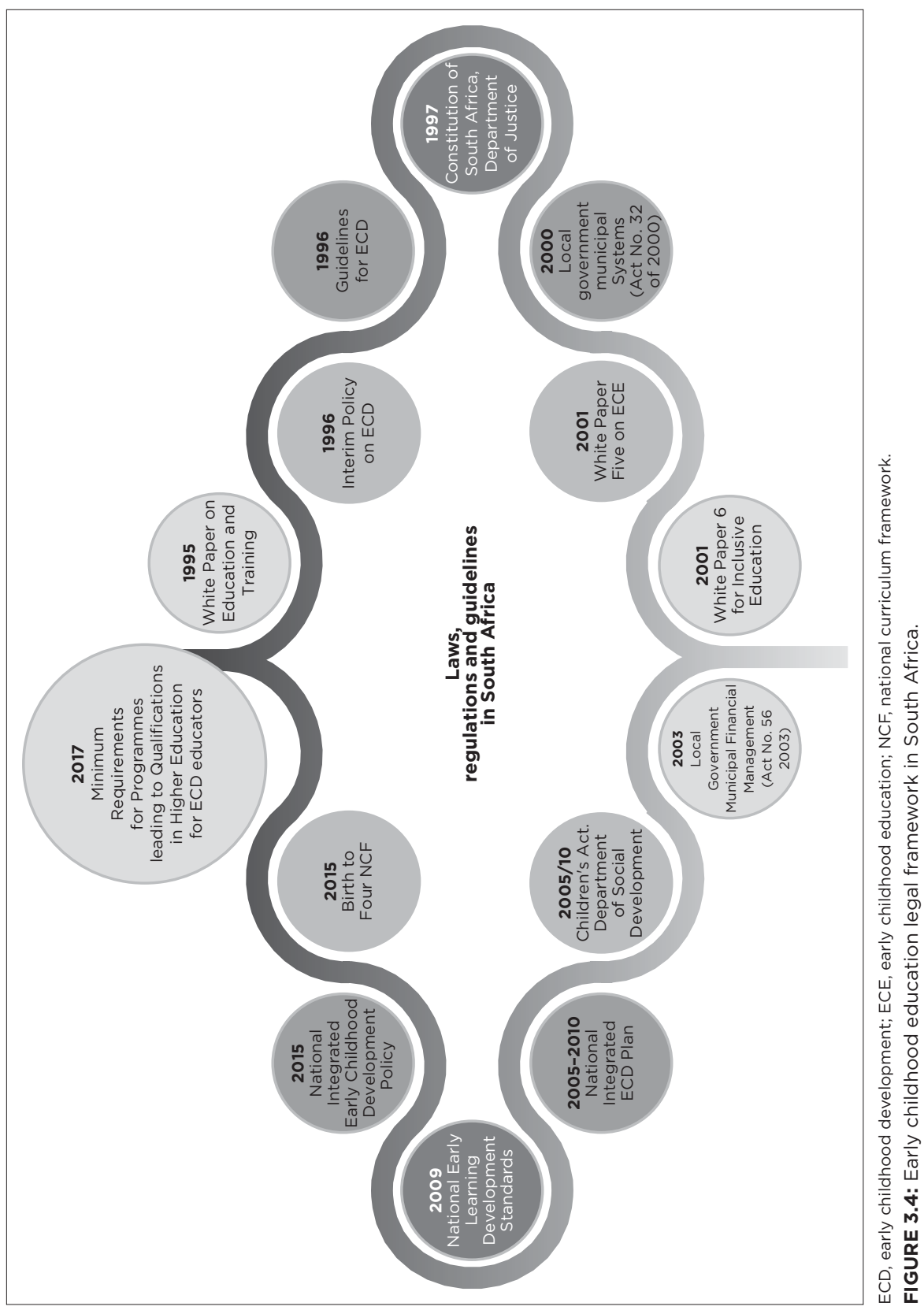


TABLE 3.2: Policy framework of South Africa.

\begin{tabular}{|c|c|c|}
\hline Year & $\begin{array}{l}\text { Policy framework } \\
\text { Department responsible }\end{array}$ & Purpose and focus \\
\hline \multirow[t]{2}{*}{1995} & $\begin{array}{l}\text { White Paper } 1 \text { on education } \\
\text { and training }\end{array}$ & \multirow[t]{2}{*}{$\begin{array}{l}\text { Highlighted the importance of ECD and why } \\
\text { the government should focus on it }\end{array}$} \\
\hline & South Africa DoE & \\
\hline \multirow[t]{2}{*}{1996} & Interim policy on ECD & \multirow{2}{*}{$\begin{array}{l}\text { The first national ECD policy initiative } \\
\text { whose vision was to address the past } \\
\text { imbalances and provide affordable and } \\
\text { equal access to a variety of ECD services } \\
\text { and programmes }\end{array}$} \\
\hline & South Africa DoE, 2001 & \\
\hline \multirow[t]{2}{*}{1996} & Guidelines for ECD & \multirow{2}{*}{$\begin{array}{l}\text { This document stipulates all the } \\
\text { requirements and regulations for setting up } \\
\text { ECD services in South Africa }\end{array}$} \\
\hline & $\begin{array}{l}\text { Department of Social } \\
\text { Development }\end{array}$ & \\
\hline \multirow[t]{2}{*}{1997} & Constitution of South Africa & \multirow{2}{*}{$\begin{array}{l}\text { Section } 27 \text { spelled out the rights of children } \\
\text { such as the right to education }\end{array}$} \\
\hline & Department of Justice & \\
\hline 2000 & $\begin{array}{l}\text { Local Government Municipal } \\
\text { Systems (Act No. } 32 \text { of } \\
\text { 2000) }\end{array}$ & $\begin{array}{l}\text { Main requirement is that the municipalities } \\
\text { ensure that Section } 27 \text { of the constitution is } \\
\text { implemented regarding children's rights }\end{array}$ \\
\hline \multirow[t]{2}{*}{2001} & White Paper 5 on ECE & \multirow{2}{*}{$\begin{array}{l}\text { This introduced the concept of integrating } \\
\text { services for young children to ensure } \\
\text { holistic development through provisions of } \\
\text { care, nutrition, health and protection as well } \\
\text { as early stimulation. It was this policy that } \\
\text { guided the introduction of the reception } \\
\text { year (Grade R) }\end{array}$} \\
\hline & South Africa DoE & \\
\hline \multirow[t]{2}{*}{2001} & $\begin{array}{l}\text { White Paper } 6 \text { for inclusive } \\
\text { education }\end{array}$ & \multirow{2}{*}{$\begin{array}{l}\text { Has a section that sets out the procedures } \\
\text { for addressing early detection and } \\
\text { intervention in ECD }\end{array}$} \\
\hline & South Africa DoE & \\
\hline 2003 & $\begin{array}{l}\text { Local Government Municipal } \\
\text { Financial Management (Act } \\
\text { No. 56, 2003) }\end{array}$ & $\begin{array}{l}\text { For ensuring that financial resources are } \\
\text { available for ECD services }\end{array}$ \\
\hline $2005 / 10$ & $\begin{array}{l}\text { Children's Act. Department } \\
\text { of Social Development }\end{array}$ & $\begin{array}{l}\text { It stipulates the standards for provision of } \\
E C D \text { and partial care for children }\end{array}$ \\
\hline $2005-2010$ & $\begin{array}{l}\text { National Integrated ECD Plan } \\
\text { South Africa DoE }\end{array}$ & $\begin{array}{l}\text { This came out in the White Paper } 5 \text {. It was } \\
\text { the first multi-sectoral plan that provided } \\
\text { for a comprehensive programme for young } \\
\text { children from birth to five years. It was } \\
\text { never implemented by government but } \\
\text { many NGOs created programmes for their } \\
\text { own communities }\end{array}$ \\
\hline
\end{tabular}

Table 3.2 continues on the next page $\rightarrow$ 
TABLE 3.2 (continue): Policy framework of South Africa.

\begin{tabular}{|c|c|c|}
\hline Year & $\begin{array}{l}\text { Policy framework } \\
\text { Department responsible }\end{array}$ & Purpose and focus \\
\hline 2009 & $\begin{array}{l}\text { National Early Learning } \\
\text { Development Standards } \\
\text { South Africa DoE }\end{array}$ & $\begin{array}{l}\text { These provide the early learning } \\
\text { developmental expectations of children } \\
\text { from birth to four years. They are a guide on } \\
\text { what to consider with regard to children's } \\
\text { early learning competencies whilst } \\
\text { developing materials such as curriculum } \\
\text { and training programmes }\end{array}$ \\
\hline 2015 & $\begin{array}{l}\text { National Integrated Early } \\
\text { Childhood Development } \\
\text { Policy } \\
\text { Department of Social } \\
\text { Development }\end{array}$ & $\begin{array}{l}\text { This framework is designed to provide } \\
\text { from conception to five years with a } \\
\text { comprehensive package of programmes and } \\
\text { services through an inter-sectoral system of } \\
\text { delivery at national and provincial levels }\end{array}$ \\
\hline 2015 & $\begin{array}{l}\text { Birth to Four National } \\
\text { Curriculum Framework DBE }\end{array}$ & $\begin{array}{l}\text { This provides guidance on how to develop } \\
\text { programmes and implement teaching and } \\
\text { learning experiences for young children } \\
\text { from birth to four years }\end{array}$ \\
\hline 2017 & $\begin{array}{l}\text { Minimum Requirements } \\
\text { for Programmes Leading } \\
\text { to Qualifications in Higher } \\
\text { Education for Early } \\
\text { Childhood Development } \\
\text { Educators } \\
\text { South Africa Department of } \\
\text { Higher Education }\end{array}$ & $\begin{array}{l}\text { These are the guidelines referring to } \\
\text { development of quality training for EC care } \\
\text { and education ( } 0-4 \text { years) practitioners }\end{array}$ \\
\hline
\end{tabular}

Source: DBE (2015:1-81).

DBE, Department of Basic Education; DoE, Department of Education; EC, early childhood; ECD, early childhood development; ECE, early childhood education.

organisations are pioneers who paved the way for ECD training in South Africa. The NGOs started providing training as far back as in the 1980s when they started providing non-accredited training programmes to ECD practitioners. After 1994, the then DoE in collaboration with the South African Qualifications Authority (SAQA) developed ECD qualifications. Today, South Africa has ECD qualifications from the NQF level 4/5 and 5, certificates and diplomas offered predominantly by NGOs, private colleges, government further education and training (FET) colleges and HEIs. Even though the HEls provide diplomas, they especially focus on developing and establishing degree level programmes, including BEd, BEd Honours, Masters and 
PhD degrees in the field of ECD, which are respectively of NQF levels 6, 7, 8 and 9 on the SAQA qualifications band. There are training and development policies that support various qualification processes. The latest qualification which has been introduced and developed nationally is the diploma in ECCE (birth to four years of age) as well as the BEd degree in ECCE (birth to four years of age). The development of these qualifications has been guided by the policy on minimum requirements for programmes leading to qualifications in higher education for EC development educators, March 2017 (DHET 2017:4-45). There are other systems that provide ECD qualifications, for example there is a government agency called the Education Training Development Practices Sector Education and Training Authority (ETDP SETA) which supports training organisations to provide learnerships, which are work-based skills programmes that lead to accredited qualifications in a specific sector. The ETDP SETA supports training organisations to provide ECD learnerships at NQF levels 4 and 5.

\section{Quality of early childhood education services in South Africa}

Historically, prior to 1994, NGOs have been the backbone for providing ECD programmes and services across the country. These NGOs have worked mainly in the townships and communities providing services relating to education care and protection of young children and their families. These organisations range from community daycare centres to big training organisations. The NGOs have relied on meagre fees, and in some cases, they have sought and received funding from corporates and philanthropic organisations. These NGOs have provided a plethora of services and programmes over the years and it is upon this foundation that the government established its programmes after 1994. The department of social development implemented the children's grant in the registered community ECD centres, where stipulated requirements for these grants 
are met. This specific grant is utilised to enhance nutrition learning resources and where necessary for remunerations. The ECD programmes and services in South Africa are currently provided by government and NGOs supported by funders and private entities. Sometimes the government departments have partnered with NGOs and funders for providing specific programmes and services. The programmes and services fall under the categories of healthcare and wellbeing, education as well as safety and protection. It is impossible to discuss all of them in this chapter, but in the context of education programmes and services the programmes are as follows:

- The Grade R programme is provided in both government and private schools and some community centres for 5-year-old children, and is equivalent to kindergarten.

- The school nutrition programme in primary schools and includes children from Grade R to 12.

- Home-based ECD programmes are mainly offered by NGOs at homes for early stimulation and referral services.

- Centre-based programmes are offered by communities who come together and set up a centre.

- Mobile ECD programmes are usually offered by NGOs in rural areas to provide early stimulation and referral services.

- Play groups are offered by organisations mainly in rural areas and some informal settlements to give children an opportunity to be stimulated through games. Very young children attend these with their parents.

- Toy libraries are provided in many communities of urban and rural areas. They give children and their parents access to educationally appropriate toys and materials for learning through games. Often times, toy libraries assist parents on how to use toys and materials for their benefits.

- Outreach programmes are often linked to community centres. They target parents, caregivers and families in general, capacitating them and sometimes providing them with resources on how to take care of their children. 
- Child minding services are normal services arranged by parents for their children whilst they are at work. Their companies now offer professional child minding services using trained child minders (DBE 2009).

One of the announcements made by President Ramaphosa during the SONA in February 2019 was that the South African government would introduce and implement two years of compulsory ECD for all children before they enter Grade 1 (SONA 2019). President Ramaphosa indicated that a pre-Grade $R$ class would offer an extra two years of preschool education in South Africa.

Another critical announcement for the ECD sector made by the president in February 2019 relates to the shift of responsibilities of ECD. The president stated that the responsibilities of ECD would move from social development to DBE. This is a critical milestone in the history of ECD that would have many positive and negative repercussions on ECD provisioning. It must be noted that municipalities have legal requirements to provide and support ECD services and programmes in their localities mainly through provision of infrastructure. This shift would affect municipalities as they now have to align with the requirements of the shift.

\section{Curriculum}

South Africa has several policies to guide development of curriculum at different levels of ECD provisioning, which are preGrade R and Grade R to Grade 3, also known as the foundation phase, which are equivalent to lower primary school. The curriculum for pre-Grade $\mathrm{R}$ and from birth to five years of age is guided by the 'Birth to Four Curriculum Framework'. This framework is now publicised and implemented through training workshops in the ECD sector so that trainers, practitioners and parents are aware of its contents and how they can use it in different ECD contexts. The training organisations, including 
HEIs, are using the NCF to develop training materials and manuals or modules on ECD. The curriculum for Grade R to Grade 3 is included in the National Curriculum Statements (NCS) for Grade R to 12. The NCS includes the curriculum assessment policy statements (CAPS) which provide curriculum guidance in the following three subjects: life skills, language and mathematics in the Foundation Phase (DBE 2009; DoE 2009).

\section{- Comparing early childhood education in China, India, Brazil and South Africa}

The selected four countries discussed in this chapter have several similarities and differences regarding their experiences in ECD. Each of them has unique contexts in which ECD has evolved at social, economic, historical and political levels. This section highlights some of the similarities and differences that these countries have regarding how they have developed and implemented ECD. To start with, Table 3.3 provides a bird's eye view of ECD in CIBSA using the approach of looking at eight ECD elements in the first column as discussed above in the chapter. This is followed by a brief comparative synopsis across the countries.

One common characteristic that CIBSA have is that, like the rest of the world, they have embraced and recognised the importance of EC years and its benefits for the whole human development trajectory. They have actively put in place different legal frameworks to support the holistic development of young citizens, although they have also experienced challenges with the implementation of some of these legal frameworks.

The general definition of ECE includes care and education of children from birth to six years of age by providing holistic development interventions relating to their health, nutrition and education needs through a variety of settings such as crèches/ daycare centres, home-based parent education programmes 


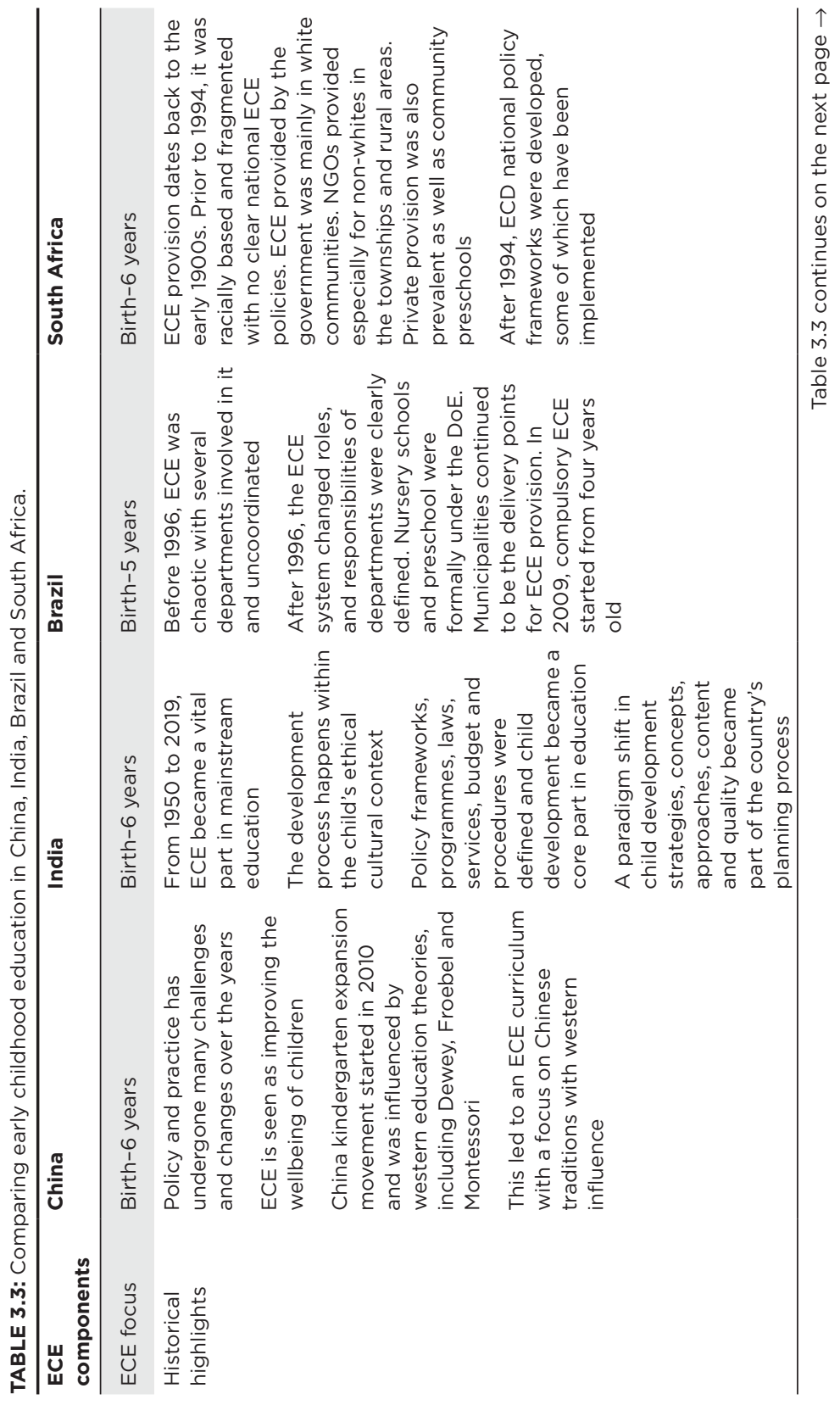




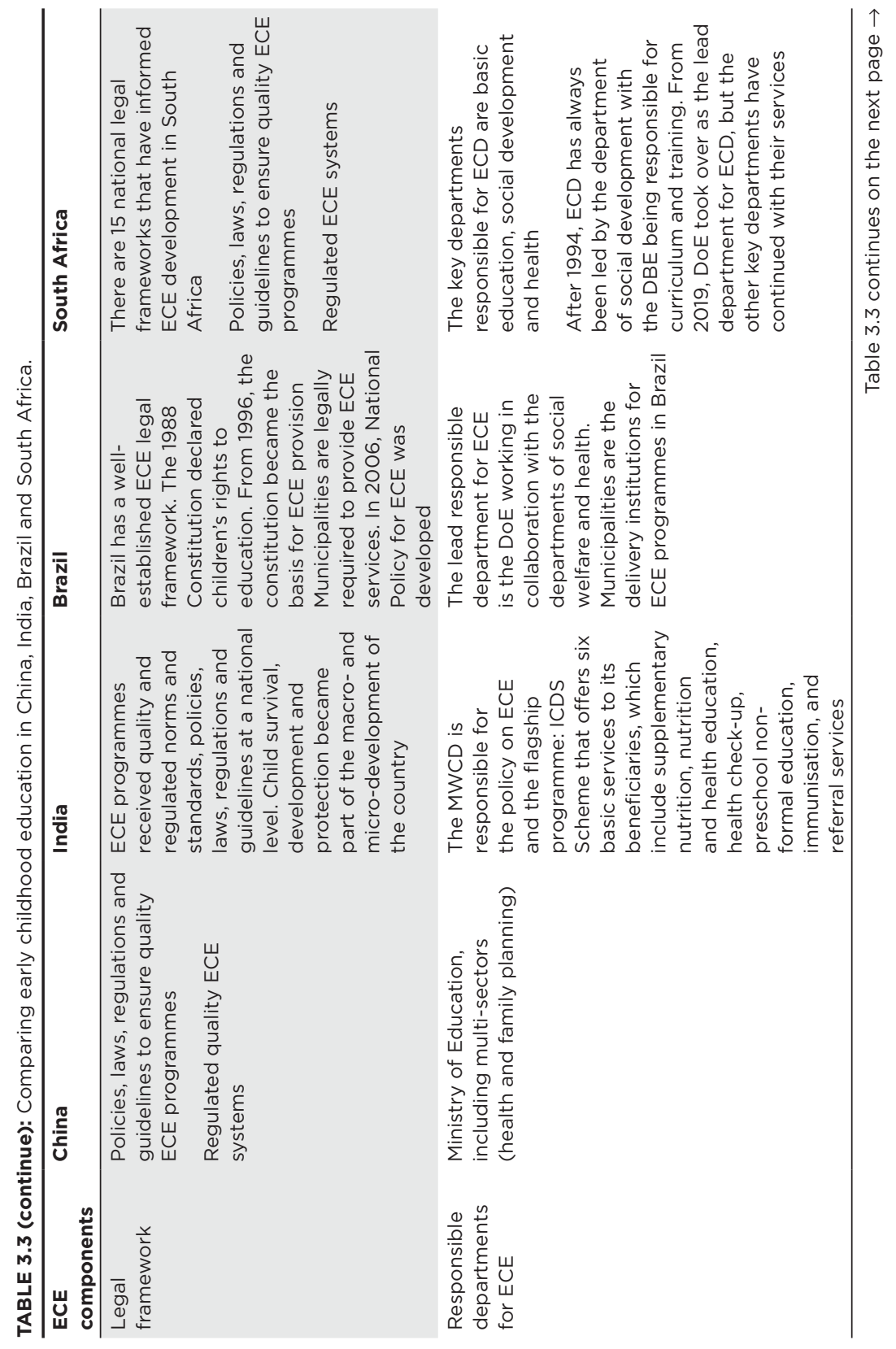




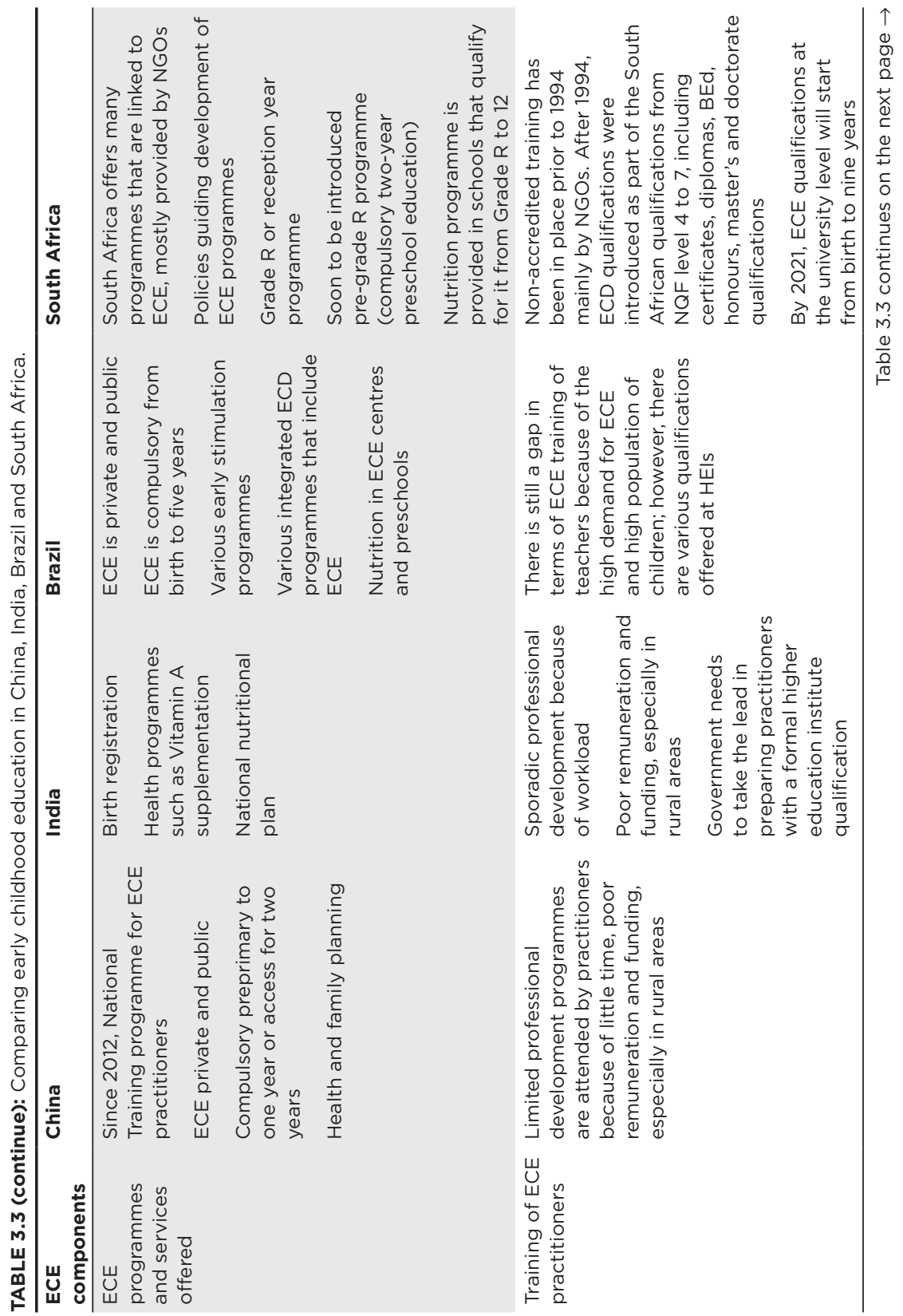




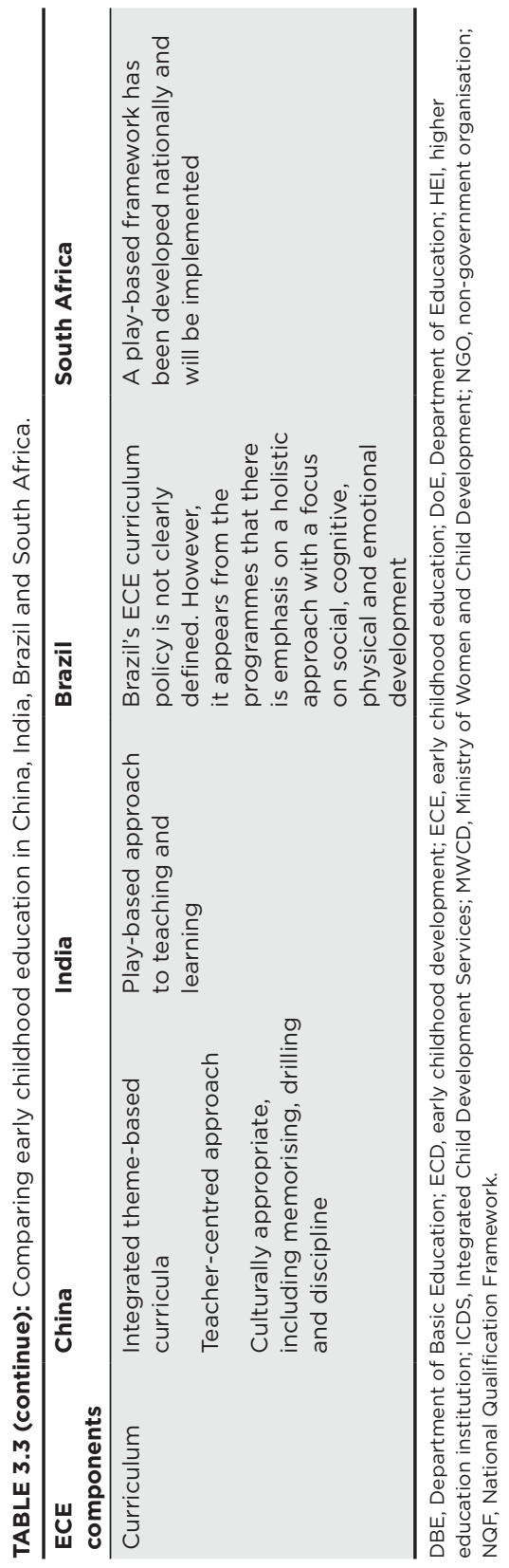


and preschools. It is noted that the term ECE in China, India and South Africa includes and refers to children from birth to six years of age but in Brazil, ECE refers to children from birth to five years of age. Diversity in China and India is mainly due to language differences, whilst Brazil and South Africa have diverse ethnic, racial, language and cultural groups. South Africa could learn from Brazil since the country is currently (as in 2019) experiencing a shift of responsibilities from the department of social development to the DoE. Brazil, China and India have gone through some challenges, for example creating a viable ECD financial system, positioned in basic education and established new role and functions within ECD.

Another lesson that South Africa could learn from these countries is to ensure the involvement of multi sectors, such as health and family planning, to ensure that social and health wellbeing needs of children are not neglected in the transfer of ECD responsibilities from social development to basic education. South Africa needs to ensure that in the process of transfer of power, the essential package of ECD services mentioned in the National Integrated Early Childhood Development Policy is not lost or neglected. In essence, mechanisms need to be put in place to ensure that the roles of other departments and their services still reach the targeted children.

As in South Africa, Brazil provides a National Plan for Birth Registration, and various health programmes such as vitamin A supplementation. India has a national population register for births in hospitals. South Africa and Brazil have a national nutrition programme that covers financial transfers such as school subsidies for food programmes. It was suggested that China look at implementing a national nutritional plan to ensure overcoming nutritional barriers and common diseases at ECE sites. In India, the MWCD is the nodal department for ECE, and is responsible for the ICDS in rural areas. They supplement nutrition, immunisation, health checkup, preschool education, referral services, and nutrition and health education. However, to receive 
benefits, families must follow specific routines related to health such as vaccinations and post-natal care. South Africa does not have such incentive approaches and as a result some families do not follow through or complete their children's vaccinations and antenatal care.

Brazil and India have had a long history of provision of preschool education for children aged four to six years. After the Grade R system for five-year olds was introduced in 2001, South Africa is currently in the process of introducing Grade RR, which includes 4-year-olds into pre-primary school. With the introduction of pre-Grade R for 4-year-olds, the community ECD institutions would lose a lot of their four-year-old children to the school system. Already the NGO sector has concerns about the effects that this would have on the centres and practitioners who provide these communities with their ECD services. For many of them, the ECD centres are a source of employment and income and they will not be able to compete with the government's free pre-grade $\mathrm{R}$ provision, which is in the pipeline.

The provision of two-year preschool education system is the fulfilment of the National Development Plan (2019) announced by the president of South Africa in February 2019. However, the actual implementation will take some time to allow for the development of systems and preparedness by the DBE. Following the footsteps of China, Brazil, India and many other countries across the globe, the South African government announced the transfer of ECD responsibilities from the department of social development to the DBE. In this policy move, South Africa and Brazil will have a similar experience with the transfer of ECD responsibilities and the introduction of preschool education into the school system and the community daycare centres as in the case of China and India.

In CIBSA, qualified practitioners in ECE centres are rare. Currently, the European Union (EU) is funding the development of diploma and BEd degree programmes in ECE ( $\mathrm{O}-4$ years) for the training of practitioners at different HEls across South Africa. 
Part of the funding was for the development of a national playbased framework for ECE in South Africa. In 2012, a training programme for ECE practitioners in China was launched to take care of 0 - to 3-year-old and 3- to 7-year-old children. The potential practitioners caring for the 0- to 3-year-old children have acquired at least a high school qualification, and the practitioners caring for the older children are expected to have completed a vocational ECE training programme.

Children in more affluent parts have access to private ECE services, which are often of good quality, whereas children from poor regions or rural areas either have no access or have inadequate services provided by a variety of unregulated institutions, including lack of proper teacher training with poor remuneration and attitude, poor child-teacher ratios and poor support of children (UNESCO 2007:20-26).

\section{Conclusion}

It is clear from the above discussion that the foundations of ECE in the four countries are well laid; however, it needs improvement in terms of implementation, especially in the areas such as infrastructure, relevant laws and regulations, resources, monitoring, student-teacher ratios and practitioner training to ensure quality education.

It is further noted that all the four countries agree that investing in ECE has the potential to fundamentally transform the lives of children and their families and to have positive impact on country's prosperity.

Early childhood education in the four countries is far from satisfactory; therefore, the following may contribute to its success:

- Policy frameworks alone are not enough. Programmes, laws, services, budget and procedures must consider development and protection as a core part of child development. 
- Current preschool services cannot provide for a large number of children and the child-practitioner ratio is not sufficient for quality child development.

- A paradigm shift in child development strategies, concepts, approaches, content and quality is needed as part of the different country's planning process.

- Government has to accept that child survival, development and protection are part of the macro and micro development of a country.

- Early childhood education needs to be valued unambiguously as a vital part of mainstream education.

- Early childhood education needs quality norms and standards at a national level.

- Early childhood education needs five quality capacities: curriculum, practitioners, child-practitioner ratio, infrastructure and supervisory mechanism.

- Different governments need to take lead in preparing practitioners with formal higher qualifications to assure quality practitioners in preschools.

- It is important that preschools are accredited and registered according to specific criteria to ensure quality care and education of young children.

- Governments need to support, invest and intervene for quality and sustainable ECE programmes.

- To provide regulated quality ECE systems, it is necessary that research is conducted on the challenges experienced in different countries.

- All the four mentioned countries experience similar economic challenges and lack of ECE priorities associated with uneducated parents and logistics; therefore, the countries need to collaborate and learn from one another to overcome the challenges hindering the development and successful expansion of ECD globally. 
It is noted that in all four countries, challenges to ECE access still exist with disparities and gaps along socio-economic inequities. Child-teacher ratio, availability of facilities, lack of qualified practitioners, culturally appropriate curricula, pedagogies for sustainable quality ECE programmes and need for sustainable nutritional plans are common gaps identified in these four countries. 



\section{Chapter 4}

\section{Language of learning and teaching in South Africa and India: A comparative study}

V. Santhakumar

School of Development, Azim Premji University,

Bangalore, India

Charl C. Wolhuter

Subject Group Comparative and International Education, Education and Human Rights in Diversity Research Unit,

Faculty of Education, North-West University,

Potchefstroom, South Africa

\section{Abstract}

Whilst there is a widespread agreement that language hampers a large section of learners in South African school, this is a very

How to cite: Santhakumar, V. \& Wolhuter, C.C., 2020, 'Language of learning and teaching in South Africa and India: A comparative study', in C.C. Wolhuter (ed.), Critical Issues in South African Education: Illumination from international comparative perspectives from the BRICS countries (BRICS Education Volume 2), pp. 109-137, AOSIS, Cape Town. https://doi. org/10.4102/aosis.2020.BK207.04 
complicated and remains to be a very controversial issue in South Africa. India with 22 official languages acknowledged in the Constitution finds itself in the situation where the value of English as international lingua franca constitutes a force, making it difficult for indigenous languages to make headway in their development as languages of learning and teaching; this shows similarities with the South African context. The Seminal Report of the Kothari Commission in 1967 was to be a blueprint for the radical decolonialisation of education in India, replacing the British education system inherited the time of independence in 1947 with an education system consonant with the context of India. Yet India is still wrestling with the issue of language in education; this is one aspect where the colonial vestige is still conspicuously present. The purpose of this chapter is to extract the value of the Indian experience regarding language of learning and teaching for South Africa. The chapter surveys the issue of language of learning and teaching, firstly in South Africa and then in India, and finally compares the two cases. Whilst both nations are characterised by indigenous linguistic diversity, being overlaid by the strong position of English, both as ex-colonial language and as international lingua franca, there are stark differences between the two cases. The longer history of India, and it having regionally more concentrated languages and despite national government's efforts to promote the strongest indigenous language Hindi, and the fact that the promotion of other indigenous languages has been on the political agenda, all this show the futility of attempting to wage a campaign to dislodge English and replace it with indigenous languages as language of learning and teaching in education institutions. These are the advantages that South Africa does not have. The experience of India points to a futility of attempts to dislodge the hegemonic position of English as a language of learning and teaching in educational institutions and replace it with indigenous languages, although strong arguments are there from an educational point of view for such a change. Another angle should be considered to retain or develop other languages as a 
medium of learning and teaching. It is here that the multilingual model of China emerges. In Chapter 7 of this volume, the potential of this model for South Africa is investigated.

Keywords: BRICS; Comparative education; India; Language of learning and teaching; South Africa.

\section{Introduction}

One very compelling - in terms of importance for learning, and in terms of emotion it generates - issue in South African education at present is that of language. Being similar to South Africa, a former British Colony and still part of the Anglophone world, and containing a rich diversity of languages, India prima facie appears to be a good candidate, with a rich tertium comparationis, for the illumination of the language in the challenge of education in South Africa from an example of international comparison. The aim of this chapter is to compare the experience of India, with its longer history of independence (1947), regarding the handling of the issue of language in education and to extract the relevance of that experience for South Africa.

The chapter commences with the explanation and motivation of the research methodology. The South African language diversity and the history of formal education in the country, with special attention to the handling of the question of language, and culminating in recapturing the present conundrum regarding language in education in South Africa is reconstructed. The focus then moves to India, to survey the handling of language in the Indian context. In conclusion, the relevance of the Indian experience regarding the handling of language in education for South Africa is identified.

\section{Research methodology}

In explaining the method used for this research, the taxonomy of methods of social science research developed by Robson (2011) is used. 
According to Robson (2011), three levels or categories of methods figure in research, namely:

- Methods of data collection.

- Methods of data analysis.

- Methods of data interpretation.

Research commences as a data collection exercise. At the next level, the collected data mass are analysed in order to reduce it to sensible proportions, that is, to summarise and order it. After having summarised the data mass into manageable and understandable proportions, at the next level, the researcher works to assign a particular meaning or understanding or explanation to the analysed data, which means the data are interpreted. For each of these levels, several methods are available.

For this research, the methods of literature survey and documentary analyses were used to collect information. Whilst the literature survey can serve one or more of the purposes in a research project (see Gasa, Mafora \& Maphalala 2015:133-134), in this research, it was conducted in order to gain a pool of base data from which a comparison could be done between the languages of learning and teaching in India and South Africa. Literature was consulted on the following topics: the education history and system of India and South Africa, and the societal contexts of India and South Africa, as these have shaped education, especially the language situation. Literature used included books by renowned authors and journal articles published in peer-reviewed journals. Documents consulted included Education Acts, Reports of Commissions of Inquiry into Education, and Education Policy Statements.

Regarding the methods of analysis and interpretation, for these the education system perspective and the contextual and comparative perspective (for interpretation) moments of Comparative and International Education, as explained in Chapter 2 of this volume, were used. The data on language of learning and 
teaching in India and South Africa were ordered in the education system and societal contextual frameworks as they manifest in these two countries. The appearance of language of learning and teaching in education was interpreted and assessed against the background of the societal contexts of the two countries, and from a comparison of all these, the relevance of the Indian experience with language of learning and teaching in education for South Africa was extracted.

\section{The linguistic diversity of South Africa}

South Africa has 11 official languages. These are (in parenthesis after each language appears the percentage of population speaking that language as their first language) as follows: isiZulu (23.8\%), isiXhosa (17.6\%), Afrikaans (13.3\%), Sepedi (9.4\%), English (8.2\%), Setswana (8.2\%), Sesotho (7.9\%), Xitsonga (4.4\%), siSwati (2.7\%), Tshivenda (2.3\%) and isiNdebele (1.6\%) (RSA 2018). Furthermore, according to official census statistics (RSA 2018), almost one million South Africans (to be exact, 828 258, or $1.6 \%$ of the census-counted population) have a home language other than the 11 official languages. By the very nature of their situation, it is difficult to determine the precise number of illegal immigrants, but census data probably represent a substantial undercount. Estimations of illegal immigrants in South Africa are in the region of 5 million (Wilkinson 2018). However, the situation is even more complicated than this.

To commence with, because of inter-marriage, 'first language' and 'home language' are not the same in many instances. Secondly, the languages in terms of the first language or home language speakers are not located in geographically compartmentalised and mutually isolated areas. There are very few areas where one language constitutes the first language of more than $90 \%$ of residents, and such areas are mostly in the deep rural pockets. Linguistic diversity is especially acute in urban settings. The best that could be demarcated are the 
'heartlands' (also a term that has, unfortunately, fallen into some political controversy) of languages, where there are discernable concentrations of speakers of particular languages.

Thirdly, the languages have unequal patterns of historical development of empowerment. English has a history of a written language of almost a millennium (more than a millennium if one of its progenitor languages, Latin, is also taken into account). More than that, with the momentum provided by the United States of America (USA) as a global superpower, English has become the international lingua franca in a globalised world, particularly that of the academic world, the publishing industry, and of the commercial and business world. Afrikaans has a written history of over 100 years (if its progenitor language Dutch is included, it has a history of almost a millennium). In the space of these 100 years, it has developed and empowered not only as a language of learning and teaching in education institutions, right up to higher education, but also as a carrier of cultural expression and a language of political, business, industrial, military, journalism and sports world, although - even when first Afrikaans speakers were at the height of their political power, c. 1948-1988 - it has never, not even remotely, carried the same cultural and symbolic, and even economic and capital generating potential (to use the terms of Bourdieu 1986) as English. The other nine official languages lag behind English and Afrikaans regarding empowerment in the domains of usage of different languages (this term is used for a number of times in this chapter; for an enumeration of the hierarchy of language usage domains, see Fishman 1991). Whilst the Bible has been translated into some of the languages, such as isiXhosa and Setswana, as far back as the mid-19th century, compared with the first Afrikaans translation of the Bible, completed in 1933; none of these languages has ever been developed as a language of learning and teaching in education institutions beyond the third year of school.

The language division markedly corresponds with the racial divide, with Afrikaans being the home language of the majority (some $65 \%$ ) of white as well as mixed section of the population, 
and English being the home language of the second largest part of white community (after Afrikaans) as well as the majority of the Indian section of population; the remaining 10 languages are the first languages of black South Africans. The racial divide (and the language divisions) runs to a substantial degree coterminous with socio-economic divisions. With a political history and political power relations also a function of the racial divide, this means that languages are in very delicate and potentially conflict-igniting positions. As power relations and the gravity of politics changed after 1994, Afrikaans no longer had the backing of political power. The status of the language was visibly downgraded in many domains, from being a language of jurisprudence to changing the names of state-owned enterprisescum-national symbols, such as the national airline, the electricity supply commission, and the public broadcaster - these had had bilingual names but after 1994 acquired unilingual English names - to the notices and names of commercial products; and above all as a language of learning and teaching, where the marginalisation and outright excommunication of the language took place in glaring contradiction of the Constitutional (Bill of Human Rights) provisions (this aspect is discussed in the 'Language as a medium of education in South Africa' section.

\section{Language as a medium of education in South Africa}

\section{Historical evolution of formal education in South Africa}

Formal schooling in South Africa began when the Dutch East Indian Company established a supply post at the Cape in 1652. As was the pattern in colonies, education (as was the society) was on racially segregated lines. Separate schools started for black and white children. The Dutch East Indian Company administration set up schools for white children.

On the other hand, formal schools for black children were opened by missionaries. Since the end of the 18th century, 
missionaries from Europe had entered South Africa in large numbers for missionary work amongst black communities to convert black people to the Christian religion. As part of their activities, 'they established churches, hospitals and schools' (Christie 1991:74) for black South Africans. However, the education supplied by the missionaries benefited only a very tiny percentage of black children. On top of that, education was limited to the lower rungs of primary education and was of a poor quality (cf. Christie 1991:74). Contemporary progressive scholarship also criticised missionary education for having educated black children away from their African culture and teaching them that African culture was inferior, and for serving as an instrument of western cultural imperialism, especially for having taught black children defer to white rule.

In 1953, the South African government too became active in providing schooling to black children. For this purpose, a government department for black education was established. The ministry set up public schools for black children. In the black community, there were strong objections and even resistance to the system of 'segregated education' (Mphahlele \& Mminele 1997:167) and particularly to black education. Their rejection was based on the following (cf. Mphahlele \& Mmninele 1997:104-119) reasons:

- Grave inequalities in the South African education system. Schools for black children had an infrastructure and resources substantially lower than that of white schools, and the teachers of black schools were also not as well qualified as the teachers in white schools. Per pupil public expenditure on black school children was much lower than that on white children.

- Black education was deemed to be extremely authoritarian.

- Black education was criticised as being too Europe-centred, to the exclusion of cultural heritage and achievements of the rest of humanity; especially neglecting African cultures.

In the socio-political turmoil in the run-up to the Constitutional change in 1994, education served as a rallying point, particularly the pattern of unequal education and the issue of language of 
learning and teaching in education, the latter brought to a head in 1976. The situation of language learning and teaching at educational institutions in South Africa had historically developed comparable to the situation elsewhere in sub-Saharan Africa. In Anglophone sub-Saharan Africa, the colonial arrangement has been kept intact after independence, whereby the dominant home language in the catchment area of a school is used as the language of learning and teaching during the first three years of schooling, after which the language of the colonial power, that is English, is switched to. Similarly, in South Africa, the historically developed situation was the first language for first three years of schooling, then English (with the exception of Afrikaans, which the Afrikaans-speaking community has, during the 20th century, developed to the language of learning and teaching right up to the level of doctoral programmes at universities). In 1976, the government department tasked with Education to black South Africans made a decision that after the third year of schooling, half of the school subjects would be taught in English and the rest in Afrikaans. This was the immediate spark for the 1976 Soweto school protest, named so after the residential area on the South of Johannesburg where the protest started. However, this civic action soon spread to other parts of South Africa and had occurred after 1976 regularly (see Hyslop 1999). Whilst the immediate cause of the activism was the use of Afrikaans as a language of learning and teaching in black schools - this in any case was done away with within a year after 1976 - the broader cause was the issue of unequal, segregated education and the political dispensation of minority white rule (see Christie 1991; Hyslop 1999). In the run-up to the political change of 1994, education served as a rallying point to mobilise people and education institutions frequently became the site of activism (see Christie 1991; Hyslop 1999).

\section{Objectives of post-1994 education}

After forming the government in 1994, the African National Congress (ANC) formulated an education policy drafted upon its vision. Following were the foundations of this policy, the intrinsic goals of the post-1994 education system (cf. Wolhuter 1999): 
- Democratisation.

- Desegregation.

- Decentralisation.

- Equal educational opportunities.

- Multicultural education.

The antecedents of these principles are traced back to the Constitution and the Bill of Human Rights, which is a part of the Constitution.

The whole education system has to strive to develop the total population and to pursue a parade of societal aims. These aims, the extrinsic goals of education, are as follows (Wolhuter 2020):

- Economic goals: Stamping out poverty and serve as an instrument to effect economic productivity and development.

- Social goals: Constructing a society in which racial, gender and other forms of unfair discrimination are absent, a society characterised by social mobility and the absence of stifling hierarchies and obstructions hampering the progress.

- Cultural goals: Empowering people to take part in the processes of cultural expression.

- Political goals: Enlightening citizens to take part in a meaningful, considerate way in the political processes of a democratic society, forging national unity: Establishing a common value system for a society where democracy, equality, freedom, peace, justice, tolerance and stability will be the hallmarks.

The antecedents of these principles could be traced back to the Constitution and the Bill of Human Rights, which is a part of the Constitution.

Chapter 6 of the Constitution states the following regarding language (RSA 1996):

6. (1) The official languages of the Republic are Sepedi, Sesotho, Setswana, siSwati, Tshivenda, Xitsonga, Afrikaans, English, isiNdebele, isiXhosa and isiZulu. (2) Recognising the historically diminished use and status of the indigenous languages of our people, the state 
must take practical and positive measures to elevate the status and advance the use of these languages.

(4) The national government and provincial governments, by legislative and other measures, must regulate and monitor their use of official languages. Without detracting from the provisions of subsection (2), all official languages must enjoy parity of esteem and must be treated equitably. (5) A Pan South African Language Board established by national legislation must - (a) promote, and create conditions for, the development and use of - (i) all official languages; (ii) the Khoi, Nama and San languages; and (iii) sign language; and (b) promote and ensure respect for - (i) all languages commonly used by communities in South Africa, including German, Greek, Gujarati, Hindi, Portuguese, Tamil, Telugu and Urdu; and (ii) Arabic, Hebrew, Sanskrit and other languages used for religious purposes in South Africa. (ch. 6)

On the language of learning and teaching in public schools, and the right to establish private schools, Section 29 states (RSA 1996):

(2) Everyone has the right to receive education in the official language or languages of their choice in public educational institutions where that education is reasonably practicable. In order to ensure the effective access to, and implementation of, this right, the state must consider all reasonable educational alternatives, including single medium institutions, taking into account - (a) equity; (b) practicability; and (c) the need to redress the results of past racially discriminatory laws and practices. (3) Everyone has the right to establish and maintain, at their own expense, independent educational institutions that - (a) do not discriminate on the basis of race; (b) are registered with the state; and (c) maintain standards that are not inferior to standards at comparable public educational institutions. (s. 29)

To connect to and belabour the statement made in the previous section, notwithstanding noble intentions in incipient policy statements, and in glaring contradiction to the Constitution and the Bill of Rights, virtually nothing has been done to empower or develop languages other than English as a medium of instruction in schools. The empowerment of indigenous languages as a medium of instruction has not gone further than the third year of school (i.e. the pre-1994 status quo remains). Moreover, 
departments of African languages at various universities and number of students at these departments have come down (cf. Mgqwashu 2013:2). The marginalisation and outright scrubbing of Afrikaans as a language of medium at universities, and the fever with which government pressurises and resorts to litigations and changes policy to make the continual use of Afrikaans as a language of learning and teaching untenable, makes it difficult to avoid suspecting that a deliberate campaign against Afrikaans is being waged. This has been pronounced by even very progressive political commentators (who can by no means be regarded as conservative, or as hankering back to a past dispensation) (e.g. see Eloff 2020:11; Giliomee 2019; Joubert 2019:171-183). Even a private Afrikaans-medium $\mathrm{HEl}$, doing commendable work with no public funding whatsoever, drew the most vituperative comments from the minister of higher education in 2019 (see Suid-Afrikaanse Akademie vir Wetenskap en Kuns 2019).

It is not only Constitutional imperatives which are at odds with the above policy directions, but a mass of evidence globally also speaks in favour of the first language being the optimal medium of instruction. The desirability of the first language as a language of learning and teaching is acknowledged right up to the UNESCO (see UNESCO 1953) and the World Bank (see World Bank 2005). How detrimental is the changing over to English as a medium of instruction o non-English first-language speakers is clear from the research conducted by MacDonald and Burroughs (1990), who established that the average English second language learner in their sample of South African schools had, at the end of Grade 4, an English vocabulary of 800 words whereas the Grade 5 curriculum requires a vocabulary of at least 5000 words. Against the arguments that English is a sine qua non for the business and academic worlds of the 21st century - arguments often proffered by the pro-English lobby - there is a body of evidence demonstrating that the statements that English as a medium of instruction results in English second language learners having a better command over English are false. It is also not true that the sooner the switch is made to English as a language of 
learning and teaching, the better is proficiency in English for second language learners (Dalvit, Murray \& Terzoli 2009). This is also concluded by Setati, Chitera and Essien (2009) based on their literature review of research conducted on this topic in the South African context during 2000-2006. As such, their findings are a confirmation of the Double Iceberg Theory of Jim Cummings - one of the world's leading authorities on bilingual education. According to Cummings, concepts learned in the first language can be transferred to the second language (Barzalo 2020). This theory then supports learning in the first language for maximum period in a school cycle, postponing the switch to a second language as a medium of instruction for as long as possible, then the benefits of the first language learning will spill over to the second language.

\section{The language of learning and teaching in Indian education: Changes driven by historical, political, social and economic reasons}

\section{The language of learning and teaching and the history of education in India}

There were schools teaching in one or other Indian language and catering to a very small share of population even before the expansion of education in the British India (Acharya 1978). However, it may not be that incorrect to note that the formal education in India started during the British colonial rule. The purpose of the colonial rulers in India was to produce human resources who could be a part of the middle or lower levels of their administrative system. The well known quote from Macaulay (1835) summarises this attitude:

We must at present do our best to form a class who may be interpreters between us and the millions whom we govern, - a class of persons Indian in blood and colour, but English in tastes, in opinions, in morals and in intellect. To that class we may leave it to refine the vernacular 
dialects of the country, to enrich those dialects with terms of science borrowed from the Western nomenclature, and to render them by degrees fit vehicles for conveying knowledge to the great mass of the population. (n.p.)

This necessitated training in English, and hence the colonial rulers encouraged English-medium schooling (from secondary grades). Providing 'schooling to all' was not the intention of colonial rulers, and hence the language capacities or endowments of the majority of population or their education needs were not important for this colonial education. However, there was a small section of Indian people who were interested in acquiring this colonial education (Santhakumar 2016). They were looking for jobs in the colonial administration. Hence, there was no dearth of demand for the English-medium education provided by colonial rulers.

There were certain efforts during the colonial period to integrate or upgrade the traditional learning centres in local languages into the formal education system. This happened more in those areas where there had been a tradition of education in local languages. In addition, there were efforts by nationalists and freedom fighters who saw the education in local languages important for independence and anti-colonial struggles. This can be seen, for example, in the actions of nationalists and freedom fighters such as Balgangadhar Tilak, Gopal Krishna Gokhale and Mahatma Gandhi. A few institutes of higher education were also created as part of the nationalist/ independence movement and these too focused on Indian languages. These included Kashi Vidyapeeth, Gujarat Vidyapeeth, Jamia Millia Islamia, et cetera, which came into existence in the first half of the 20th century. However, these vernacular institutes were not part of the dominant form of education in colonial India. Moreover, those who came out of vernacular schools did not have many employment opportunities in the colonial administration (other than those as teachers in vernacular schools or employees in local-level administration). 


\section{Limited focus on mass education during initial decades after independence and its impact on the medium of instruction}

The education designed by colonial rulers - English-medium secondary schooling and higher education - continued to be in the dominant form during the first three to four decades after India's independence. There were a number of reasons for this state of affairs. The enrolment in school education during that period was only from a small section of Indian society which was interested in education, and others were focusing on agriculture or artisanal jobs. There were no major efforts on the part of national government to expand schooling to the majority. (The successive Indian governments followed a liberal approach to schooling by providing to those who demanded it [Santhakumar, Gupta \& Sripada 2016].) This has sustained the use of English as a language of learning and teaching. On the other hand, efforts towards mass education, if these were made, would have necessitated addressing the issue of language (as for most people in India, English was not their home language).

The economic development of India during the initial decades only enabled the majority to be employed in agriculture, and a small minority to take up civil service posts. The economic policies of those times in India did not enable the majority to move out of agriculture and take up jobs in the industrial sector, which would have required certain levels of education. Those in agriculture did not opt for education at all, but those in the industrial sector found the English-medium education to their advantage. This is another reason for the continuation of Englishmedium education as the dominant form even after India's independence.

There is yet another reason and that is related to the formation of India as a nation. It relates to the existence of different regions, and people in a number of these regions using their own 
languages. Although there was an effort to develop Hindi as a national language, it was not a success to make it acceptable in all parts of India, especially because of the opposition from southern states (a political and administrative territory in India). In that sense, India was different from many other countries which became independent in the 20th century. Some of these countries (such as Indonesia) or the erstwhile socialist countries (such as the formerly USSR or China) could adopt a single national language and education is promoted in that language. Such language integration has not occurred in India. The postindependent government in India was somewhat sceptical of its ability to impose a cohesive national agenda on all parts of the country. This can be seen in other policies too. For example, governments were reluctant to impose taxes on richer farmers and opted for a lower saving and lower growth policy because of the fear of political disintegration. The governments feared that such an imposition would lead to political disintegration of the country. Hence, the use and adoption of national language became voluntary and not mandatory. (This has led to limited investments in the national language to make it adequate to assimilate modern knowledge in different spheres.) This has created a situation where people belonging to different states continue to speak their language, and hence, by default, a vestige from the colonial era, that is, English remained the only connecting language. It should be noted that Indian states were formed by and large on the basis of languages spoken by the majority of people. This is another reason for the continuation of English as a language of learning and teaching in education during this phase.

\section{Expansion of schooling in certain states focused on regional languages}

Whilst the national picture was the one described earlier, there were certain different trends followed in a few states (initially in the 1960s and 1970s) and followed in others later on. There was a 
deepening of democracy in these states with non-elites started asserting their rights politically and electorally (see Santhakumar 2014). These political assertions of non-elites were also based on a regional or ethnic identity, and the pride in regional language was part of that identity. These developments had an impact on education and also on the medium of instruction (especially in schooling). There were efforts at the state level to expand the coverage of schooling and non-elites started using school and college education. There was an ideological interest in having a greater focus on regional language in education - ideological in the sense that it did not take into account the challenges in following such an approach (considering the scale of economies in each state, the nature of labour market and also the language needs for different kinds of jobs in Indian economy). (Although later on this created certain problems, which are discussed in the following section.)

Such a non-elite political mobilisation first happened in Kerala, although it had not taken any anti-English or anti-Hindi (the national language) form. However, there was an expansion of schooling with the local language (Malayalam) as the medium of instruction. The next state in this category was Tamil Nadu. There the regional language was an emotive issue as against the efforts to impose Hindi as the national language. Although the people of the state were not against English, the non-elite assertion in the state has led to the expansion of Tamil-medium schooling. There was an implicit regional pride in the class-based mobilisation of non-elites in West Bengal, which happened in the 1970s, and there too was a focus on Bengali-medium schooling as part of this mobilisation. There was a political mobilisation in Andhra Pradesh in the 1980s, which prioritised regional pride, and another one in Maharashtra, and all these have led to a greater focus on non-English and non-Hindi languages as the languages of learning and teaching. The northern states of India where the predominant language is Hindi (the one recognised as the national language) have also started experiencing non-elite assertions after the 1990s, and these too have led to the increased 
coverage of schooling and also the use of Hindi as the medium of instruction. Hence, an important outcome of the process of democratisation which has happened slowly after Indian independence is the expansion of schooling and the focus on regional languages as the medium of instruction.

Moreover, educationists and intellectuals who were concerned about the lack of schooling for the majority in India started talking about the English medium as a possible barrier against the 'schooling for all'. This view transpired in the Report of the Kothari Commission of 1967, a seminal report which was meant to be a blueprint for the decolonisation of education in India. This is relevant as English was not the mother tongue of even $1 \%$ of Indians, and hence no country could achieve schooling for the majority through a foreign language. Hence, these scholars wanted education in mother tongues. However, the efforts in this direction have led to the use of only regional languages as languages of learning and teaching, but not all mother tongues. This issue is discussed in the 'Many other languages and mother tongues neglected' section.

\section{Many other languages and mother tongues neglected}

Although there was a growing aspiration to use regional language as the language of learning and teaching in schools as part of the deepening of democracy in India, we should not forget that many other languages and mother tongues were neglected, and most of them did not find a place in the formal education. The noted linguist Devy (2020) has identified 860 languages in India. This itself might indicate the death of many languages as the Census of India in 1961 has noted 1652 mother tongues. Out of these, there are 22 scheduled languages, which were discussed as regional languages in the previous sections. Out of the 860 languages identified by Devy, around 450 are spoken by the tribal people or traditional forest dwellers. 
There are a number of reasons for the limited attention and gradual disappearance of these languages. These are spoken by a fewer people (say, a couple of 10000s). Even when these are spoken by more than 100000 people, such people (say one or other tribal group) would constitute only $2 \%-3 \%$ of state population, and their language may not have enough prominence in the system of formal education. (On the other hand, there were greater efforts to use one or other tribal language in states where such people constitute the majority as in the case of Mizoram.) Although there is a perception that English and Hindi are alien to many people of India and imposed from elsewhere, it is also true that the dominant language of a region (or the scheduled language) is imposed on all people of the state by suppressing diverse languages or mother tongues which are spoken by few in different groups.

This neglect of local languages (or those used by specific social groups) has implications on the education of indigenous or tribal people. Education in regional language or English may not be of interest to their children. Although bilingual (and multilingual) education has been tried out for the indigenous people of Latin America, this process has started only lately and in a too limited manner in parts of India. Even when efforts were made to use one or other tribal language as the medium of instruction in grades 1-3, there were not enough trained teachers and learning materials available and there were challenges in the transition of students to upper grades where the regional language became the medium of instruction (Santhakumar \& Das 2018). In summary, the democratisation of states or regions has helped the use of certain languages but not all.

\section{Higher education continued with English medium}

The trends described in the previous sections have not changed the official medium of instruction in higher education and it 
continued to be English (in courses other than those dealing with non-English languages). A number of factors played a role here: Historical focus on English-medium education; and the requirements and interests of the minority which has used higher education during the initial decades of independence. It is from this minority that academics (who are the leaders of different academic disciplines within the country) and faculty in reputed institutes have come out. They have an important role in designing the curriculum and pedagogy in higher education. Some of them also have higher levels of education (including PhDs) from English-speaking countries such as the USA and the UK. India has been using the learning materials of higher education that are available mostly in English language. Although there have been certain efforts to expand schooling (especially in states) with one or other regional language as the medium of instruction, there have not been that kind of efforts in higher education. The presence of multiple regional languages might have discouraged such efforts. (Although there are some state-level efforts to translate knowledge into regional languages that can be used in higher education.) This has also limited the availability of learning materials in non-English languages in India.

Those people who opt for higher education value English medium for a number of reasons. As higher education itself is through the medium of English, it is a preferred option for those who want to have jobs in colleges and universities. The job of a teacher (in college and university) has been valued highly even though salaries were not that high, and it could be because of the influence of Brahmanism prevalent in India. English is the most common and probably the most preferred language at the top echelons of the civil service, judiciary, medical care and management. Hence, it is natural that students (even those who have not gone through school education in English medium) prefer to have higher education in English medium, as the most sought after jobs are somewhat connected with the use of English. Those students who could not have a higher proficiency 
in English are considered less successful in higher education. Higher education is not conceived as something that is necessary to address social issues, and the one requiring social capabilities of all kind (including the ability to connect with the social realities of the country) and this has also worked against the visualisation of such an education in the medium of Indian languages.

However, the expansion of school education in the medium of regional languages, and the increasing representation of nonelites in higher education have resulted in the use of regional languages in the space of higher education in informal ways, and we discuss this issue in the following section.

\section{Higher education informally in regional languages}

Although the formal language of learning and teaching in higher education is English, much of its transaction in colleges located in non-metropolitan cities happens in regional languages. A good share of students who are currently in these colleges have had their schooling in regional language as the language of learning and teaching, and they are not proficient in English. Although they have studied English as a subject in schools, and that should be adequate theoretically to develop proficiency in that language so as to enable their English-medium higher education, the subject is not taught well in schools to develop that capacity. The teachers in schools, including those who teach English, do not have adequate proficiency, especially related to its functional aspects (say in speaking and writing) and that too affect the effectiveness of English education in schools. As part of the non-elite mobilisation and the deepening of democracy, there are job reservations for less privileged social groups (which have been excluded historically from the education process), and some of them may not have (and this is not because of their 
mistake) a higher proficiency in education. Although the position of a school teacher was attractive and taken up by the most educated section of the society in the past, this has also changed over time. The opening up of Indian economy has created many more jobs for people with higher education in its service sector, and hence those who become school teachers need not be those who do very well in education. To a great extent, one can also see a similar trend in the colleges of tier-2 and tier-3 cities. It is not unusual to see college teachers who teach conventional subjects such as Economics (which is expected to be taught in English) without an adequate proficiency in the writing and speaking of English language (this became evident to one of the authors, Santhakumar whilst participating in an effort to orient college teachers in different parts of the country).

However, this situation in which the formal medium continues to be English but the actual transaction happens in regional languages creates a newer set of problems. The learning materials continue to be in English. Students do not develop a strong connection with the subject. Students who are not proficient in English may not do well even if they have the interest and capability to study one or other subject. This creates an unwanted hierarchy between those minority of students who can complete higher education well in English and others who cannot (irrespective of their ability to learn and achieve proficiency in other subjects). Moreover, those students who might have done well in higher education in their own regional language may not obtain admission in the reputed institutes of the country. The entrance examinations or screening tests in such institutes may privilege students with a higher fluency in English. It may work against the achievement of certain social objectives of higher education. For example, higher education can have the objective of facilitating social development, and such a change is more important for the economically and socially underprivileged groups in the country. However, students belonging to these groups may not be able to access good quality education, as the medium of instruction of higher education is English. 


\section{Nature of employment in India and its role in the medium of instruction}

The nature of Indian economy even during the period when the country has witnessed a higher economic growth (i.e. after the 1980s) has strengthened the demand for English. It is well known that Indian economy has continued with the majority employed in agricultural sector, but its growth is driven primarily by the service sector. The growing parts of the service sector include the outsourcing activities in information technology (IT) and ITenabled services (ITES). These outsourcing opportunities that India used were with the English-speaking countries. The job opportunities in this domain were an important driving force for the expansion of higher education in India after the 1990s (which has also resulted in the expansion of self-financing colleges). Jobs in other services such as healthcare and higher education also need a good command over English.

On the other hand, India did not see a rapid growth of the manufacturing sector as happening in countries such as China or others in the east and southeast Asia. Those who have acquired school education with the regional language as the medium of instruction may not make for better job opportunities in the service sector (i.e. the ITES) because of their lack of proficiency in English. They may not have employment in manufacturing as this sector has not been that vibrant to create many jobs in India.

This situation in India is somewhat different from other countries, including the emerging economies in the east and southeast Asia which could participate in the global production of goods and services with the education in a non-English (or non-European) language. For example, although there is a small section of Chinese people who know English and use that language in global communication, most of the domestic production in China which is aimed at global consumption happens through the use of Chinese language. For example, most of the transactions (including that of technical knowledge) within the factories located in China happen in Chinese language. 
Hence, the lack of English education need not be a major constraint in having a manufacturing sector job (which are also available in plenty) for a Chinese citizen. The lack of English proficiency does not seem to be an insurmountable problem even for the Chinese workers who participate in the infrastructure development in other countries such as those in Africa. To some extent, this is true for Japan, South Korea, Thailand, Indonesia and so on. This experience shows that the participation in the global production of goods and services even in a context where the Europe and the USA (and other countries in the Latin America and the Pacific) continue to be important destinations for products, do not really require a higher proficiency in a European language.

However, this is not the case in India. It belongs to a special case where the lack of education in English medium can affect the job prospects of people living here. Before the opening up of its economy, India had agriculture, services and limited industrial activities. Education was important to have a job in the government and public sector organisations and here English was useful for historical reasons. However, after the opening up of the economy, the growth happened mainly in English-using service sector. Those sectors which could create jobs even with an education in regional languages did not thrive in the country. This could be shaped by the way education has developed historically in independent India. Only a minority completed schooling and the majority could not do so even a couple of decades ago, and hence the availability of those who have just completed schooling and looking for a factory job was limited in India compared to countries such as China and others which have expanded the mass education since the 1950s. The nature of the supply of educated workers might have played an important role in the way manufacturing industries have developed in India versus other countries such as China. Hence, the current situation in India is one in which the knowledge of English (or the ability to handle English) gives a clear advantage in having a formal sector job. 


\section{Losing interest in schooling in regional languages and the growth of demand for English medium}

For the reasons mentioned earlier, the majority of people who look for education for a better life of their wards demand Englishmedium schooling in India. When government schools in different states continued with the regional language as the language of learning and teaching in education (as part of the ideological democratisation mentioned earlier), these parents moved away from such schools and opted for one or other private school providing English-medium education.

In fact, this demand for English-medium education is so intense that these parents are willing to trade off better facilities and better trained teachers in government schools (provided at free of cost) for the limited facilities and not so qualified teachers in private schools and that too by paying significant charges. This demand has led to the withdrawal of a significant share of children from government schools, leading to their under-utilisation. This is encouraging governments to change its policies related to the medium of instruction.

It may be noted that India continued with different kinds of medium of instructions in schooling. There is a set of schools managed and/or regulated by the government of India and these continue to have English-medium instructions. This is needed because there are different regional languages in India, and the national language is not spoken by the people in significant parts of the country, and hence English is serving as the link language. There is a very high demand for such schools not only because of the English medium but also because of better facilities and for their national curriculum. Then there are private schools which transact syllabuses prescribed by state governments but in English medium, but these schools are of different quality depending on the fees charged. As noted in the previous section, 
there is an exodus towards such schools by the children from middle- and lower middle-class households mainly because of English-medium instructions. Then there are (a numerically large number of) schools controlled by the state governments and this is where the regional language is used as the medium of instruction.

Because of growth in the demand for English-medium education and also the exodus of students from government schools for that reason, the state governments are currently rethinking their policy of the sole use of regional language as the language of learning and teaching in their schools. A number of states have started English-medium sections (in addition to those where the regional language is the medium of instruction) in government schools. This is mainly to retain students from the middle and lower middle-class households in public (government) schools. This is partly to mitigate the situation wherein enrolment in government schools declines drastically. Even when the enrolment comes down, governments cannot close down such schools because these meet the needs of poorer students. It is better to have government schools as the main form of organisation for schooling for a number of reasons. However, such a strategy of strengthening public education (government schools) in the current context of India requires the starting of English-medium sections. Anecdotal evidence from different parts of the country indicates that such a strategy is useful to retain children (from middle-class backgrounds) in government schools.

In one sense, India has gone through a circuitous route in terms of the medium of instruction in schooling. It started with a greater emphasis on English medium because of the colonial rule. Then it went through a period of using regional language as the medium as part of the democratisation that emphasised regional ethnic identity. Currently, it is rethinking its policy on the medium of instruction because of the 'demand' by an important section of parents. In one sense, the medium of instruction has moved away from an externally imposed one to an ideologically 
assimilated one and then to a more pragmatic one determined by the demand of parents (which reflects the conditions of the economy, including the labour market).

\section{Conclusion: India's struggle with the medium of instruction}

In summary, India is yet to find a desirable equilibrium in terms of the language of learning and teaching in education. Higher education continues to be in a language which is not the home language of even $1 \%$ of its population. The majority of educational institutes sustain an inferior equilibrium where most of the transactions take place in languages which are not the medium of instruction and in which there are no formally recognised and quality learning materials.

In that sense, the situation in India is worse than that in South Africa (where English is spoken by higher share of the population). There have been political and ideological attempts in India towards the adoption of regional languages as the medium of instruction in schools. However, that medium is becoming unacceptable to the middle-class parents, and hence they are opting out of such an education and accepting schooling in English medium. The governments cannot neglect this trend and are making amendments to its policies to accommodate this demand. In between, there are millions of others, including tribal populations, who find it difficult to obtain even primary education in their mother tongues given way the Indian economy has developed incentives to sustain and demand an English-medium education. The fact that Indians speak different languages, and one of these could not be the link language (despite efforts in that direction), also enhances the value of English.

By and large, India has failed in dealing with the language issue. It could have adopted one language (either English or Hindi) and ensure that it serves as the main medium of instruction in secondary schooling but with adequate facilities to start primary schooling in mother tongues (not only in regional 
languages but also those spoken by different groups of tribal people). It could have taken efforts to enhance the proficiency of the majority of students in that language. It could have ensured that higher education takes place in that language with a reasonable proficiency for the majority of students and teachers.

By and large, the failure of India in terms of the medium of instruction is somewhat connected with its failure in education in general. It did not take efforts to expand education to the nonelite sections of the society, or it provided schooling only to those who demanded it for the first four decades after its independence. The language issue is also enmeshed in this 'liberal' policy that did not make a sincere attempt to develop the educational proficiency of the majority of population. This has resulted in certain economic outcomes shaped by the limited achievements that the country has made through education. These economic outcomes too sustain the not-so-sound equilibrium in terms of the use of a language as the language of learning and teaching in education.

\section{Conclusion}

Comparing India and South Africa, similarities are indigenous linguistic diversity, and on top of that the strong position - also as medium of education - of English as ex-colonial language and current international lingua franca. However, there are also differences, some of these very instructive. In India, indigenous languages are much more concentrated regionally than in South Africa. The strongest indigenous language, Hindi, has been on the agenda of government, to promote it as a national language. Furthermore, regional governments and avant garde political groups have had the promotion of regional indigenous languages on their programmes. None of these advantageous forces are present in South Africa. In contrast to India, in South Africa, the strongest (in terms of domains of usage, language of learning and teaching in particular) of the languages besides English, 
namely Afrikaans, has fallen into political disfavour. It is not difficult to see, ever since the dawn of the new political order in 1994, action along a broad front, by the government and political leaders outside the government to marginalise the language, and to scrub it as a language of learning and teaching in educational institutions. In other Asian countries such as Japan, Indonesia, Vietnam and China (although, the case of China is more complex, as is expatiated in ch. 7), with a more homogenous linguistic context, the existence of one stronger (geographically, demographically and developed in domains of usage) language, it has seemed viable for the dominant indigenous language to hold ground as a language of learning and teaching against the compelling force of English.

From a South African vantage point, what can be learned from India with its longer history of its post-colonial dispensation, is that attempts in India to wage a campaign against English and to replace it with indigenous languages has hitherto been a fairly futile exercise. This despite the advantages, compared to South Africa, of having indigenous languages being geographically more concentrated, and of the promotion of strongest indigenous language, Hindi, being part of the programme of government and on top of that regional governments and avant garde political groups have had the promotion of regional indigenous languages on their agenda. If, with all these forces favouring them, English could not be dislodged from its hegemonic position as a language of learning and teaching in India, it can be predicted that the chances of so doing in South Africa, where these contextual advantages are not present, must be zero. Lateral thought should be employed in search of another angle to realise the strong educational arguments in favour of the use of indigenous languages (first languages of learners) as languages of learning and teaching. It is in this regard where the trilingual models of education in China surface as a possible better model to follow. This model and its relevance for South Africa are investigated in Chapter 7 of this volume. 



\section{Chapter 5}

\section{Aligning education with employment: Lessons from vocational education in India and South Africa}

Artwell Marimo

Faculty of Mechanical Technology Teaching, Applied Technology High School, Abu Dhabi, United Arab Emirates

Hennie J. Steyn

Subject Group Comparative and International Education, Education and Human Rights in Diversity Research Unit, Faculty of Education, North-West University, Potchefstroom, South Africa

Ewelina K. Niemczyk Subject Group Comparative and International Education, Education and Human Rights in Diversity Research Unit,

Faculty of Education, North-West University, Potchefstroom, South Africa

How to cite: Marimo, A., Steyn, H.J. \& Niemczyk, E.K., 2020, 'Aligning education with employment: Lessons from vocational education in India and South Africa', in C.C. Wolhuter (ed.), Critical Issues in South African Education: Illumination from international comparative perspectives from the BRICS countries (BRICS Education Volume 2), pp. 139-174, AOSIS, Cape Town. https://doi.org/10.4102/aosis.2020.BK207.05 


\section{Abstract}

It is generally accepted that vocational education (VE) plays a vital role in facilitating the acquisition of the required knowledge, skills and values for the socio-economic development of any country, although its value is not fully recognised by many educationally interested circles. If properly implemented, government efforts in this sector could be an answer to the empowerment of citizens with various skills, which could provide employment opportunities to many. The final aim of the proposed chapter is to identify lessons to be learned from the field of VE in India and South Africa in order to enhance the socio-economic standing and thus quality of life in the countries under investigation and beyond. The qualitative research tradition, the structured analysis of primary and secondary data sources, was used as a research method.

The following recommendations are put forward to increase the position of $\mathrm{VE}$ :

- Enabling policies should be developed to promote access to VE by all population groups and should be crafted by policy makers in collaboration with all relevant stakeholders.

- Policy makers should ensure that acceptable tools are in place for thorough monitoring and evaluation of policy performance.

- Governments should guarantee quality and relevance of skills development.

- There should be sufficient funding for vocational programmes.

- Career guidance should be provided in institutions to enable students to see worthiness of VE.

- Partnerships should be encouraged between the main stakeholders of VE.

Keywords: Vocational education; Key features of vocational education; Core characteristics of vocational education in South Africa; Core characteristics of vocational education in India; Lessons to be learned regarding vocational education from South Africa and India. 


\section{Introduction}

The acquisition of workplace competencies is internationally regarded as a key driver of economic and technological development globally as well as locally. Vocational education plays a vital role in facilitating the acquisition of the required knowledge, skills and values for the socio-economic development of any country, although its value is not fully recognised by many educationally interested circles. Provision of VE gives citizens choices other than studying at a university. If properly implemented, government efforts in this sector could be an answer to the empowerment of citizens with different skills, which could provide employment opportunities to many.

In this chapter, VE in India and South Africa is explored along with the associated opportunities and challenges. South Africa and India were chosen of the BRICS countries purely on the basis of convenience sampling because South Africa is the home education system and the Indian education system is the second largest system in the BRICS community and more easily accessible because of its fairly wide use of English. The final aim of the proposed chapter is to identify lessons to be learned from the field of VE in India and South Africa in order to enhance the socio-economic standing and thus quality of life in the countries under investigation and beyond.

Within the qualitative research tradition, the structured analysis of primary and secondary data sources was used as the research method to execute this study. Primary data are collected for a particular research situation, making use of strategies that best address the research situation. Secondary data are already available and used for other intentions but is applicable for a new research objective (Cresswell 2009). Primary data provide better accuracy, with a high level of control, and are up-to-date and trustworthy. However, primary data are said to be costeffective, time-consuming and not available immediately. On the other hand, secondary data have ease of access, less costly and undertaking the research is time saving (Smith 2008). 
Boslaugh (2007) described secondary data as being potentially biased with a high opportunity of being outdated.

\section{The nature of vocational education Defining vocational education}

Vocational education presents learners with the opportunity to acquire indispensable and quality competencies. These competencies refer to the unique combination of acquired knowledge, skills and values required for employment through the use of conventional, non-conventional and informal learning approaches. Vocational education is a channel for conveying social equality and sustainable development (UNESCO 2018). Thus, VE refers to the intentional, integrated and planned set of systems, facilities, programmes and strategies of education managers, administrators, lecturers and teachers within the education system, education institutions and in classrooms. All these with the focus on distinct trades and impacting the practical skills which allow individuals to engage in a particular occupational activity.

Vocational education can also be defined as educational initiatives that are tailored for learners to gain knowledge, skills and values peculiar to a specific field or trade. In the field of VE, learners are supported to acquire the required competencies according to the needs of the job market in particular occupations and employment sectors. The European Centre for the Development of Vocational Training (Cedefop) (2014:292) has expressed VE as education and training directed at furnishing people with knowledge, know-how and skills required in specific job fields. Vocational education is a linchpin for lifelong learning systems, assisting people to gain the competencies prescribed by the labour market. Kulkarni (2013) reiterated VE to be the nerve that uplifts the quality of work, livelihood of employees and expansion of enterprise.

Vocational education is not only a hands-on-based learning system but a schooling or preparation directed to support the 
learners with adequate opportunities to acquire required competencies (knowledge, skills and attitude and values) in order to gain access to a specific occupation or group of related occupations.

\section{Key features of vocational education}

Vocational education is a doorway for anyone who wishes to acquire qualifications for an array of occupational opportunities. The key features that distinguish VE to be explored in this chapter include its aims, governance, curricula, funding, provisioning, stakeholders, quality assurance and delivery methods.

\section{$\square$ Aims of vocational education}

The basic aim of VE constitutes the planned action of competent educationists to support learners for successful participation in the labour market. Vocational education differs from country to country. In some countries, it is part of the education system comprising primary, secondary and tertiary levels, all primarily meant to address skills shortage in the labour market. Primarily, $V E$ is aimed at the acquisition of applicable competencies for profitable employment in a specific field of occupation.

Vocational education targets both young and adult learners with skills for work and life. Vocational education is regarded as a building block of lifelong learning for all because it strives to allow equal opportunities for all age groups to acquire relevant competencies.

According to Kotsikis (2007), the aims of VE are summarised as follows:

- To provide for the continuing changing needs of the labour market through ongoing skills development based on relevant knowledge and values.

- To optimise individuals' employability through acquisition of skills. 
- To lessen the incongruity between the demand and supply of skilled manpower.

- To minimise the level of unemployment by contributing to the opportunities of achievable self-employment schemes.

\section{Governance of vocational education}

In VE, governance particularly refers to the institutions responsible for the administration of education system, including the elements of institutions responsible for the making and implementing of policy, the funding of VE and the required internal and external communication to all interested parties of $V E$ to ensure that quality service is provided. Governance in VE as highlighted by Cedefop (2011) stresses upon policy-making management grounded on the engagement of partners at all levels for designing goals, execution and overseeing. Governance has an impact on the formulation and implementation of programmes, and forms the premise on which programmes are kept track of to enhance answerability, openness and productiveness of policy (Cedefop 2011). There exists three major players in the governance of $\mathrm{VE}$. These are the state or centralised institutions on national, local or regional levels; the clientele, including the employers, individuals and communities; the training providers; and finally the bodies awarding qualifications. Good VE governance can have a multilevel characteristics, whereby there is shared and organised responsibility and harmonised action between different role players (Schmitter 2004).

\section{$\square$ Quality assurance}

Adegbesan (2010) described quality as not just a feature of an outcome but the concept that also calls for a focus on the nature of internal processes in order to reach the required outcomes. Quality assurance is a generic term that implies contrasting meanings in different contexts. Quality assurance as applied in 
education involves different forms of internal and external monitoring, evaluation and review of educational programmes to ensure that the pre-agreed upon standards are being adhered to (African Union 2007).

Quality assurance in education includes all measures, activities and approaches for ensuring that all 'assessment procedures', qualifications and 'programme delivery' meet agreed upon quality standards. Quality assurance of VE qualifications is the responsibility of all key stakeholders at all levels of VE qualifications system. Quite often these various levels are linked and intertwined. Quality assurance of qualifications thus stretches over a particular time frame and envelops many steps, including the task of designing, developing, implementing and monitoring of qualifications (UNESCO 2017).

Qualifications must fit for the purpose and completely placed on the link between the skills, knowledge and understanding and values specified in occupational standards and that of labour market requirements (UNESCO 2017). Industry collaboration in all phases of qualification acquisitioning and quality assurance process is critical for reinforcing fitness for the purpose of qualifications and the endorsement of and faith in the outcomes by employing organisations.

\section{$\square$ Funding vocational education}

In most of the developing countries, there are primarily three pivotal sources involved in the funding of VE. These are state grants, student fees and contributions in one way or the other from private sector. Other sources include employee contributions, special private donations and developmental grants. Providers of VE do have particular funding streams. The primary source of the most public VE institutions originates in the state financial resources, whilst with privately run institutions, student fees constitute the primary source of funding. Individual companies fund their own in-service training costs. 


\section{$\square$ Curriculum for vocational education}

Curriculum for VE is widely classified on the basis of competency. A competency-based curriculum is designed on the needs of labour market and can be delivered as long, short or modular programmes. A competency-based curriculum is a curriculum that centralises on the end results of a learning process (the knowledge, skills and attitudes relevant to the learner) instead of focusing on the full content matter of a programme. The curriculum itself focuses more on the ability of the learner to do and is flexible to the ever-changing learner, instructor and market needs. The learner has to master certain performance and learning outcomes as described in the course outline.

\section{Stakeholders in vocational education}

The involvement of social partners in VE is pivotal. The participation of stakeholders ensures the labour market relevance of VE programmes. Social partnerships between private and public players are crucial for the delivery of high-quality VE as they give room to interaction between employers and vocational institutions. The interaction allows for institutions to figure out the skill requirements of the labour market. Also, the communication enables employers to contribute towards the development of vocational curriculum.

The following are amongst the various partners who can be engaged in VE:

- Teachers (lecturers and instructors).

- Academic and training institutions.

- Industries.

- Government.

\section{Role of teaching personnel}

Teachers play a critical role in training students to become competent employees. They should be able to correctly assess 
the level to which the students have acquired the required knowledge and skills to confer the relevant competency and qualifications. Training of students commences in the institutions, hence the teaching personnel need to assist the learners to acquire the required attitudes regarding the world of work. Teachers as professionals in VE deliver educational programmes in line with relevant $V E$ standards and encourage the development of the attitude of innovation and independence in learners.

\section{Role of training institutions}

The training institutions provide enabling surroundings for teaching personnel and students in order to engage in stimulating and creative teaching and learning process through the provision of required infrastructure. Therefore, the training institutions should take all necessary steps to ensure the availability of applicable policies, the funding and the administrative processes to facilitate quality teaching and learning and the availability of required support services in order to facilitate the richness of training sequences. Furthermore, the institution management should cooperate with appropriate organisations to help students with workplace attachment and should put in place the much-needed opportunities for staff development and training (Alam et al. 2010).

\section{Role of industry}

Industries provide environment for students to apply the competencies they have learned at training institutions. Industries take students for industrial attachment, excursions and demonstrations. At times specialists from industries are invited to institutions to participate in training programmes. Industry should also play a crucial and pertinent role in the crafting of relevant vocational curricula in areas of research, development and dissemination of appropriate technology.

\section{Role of government}

The government through various ministries and departments has a crucial role to play in ensuring the proper implementation of VE 
programmes. This includes supervising and coordinating all aspects of VE. As suggested by Alam et al. (2010), the following are some of the roles that government can play to ensure achieving useful and applicable skills development through VE:

- to fund vocational institutions responsible for competencybuilding

- to allocate equipment and infrastructure in vocational institutions

- to provide incentives to motivate industries to be involved in the training of VE students

- to formulate policies to streamline industrial training for both staff and students

- to establish training centres of quality in order to contribute to the development of students' competencies for industry.

\section{$\square$ Provision of vocational education}

Provision of VE is usually highly regulated by state governments. The vocational institutions can be public (state and local government) or private institutions. Students are usually enrolled in vocational courses according to enrolment institution's plans and minimum entry requirements.

Vocational education institutes offer programmes in various study fields and in levels classified as follows:

- Basic VE.

- Secondary VE.

- Post-secondary VE.

\section{Basic vocational education}

Programmes at this level are mostly provided by basic vocational schools at lower secondary level and include programmes of a 
general nature that form the basis of entry in more specialised programmes applicable to a particular field of employment.

\section{Secondary vocational education}

Upper secondary VE builds on students' basic skills and knowledge and assists them to prepare themselves for higher VE or the labour market (OECD 2014). At upper secondary level, the entry requirement is usually the completion of basic VE programmes. To acquire a qualification in higher VE, students need to be assessed through the state qualification examination process at the end of the VE programme. The government usually determines the assessment content and how it should be conducted.

\section{Post-secondary vocational education}

Post-secondary VE aims at closing the gap between the training field that emanated from the demand for technical skills from the labour market and request for high-level qualifications in the market. To counter such a challenge, post-secondary VE develops strong partnerships with the labour market. Post-secondary VE primarily has two principal roles, namely: provision of initial training in higher-level VE and provisioning of up-skilling opportunities. Training provided may include the offerings of job-specific skills to new recruits or to those with relevant skills who are in need of the upgrading of applicable competencies.

\section{The informal sector as a training provider}

As a result of lack of employment opportunities in dwindling formal economies, people have to seek other sources of livelihood that are available in the informal sector. According to the World Bank (2009), in many emerging nations, a great number of new jobs are produced in the informal sector. The informal sector usually provides initial training ground for school leavers. The 
formal vocational system does not accommodate all prospective students and as a result, many young people start their careers by means of on-the-job training in the informal zone.

\section{Delivery methods for vocational education}

Today's world of work demands modern approaches to learning and training. This calls for educational institutions to fill their students with practical lifelong learning abilities so that they can overcome the modern-day challenges. On many occasions, skilling for employment is delivered within training institutions, and according to Hager (2004), this approach has its own limitations and gives rise to the incorporation of on-the-job and off-the-job training.

The teaching personnel in most of the vocational institutions in developing countries are accustomed to the traditional teaching methods, including lecture methods and demonstration. In the present-day instruction, information and communication technology is a valued addition to vocational teaching and learning. This can be through simulations and computersupported learning, which boost relevancy of certain skills and make the workplace readily available. In addition, online delivery of vocational soft skills can be achieved through IT.

Vocational education can be easily delivered at the workplace. The workplace gives the most original learning conditions in order for the learner to relate theory into practice (Billett \& Boud 2001). Workplace experiences could be in the form of industrial attachments, apprenticeship, traineeship and cadetship.

Modularisation as a concept allows for VE programmes to be delivered in a modular format to meet the eventual learning outcomes. Modularisation as stated by Pilz (2012) is a procedure of splitting a training programme into smaller manageable units. In this case, each module would cover a set of competences and the modules can be merged to achieve an occupational qualification. The successful completion of a module depends on particular assessment specifications. 


\section{Challenges to vocational education}

In the international field of $V E$, the following challenges are identified:

- A poor awareness of labour market requirements and needs: There exists a weak link between vocational providers and the world of employment. Usman and Abdullahi (2013) emphasised that skills development of a country needs to have close partnerships with the labour market, especially in the trades of prime concern.

- Poor organisational arrangements and institutional management: Many of the developing nations lack the capacity to run and manage vocational institutions. Institutions are equipped with poor infrastructure, irrelevant curricula and less qualified teachers.

- Limited access to disadvantaged groups: Vocational education is not easily accessible to impoverished people living in remote areas because most of the institutes are located in urban areas, thereby giving rise to gender and geographic imbalances (African Union 2007). Also, it is a major concern that women and other ethnic minority sections of the society experience limited access, especially when vocational programmes are conveyed in official or popular languages only. Vocational training is generally intended for the youth and leaves out older people from training opportunities.

- Lack of proper curriculum development and quality assurance: Many of the provisions of VE in developing countries are more theory-focused, lacking the practical component, which makes it irrelevant for the job market. Furthermore, VE is affected by a more stagnant curriculum, which has not managed to keep abreast with technological advancement.

- High costs and sustainability: Financing of VE in the regions such as sub-Saharan Africa is one of the toughest challenges. There is underinvestment in machinery and equipment, low salaries for trainers and higher operating costs. Studies show that limited funding is a major constraint to VE especially in 
developing countries. Running vocational programmes is costextensive. The costs can be soaring, resulting in unsustainable programmes. There is often an insufficient budget allocation for maintenance or upgrading of vocational infrastructure. Lack of specialised hardware and amenities is a significant factor for ineffective VE (Darvas \& Palmer 2014).

- Poor perceptions regarding vocational education: Many societies view vocational programmes as meant for academically challenged persons, and university education is regarded as the gateway to a sustainable life. In many developing countries, VE graduates experience challenges to move to higher education. More is required to make VE less of a dead-end job.

- Gender stereotyping: A number of vocational courses, such as hospitality, beauty therapy and dressmaking, are often related to girls.

- Low quality of primary and secondary education: Low enrolment requirements and low secondary education in developing countries has a bearing on the acquisition of competencies in vocational programmes.

\section{Vocational education in India}

Vocational education plays a crucial role in supporting learners to acquire the competencies (knowledge, skills and values) linked to particular trades and occupations. Vocational education in India is multi-sectoral in nature with different state governments and ministries involved in development of skills. Currently in India, about 17 different ministries along with the private sector are responsible for development of skills in different areas ranging from financing to the provision of vocational programmes. India's skill development ecosphere is complex with a wide spectrum of skills across a diverse population. The private industrial training centres (ITCS) and the public industrial training institutes (ITIS) are the two main bodies that impart VE in India (Agrawal 2012). The summit of vocational training in India is the directorate 
general of employment and training (DGE\&T), which is operated by the Ministry of Skills Development and Entrepreneurship (MSDE).

\section{Aims of vocational education}

According to Mehrotra et al. (2012), the following are some of the aims of VE in India:

- To promote employability amongst vocational graduates.

- To meet the needs of an ever-changing job market.

- To provide vocational graduates for specific occupations.

- To improve the financial livelihood of people.

- To offer opportunities and fulfil the needs of the disadvantaged in society.

\section{Provisioning}

In India, vocational-related skills are acquired through formal and informal training programmes. Both private and public sectors provide formal vocational skills through state-managed ITIs, private ITCs, vocational centres and on-the job apprenticeship. Vocational courses are rendered in classes 11th and 12th under the Vocationalisation of Secondary Education Plan. Under this scheme, students commit part of their school time to vocational subjects.

Vocational training in India is primarily a post-school training and is administered by the DGE\&T (part of the Ministry of Labour, Government of India). The craftsmen training scheme (CTS) and the apprenticeship scheme fall under vocational training. The CTS supplies skilled expertise to industries and provides training in industrial trades skills to the youth through ITIs and ITCs. The apprenticeship training scheme provides skilling opportunities under the Apprenticeship Act 1961. Provision of apprenticeship is divided in four categories, namely: trade apprentices, graduate apprentices, technician apprentices and technician (vocational) apprentices. 


\section{Governance}

In India, the Ministry of Human Resource Development and MSDE are responsible for policy formulation regarding $V E$. Vocational education is controlled in a decentralised manner across various departments and levels. Different institutes that govern VE in India include the National Skills Development Agency (NSDA), National Skills Development Council (NSDC) and All India Council for Technical Education (AICTE 2017). The NSDA coordinates skilling activities and oversees execution of the national skill qualifications framework under MSDE. The NSDC encourages skills development initiatives through financial assistance to skilling organisations, supports curriculum development and provides a link with industrial associations. The issues related to quality assurance, certification and awards, and funding on priority basis are handled by the AICTE ( 2017).

\section{Curriculum}

The vocational curriculum in India covers a wide spectrum of fields, ranging from engineering, hospitality studies, arts and crafts, and all forms of technology such as leather technology, printing technology, et cetera. The curriculum is offered in senior secondary schools, ITIS, ITCs and polytechnics offering both certificate and diploma qualifications. The government designs curriculum through structures in its various ministries and departments, and ensures its full implementation in the institutes. There is less of labour market consultation in the designing of the curriculum; hence, graduates from vocational institutions normally end up on the streets, failing to be absorbed by the industry.

\section{Funding}

The Government of India through MSDE manages financial allocation for the implementation of VE. Finances for skilling are 
collected through general tax revenue and levies on companies. In addition, corporate social responsibility funding and in-firm financing by a company conducting its own training are also the sources of vocational funding. Other forms of funding can be through NGOs, especially when offering community skills development. There are three main categories involved in financing and legal status of vocational institutions, namely private, public and non-profit. The private institutes self-finance through high student fees. Non-profit institutions fund trust institutes, and the government meets all the costs of public institutions.

\section{Stakeholders in vocational education}

The main players involved in VE are central and state governments, private sector, NGOs, private institutions and communities.

\section{$\square$ Central government}

The central government is involved in all policy formulations regarding VE as well as its implementation. The central government comprises the following divisions: NSDC; Ministry of Human Resource Development (for vocational programmes in senior secondary schools) and Ministry of Labour and Employment (through DGE\&T responsible for vocational training).

\section{Teachers and trainers}

Vocational teachers and trainers instruct students at vocational institutes with generic and job-related skills. The teachers and trainers according to the Government of India (2015) requirements are expected to have subject specialisation, industrial experience and pedagogical skills.

\section{Quality assurance}

The AICTE has control and authority over quality assurance, accreditation and consistency in certification and awards. 
To maintain quality in qualifications, the National Skills Qualifications Framework (NSQF) of India oversees all qualifications issued across all awarding bodies, and in partnership with the National Skills Qualifications Committee designs occupational standards and develops nationally recognised qualifications for each level. The NSDA and Directorate General of Training are the pinnacle organisations for quality assurance in VE (Government of India 2015).

\section{Challenges}

Parallel to the huge challenge of providing enough differentiated education and training opportunities to the youth, several aspects have caused setbacks to VE in India. The ecosphere of skills development cannot sustain the pressures related to quality and relevancy according to the expectations of the labour market. The Draft National Skills Development Policy (Government of India 2015) that supersedes the 2009 policy cited a multitude of crucial challenges that exist within the skills environment in India. Below are some of the challenges faced by VE in India.

\section{$\square$ Limited capacity}

Considering the future needs of skilled manpower, the existing infrastructure of both human and material nature is insufficient. Institutes lack relevant training facilities and expertise. Industrial training institutes experience a shortage of trained teachers, and many of the available teachers lack training according to the demands of new technologies and the labour market. Other limitations include the financing of $V E$ and ineffective funding modalities (Agrawal 2012). India has a vast population and the same time has no capacity to accommodate new entrants into the existing vocational institutes.

\section{$\square$ Awareness}

Lack of consciousness on vocational programmes and career guidance has had a negative effect on the development of VE. 
Vocational education has not been a favourite with many school leavers and has been seen as of less status and the one primarily meant for those who had failed in the formal academic system of education. This stigma attached with vocational studies has resulted in low admissions in vocational programmes (World Bank 2006).

\section{$\square$ Placement-linked challenges}

One major challenge with vocational programmes in India is placing students in jobs. Lack of interdependence and cooperation between education institutes and the labour market in India makes it difficult to place students in industrial attachments. Owing to its cost intensiveness and little return on investment, $V E$ in India has remained an underinvested field. There is minimum employer involvement in vocational institutes as many industries run their own training divisions.

\section{$\square$ Quality of training}

There exists a discrepancy between the labour market expectations and the competencies that learners acquire in vocational institutes. The curriculum offered in institutes is out of date and irrelevant with the current trends of the labour market. Also, the lack of employer-institution partnership leads to irrelevant training in institutes. Limited or no efforts at staff-developing has had a downturn effect on the quality of training offered in VE institutes. The quality of apprenticeship training in India is weak, as private industries have shown no keenness in providing training because of high cost implications (Agrawal 2012).

\section{$\square$ Mobility concerns}

Vocational qualifications conferred in India tend to be dead ends unlike academic qualifications. Graduates from vocational institutes find it difficult to move to higher education institutes unlike their counterparts with academic qualifications. 


\section{$\square$ Basic infrastructure challenge}

The basic requirement for meaningful training is the availability of proper infrastructure. Many of the training institutes lack proper training facilities such as equipment, specialised laboratories, machinery and tools. As a result, vocational graduates when employed find themselves incapable to perform at a particular job (Mehrotra 2013).

\section{$\square$ High levels of unemployment}

Lack of employment for graduates is one major challenge facing India (Agrawal 2012). This is because the institutes not able to provide relevant training for the formal and informal labour market (World Bank 2008). Skills development, especially related to the youth, has been lacking, which has further worsened the employment levels. A large discrepancy exists between the demand and supply of labour (Agrawal 2012).

\section{$\square$ Complexity of the system}

The complexity of the Indian skills development system poses a great challenge to the execution of vocational programmes. The fragmented approach to management of the VE sector at both national and state levels leads to replication of functions. Various ministries are involved in both national and state levels of skills development.

\section{Achievements}

Notwithstanding all the challenges, particular achievements are visible in the Indian VE sector. An example of such achievements is the work of the MSDE to formulate policies aimed at addressing critical skilling challenges of large scale, job opportunities, quality andaspirations. Throughthevocationalisation of secondary education, the government has earmarked $25 \%$ of secondary education as vocational (World Bank 2012:20). 


\section{$\square$ Achieving scale}

Industrial training institutes have witnessed capacity addition between 2014 and 2017. There has been a 24\% growth in the number of ITIs between 2014 and 2017. The government has put in place special discount in training fees for female candidates and those from minority classes to motivate them to participate in skills development. In addition, assessments in VE institutions have focused on VE graduates. All these initiatives and plans are aimed at empowering citizens with improved skills and help them in securing employment.

\section{$\square$ Boosting quality}

A number of interventions have been put in place to increase the quality of training. These include grading, whereby institutes are categorised as performing or non-performing institutes based on infrastructure availability, labour market links and skilling outcomes. The government has reinforced accreditation and affiliation of ITIs. It has also articulated National Skills Development policies and set up institutional structures to speed up skills development efforts and develop the National Vocational Education Qualification Framework. Large-scale improvements in curriculum have been undertaken in active partnership with the industry. This has seen new trades such as renewable energy, being introduced. There has been better communication with the industry, resulting in more students getting workplace attachments.

\section{$\square$ Improvement in the status of vocational education}

The government of India through the skills ministry is embarking on awareness programmes to make VE more appealing and benchmarking it with international standards. This is being carried out through the provision of world-class training standards that would enable graduates to be employed in other countries. 
Furthermore, the government is in effort to make VE more accessible. It has launched women's vocational training programmes, which clearly focus on promoting women's engagement in vocational training courses. Also, new career pathways have been created through equivalent frameworks for young people who wish to progress between formal and VE streams. The government has also put in place a number of initiatives to promote VE. One such initiative is the launching of the sector skills councils, with the mission to partner with the industry in imparting training as well as to set occupational standards and accredit qualifications. Some short-term modular employable skills (MES) have been started. These MES target sectors and industries that have a high demand of skilled labour.

\section{Vocational education in South Africa Introduction}

The state of VE in South Africa should be understood within the context of different policies that were promulgated to construct the post-apartheid era. All these major policies such as reconstruction and development (1994); growth, employment and redistribution (1996); the Skills Accord (2010); the National Skills Development Strategy (2010) and National Development Plan (2012) turn around the idea of South Africa becoming a developing country.

Vocational programmes in South Africa have become an important solution to its unemployment crisis. A large number of jobless youth, together with shortage of skills, has become a driving force for making $V E$ a solution to all these ills.

\section{Aims of vocational education}

The aims of VE in South Africa include the following:

- VE is focused on skilling for employment by preparing graduates with relevant workplace skills. 
- An important aim is to employ VE to ease poverty and encourage social welfare (Tikly 2013).

- Employed workers and job seekers should acquire the necessary skills for employment and also to help equip individuals with sustainable skills for self-employment.

- Learners should be able to acquire competencies relevant to the demands of the economy (Buthelezi 2016).

\section{Governance}

Management and governance of VE in South Africa is based on the principles of collaborative governance between public and private sectors, giving the government a navigating role. The government at national and provincial levels manages all public vocational institutions. The private vocational institutions are controlled by their respective owners. Nevertheless, the private institutions in order to be accredited by the government need to have relevant facilities and resources for the quality delivery of vocational programmes. The government controls VE through the Department of Higher Education and Training (DHET) and Department of Labour. The DHET's foremost responsibilities include formulating policies and guidelines, norms and standards. Other duties of the DHET are to develop vocational curriculum, funding of vocational programmes and upgrading of policies. The Department of Labour operates competency-based vocational training through components such as learnerships, National skills authority and skills development funding.

\section{Funding vocational education}

The dominant source of VE funding in South Africa is the government with additional support coming from private players, including employers, individuals and international organisations. Enterprises contribute to VE funding through paying special levies (Afeti 2009) and taxation (Johanson 2009). The bulk of VE funding ( $85 \%$ and more) comes from the DHET (DNA 
Economics 2015). Levy grant system and students' fees are also essential sources of vocational funding.

\section{Quality assurance}

The government through its various units oversees quality assurance in VE institutions. The major government units that are involved in quality issues in VE include the SAQA, UMALUSI ( the body that is responsible for standards of general and further education and training in South Africa) and Quality Council for Trades and Occupations (QCTO). The SAQA manages implementation of the national qualifications framework. Education and training at the workplace is handled by the QCTO, and UMALUSI monitors the delivery and assessment of qualifications (DHET 2016).

\section{Stakeholders}

In order to successfully execute VE programmes, there is a need to promote partnership between crucial stakeholders. The stakeholders are the SETAs, VE and training institutes as well as the industry, which is the private sector. The DHET (2018) prepares the strategic direction for the formulation and implementation of policies for institutes. Other stakeholders, such as vocational institutes, provide necessary environment for the training of school leaving students with relevant skills for employment. The SETA ensures that quality training is provided in line with relevant sector guidelines (Safety and Security Sector Education and Training Authority 2018). Being an employer, the industry is a crucial player in the partnership as it spells out workplace expectations for other players so that training is patterned along the labour market expectations. 


\section{Provision of vocational education}

In order to comprehend the VE system of South Africa, it is equally significant to understand the basic construction of South Africa's education system. The school system consists of four levels, namely the pre-primary, primary, secondary and tertiary levels. In the primary and secondary levels, four phases exist, namely the foundation phase (grades 1-3); intermediate phase (grades 4-6); senior phase (grades 7-9) and the further education and training phase (grades 10-12). Matriculation certificate and a school leaving certificate are issued upon completion of Grade 12.

In South Africa, both public and private sectors provide VE at secondary and tertiary education levels. Tertiary institutions include both private and public institutions. In addition, apprenticeships and workplace attachments are also used in the delivery of VE. Provision of VE is also provided through learnerships. A learnership is a programme which earmarks to address the low skills level and weak productivity signs characterising the unemployed. The theory can be learned at a college or training centre, whilst the practice is achieved in an onthe-job environment. Learnerships fully expose a learner to the actual workplace environment and help them prepare for full employment upon completion of a study programme.

\section{Curriculum}

The principal programmes offered in the South African VE landscape are the National Certificate (vocational; NCV) and the NATED (N1-N6). The NCV is a general three-year vocational programme, which is college-based. The N1-N6 programme is modularised and runs in semesters. After completing of N1-N3 in an engineering field, one gets access to an engineering apprenticeship. The introduction of NCV was meant to help institutes have the better of NATED programmes, which the 
government asserted had restricted employment opportunities for students. The NCV was regarded as a ray of light for sustainable growth and development, but this did not materialise. The NCV was meant to prepare college graduates to have an easy entry into the job market and also provides an avenue for students who had completed their grade 9 and willing to enter VE (DHET 2012).

\section{Challenges}

Basically, the success and wealth of a nation depend on the productivity of its workforce. The productivity of the workforce is based on the level of skills possessed by the employees and how they use these skills. Somehow a proper execution of vocational training programmes might solve the challenge of joblessness in South Africa. However, the following are some of the major challenges faced by VE in South Africa. The DHET (2013) through the White Paper for post-school education and training spells out the challenges facing VE in South Africa. A great consensus still exists that the vocational college sector in South Africa is not meeting the requirements of the economy to its fullness (DHET 2012).

\section{$\square$ Curriculum challenges}

The current vocational programmes have failed to address the unemployment crisis. Vocational programmes running in the South African institutes for VE are not in tandem with the industry expectations; hence, there is a non-acceptance and/or nonrecognition of programmes by the labour market. Curriculum should be constructed based on the requirements of the industry. Currently, South Africa experiences a shortage of artisans; however, the VE being offered has not met the national demand for artisans. Producing an artisan through the NCV route has proven to be lengthy. It takes three years to complete an NCV programme, and upon completion, a student has to complete artisan training. 


\section{$\square$ Overlapping qualifications}

There are two programmes (NCV and NATED) running simultaneously and this has raised quality concerns in the VE sector. The content in the two programmes (NCV and N1-N3) is identical with components of high school matric, and this in itself has made the vocational sector unappealing. The NCV represents a three-year vocational qualification offered at vocational institutes and is equal to the school leaving National Senior Certificate.

\section{$\square$ Lack of institution-industry partnership}

Vocational education programmes in South Africa are not fully responsive to the ever-changing demands of the industry. Vocational education graduates end up being employed in the fields which are not their specialty. Lack of industry-institution partnership has produced vocational graduates with skills non-responsive to the labour market needs, thus resulting in skills mismatch.

\section{$\square$ Lack of coherence at post-school stage}

Graduates from vocational institutes cannot be easily enrolled in $\mathrm{HEls}$ such as universities, indicating that post-school education system in South Africa is still a single coordinated system (DHET 2012:12-13). There is a little blending across providers of postschool education, thus making it difficult for students to have transfer between institutes (RSA 2013:324).

\section{Weak infrastructure}

The available infrastructure existing in most of the vocational institutes is not up to the standards to meet the technological demands of the labour market. Most of the machinery and equipment in practical rooms are outdated, which inhibits carrying out simulations and other practical tasks. Studies have 
highlighted that some VE material and infrastructure are outdated, and this compromises the quality of vocational graduates.

\section{$\square$ Hybrid classes}

According to the DHET (2012) policy, the minimum entry requirement for NCV programmes is a high school grade 9 level qualification. Nevertheless, students with grades 9, 10, 11 and 12 have found themselves in NCV programmes, creating mixedability classroom environments.

\section{$\square$ Negative perceptions}

The negative impression of $V E$ is disheartening for students to follow a vocational profession. A dead-end syndrome has been attached to VE institutes and this has been worsened by shallow entry requirements and limited higher education prospects.

\section{$\square$ Lack of trained staff}

There is a lack of qualified teaching personnel and managers in VE institutes. This has resulted in poor learner results and low throughput levels.

\section{$\square$ Skills gap and unemployment}

South Africa has experienced persistent unemployment, college students do not find occupational experience, let alone be employed. In light of this, the vocational institutes have a great responsibility in addressing joblessness through a choice of programmes for different population groups - the unemployed, school dropouts, underemployed and adult population. Employers experience the frustration of market with unskilled labour. Vocational graduates have been seen by the industry as valueless and inadequate, which boils down to insufficient practical work during college studies and the absence of collaboration between vocational institutes and the industry. 


\section{Achievements}

Notwithstanding the challenges in the VE environment of South Africa, the following are some of the achievements that can be noted.

\section{$\square$ Establishment of the department of higher education and training}

Governance of VE in many countries involves a network of departments, resulting in the duplication of tasks and red tape when it comes to implementing policies. In South Africa, the DHET has the sole authority and responsibility for the running of vocational programmes. The DHET (2013) was created in 2009 out of a government restructuring programme and its sole mandate is skills development and training. The government directs VE in different ways through the DHET. The DHET has responsibilities that include the development of vocational curriculum, student funding and policy implementation.

\section{$\square$ Creation of agencies for skills development}

Creation of the national qualifications framework helps locate level of qualifications on the framework and relates local programmes with international qualifications. The skills Development Act, which is aimed at skilling the employees and ensuring that workers have access to training, is also an important achievement. The SAQA was established to guarantee highquality education and training.and the national skills fund was set up to facilitate funding of all types of training.

\section{Strategic partnership between Sector Education and Training Authority and institutions}

The cooperation between institutes and SETA is crucial. Sector Education and Training Authority has set up skills centres in 
partnership with vocational institutes. This includes launching of industry-community initiatives aimed at empowering communities with vocational skills. The industry has also partnered with vocational institutes in setting up of vocational centres of specialisation and excellence.

\section{Comparison}

In analysing the similarities and differences in the provisioning of VE in India and South Africa, the following comparisons are made regarding the issues that were the focus of this chapter.

\section{Aims}

The motive behind vocational systems is indistinguishable for India and South Africa. It is the equipping of students with competency to enable them to secure employment and bridge the skills gap with employers. Vocational education in both India and South Africa targets the development of skills and employment opportunities as important measures to develop a sustainable country and society. The ultimate aim of VE is to make learners acquire competencies that would prepare them for integration into the workplace (see the section 'Aims of vocational education'). Both India and South Africa believe that the blending of theory and practice in VE supports learners to achieve an easy transition from school to work (see the sections 'Provisioning' and 'Aims of vocational education'). In both countries the aims of VE are similar. However, the college to work transition in both countries has not been smooth, as vocational graduates enter the industry without the necessary level of skills (see the 'Curriculum challenges' section).

\section{Governance}

Governance of VE in India and South Africa is collaborative, meaning that both private and public sectors are involved (see the 'Governance of vocational education' section). The 
governments of both countries formulate vocational policies and ensure that such policies are implemented in institutes. In South Africa, the government through the DHET ensures compliance of all vocational policies (see the 'Establishment of the department of higher education and training' section). The governments also put checks and balances in the way vocational training is implemented, accredit private providers as well as deregister all non-complying institutes. Other players such as private institutes, industries and NGOs are also involved in the governance of VE in both the countries (see the sections 'Curriculum' and 'Governance').

\section{Curriculum}

The curricula of VE in both India and South Africa have some similarities. Much focus is on the acquisition of skills through competency-based learning. Both countries stress on the value of work-placement of trainees, although not much is performed on the ground with regard to this (see the sections 'Funding' and 'Curriculum'). However, there is more of theory and little integration of practice in the implementation of VE in both countries. This is a result of weak links between institutes and the industry, thereby causing institutes and the industry move in opposite directions in addressing the shortage of skills, with the end result of skills mismatch (see the sections under 'Curriculum 'and 'Lack of institutionindustry partnership'). There is a similarity in the way the curriculum is designed in both India and South Africa. The respective governments through various institutions take lead in designing the vocational training curriculum (see the sections 'Funding' and 'Establishment of the department of higher education and training'). Similarly, there is less of industry consultation in the designing of vocational training curriculum in both India and South Africa (see the sections 'Improvement of the status of vocational education' and 'Curriculum challenges'). 


\section{Quality assurance}

India and South Africa have a common approach to quality assurance in VE. Various initiatives are in place to promote quality in the execution of vocational programmes (see the sections 'Challenges' and 'Quality assurance'). They all focus on qualifications framework to coordinate different qualifications offered by various training institutes. However, these frameworks have not performed much to address the mismatch in skills, as the standard and relevance of some programmes, such as NCV in South Africa, are incognisant with industry demands (see the section 'Establishment of the department of higher education and training').

\section{Funding}

In South Africa and India, governments are involved through state revenues to finance VE. Both the governments, private sectors and students provide VE funding through training levies, student loans and corporate taxes (see the sections 'Funding vocational education', 'Stakeholders in vocational education' and 'Funding vocational education'). In both countries, public institutes receive funding from governments, whereas private individuals do their own funding. Non-governmental organisations do play a part in the funding of VE, especially when conducting small-scale training programmes for rural communities.

\section{Stakeholders}

Partners in VE are the same in India and South Africa. They include the government, industry, NGOs, students and communities (see the section 'Stakeholders in vocational education'). They all have similar responsibilities to ensure successful implementation of VE programmes (see the sections 'Quality assurance' and 'Stakeholders'). 


\section{Challenges}

Similar challenges are found in the VE systems of both countries. Society still has a negative perception about VE in both countries (see the sections 'Boosting quality' and 'Negative perceptions'); however, India has managed to unpack a range of initiatives aimed at addressing negative stereotyping of VE. India and South Africa still experience great challenges in implementing vocational programmes because of insufficient funding and weak VE infrastructure (see the sections on 'Funding' and 'Weak infrastructure'). In some institutes, equipment is run down and appropriate training facilities, such as experiment rooms, are not available.

Institutions in India and South Africa experience limited capacity in terms of running VE programmes. Both ITIs in India and vocational institutes in South Africa experience shortage of trained staff and modern equipment to successfully conduct vocational programmes (see the sections 'Achieving scale' and 'Lack of trained staff'). Furthermore, graduates from vocational institutes in India and South Africa experience difficulties in trying to proceed to higher tertiary education or getting employment in the industry (see the sections 'Lack of coherence at post-school stage' and 'Skills gap and unemployment').

It has been noted that the lack of industry-institution partnership affects both India and South Africa (see the sections 'Improvement of the status of vocational education' and 'Lack of institution-industry partnership'). There has been no industry engagement in designing vocational training material in the two countries. In both countries, this has resulted in continued jobless graduates (seethe section 'Skills gap and unemployment').

\section{Achievements}

The two countries have made great achievements in trying to resolve challenges being faced by $V E$ in their respective regions. 
Unlike India, South Africa created the DHET, an autonomous department which oversees VE and training in the country and designs policies earmarked for development of skills (see the section 'Establishment of the department of higher education and training'). Similarly, quality assurance bodies were set up to assure the quality of all vocational training courses in both India and South Africa (see the sections 'Challenges' and 'Quality assurance'). Both India and South Africa are on a VE drive, setting up various institutions for promoting the development of skills through funding, skills provision and vocational career awareness drives. New institutions are being set up in India to make vocational training easily accessible to all.

The two countries have embarked on active collaboration with industry, with South Africa launching Industry-Community initiatives aimed at skills development amongst communities (see the section 'Strategic partnership between sector education and training authority and institutions'). Similarly, India has actively engaged industry in the improvement of curriculum and launching of new community vocational programmes to empower the previously disadvantaged. (see the section 'Achieving scale'). Such programmes include women vocational training programmes. India on a greater scale than South Africa has launched far-reaching reforms of its skills development policy and strengthening attempts to increase the number of skilled workers (see the section 'Improvement in status of vocational education').

\section{口 Conclusion}

The chapter has accentuated that the principal aim of VE is to empower workers or students with skills and knowledge relevant to the job market. Various factors have been pointed out as the key features of VE in India and South Africa. Challenges to achieving sustainable VE were spelled out; some of these 
challenges include lack of funding, inappropriate curriculum, and a lack of synergy between the industry and vocational institutes. Vocational institutes in India and South Africa have experienced insufficiencies of infrastructure and funding, thereby limiting the quality of providing vocational training to their students. The result has been an ill-prepared vocational graduate for the job market. In addition, the chapter exposed that VE in the two countries has minimum influence on employability and national development because of the features such as funding mechanism, collaboration of stakeholders and public perception of VE.

In order for vocational training to become more influential for employability and economic development, the following recommendations are put forward for implementation by lawmakers and all stakeholders:

- Enabling policies should be developed to promote access to VE by all population groups and should be crafted by policy makers in collaboration with all relevant stakeholders. Policies ought to promote participation of all genders in skills training and raising awareness on the importance of VE as a learning option. This approach should accelerate the attitudinal transformation and bring out a constructive commitment from parents, teachers and all stakeholders.

- Policy makers should ensure that acceptable tools are in place for thorough monitoring and evaluation of policy performance. Provision should be in place for periodic analysis and evaluation of policies to ensure sustained relevance and applicability of programmes.

- Governments should guarantee quality and relevance of skills development. This can be through training policies that allow for staff development and skills upgrading for teachers. This would allow for the successful delivering of vocational programmes. 
- There should be sufficient funding for vocational programmes. Finance should be for capacity-building, new acquisitions of machinery and equipment to mirror new technologies and more engaging teaching and learning methods.

- Career guidance should be provided in institutions to enable students to see worthiness of VE and allow them to pinpoint programmes that suit their interests and capabilities. In addition, businesses and employment agencies should be involved in career guidance and inspiring applicants of the value of VE for national development.

- Partnerships should be encouraged between main stakeholders in VE. The state, employers, vocational institutes and other stakeholders should focus on the best practices in VE that have been successful in other countries. Through industryinstitution collaboration, employers should provide workbased training to vocational students and at the same time be involved in the designing of curriculum for vocational programmes. Partnerships should give room to programmes meant to enhance the practical skills of teachers and learners to meet the needs of the industry. Industry-institution programmes should bridge the gaps between the theory as communicated in the classroom and the practice as represented in the industry. 


\section{Chapter 6}

\section{Providing for the unique educational needs of minority groups: Lessons from the BRICS countries}

Hennie J. Steyn

Subject Group Comparative and International Education, Education and Human Rights in Diversity Research Unit, Faculty of Education, North-West University, Potchefstroom, South Africa

Z.L. (Louw) De Beer

Subject Group Comparative and International Education, Education and Human Rights in Diversity Research Unit, Faculty of Education, North-West University, Potchefstroom, South Africa 


\section{Abstract}

The human rights of individuals and groups are a topic of major debate since the 1950s, and quite often these rights are being treated as if they are of opposing nature. However, during the second part of the 20th century, the political rights of minority groups were recognised in two important treaties signed by the member states of the United Nations (UN) and the European Community. These rights are still being contested across the world. The educational rights of minorities are regarded as one of the most important rights of minority groups and are explicitly included in the particular international treaties which focus on the rights of minorities to education. The aim of this chapter is to identify lessons to be learned from member states of BRICS regarding the manner in which the educational rights of minority groups are respected and supported. The qualitative research tradition, the structured analysis of primary and secondary data sources, was used as research method. The immense challenges faced by the BRICS member states regarding education for minorities were highlighted. Legally and constitutionally the BRICS countries protect the human rights regarding non-discrimination and the establishment of schools with a unique cultural and linguistic ethos. In South Africa, several legal cases state the difficulties regarding mother tongue education. Although legislation protects minorities' education, it seems that it is still a challenge to implement. The BRICS member states should highlight the plight of minorities regularly in their annual summit. Because of the fact that all the member states have different languages, culture and religions, it is difficult to fully protect education minority rights.

Keywords: International education; Minority groups; Minority rights; BRICS countries; Educational rights. 


\section{Introduction}

For many decades the human rights of individuals and groups are a topic of major debates and quite often these rights are being treated as if they are of opposing nature. These debates lead to the recognition of two types of human rights by the United Nations (UN 1948), namely the acceptance of the International Bill of Human Rights to recognise the rights of individuals and the qualifier regarding group rights in the International Covenant on Civil and Political Rights (UN 1966) as well as by the Charter of Paris (1990) by the EU. Thus, the political rights of minority groups are recognised in two important treaties signed by the member states of the UN and the European Community. These rights require that the human dignity of individuals and communities should be respected and that equals should be treated equally and unequals should be treated unequally (Larorest 1993:x) and thus providing minorities to cherish, develop and allow for their unique characteristics and needs. These rights are still being contested across the world (Parnell-Berry \& Lawton 2019:35). The educational rights of minorities are regarded as one of the most important rights of minority groups and are included in the particular international treaties which focus on the rights of minorities to education that support them to cherish and develop their unique characteristics and developmental needs. However, it is the global experience that the majority finds it extremely difficult to provide minorities with sufficient space and infrastructure to satisfy these rights. Minorities usually have to provide for their own educational needs. Therefore, the aim of this chapter is to identify lessons to be learned from member states of BRICS regarding the manner in which the educational rights of minority groups are respected and supported. Within the qualitative research tradition, the structured analysis of primary and secondary data sources was used as a research method to execute this study. Primary data 
were collected for the particular research project, making use of those strategies that best address the research situation. Secondary data are the data that are already available and used for other intentions and are applicable for a new research objective (Cresswell 2009).

\section{International guidelines of education for minorities \\ Defining minority groups}

Minority groups are defined on the basis of unique characteristics that, willingly or unwillingly, recognise them as a group and, at the same time, distinguish them from other groups. These characteristics include issues such as ethnicity, history, traditions, religion, core values, age groups, gender orientation and/or physical disabilities (Southiram 1995:3). A minority group is also characterised by the fact that this group is inferior in numbers to the rest of the population and/or that its members are also in one way or the other in a non-dominant position in the society that constitute the people of a particular country (Lerner 1993:79). The concept usually applies not only to those groups who are numerically in an inferior position but also who have a strong sense of solidarity, and the fact that they, implicitly or explicitly, wish to maintain and, if relevant, develop these unique characteristics to maintain and strengthen the sense of unity amongst the particular group. Sometimes a minority group can also be defined as a group that is in numbers larger than the rest of the population but who have a particular lack of power or skills (Claassen 1996:9).

\section{$\square$ A minority group can be identified by its religion}

Regarding the fact that religion can be used to identify a minority group, the two meanings of religion should be taken into consideration. According to the one meaning, religion refers to the worshipping of a particular god, but usually a minority group can be 
identified according to the second meaning of religion, namely that a particular belief in a god can determine the whole life of a particular individual or group of people. In this way, the nature of living of a particular group is determined and characterised by its belief system or philosophy. This system includes the group's cosmology, anthropology, principles and values and thus it influences the total life of the individuals that constitute that group regarding their, for example functionality in society, politics, economics, science and technology. The religion as the basis of the philosophy determines what is good and bad and what will be valued.

\section{$\square$ Culture as an identifier of a minority group}

A broader definition of the concept of culture explains that individual and group culture can be distinguished, but in both cases, all the work of man, as well as the product of work of man (individually or in a group), constitutes the culture of that individual or group. Therefore, a group culture (cf. Mochwanaesi, Steyn \& Van der Walt 2005:287) can be described as, inter alia, the unique ideals, aims, activities, interests and behavioural patterns of that particular identifiable group under the guidance of a particular view of life, as embodied, for example by the belief, origin, history, art, science, technology, language, politics, economics, industries and religious practices of that group (Steyn 1998:15). The culture of the group is not only the sum of the work and work product of the individual members of that group but also includes a particular unambiguousness between that work and the work product. In this sense, as an example, language can be a clear cultural identifier of a particular group as it refers to an unambiguousness of the major language used by the members of the group.

As a cultural identifier, certain elements of a particular culture are usually used, such as language or traditions or political institutions or economic activities. These elements are explicit elements indicating the uniqueness of a particular group in a clearly observable manner. However, elements such as values, opinions, traditions, interests and behavioural patterns also indicate the uniqueness of a particular group, but these unique 
characteristics as implicit elements, are more difficult to detect than the explicit elements. However, it is clear that uniqueness in one or the combination of more than one of the elements of the respective culture can serve as the identifier(s) of that group as a discernible group within a particular national society.

\section{$\square$ Ethnicity as an identifier of a minority group}

'Ethnic' and 'ethnicity' as terms are widely used, but in different meanings and contexts, in a popular and political discourse. Although hesitantly, ethnicity is widely used to identify particular groups of people, it is especially the racial basis of ethnicity that is frequently used as an explicit element to identify a particular group (Bhandari 2014:331). However, as a form of a deceptive discrepancy, whilst race is, on the one hand, rejected as an element in identifying differences, the race is in many instances used to identify the beneficiaries of affirmative action, such as is the case in South Africa.

\section{The internationally recognised rights of minority groups}

The rights of minorities (cf. Steyn 2009:65-80) are an international focus since the 1960 s and received official international recognition by the UN, the European Community and UNESCO. The following are some of these recognitions.

\section{$\square$ The International Covenant on Civil and Political Rights (1966)}

This covenant focuses on the general as well as particular rights of minority groups by stating that all member states of the UN, in which ethnic, religious and/or linguistic minorities reside, should ensure that the members of these groups have full opportunity to enjoy their own culture and/or to profess and/or practice their own religion and/or their own culture and/or their own language and/or their own uniquenesses (UN 1988:28). By acknowledging 
these rights, it is implicitly recognised that the rights of individuals cannot be fully protected by their individual rights, but that the recognition of the well-defined 'group rights' (Steyn 2009:70) is required as a balancing instrument, and thus a better harmony is developed between the functioning of individuals and/or groups and the state (Lerner 1993:81).

\section{$\square$ The Charter of Paris for a New Europe}

When the Charter of Paris for a New Europe was accepted in 1990 by the EU, it served as a major support of the International Covenant on Civil and Political Rights of 1966 (see Steyn 2009:71). It was recognised in the charter that the unique ethnic and/or cultural and/or religious characteristics of minorities in nation states should be protected and that their members have the right to freely express, preserve and develop their own identity without experiencing any discrimination whilst their equality before the law are recognised. A result of the institution of this charter is the recognition that issues concerning the protection and development of minorities is not only an internal matter but that these rights are also, without doubt, a matter of continuous international concern (Doliwa-Klepacka 2019:59; Lerner 1993:98).

\section{$\square$ Implications of international instruments for minority rights}

The rights of minorities, as developed in the different treaties, conventions and international deliberations, focus primarily on two issues, namely the right to an own identity and the right not to be discriminated against (Doliwa-Klepacka 2019:61; Thornberry 1991:137). These rights boil down to the following, namely as the rights (Steyn 1998:4):

- To experience security of life.

- To effectively experience equality, including the security not to be discriminated against and that of group violence and hatred will not be incited by the majority. 
- To be different, without being forced to assimilate according to the wishes of the majority.

- To have affirmative actions that usually refer to special measures that are provided, for example regarding the maintenance and development of their preferred language, education, own organisations, freedom of movement, information, the use of government agencies and political representation as minority groups.

- To be able to have self-determination regarding the scope and membership of the group with due regard to individual rights and liberties of the population of the nation.

- To establish and maintain their own institutions within the recognised ambit of the national society.

- To communicate, federate and cooperate nationally and internationally without being threatened.

- To impose duties on the members of the group.

- To have the right of self-determination and at least to local self-government.

- To have the right of own education provision.

It should always be acknowledged that the individual rights and the rights of minorities should work in an interactive manner, namely to protect the two sides of human rights which refer to the rights of human beings and human communities (DoliwaKlepacka 2019:62). It is also a fact that the preservation of individual rights is receiving more attention than the preservation of the rights of minorities, also because the rights of minorities have a more direct effect on the political scenery of a particular country (De Witte 1993:179; Du Buisson 2018:613). During the 1990s, when the debate on minority rights was very rife, Laforest (1993:x) claimed that justice, in modern terminology, consisted of treating equals equally and unequals unequally. Taylor (1993:42-50) found that modern emancipated people find it important to have an identity, also a group identity and that the group is to a large extent not any more built on a common religion or common traditions or a common history, but that a common language tends to be a strong foundation of modern 
identification of people (Dombrowskia et al. 2014:119), especially languages that have expressive powers in the modern world, for example regarding technology, economy and other sectors that are valued in present days. The constant modification and change of understanding, for example regarding the local and national contexts and the own and the overarching community, also changes the perspectives and needs of minority groups (Parnell-Berry \& Lawton 2019:37).

In modern terminology, justice consists of treating equals equally and unequals unequally (Laforest 1993:x) and understanding the 'universality of particularism' (Taylor 1993:139) and that the state should provide these opportunities (Du Buisson 2018:610). A well-developed individual personality is considered to be a necessary prerequisite for (1) effective functioning in a diverse community, and (2) for the diverse community to function effectively as a unit, for example a diverse South African community as well as a diverse international community (Steyn, 2009: 67). Understanding one's cultural system leads to greater skills in appreciating other cultures, although, together with an individual identity, the individual should also develop a collective identity in order to 'move' between different cultural groups and to function in harmony and coherence in a diverse community. This coherence can, for example be brought about by dominant values which can produce a degree of equity in the greater society. Although national unity is important, the rights of individuals and groups to contribute to the unity of the whole should not be overlooked (Steyn, 2009:65).

\section{The internationally recognised educational rights of minority groups}

The internationally recognised educational rights of minority groups are further explained in the Convention against Discrimination in Education by UNESCO (1960) and the United Nations Convention on the Rights of the Child (UN 1990). These established rights of children to receive education according to 
their unique religious and/or cultural and/or situational needs were affirmed and the protection of the child's own and unique identity was recognised as the main focus of these instruments (Detrick 1992:ix; Qureshi \& Janmaat 2015:727). These rights regarding education should be interpreted in the context of educational provision as stipulated in the International Bill of Human Rights (UN 1948:art. 13). According to the different instruments of education provision, education shall be provided to support the full development of an individual learner and at the end to enable all individuals to participate effectively in a free society and to promote good relationships amongst different groups. Education should be accessible to all, but the prerogative of parents to choose schools for their children, other than those provided by the public national and local authorities, should be recognised (Steyn 2009:78). The right of minorities to establish and maintain schools, subject to the minimum standards of the educational authorities, are also recognised.

\section{$\square$ The Convention against discrimination in education as adopted by the UNESCO, 1960}

In the UNESCO Convention (1960), particular measures were employed to prevent possible discrimination in education. Discrimination was explained and refers to the damaging or the negligence of equality of educational provisioning and opportunities. No undue distinction, exclusion, limitation or preference should be based on race, colour, sex, language, religion, political or any other opinion or orientation. It is accepted that separate educational institutions and/or private education systems may be established and maintained for specific cultural and/or religious reasons. These institutions shall not be regarded as any form of discrimination as long as these are according to the wishes of the parents or guardians and whether the attendance of these educational facilities are optional and conforms to the national educational standards as 
approved by the relevant educational authorities. Educational authorities of the national departments should not in any manner provide barriers solely on the basis that these learners differ from the majority, such as limited funding and opportunities, that will educationally disadvantage the learners in these schools. It is stipulated that the right of parents to choose educational institutions, which are assured regarding their quality, should not be limited as long as these learners are not prevented to learn the culture of the majority people of the nation (UNESCO 1960:art. 1-5).

\section{$\square$ The United Nations Convention on the Rights of the Child, 1990}

One of the basic characteristics of this UN Convention (1990) was the rights of all children, including the rights of children from minority groups, to receive quality education according to their unique contexts and educational needs, also referring to their unique and diverse religious and cultural needs, which were detailed and reaffirmed. Another main focus of the convention was that the protection of the children's own identities is recognised and confirmed (UN 1990:art. 28, 30). Rights of these children were directly related to the International Bill of Human Rights, which reaffirmed, inter alia, the right of everyone to education according to their individual needs, the fact that education should be directed to the full development of individuals' potentials and to enable everyone to participate effectively in a free society. Education should also be used to promote understanding, tolerance and friendship amongst all individuals as well as all nations, including all racial, ethnic and religious groups (cf. Steyn 2009:71). In the Bill of Human Rights, the right of individuals to choose schools, other than those provided by the state, for their children and to support their unique religious and moral convictions are supported (UN 1990:art. 13). 


\section{$\square$ Implications of the two conventions regarding the educational rights of minorities}

In both conventions, the rights of learners from minority groups to obtain quality education according to their unique educational needs, which can be qualified by their own religion, culture and local and national contexts are recognised and should be recognised by all members of the UN in individual states. Tailormade education according to the needs of the minority learners improves their opportunities for quality education (Anderson \& Boyle 2015:5). The right of minorities to provide own educational institutions, according to their own needs, language and preferences, are also recognised as long as these educational opportunities comply with the minimum educational standards of the country and as long as these own educational opportunities do not alienate the minorities from the majority of the national society (MacQuarrie \& Lyon 2018:617; Tomlinson 2015:513).

However, the recognition of these educational rights means that governments should only respect these rights but do not put any responsibility on individual governments to actively support the promotion and development of these rights, for example by means of particular financial support. This support is more than often lacking in the majority of countries (Qureshi \& Janmaat 2015:711). Furthermore, the tension between the common and the particular always prevails in the educational provision of minority groups (Claassen 1996:23; Du Buisson 2018:612). 'The common', in general, refers to the common educational needs of the community at large that they require to successfully participate in society. 'The particular' refers to the unique educational needs of the minority group which should be provided for in order to enable them to preserve and maintain what is valuable to them and to successfully function and interact in the national society. The tension between the educational needs of the majority and the minority group(s) is a common feature of every education system and should be recognised and be an integral part of all educational planning programmes 
(see Steyn 2009:65-80). The solution will most probably be found on a continuum between, on the one hand, education aiming at enabling the minority to effectively function within the larger national society whilst ensuring sufficient opportunity to preserve and maintain their own unique characteristics that they regarded as valuable. The solution will most probably be found in the balance between emphasising the common needs of the national community whilst at the same time the required education provisions according to the unique educational needs of the minority group, which should not be negated.

\section{The expectations of minority groups from the education system}

The education system is being defined as the educationally qualified structure consisting of different components and elements with the primary aim of providing the educational needs of the target group. Different types of education systems can be identified, namely the national education system that is constructed to serve the educational needs of all the citizens of a particular country; the 'mini-education system' (Steyn 2009:74) that is constructed to serve the educational needs of a particular target group that does not coincide with all the citizens of a particular country having unique educational needs that are not sufficiently provided by the relevant national education system; the dependent (usually nationally) education system owned by a particular target group (the citizens of that nation) whose educational needs should be provided for (managed by the national government); and lastly the independent education system that is not owned by a target group but the owners of the (usually) mini-education system choose their own target group to provide educational needs of that group. The majority of modern societies are characterised as multi-ethnic, multi-religious, multicultural and multilingual that function in a complex and integrated manner to assist individual citizens to cater economically and socially for their own welfare and simultaneously contribute towards healthy and prosperous 
national communities. In the majority of these modern national societies, identifiable minority groups are found that want to maintain their own identity within and as part of the broader society. The issue of national unity and the recognition of minority needs should not be regarded as opposing concepts (Steyn, Alkan, Tupan \& Oeyen 2007:10), but it should be used to strengthen the national community regarding interacting with the challenges of the modern world.

Firstly, these expectations imply that these minorities wish to be recognised as identifiable interest groups in the target group and the government and functionaries should constructively communicate with them to identify their unique educational needs and that particular measures are taken to allow for these unique educational needs. They expect to be supported in such a manner that they can prepare themselves to function effectively as members of the minority group as well as respected members of the broader national society (Steyn, Alkan, Tupan \& Oeyen 2007:9; Tomlinson 2016:515). Secondly, they wish that their children shall receive education of high quality. This means that all elements of the education system process should be put in place in order to recognise the unique educational needs and successfully provide for their realisation.

This necessitates that particular attention should be paid to establish correct educational policies that support sufficient educational structures and opportunities to adequately support learners from minority groups, for example in language education (MacQuarrie \& Lyon 2018:619). In the component 'education system administration' provision should be made to make available motivated management, also representing the minority group, in order to support the planning and implementation of applicable educational provisioning as well as allocate funding for quality education to minorities. Lastly, adequate structures should be put in place to enable meaningful communication between the functionaries of the education system and $a$ particular minority group. 
However, it is primarily at the heart of the education system, namely the structure for teaching, that the required measures and procedures should be taken to provide for the unique educational needs of minority learners (Dombrowskia et al. 2014:119). The focus of the educational provisioning for minority groups should be aimed at preparing their learners to function effectively in their different roles of life. The education system should provide these opportunities to the learners of the minority groups to realise their own potential and thus contribute to the welfare of the whole community (Tomlinson 2015:520). Minority groups (see Steyn 2009:65-80) quite often find that because their numbers are wanting in the whole of the education system, the trend is to focus on educational provisioning at an institutional level such as schools and/or universities in order to render their unique educational needs. It is a logical step because the school is a smaller institution than the education system, and there is usually a provision in the education system for the delegation of powers up to the school level. Delegated powers up to the school level make it more achievable to serve the educational needs of the minority groups at the level of an educational institution. However, to use a particular educational institution is not a guarantee that the educational needs of the minority group will be served. The minority group should be able to associate with a particular educational institution. The minority group, as a target group of a particular institution, should be able to take overall ownership (not necessarily in a physical or financial manner) of an education institution. However, the sense of ownership is acknowledged to be an important prerequisite for the provisioning of effective education to minority groups (Steyn 1998:10). The educational institution should meet particular requirements to ensure that the minority group takes ownership of that particular educational institution. The level to which a particular minority group can take ownership of a particular education system strengthens, for example the culture of the minority group, and the culture of the school is in harmony with the culture of the minority group. 
To identify with and relate to a particular educational institution, the minority group should also be able to identify and relate to the learners and educators of that institution. The quality and quantity of educators from the minority group in an education system can, for example serve as role models, which will enhance the level to which the minority group can relate to a particular educational institution (Grant \& Gillette 1987). Similarly, the learners of that particular educational institution should be able to positively relate to each other, because the success of a particular educational institution rests to a large extent on the positive level of its interpersonal and social interactions. The higher the number of learners of a particular minority group that attends a particular school, the higher the experience of coherence and security that the learners experience and the fewer are the learners that experience a degree of marginalisation (Klausky 1995:1-24). This feeling of being at home is also strengthened if the home language of a particular minority group is being used as the language-of-communication as well as the language of teaching and learning in a particular educational institution. This increases the learners' self-perception and they are able to interact on a wider and deeper level with the learning outcomes and the learning material, which increase the quality of teaching and learning and academic achievements. Although quite often recognised as important, the artfulness, quality, neatness and functionality of the teaching facilities support the level to which the minority group can relate with the place of education and thus it supports the quality of education. Finally, it is true that if the type of authority and management styles relate to what is collectively accepted by a particular minority group then the identification of that group with that institution is increased, especially if the parents and members of the local community are involved in the local governance of the school (Pretorius 1996:141).

The classroom culture and climate should also be of an inviting nature for learners of the minority group. They should feel welcome and embraced and the values that underpin the classroom activities should correlate with those of the 
minority group. Therefore, the context of teaching and learning should be relevant and familiar to the learners of the minority group, and in the actual teaching-learning situation the effectiveness is improved if the aims of teaching directly relate to the real educational needs of the minority group and provide them with sufficient opportunities to acquire the relevant competencies in terms of knowledge, skills and values. The teaching content should also be relevant to the life situations of that minority group and successfully assist the members of the minority group to prepare them for their individual roles of life. To strengthen this aim, the teaching and learning material, as well as the teaching strategies and methods, should relate to the context of particular minority group and assist it to prepare for the future and interacting with members of the majority. In addition to the above, the interpersonal nature which is an intrinsic part of teaching and learning, including the discipline and assessment, should correspond with the interpersonal styles, traditions and practices of the minority group.

In order to support the minority group regarding their real and perceived challenges in education, applicable educational support services should be made available for their use. In order to introduce relevant teaching strategies, the support services to teaching and learning should consider the needs of minorities, and similar to the unique needs of learners and teachers regarding, for example media services, housing services, pedagogical services and employment services.

Therefore, in general, the minority groups as part of the national society wish for good quality education for their children. In order to achieve this, they expect the following:

- Their educational needs should be fully recognised as part of the educational needs of the national education system.

- The policies of education system should make successful education possible for their children.

- In education system, administration and compassionate management structures should be available, accompanied 
with sufficient allocation of resources and meaningful communication with minority groups.

- The structure of teaching should allow for the unique characteristics of minorities, such as the availability of schools of which the minority group can take ownership in terms of, for example school culture and climate, sufficient presence of teachers and learners from the minority, applicable curricula, the home language of learning and teaching and communication and teaching strategies applicable to the nature of particular minority group.

- Applicable educational support and services should be provided to strengthen the teaching and learning of minorities as well as the unique challenges of learners and teachers of minority group.

\section{The recognition of educational rights of minorities: The consequences}

The obvious consequences of the recognition of the educational rights of minorities for national education systems, within the context of the guidelines of national education systems to successfully provide for the educational needs of national society as the target group, are summarised as follows (Steyn \& Wolhuter 2014):

- The minorities should be duly recognised as part of the target group of that education system.

- Sufficient external communication with the minority group(s) and internal communication about education to the minorities should be in place.

- The educational needs of minority group(s) should be attainable and included in relevant educational policies.

- Adequate provisioning should be made for the representation of minorities in several levels of education management and control. 
- The structure for teaching, for example regarding education institutions, education curricula, learners, educators, language and facilities, should be duly provided for quality education to minority group(s).

- Sufficient educational support services, referring to the services of teaching and learning activities, and the learners and educators, should be in place to ensure that relevant noneducational services be adequately employed to support quality of education for minority group(s). (ch. 4 - ch. 6)

These aspects should be used by minority groups to ensure the quality of their education and identify and measure the provisioning of quality of education to minorities in particular countries.

\section{Recognising minority educational rights in the member states of BRICS Introduction}

All of the national societies of the member states are, in different proportions, multicultural and multi-ethnic in nature. For the BRICS organisation, it is of importance that in each of its member states, stable and healthy societies are developed and maintained. Therefore, it is important to analyse the level of minority rights in each country, but more so, to analyse the level of education in minority rights, because education in all minorities is one of their most important possessions. Thus, it is time to analyse and discuss the recognition of minority rights in each of the national societies of the member states, but primarily to focus on the educational rights that are provided to minorities in these member states and as described in the paragraph above. In this manner, workable comparisons can be made and lessons learned through which each of the multi-ethnic and multicultural national societies can be strengthened. 


\section{Education to minorities in South Africa: Frameworks, practices and challenges}

The South African education, pre-1994, was a segregated education system that consists of different education systems for individual racial groupings. The following applicable education laws were used to differentiate and separate the races with the aim of 'meeting the individual needs of each the racial grouping' (Unterhalter et al. 1991:59): the Coloured Persons Education Act No. 47, the Indians Education Act No. 61 of 1965 and 1963, and the Bantu Education Act No. 47 of 1953 promulgated for Africans. After the first democratic election in 1994, the Constitution of the Republic of South Africa (RSA) (Act No. 108 of 1996), as well as the South African School Act (SASA) (Act No. 84 of 1996), was adopted, which eliminated and replaced all the previous discriminatory laws.

\section{$\square$ The Constitution of the Republic of South Africa (Act No. 108 of 1996)}

Chapter 9 on state institutions that supports South Africa's constitutional democracy in the Constitution of South Africa is the Commission for the Promotion and Protection of the Rights of Cultural, Religious and Linguistic Communities (RSA 1996a). The term 'minorities' is not explicitly mentioned in the Constitution of South Africa but articles 185 and 186 of Chapter 9 refer to peoples of different languages, religions and cultures as minorities.

Following are the primary objectives of the Commission for the Promotion and Protection of the Rights of Cultural, Religious and Linguistic Communities listed in Article 185 (RSA 1996a):

$[T]$ o promote respect for the rights of cultural, religious and linguistic communities; to promote and develop peace, friendship, humanity, tolerance, and national unity amongst cultural, religious and linguistic communities, based on equality, non-discrimination and free association; and to recommend the establishment or recognition, in accordance with national legislation, of a cultural or other council or councils for a community or communities in South Africa. 
The Commission has the power, as regulated by national legislation, necessary to achieve its primary objects, including the power to monitor, investigate, research, educate, lobby, advise and report on issues concerning the rights of cultural, religious and linguistic communities. (p. 94)

The Commission has certain functions and powers as prescribed by relevant national legislations. Article 186 formulates the composition of this commission. As mentioned, the term 'minorities' is not used in the Constitution of South Africa, but instead it uses the term 'communities'. Although the concept of minorities is not mentioned but the concept of 'communities' is mentioned, the concept of 'communities' is also not defined in the constitution. But there are certain sections in the constitution that are relevant to education for minorities/communities. The relevant sections are as follows: Section 31 (cultural, religious and linguistic communities), Section 30 (language and culture); Section 15 (freedom of religion, belief, and opinion); Section 9 (equality) and Section 29 (education).

The focus of this chapter is education for minorities; hence, Section 29 and its subsections are highlighted. Section 29 states that (RSA 1996a):

Everyone has the right to basic education, including adult basic education and to further education, which the state, through reasonable measures, must make progressively available and accessible.

Everyone has the right to receive education in the official language or languages of their choice in public educational institutions where that education is reasonably practicable. In order to ensure the effective access to, and implementation of, this right, the state must consider all reasonable educational alternatives, including single medium institutions, considering equity; practicability; and the need to redress the results of past racially discriminatory laws and practices.

Everyone also has the right to establish and maintain, at their own expense, independent educational institutions that do not discriminate based on race; they are registered with the state, and maintain standards that are not inferior to standards at comparable public educational institutions. (p. 1257) 
Therefore, limited to Section 36 (limitation of rights), minorities in South Africa can make decisions regarding religion, culture and choice of language and can open their own schools. Minorities and communities, therefore, can establish schools with a unique cultural and linguistic ethos if it does not infringe the rights of other South Africans.

\section{$\square$ The South African Schools Act (Act No. 84 of 1996)}

The aim of SASA (Act No. 84 of 1996) is to provide a uniform education system for all South Africans, without any discrimination, to organise, govern and fund schools in South Africa. Section 3 of SASA indicates that every parent must send every learner for whom he or she is responsible to attend a school from the first school day of the year (RSA 1996b). Parents of minority groups must send their children to school. Section 5.1 of SASA governs admissions to schools. This section states that a public school must admit without unfair discrimination. Children of minorities must be admitted to any schools, and no admission test for children or financial liabilities on parents (parents not able to pay school fees) can be used for exclusion criteria. Section 6 of SASA frameworks language policy of public schools (RSA 1996b). The school governing body (SGB) may determine the language policy of a school but it must adhere to other relevant legislations and must not be discriminatory (RSA 1996b). Minorities must not be excluded based on language. Section 6 on 'Freedom of conscience and religion at public schools' states that religious observance may be conducted at public schools but it must be voluntary. Minorities may observe their own practices at public schools (RSA 1996b). Section 45 of SASA declares that any individual can establish a school at his or her own cost. Minorities can establish schools with a unique ethos based on language, culture and religion as long as it's not discriminatory (RSA 1996b). The South African School Act also does not explicitly refer to minorities, but the above provisions protect the rights of minorities. 


\section{$\square$ Language in education policy}

The preamble of the language in education policy (National Department of Education 1997) recognises cultural diversity and respect for the use of all languages in the country (s. 1). It also highlights the underlying principle to maintain home languages but also to provide access to the acquisition of additional language (s. 5) (National Department of Education 1997). Section 6 emphasises that the right to choose the language of learning and teaching is vested in the individual (National Department of Education 1997). Children of minority groups can, therefore, choose the language of learning and teaching. The following legal case highlights the issues regarding languages. In the case of Matukane and Others v. Laerskool Potgietersrus, the SGB wanted to exclude black learners who wanted instructions in English medium from a parallel medium school. The court found that it is unfair and discriminatory to exclude black learners and ordered the school to admit them (Matukane and Others v. Laerskool Potgietersrus 1996). In the case of Laerskool Middelburg V. Departementshoof, Mpumalanga Departement van Onderwys, the court confirms that the powers of a governing body to adopt a language policy must be inclusive (Laerskool Middelburg v. Departementshoof, Mpumalanga Department van Onderwys 2002). The last example of a relevant legal case is the case of the Minister of Education, Western Cape and others v. Governing Body, Mikro Primary and another. In this case, the education department did not follow the prescribed procedures and the court upheld the language policy adopted by the SGB (Western Cape and others V. Governing Body, Mikro Primary and another 2005). Notably, all the cases involved the Afrikaans language which forms part of a minority grouping in South Africa.

\section{South African languages, religions and culture}

The main languages of South Africa are English, Afrikaans, Zulu, Xhosa, Northern Sotho, Southern Sotho, Tswana, Shangaan, Ndebele, Swazi and Venda; all these are official languages. 
The major religions include Christianity, Islam, Judaism, Hinduism and indigenous beliefs. The population consists of black Africans (41 million or $79.2 \%$ ), white people (4.6 million or $8.9 \%$ ), coloured people (4.6 million or $8.9 \%$ ), Indians/Asians (1.3 million or $2.5 \%$ ), and other nationalities ( 0.3 million or $0.5 \%$ ). It is a challenge to have 11 official languages implemented in all the spheres (academic, governmental, education, etc.) of South African life (RSA 2011).

\section{Education to minorities in Russia: Practices and challenges}

The Advisory Committee on the Framework Convention for the Protection of National Minorities (FCNM) states the following key findings regarding minorities in Russian Federation (FNCM 2018):

Society in Russia is characterised by a climate of appreciation for ethnic diversity; the immense variety of ethnic groups, languages, and religions is perceived as an asset; progress has been observed in residency registration and in the field of minority media.

However, the official rhetoric portraying multicultural societies as failed, marginalization of national minorities against the backdrop of the increasing emphasis on the Russian language and culture, reduction of minority language education, as well as general restrictions on basic freedoms undermine the ability of persons belonging to national minorities to fully exercise their rights. (pp. 5-11)

The European body of the FNMC highlights concerns regarding restrictive legislation and education policy that affects minority rights in Russia.

\section{$\square$ The Russian Constitution}

The Constitution of the Federal Republic of Russia (1993) states the following:

All forms of limitations of human rights on social, racial, national, language or religious grounds shall be prohibited. The State guarantees the equality of human and civil rights and freedoms regardless of sex, race, nationality, language, origin, material and 
official status, place of residence, attitude to religion, convictions, membership of public associations, or of other circumstances and that all people shall be equal before the law and court. (pp. 1-3)

The constitution further guarantees minorities grouping rights in Article 26(2) and Article 68(3) and states that:

Everyone shall have the right to use his or her native language and to a free choice of the language of communication, upbringing, education and creative work (Art. 26(2)). And that the Russian Federation shall guarantee to all of its peoples the right to preserve their native language and to create conditions for its study and development. (Art. 68[3])

Article 29(2) targets propaganda and states that:

Propaganda or agitation, which arouses social, racial, national or religious hatred and hostility shall be prohibited and that Propaganda of social, racial, national, religious or linguistic supremacy shall also be prohibited. (Art. 29[2])

The Federal Republic of Russia's legislative framework protects minority groupings. Russians cannot discriminate or propagandise against minorities.

\section{$\square$ Language and cultural legislation}

The law about the language of the people of the Federal Republic of Russia (1991) protects the right of minorities regarding language. Article 9(2) on rights on language says that everyone has the right to receive basic general education in one's native language and the right to choose the language of instruction.

Regarding cultural rights for minorities, the federal law prescribes that the Russian government must establish national cultural autonomies for the linguistic, educational and national cultural development of minority communities (MRGI 2020).

\section{$\square$ Russian language, religions and culture}

The main language in Russia is Russian and the main religions are Shamanism, Islam, Eastern Orthodox Christianity and Buddhism (MRGI 2020). The biggest minority groups of Russia are Chuvash 
1435872 (1.05\%), Tatars 5310649 (3.87\%), Avars 912090 (0.66\%), Bashkirs 1584554 (1.15\%), Ukrainians 1927988 (1.4\%), Chechens 1431360 (1.04\%), Armenians 1182388 (0.86\%) and Mordovans 744237 (0.54\%). The remaining 8.5\% of the population is made up of other, much smaller ethnicities (Federal Republic of Russia 2010; MRGI 2020).

\section{Education to minorities in India: Practices and challenges}

\section{$\square$ The Constitution of the Republic of India}

The preamble of Constitution of the Republic of India (1950) states that India is a 'sovereign socialist secular democratic republic'. India secures all its citizens equally regarding status and opportunity, fraternity in assuring the dignity of the individual and the unity of the nation, and social-, economical- and political justice as well as liberty through expression, belief, faith and worship. Securing these rights in the constitution for all citizens implies that minorities have the same rights. Article 29 of the Constitution of India focuses on the cultural and educational rights of minorities and states in Subsection 1 that 'any section of the citizens residing in the territory of India or any part thereof having a distinct language, script or culture of its own shall have the right to conserve the same'. Subsection 2 states that (Republic of India 1950):

$[N]$ o citizen shall be denied admission into any educational institution maintained by the State or receiving aid out of State funds on grounds only of religion, race, caste, language or any of them. (p. 30)

The constitution further highlights the importance of the rights of minorities in Article 30 of the Constitution of India, which declares that (Republic of India 1950):

$[A]$ Il minorities, whether based on religion or language, shall have the right to establish and administer educational institutions of their choice and secondly that the State shall not, in granting aid to educational institutions, discriminate against any educational institution on the ground that it is under the management of a minority, whether based on religion or language. (p. 30) 
Article 30 gives rights to minorities 'to establish and manage the educational institution and prevents the state from discriminating whilst granting aid to these educational institutions' (Republic of India 1950).

\section{$\square$ India's Ministry of Minority Affairs}

The Ministry of Minority Affairs was established in 2006 to ensure a more direct approach towards affairs relating to identified minority communities, namely Jains, Sikhs, Buddhists, Christians, Parsis and Muslims. The ministry must plan and formulate policy; coordinate, evaluate and review the regulatory framework and development of relevant programmes for the benefit of minority communities (Republic of India 2020). The vision and mission of the Ministry of Minority Affairs are to empower minorities and create a validatory environment for strengthening the multireligious, multi-racial, multi-ethnic, multicultural, multilingual and multi-characteristic facet of India. The vision and mission of the Ministry of Minority Affairs also aim to ameliorate the socioeconomic situation for minority communities through inclusive development and affirmative action and to facilitate an equitable share for minorities in economic activities, employment and education to ensure their upliftment. India has realised the importance of the protection of minorities and has a dedicated ministry to advance and protect their interests.

\section{$\square$ Indian prime minister's new 15-point programme for the welfare of minorities}

India prioritises the status of minorities. In 2009, the prime minister of the Republic of India adapted and prioritise a 15-point programme for minorities, which was first communicated by Indira Gandhi in 1985 (Republic of India 2009). This programme focuses on the following four pillars: Prevention and control of communal riots; improving the conditions of living for minorities; enhancing opportunities for education; and equitable share in economic activities and employment (Republic of India 2009). 
Education for minorities and opportunities for enhancing the same will be the focus.

The 15-point programme firstly focuses on education for minorities to outline the equitable availability of ICDS (Republic of India 2009):

- The ICDS scheme is focused on an all-encompassing advancement of kids and pregnant and lactating mothers from burdened areas by offering all types of assistance through Anganwadi centres, for example strengthening nourishment, inoculation, wellbeing registration, referral administration, pre-school and non-formal training.

- A specific level of ICDS tasks and Anganwadi centres are established in villages and towns with a considerable minority networks to guarantee that the advantages of this plan are accessible to such networks.

- Improving access to school education: Under the Sarva Shiksha Abhiyan, the Kasturba Gandhi Balika Vidyalaya scheme and other comparative government plans guarantee that a specific level of every single such school is located in towns and territories having a considerable minority population.

- Greater assets for teaching Urdu: Central government's help will accommodate enrolment and posting of Urdu language instructors in lower and upper elementary schools that serve Muslim population, wherein at least one-fourth have a place with Urdu language gathering.

- Provide basic educational infrastructure and resources for the modernisation of the Madarsa education.

- Scholarships for meritorious students for minority groupings.

- Improving instructive framework through the Maulana Azad Education Foundation (MAEF): The government gives all conceivable help to MAEF to fortify and empower it to extend its exercises all the more successfully. Brazil, Russia, South Africa, and China can empower minority rights by following the Indian model. The Republic of India has a dedicated ministry to protect and enhance the minority grouping with focus on education. 


\section{$\square$ Indian languages, religions and culture}

The main languages of the Republic of India are Hindi (official), English and Urdu. The major religions are Islam, Hinduism, Buddhism, Christianity, Jainism, Judaism and Sikhism. Minority grouping of the population includes the Dalits (166.6 million or $16 \%$ ), Muslims (120 million or $13.4 \%$ ), Adivasis (84 million or $8 \%$ ), Nagas (100000 or 0.1\%), Christians (25080000 or 2.4\%), Sikhs ( 14800000 or $1.9 \%$ ), Kashmiris (9 million or $0.9 \%$ ) and other groups, which include Anglo-Indians, Jews, Buddhists, Parsis and the Andaman Islanders (Census India 2011). The diversity of India's minority groups regarding language, culture and religion is quite clear.

\section{Education to minorities in China: Practices and challenges}

China is often considered as a country for the Chinese, where only Chinese people are found. This is true, but most probably because of its demographic size of more than 1.3 billion people, the minority groups are less 'visible'. China is recognised as a state that is unitary but of multi-national nature. The multi-national nature is characterised by the fact that 55 officially ethnic minorities with a population of about 113 million live in China. These groups live in about $60 \%$ of the country and are primarily found in the northwest, north, northeast, south and southwest border areas of China. The Han is the largest ethnic group in China and constitutes about $92 \%$ of the Chinese community. The major officially recognised minority groups in China are the Manchu, Zhuang, Tujia, Hui, Dai, Uyghur, Miao, Tibetan, Li, Mongol, Dong, Buyei, Yao, Bai, Korean, Hani, Kazakh and the Yi as well as undistinguished ethnic groups such as the Chuanging people. The minorities use more than 80 languages that have developed from five language-families, of which about 30 languages can be communicated in written form, whilst others have no written basis (Wang 2013:50). 
The national societal landscape of the Han majority and many minority groups is further explained by the fact that widespread poverty characterised the situation in minority areas (Sautman 1999:287). The economically based differences amongst the majority and minorities were primarily the result of market reforms, financial decentralisation and economic globalisation that occurred after the 1960s. The inequalities were also the result of the rise of Chinese middle class, a change in the general status of women, a new discovery and appreciation of ethnic identities, the remoteness of the areas where the largest number of minorities are found, an increased rural-to-urban migration as well as the distinct cultural differences of the minorities that had complicated the integration of minorities in the broader modern Chinese economical and living arena (Zhu 2010:13, 18). To change this 'institutionalised' ethnic inequality, it was included in the New China's constitution that the state must particularly support all the minority groups during the period of economic and cultural changes in China in order to capacitate them to become a full part of the Chinese community (Lang Weiwei 2010:45).

In order to enable minorities to escape from poverty and differences in relation to the majorities, governmental actions were taken, which included the implementation of preferential policies the support the guided development of minority groups. These policies were characterised by the fact that they were targeted to specific areas, and were flexible and linked to particular time frames (Lang Weiwei 2010:45-47). Education was generally regarded as the obvious solution to the societal problems that minorities experienced, particularly regarding increased participation of minorities in higher education (Wang 2013:55). Thus, during the years prior to the significant changes that followed the cultural revolution in China (1966-1976), the government started to emphasise the principle of 'equality within class' (Zhiyong Zhu 2010:14) that prioritised the educational rights of the underprivileged, such as the minority groups, but obviously impacted the rights of other classes. In order to implement such 'discriminatory policies', the government had to 
convince the majority and minorities that these changes would result in the economic empowerment of all Chinese citizens, enable the participation of minorities in mainstream activities and that it would build interethnic unity that would finally support the development of the Chinese nation-state (Wang 2013:60).

\section{$\square$ Policy provisions}

In order to facilitate the attempts to improve the situation of disempowerment, poverty and lack of opportunities that were experienced by the minority societies, it was included in the Constitution of China that all citizens are equal before the law (Wang 2013:48). By accepting this point of departure to approach ethnic problems and to improve interethnic cooperation, the principle of ethnic equality was accepted (Lang Weiwei 2010:45). In the constitution, it was documented that the state would provide directed financial, material and technical assistance to officially recognised minority groups and that preferential policies would be instituted to accelerate their economic and societal development. Hereby, the ultimate aim of 'equality-in-fact' was entrenched (Sautman 1999:287-288). However, it was realised that these practices of horizontal and vertical equity do not necessarily implies that treating everyone equally does not imply that everyone would achieve educational equality, but that the internal and implicit inequalities amongst groups should be well taken into regard (Wang 2013:49).

As a consequence of the integrated societal context of education in China, the educational policy recognised and built on the importance of acquired competencies that are acquired through education and the value of equal educational opportunities for all its citizens, including the members of minority groups (Zhiyong Zhu 2010:14). The education policy shifted from an acceptance of inherited merit, namely the students were only selected based on their academic performance, to the equality of rights in which more aspects than the 'inherited privileges' were recognised. Since the 1990s, the consolidation of 
several policies that entrenched the preferential education provisioning to minorities occurred (Wang 2013:51, 55).

\section{$\square$ Administration of education}

The Ministry of Education is the central executive organisation with the responsibility for the implementation and development of education in China. It is responsible for policy development and implementation and coordination of the work of several agencies at macro-level that are involved in the control of education. However, the Ministry of Education is primarily directly responsible for higher education, whilst the actual control of primary and secondary education is decentralised to different local authorities on provincial, county and township levels (Yang 2008:435-436).

Therefore, the implementation of the policies regarding education provisioning to the recognised minority groups is executed by all education administrations on central, provincial and county levels. These policies have to be flexibly implemented according to each minority's unique situations and contexts. It has to be ensured that the policies that were deliberately preferentially skewed according to the needs of minority groups are implemented correctly. Thus, the education authorities of a highly centralised education system take the responsibility for the education policies with regards to minorities. They must plan, legislate, fund and evaluate the education for these minorities (Wang 2013:56).

\section{Sufficient funding as the keystone for successful education to minorities}

The central education administration of China went a long way to provide sufficient funding for the successful implementation and it started with a significant increase in the budget for minority educational opportunities (Sautman 1999:293). Students from minority groups were supported with special subsidies, especially 
at higher levels of education and a stipend system was started to assist college minority students to cover their own living costs (Wang 2013:52). Boarding schools were also provided to minority students and a higher proportion of them receive state grants than Han students (Sautman 1999:293).

\section{$\square$ The role of school system in minority education}

Compulsory education in China is of 9 years' duration. Its primary aim, as realised in the education practice, is to prepare students for university entrance examinations, rather than to support them to acquire relevant competencies required in their lives (Davey, Chuan De Lian \& Higgins 2007:386, 387, 392). On the other hand, it is reported that the 2020 blueprint for education reforms has urged educational authorities and practitioners to support the development of an innovation society in China. Thus, for example universities are tasked to select and develop the elite cohort of quality students and contribute to the development of diverse potentials according to the diverse needs of students, including the unique needs of minority students (Ross \& Wang 2010:5). Furthermore, the minority students are also allowed and encouraged to use their own national languages and retain and value their own culture and related practices (Wang 2013:52).

Regarding the college system, the effect of provisioning of preferential education to minorities can particularly be noticed in higher education. A large number of HEls are available that are almost exclusively accessible to the students of ethnical minorities, and this has tremendously contributed to the admission of minorities into higher education. However, the quality and relevance of these institutions are often questioned. Universities and colleges recruit their students though the National College Entrance Examination. It is the end-of-school examination and written at the end of the Spring semester of mainland China. It serves as the main official criterion to secure admission to HEls. The preferential policies have taken effect at the lowering of admission scores of minority students by up to 
20 marks below the national standard scores and quite often without the requirement of a foreign language. It is expected that minorities will have an admission advantage if their marks are the same as that of Han students. Furthermore, preparatory courses are available to support promising minority students who failed to succeed during their previous attempts to gain admissions in the institutions of higher education. It is also noteworthy to note that the ethnic minority students sign contracts to return to their home areas after completing their education in order to enrich the development of those developing minority areas (Lang Weiwei 2010:42; Sautman 1999:293; Wang 2013:51, 56).

\section{$\square$ Findings regarding education to minorities in China}

The positive effects of affirmative preferential action are clearly noted in the Chinese education system. Similar to the situation in the Xinjiang area, the existing ethnic inequalities clearly diminished and the throughput of minorities to middle schools and tertiary education was positively influenced by the preferential actions of education. The result was that ethnic inequalities also decreased in occupational fields. The affirmative actions in education have resulted in an individual of a minority group with relevant qualifications having a better opportunity to be appointed at an elite position than an equally educated Han person. This indicates that the government's preferential measures have played the intended role of enlarging and diversifying the minority middle classes in China and they getting access to higher education (Sautman 1999:294).

Some commentators are of the opinion that the policies of preferential treatment have had unintended consequences in that the equality in educational opportunities to all Chinese citizens, as included in the constitution and other policies, is threatened because the equal rights of Han people are less 
supported than those of minorities. Understandably, the HanChinese were dissatisfied and strongly objected to the unintended effects of affirmative actions (Zhiyong Zhu 2010:21).

\section{Education to minorities in Brazil: Practices and challenges \\ Brazilian legislation}

The Constitution of Brazil (Republic of Brazil 1988) states that racial discrimination is a crime subjected to punishment by law. Article 5 of the federal constitution of 1988 indicates that all persons are equal before the law regardless of class, and all Brazilians and foreign nationals residing in the country are guaranteed the inviolable rights to life, liberty, equality, security and property (Republic of Brazil 1988). Article 5, Subsection 41 directs the punishment for all acts against fundamental human rights and liberties, and Subsection 42 states that racism is a crime where bail is not an option and the person is liable for imprisonment. The Constitution of Brazil in its Article 215 also has protection for indigenous and Afro-Brazilian cultures. Article 215 states that the national government shall guarantee to all full exercise of cultural rights and access to the resources of national culture and shall support and grant incentives for appreciation and diffusion of cultural expressions (Republic of Brazil 1988). Paragraphs 1 and 2 of Article 215 further direct the government to protect expressions of popular, indigenous and Afro-Brazilian cultures and those of other participant groups in the process of national civilisation. The law shall also provide for establishing highly significant commemorative dates for various national ethnic segments.

Law 7716 (Republic of Brazil 1989) on racism was passed in 1989 and criminalised a range of discriminatory transgressions. Law 7716 was adapted in 1997 and included hate speech. Hate speech still remains a problem and has become the norm of Brazilian society (Civicus 2019). 


\section{$\square$ Brazilian languages, religions and culture}

The languages spoken in Brazil include Portuguese and 274 indigenous languages. In larger demographical areas, indigenous people have a higher possibility of ensuring their languages, whilst in less populous communities, indigenous languages are moving towards extinction, for example the Umutina people (MRGI 2020).

Religiously speaking, the major faiths are Indigenous religions, Judaism, Christianity and Afro-Brazilian religions. Minorities include mixed ethnicity (43.1\%), Afro-Brazilians (50.7\%), Asians (1.1\%) and black people (7.6\%). The indigenous minorities (0.4\%) include Potiguara (20 554), Tikúna (46 045), Xavante (19 259), Guarani Kaiowá (43 401), Kaingang (37 470), Mundurukú (13 103), Makuxí (28 912), Terena (28 845), Yanomámi (21 982), Pataxó (13 588), Sateré-Mawé (13 310), Múra (12 479), Baré (11 990) and Xucuru (12 471) (Instituto Brasileiro de Geografia e Estatística [IBGE] 2010). Indigenous peoples live in every state of Brazil and represent 305 different ethnic groups (MRGI 2020).

\section{Conclusion}

The chapter has raised immense challenges faced by the BRICS member states regarding education for minorities. Legally and constitutionally, the BRICS countries protect human rights regarding non-discrimination and the establishment of schools with a unique cultural and linguistic ethos. India is an example of a country with its own ministry for minorities and the other BRICS member states could also look at the possibility of having an independent ministry to focus on minority rights. In the Brazilian context, hate speech and racism are punishable by law with strict measures regarding bail limitations and imprisonment. In South Africa, the law states the difficulties regarding education in mother tongue. Although legislation protects minorities' education, it seems that it is still a big challenge to implement. The BRICS member states should highlight the plight of minorities 
in their annual summit. Because of the fact that all the member states have different languages, culture and religions, it is difficult to fully protect minority rights of education. This research also accentuates the need for a separate look into minority education in the BRICS member states. 



\section{Chapter 7}

\section{Models of trilingual education in China and the relevance thereof for South Africa}

Charl C. Wolhuter

Subject Group Comparative and International Education, Education and Human Rights in Diversity Research Unit, Faculty of Education, North-West University, Potchefstroom, South Africa

\section{Abstract}

In South Africa, the public and scholarly discourse about language of learning and teaching is trapped in a narrow discourse of mother tongue versus English (with at most an occasional mooting of parallel or dual medium). Yet large-scale surveys of parents have shown what many parents want is not an 'either/or' choice. In China, where the constitution duly recognises 
55 minorities, and where the role of English as an international lingua franca is appreciated and vigorously promoted in education, there have been in existence a number of models of trilingual education, varying in different parts of the country according to the context. Prof. Bob Adamson of the Education University of Hong Kong has conducted an extensive research on these models, culminating in a publication (The findings of this research are synthesised in Feng \& Adamson 2014). In 2018, the present author spent a sabbatical as a visiting professor at the Education University of Hong Kong under Prof. Adamson. It is not always appreciated that China is also actively busy to find a way of accommodating language diversity in education. Feng and Adamson (2014) distinguished between four models of trilingual education in China: the accretive, the balanced, the transition and the depreciative models. The language context of China could be summarised as Mandarin being the hegemonic indigenous language of the majority. Myriad minority languages exist, as does the necessity of English as an international lingua franca - a situation not wholly incomparable to South Africa. Very noteworthy, for example, is the existence of 15 universities for minorities in China. This chapter surveys the experience of trilingual education models in China and spells out its relevance for South African education.

Keywords: China; Comparative and international education; Immersion programmes; Multilingual education; South Africa.

\section{Introduction}

In the first orientation chapter of this volume, language of learning and teaching was identified as one of the most critical issues in South African education. In Chapter 2, the value of international comparative perspectives in illuminating domestic educational issues was explained, and the potential of the BRICS countries as tertium comparationis for South African education was motivated. Then in Chapter 4, the longer experience of independent India regarding the handling of language of 
learning and teaching was reconstructed and the relevance thereof for South Africa at this point in time was extracted. It was concluded firstly that, in view of the Indian experience, the battle to push back English as a language of learning and teaching in South African educational institutions represents a forlorn hope; and secondly, it seems advisable to consider changing the approach to preserve and empower languages other than English as languages of learning and teaching in South Africa from a unilingual to bilingual or multilingual approach.

China has risen in recent years as one country - a BRICS country at that - where models of trilingual education have been experimented with (see eds. Feng \& Adamson 2015). The aim of this chapter is to reconstruct the Chinese experiment with trilingual education, and to spell out the relevance of that exercise for South Africa at this point in time. The chapter commences with a section outlining the pivotal importance of language of learning and teaching in any educational project. The South African (societal and educational) situation is then surveyed, as well as the direction pointed to by the Indian experience, and why the Indian case should be complemented with the case of China in any exercise of illuminating the South African issue of language of learning and teaching in education with international comparative perspectives. The Chinese societal and educational contexts are then surveyed, and the evolution of models of trilingual education within that context is reconstructed. In conclusion, the relevance of the case of China for South Africa is spelled out.

\section{The pivotal importance of language of learning and teaching in any educational project}

In their explication of factors involved in determining the quality of education (in any educational institution or education system), Wolhuter and Van der Walt (2018:476) identify language of learning and teaching as one factor. The rule of thumb is, as was 
explained in Chapter 4, that the first language of the learner is the preferred language of learning and teaching, making for better learning, better educational outcomes and, therefore, higher quality of education.

Educational institutions are teaching-learning institutions. In education, the classic theory of educational (i.e. learning) objectives is that of Benjamin Bloom, originally spelled out in his Taxonomy of educational objectives: The classification of educational goals (Bloom et al. 1956) but modified during the course of time, the last much-cited modification was done by Anderson et al. (2001). The objectives found in this taxonomy include knowledge, understanding, application, analysis, synthesis, evaluation and creativity. Even the most cursory look at these objectives reveals the pivotal role of language. For example, the most basic objectives, knowing and understanding any bit of knowledge depends on the learner understanding the words expressing the language. For higher-order learning objectives, such as creativity or synthesis, this holds even more truth. The same goes for the development of cognitive faculties such as independent and critical thinking. As was explained in Chapter 4, the desirability of the first language as a language of learning and teaching, in achieving these objects, is well confirmed by empirical research, and has also been taken up in the creed of human rights and accepted right up to the UNESCO.

On the other hand, in both India and South Africa (and especially in the Global South these are by no means exceptions), the first language as a language of learning and teaching does not come as its right. It is here that the present author wishes to bring into calculation the objectives or advantages of education for the learner beyond his or her own cognitive development.

The advantages a learner accrues from education and the mastering of language(s) as part of that education can be expressed as capital. The education or learning and teaching process equips the learner with various forms of capital, either directly or indirectly. A modified version of Bourdieu's (1986) 
taxonomy of capital is used, namely physical, intellectual, social and symbolic capital. A graduate then uses this capital to navigate his or her way through the society. Physical or economic capital is the financial resources a person can generate on the strength of his or her education and command over languages. Cultural or intellectual capital is the intellectual-cognitive resources a person possesses to navigate his or her way in the society. This does not only include knowledge gained by means of formal education but also, for example, the fluency in the lingua franca of the society. By social capital, Bourdieu (1986) means the means to exert power on other individuals or groups in the society who (can) mobilise resources.

The role of languages and specifically languages as organic part of any educational enterprise, according to the learner with various forms of capital, leads to the next consideration, namely the multilingual nature of modern societies. One of the signature trends of the contemporary world is the increasingly multicultural society, including increasingly multilingual composition of societies (see Wolhuter 2018). This is not only a horizontal diversification (i.e. different first-language communities living side by side in the same geographic area) but also vertical diversity, that is, different languages being used in different domains. Far from (only or simplistically) promoting the hegemony of one language, globalisation has created a strong imperative and reality for people to be multilingual (see King 2018). However, the nature of this multilingual world can easily be a force strengthening inequalities and other discontents (see eds. Arnaut et al. 2015; Blommaert 2010). The same goes for the way language of learning and teaching is handled. A striking illustration coming here to mind is Rubagumya's (1991) analysis of how language as a medium of education has served to reinforce socio-economic disparities in Tanzania. Tanzanian society is an example of triglossia: three languages used in various domains people communicate in their first language in villages, they use Swahili in towns, post-offices and market places, and English in the first world globalised economy of Dar es Salaam metropolis. 
The poorest of children in rural Tanzania hear only their first language and are severely hampered when entering primary schools where the language of learning and teaching is Swahili. The town children have it easy but are severely hampered upon entering secondary schools, much more higher education (in the unlikely event they can make it as far as the entrance gate of higher educational institutions) where the language of learning and teaching is English. The middle-class and upper-class urban children, for whom English is not so much a foreign language, are at advantage upon entering secondary and tertiary educational institutions. Thus, the educational dispensation serves to reinforce inequalities, doom rural children to stay in the poorest of poor class in villages, town children to proceed no further than primary school and thus unable to move further than the town people class, and the privileged urban middle- and upper-class children to proceed for successful completion of secondary school cycle and to higher education.

One the other hand, multilingualism also (and then specifically) as a medium in educational institutions, if correctly handled within the realities of a particular context, can also be a powerful asset. An example of this is the Double Iceberg Theory of Jim Cummings - one of the world's leading authorities on bilingual education. According to Cummings, concepts learned in the first language can be transferred to the second language (as explained by Barzalo 2020). Thus, the first language facilitates the learning of the second language.

The merits of a bilingual or multilingual approach to the issue of language medium in education was brought most forcefully to the foreground by the research conducted by Canadian psychologist and professor at McGill University, Wallace E. Lambert (1922-2009) and the St. Lambert School Project in Quebec, Canada. The precursor to this project was research conducted by Wallace Lambert and Elizabeth Peal, published in their 1962 article, 'The relationship of bilingualism to intelligence', in which they came, on the basis of their empirical research, to the conclusion that bilingualism in children positively correlates 
with cognitive performance, both verbal and nonverbal tests, hence taking the issue with the popular belief hitherto that bilingualism in children is associated with impaired or decreased cognitive performance (Lambert \& Peale 1962). Subsequently, in 1965, a group of parents, uncomfortable with the fact that their children were growing up as English monolinguals in the predominantly French-speaking Quebec, instituted French immersion programmes in the school in their community of St. Lambert, Quebec (see Melikoff 2018). These parents secured the assistance of Lambert and other authorities on bilingualism. As part of this project, Lambert and Tucker (1972) set up an experiment in which there were two groups of English-speaking children. One group had some subjects taught in French, with the remaining subjects taught in English, whilst the other group received all their lessons in English. Lambert and Tucker's (1972) objective was to determine whether learning French would be to the benefit of the English-speaking children. After 4 years, the children of the two groups were compared in terms of their attitudes towards the Francophone community as well as their academic scores. On both counts the immersion group outperformed those who received instructions in English only. From the theories of linguists, such as Chomsky (1959) and Krashen (1982), it is said in favour of immersion models of education that according to the comprehensible input hypothesis (Krashen 1982), when learning of subjects is through their second language, the learners are inevitably exposed to more comprehensible second language input, which then triggers the innate language acquisition device and results in better and faster learning and command over the second language.

These findings and the work of Lambert and colleagues and the St. Lambert experiment have changed Canadians' views on bilingualism and Canadian parents became less reticent about having their children learn two languages (e.g. French and English) (Manitoba Bureau de l'éducation Française 2007).

It is within the above framework that the evolved models of trilingual education in China and the relevance of the Chinese 
experience for South Africa will be looked at in the remainder of this chapter: Of the contemporary world, more and more a world of multilingualism and language in education being a source of various forms of capital or a negative force, depending on how it figures in the education system. Thus, this chapter proceeds beyond the paradigm of the either, that is, the paradigm of the first language or English as a language of learning and teaching paying heed to May's (ed. 2014) criticism to the current scholarly and public discourses on language of learning and teaching as being stuck in paradigms long ago being overtaken and rendered anachronistic by reality.

\section{The language situation in South Africa and what can be learned from India}

To recapture from Chapter 4, South Africa has 11 official languages. These are (in parenthesis appears the percentage of population speaking that language as their first language): isiZulu (23.8\%), isiXhosa (17.6\%), Afrikaans (13.3\%), Sepedi (9.4\%), English (8.2\%), Setswana (8.2\%), Sesotho (7.9\%), Xitsonga (4.4\%), siSwati (2.7\%), Tshivenda (2.3\%) and isiNdebele (1.6\%) (RSA 2018). Furthermore, there are - according to the best of estimates - about 6 million (legal and illegal) immigrants, complicating the language situation even more.

To commence with, because of inter-marriage, 'first language' and 'home language' are not the same in case of many people. Secondly, languages in terms of the first language or home language, speakers are not located in geographically compartmentalised and mutually isolated areas. The best that can be exercised is to delimit areas or what can be termed as 'heartlands' (a term that has, unfortunately, fallen into some political controversy) of languages, where there are identifiable concentrations of speakers of particular languages.

Thirdly, the languages have unequal patterns of historical development of empowerment. English with a long history of a written language has become the international lingua franca of 
a globalised world, particularly the international lingua franca of the academic world, and also nationally of the publishing industry and the commercial and business world. Afrikaans has a written history of over a 100 years (if its progenitor language Dutch is included, it has a history of almost a millennium), and in a space of a 100 years, it has developed and empowered not only as a language of learning and teaching in educational institutions, right up to higher education, but also as a carrier of cultural expression and as a language of political, business, industrial, military, journalism and sport world, although it has never, not even remotely carried the same cultural, symbolic and even the economic capital, generating potential as has been affected by English. The other nine official languages lag behind English and Afrikaans regarding empowerment in the domains of their usage. None of these languages has ever been developed as a medium of instruction in educational institutions beyond the third year of school.

The language division to a large extent is coterminous with racial divide. As power relations and gravity of politics changed after 1994, Afrikaans no longer had the backing of politically powerful, and, in fact, many speakers feel the language is singled out by the new political masters to be marginalised and even suppressed in glaring contradictions of constitutional provisions (Bill of Human Rights).

Historically, comparable to the situation elsewhere, in at least Anglophone sub-Saharan Africa, the situation has developed where the dominant first language within the catchment area of the school is used as a language of learning and teaching, with the exception of Afrikaans, which during the 20th century was developed and empowered as a language of learning and teaching right up to postgraduate study at university level. Once again, totally against the letter and spirit of the constitution, the Bill of Human Rights, since 1994, Afrikaans has been marginalised and even abolished as the language of learning and teaching in educational institutions. Moreover, not much enthusiasm was showed nor any resources allocated to the empowerment and 
development of indigenous African languages as a medium of instruction in educational institutions.

The case of India, with its longer history as an independent nation, was investigated as a possible object lesson for South Africa in Chapter 4. What transpired was the futility of attempting to wage a campaign to dislodge English and replace it with indigenous languages as languages of learning and teaching in educational institutions despite its longer history and India having regionally more concentrated languages and its national government's efforts to promote the strongest indigenous language, Hindi, and the fact that the promotion of other indigenous languages has been on political agenda. South Africa does not have these advantages. The experience of India points to a futility of attempts made to dislodge the hegemonic position of English as a language of learning and teaching in educational institutions and replace it with indigenous languages; however, strong arguments could be made from an educational point of view for such a change. Hence, another angle has to be considered to retain or develop other languages as a medium of instruction in educational institutions. It is here, in view of the de facto situation of rising multilingual societies, that the multilingual model of languages has emerged.

The situation in South Africa is that both scholarly and public discourse on education have stuck in or fixated on a discourse as to either English or the first language as a medium of instruction in educational institutions (e.g. see Spaull 2013). No doubt this framework has been reinforced by government's de facto attempts, assisted by the court rulings and student activism, to marginalise Afrikaans as a language of learning and teaching, and to replace it with English (see Giliomee 2019:316-325; Joubert 2019:172-183). Yet empirical research (which unfortunately has not made its impact on the scholarly discourse, nor has it been taken up in the public discourse) shows that not only are South Africans bilingual or multilingual, they are in favour of bilingual education. A national survey conducted by the Pan South African Language Council found 
that $88 \%$ of South Africans aged more than 15 years are in favour of the development of competence in their first language and English at all levels of education, including higher education, whilst only $12 \%$ are in favour of English as a sole medium of instruction in educational institutions (including $9 \%$ of English first-language speakers; Heugh 2013).

Exploring the potential of a bilingual or multilingual approach to the issue of language of learning and teaching in education, the international comparative perspective is invoked from a BRICS country, following the argument made in Chapter 2 regarding the BRICS countries as suitable tertium comparationis for the illumination of educational issues in South Africa. In view of the basic dictum of comparative and international education that education systems are the outcome of societal contextual forces and can be understood and assessed within the societal contexts in view that they are embedded (see Wolhuter 2015), the societal context of China is first surveyed, followed by an outline of its education system, after which the focus is narrowed to models of trilingual education in China. The situation regarding language of learning and teaching in China is compared with that of South Africa, and in conclusion the relevance of the experience of China for South Africa is spelled out.

\section{China: Societal context}

In terms of total area, China is the fourth largest country in the world, covering an area of about 9.6 million $\mathrm{km}^{2}$. China has 23 provinces, five autonomous regions, and four municipalities directly under the central government (namely, Beijing, Shanghai, Tianjin and Chongqing). The five autonomous regions are Tibet, Guangxi, Xinjiang, Ningxia and Inner Mongolia. These five autonomous regions lie at the fringe or geographical periphery of the country. Furthermore, China has two special administrative regions, namely Hong Kong and Macao.

With a population of 1.39 billion and a population growth rate of $0.56 \%$ (in 2017), China is the most populous country on the globe. 
The one-child-per-family norm instituted in 1979 has resulted in problems regarding the sustained supply of labour force for the economy; however in 2015, this resulted in a change to a two children per family policy, so the population growth rate may well begin to rise soon. China is currently the second largest economy in the world, and has been characterised by exemplary economic growth rate over the past years. Since 1979, China has been the scene of a strange combination of free market economics and strong, centralised one-party rule of a Communist Party. The existence of five autonomous regions should also be seen as exiting within the framework of centralised one-party rule. The case of constitutionally loosely connected to China is the special administrative region of Hong Kong. At the time of writing this chapter (February 2020), for months, there has been semipermanent unrest regarding the autonomy of Hong Kong concerning their own affairs. Although the state officially professes atheism, the religious-philosophical orientations of Confucianism, Taoism and Buddhism are practised by significant sections of Chinese population, with a hold on their faiths and lives, including their ideas and beliefs regarding education.

As far as the linguistic setup of China is concerned, it can be summarised as a trilingual situation.

In the first place, there is a national official language, standard Mandarin. This language has a long historical background. Historically, there were a myriad of horizontal (regional) and vertical (socio-economic strata) varieties of related tongues. The earliest form of a standardised version was Classical Chinese, a written form (not a spoken form) used by intellectually elite and in use since the time of Confucius. Then the Ming (1368-1644) and Qing dynasties (1644-1912) elevated the Beijing local variety to guānhuà (官話), or 'official speech', to the language of the court, followed by civil services. The government of the Republic of China, established in 1912, made more concrete efforts to establish a common national language by setting up a commission on the unification of pronunciation and by publishing a 
dictionary of national pronunciation, which was largely based on the Beijing dialect. This drive for a common national language continued by the government of the People's Republic of China, set up in 1949, and in 1955 they changed the name of the language to pǔtōnghuà (普通話), or 'common speech'. One of the ways through which the standard national Mandarin language was established was education, more about that in the next section.

Secondly, there are a large number of minority first languages. The constitution of China acknowledges 55 minority groups (typically, each has its own language), some of them with substantial numbers of first language speakers: Zhuang (located in the Guangxi Province, bordering Vietnam): 16.9 million, Manchu (located in the far North-East of China) 10.3 million, Uyghur (located in the Xinjiang Province in the North-West of China): 10.1 million, Yi: 8.7 million, Tibetan (located in Tibet): 6.2 million, Mongolian (located in Inner Mongolia): 5.9 million and Korean (located in the north-eastern region adjacent to South Korea and North Korea): 1.8 million. Although these 55 minorities have a total population of 108 million, or merely $9 \%$ of the total population of China, they are pivotal to the geopolitical setup of China. The areas where the minorities dominate demographically occupy $62 \%$ of the total land area of China (Zhang 2012:4). Over $90 \%$ of the border regions of China are occupied by these ethnic groups (Zhang 2012:4). The minority-dominated areas are not only the five autonomous regions but also the numerous ethnic minority autonomous prefectures scattered thought the Han- or Mandarindominated parts of the country.

It should be mentioned that one glaring omission in this scheme of things is the position of Cantonese, a language with some 68 million first-language speakers. It is the majority language of the south-eastern part of China (including the first language of the majority of citizens of Hong Kong). The refusal of the Beijing government to acknowledge Cantonese as an official language, actually an independent language (it considers Cantonese as an impure, substandard form of standard Chinese 
or Mandarin, and therefore discourages its use) is out of step with the gracious accommodation of 55 minority languages in the constitution of China.

Finally, since 1979, with the opening of China to the outside world, when Deng Xiaoping's government took over after the Mao Zedong era (which was characterised by a severe inward turning and orientation, and isolation from the rest of the world), the exigencies of the business world and the rebuilding of China's education sector (which are covered in more detail in ch. 10 of this volume) and the resultant internationalisation of Chinese universities and connecting with the global academic community led it towards English. Moreover, connecting with the world by means of ICT revolution (albeit under strong government censorship) and the aspiration for upward social mobility amongst the new generation have created an insatiable desire to learn English. English as the international lingua franca is therefore became the third component of the trilingual language situation of China.

\section{Education in China}

China has an education history reaching back to millennia. In the historical evolution of Chinese education, the following phases can be distinguished (Wolhuter 2020):

- Traditional Chinese society.

- China under western influence.

- Period of Marxism and Sovietisation of education.

- Post-1979 modernisation.

\section{Traditional Chinese education}

Education is highly valued in traditional Chinese culture. The first formal schools were established during the reign of Shun (2233-2148 BC), one of the five Chinese emperors. Schools were 
élitist institutions where specialised government employees taught the sons of the noble. Teaching content revolved around relationship and ethics. These tenets were reinforced by the teachings of Confucius, who taught one and a half millennia later. Confucianism was essentially concerned with personal ethics, good governance, respect for authority, social order and 'good society' (Ryan 2019:20-21).

The system of rigorous state examinations for selecting civil servants was established during the San (581-618 AD) and Tong (678-907 AD) dynasties. This system entrenched the absolutisation of the ethical as the primacy of education, the authoritarian nature of education and the overemphasis of socialisation as educational objective, and as such this had an incalculable impact on Chinese education (Mingyuan 2014:103).

\section{China under western influence}

Two thousand years of cultural continuity was broken by western intrusion from the 15th century onwards. At least three types of western-oriented or western-modelled schools were established. These were as follows: Firstly, foreign language schools for training translators, for example the Peking School of Combined Learning, Shanghai School of Combined Learning, Guangdong School of Combined Learning and Sinkiang Russian School. Secondly, military schools for the training of military officers, such as the Tianjin Navy School, the Tianjin Armament School and the Hubei Armament School. Finally, technology schools were established for the training of technicians, such as the Fuchow Shipping School and the Shanghai Cable School. The aim of these schools was to provide western-type education of practical-technical nature to enable the feudal rulers of the Qing Dynasty to hold their ground. Hence, it was, as observed by Mingyuan (2014:147), not a true modern education in essence. Sending Chinese students to study overseas was another important part of the Westernisation of education in China. 


\section{Period of Marxism and Sovietisation of education from 1949}

As the Red Army of Mao Zedong started to gain upper hand in more and more parts of the country, its ideas were implemented in practice. The Confucian philosophical superstructure of education was replaced by Soviet ideology. In the first few years after 1949, impressive progress was made with the massification of education at lower levels. A 5-year compulsory education (Lenin Schools) was introduced: 3 years of primary school and 2 years of junior secondary, along with the Soviet polytechnic model, that is, children spent part of the school day or school week working on farms or in factories. But the education suffered with socio-political convulsions, which became a feature of the later part of the rule of Mao Zedong (such as the Great Leap Forward and the Cultural Revolution). During the Cultural Revolution, c. 1966-1976, for example, almost all schools and universities were closed for most of the period (Ryan 2019:36). Furthermore, the Cultural Revolution did enormous damage to educational infrastructure and teaching corps (as teachers and lecturers were either killed or had to flee; Ryan 2019:38).

\section{Post-1979 modernisation}

As part of socio-political and economic reforms which commenced in 1979 with the taking over of Deng Xiaoping as the leader, education too underwent a major overhaul. Two key economic changes have been the embracement of the principles of free market economy, and a change from labour-intensive to knowledge-intensive economic activities.

Education was allocated pivotal importance in this modernisation drive of post-1979 China, and substantial public resources were allocated to education. One key project, as evidenced, has been the drive to establish world-class universities in China, which is the theme of a next chapter. 
The first national work conference on education was held by the Central Committee of Chinese Communist Party (CCCCP) and the State Council from 15 May to 20 May 1985. On this occasion, the policy of 9-year compulsory education was drafted. Within the next decade and a half, the Chinese government was largely successful in implementing this 9-year compulsory education throughout China. After the state-examination system was abolished in the early 20th century, gaokao, or the National College Entrance Examination (NCEE), was reintroduced in 1977 on a pilot basis, and rolled out countrywide in 1978.

\section{Hong Kong}

The Special Administration Area of Hong Kong is a special case because of its long period of colonial history, it being strongly connected to the world and its special autonomous status. Its history as a British colony reaches back to 1842. Since inception, there were English-medium schools for both the children of British personnel involved in colonial administration as well as the pro-English local elite. Following the Burney Commission report in 1935, the colonial administration began with Cantonesemedium primary schools, and in 1971, compulsory and free primary school education was introduced, followed by the junior secondary level in 1978. The Education Bureau of the Hong Kong government is responsible for formulating and reviewing policies and legislation related to education at various levels. Most children in Hong Kong attend 3 years of kindergarten (K1-K3) before entering primary school at the age of around 6 . The education system beyond kindergarten has a 6-3-3 ladder: 6 years of primary school (primary 1-6, for children aged 6-11 years), 6 years of secondary school (secondary 1-6, for children aged 12-17 years), and the last consisting of 3 years in junior secondary and 3 years in senior secondary. On completion of secondary 6, students take the Hong Kong Diploma of Secondary Education Examination (HKDSE), a highly centralised 
and competitive system of high stakes public examination admission to institutions of higher education, for example, depends on performance in this examination.

\section{Language in education in China}

\section{Policy}

As explained above under the contextual societal forces shaping education in China, three sets of imperatives regarding language impinge on education in China. These are Mandarin or 'common speech' or pǔtōnghuà (普通話), as a national language and language of the majority of the population; the languages of minority groups and English as international lingua franca. The 1986 Compulsory Basic Education Law, which is the legal basis for the 9-year compulsory schooling was rolled out in the late 1980s, states that Mandarin Chinese will be promoted as the national language in all primary and secondary schools of China.

This privilege provided to Mandarin in education has, of course, to be compromised by the constitutional recognition of 55 minority languages. Candidates sitting for gaokao, that is, NCEE, for example, have the option of writing in one of the six designated minority languages, namely Tibetan, Uyghur, Mongolian, Korean, Kazak and Kirgiz (Ryan 2019:130). This examination comprises Chinese (Mandarin), mathematics, a foreign language (usually English) and three optional subjects.

Finally, regarding the position of English, an official document titled 'Basic requirements for English curriculum education in primary schools' dated February 2001, states that the learning of a language is a precondition for citizens of the 21st century, and declared English as a critically important component of curriculum reform at primary school level. Hence, since 2001, English has become a compulsory part of the basic school curriculum from 
Grade 3 (Wang 2007). In zhongkao or the Senior High School Entrance Examination, students are examined in Chinese, mathematics, English, physics, chemistry, political science and physical education (Ryan 2019:68).

It should be borne in mind that the minorities mostly stay in the geographically peripheral areas of China, that is, not on the eastern coast with its more affluent cities and well integrated with the global economy and society and culture, but on geographical fringe at northern, western and southern border regions. These areas are much poorer, although well endowed with mineral deposits, and contain most of the natural forests of China as well as being the areas where most of the large rivers of China have their fountain heads. Ever since the 1950s, the Beijing government has taken substantial measures to improve education for minorities by not only investing heavily in the education of minorities but also implementing policies to improve access to education. Extra funds have been made available for schools and infrastructure, for teacher education of ethnic minority students, and for the establishment of boarding schools in remote and mountainous areas. Affirmative action policies include lower or exemption from tuition fees (Ryan 2019:130).

In the areas and schools where the majority of learners are Mandarin first-language speakers, however, the Chinese government has done little to promote the teaching of the minority languages of China. In fact, the approach has been rather to concentrate on the promotion of English as a foreign language for children and citizens of China. In the areas where one of the minority languages has significant numbers of firstlanguage speakers, four models of trilingual education (that is, minority language, Mandarin and English) have evolved, used according to the contextual ecology of a particular school. These four models, as identified and described by Adamson and Feng $(2014,2015)$ are the accretive or additive model, the balanced model, the transitional model and the depreciative or subtractive model. 


\section{Model 1: The accretive or additive model}

In this model, the minority language is at its strongest level in the school and education system. All 9-year compulsory schooling is taught through the medium of minority language. Furthermore, the official language of communication in the school (i.e. between principal and teachers, school and parents, on notice boards etc.) is the minority language. Mandarin and English are taught as subjects. This model exists in regions where there is a strong concentration of minority speakers, where such speakers constitute the majority in the catchment areas of the school, and where this language is one of the languages in which gaokao or NCCE can be taken. In Inner Mongolia, many such Mongolianmedium schools exist, and near the Korean border, where there are regions with large numbers of Korean first-language speakers, Korean-medium schools exist. In the regions of China where these types of schools function, Mandarin-speaking learners attend either the schools where Mandarin is the language of learning and teaching or the classes where Mandarin is the language of learning and teaching in the minority languagemedium schools, although in the latter the school would be imbued in the ethos of the minority ethnic group. Educational arrangements are finely attuned to the context. For example, in the peripheral regions close to the Korean border, where the majority of people are first-language Korean speakers, but where official documentation and the majority of books, as found all over China, are in Mandarin; the teaching of Mandarin to both Korean and Mandarin first-language speakers focuses more on the speaking skills (as learners encounter Mandarin more in a written form outside the classroom), whilst the teaching of Korean to both Korean and Mandarin first-language speakers concentrates more on writing skills (being the dominant spoken language of the region, learners encounter Korean outside the classroom in the community more in a spoken form). 


\section{Model 2: The balanced model}

In this second model, a balance is struck between the Chinese and the minority language. The balance refers to both mediums of instruction and ethnicity or the first language of teachers and students. For example, Adamson and Feng (2014:10) related that in one school of their research project, which was a school in Inner Mongolia, the ratio of Mandarin teachers to Mongolian teachers was 30:70, whilst in the case of learners, although a balanced composition exists, it was almost the reverse of the teacher composition, the ratio of Han learners to Mongolian learners was 60:40. Notice boards and official communication were bilingual, and on the playing ground both languages could be heard as well. English was taught as a subject. Other subjects were taught in either Mandarin or the minority language, depending on the fluency of the teacher and the learners.

It should be mentioned regarding this model as well as the additive models that despite gaokao being available in six minority languages and admission requirements to universities of minorities being lower for minority students, empirical research investigating the relation between educational attainment, command over Mandarin language and socio-economic status has found that fluency in Mandarin definitely affects career prospects positively (Tang, Hu \& Yin 2016). Dropout rate for minority students is also higher than for Mandarin first-language speakers, regardless of what type of school the learners attend ( $L u$ et al. 2016). Adamson and Feng (2014:33-34) also remark that the schools, in terms of infrastructure, attended by minority students are worse than the schools attended by Mandarin majority learners. Furthermore, mainly located in the isolated and peripheral parts of China, for minority learners, Chinese is a distant and difficult to learn compared to their own language. Moreover, as a result of their geographical location, minority learners find English also a much more distant and difficult language to learn because they have a much less exposure compared to the metropolitan majority Mandarin-speaking learners. 


\section{Model 3: The transitional model}

This model appears in two varieties. In the first, amongst mixed communities in cities and towns where there are substantial numbers of minority learners besides substantial numbers of Mandarin first-language speakers, the converse of the additive model occurs, that is, Mandarin is employed as a medium of instruction. The dominant minority language of the area is taught as a school subject. The second variant occurs in remote village schools where one minority language dominates. The minority language is used as a medium of instruction during the first years of the primary school cycle, and then in the third or the fourth year, the change is made to Mandarin. In either of these variants, English is taught as a subject. So the common and distinguishing feature of both is the transition to Mandarin. The second variant tends to occur in regions where the minority group is not demographically strong compared to the Mandarin firstlanguage-speaking group and/or where the minority language group looks up to Mandarin or even English as the language to propel the upward social mobility or economic empowerment of their children (Adamson \& Feng 2015:248). In the case of first variant, this occurs in minority language areas where numbers of Mandarin first-language speakers are strong, the relations between Mandarin and minority first-language speakers are good and/or a high degree of assimilation exists between the two language communities.

\section{Model 4: The depreciative or subtractive model}

The depreciative or subtractive model is the one in which although schools claim to be an ethnic minority language schools, in practice they do not employ the minority language as a language of learning and teaching nor even teach it as a school subject. Mandarin and English are taught as subjects in the curriculum and Mandarin serves as a language of learning and teaching. 
These schools can probably more correctly be called bilingual schools, or trilingual as far as the ethnic or linguistic identity of learners is included in the linguistic descriptors of the school. These schools occur where different minorities are found in a community or at a catchment area of school and/or minority speakers do not attach much value to their language and its preservation and development but prefer to invest energy and resources in gaining a better command over dominant language for the sake of career prospects and upward social mobility (Adamson \& Feng 2015:250). It should finally be mentioned that in some schools, especially in metropolitan and well-affluent eastern China, English and Mandarin are beginning to be used as languages of learning and teaching. Furthermore, there is a burgeoning sector of private international English-medium schools in China. In fact, by the end of 2017 China became the world leader with the largest number of English-medium international private schools - 806 such schools were in China at that stage (Keeling 2017).

\section{Universities}

For university-level education, students from minority ethnic groups can choose and attend either one of the mainstream universities or one of the $15 \mathrm{minzu}$ universities or universities of nationalities located all over China. Gaokao entry scores needed to qualify for university admission are lower for minority students in the case of some of these universities. Some courses in these universities are taught through the medium of one of the minority languages - notably the minority language courses (e.g. where the minority language is taught as a subject) and courses of the cultural heritage of minority groups. These universities have as a special mission of preservation and development of cultural heritage of minority groups. The quality of education in these universities vary, as those located in remote areas tend to be poorer in quality (Ryan 2019:133) whereas those in metro politan areas are better endowed and offer higher-quality 
education; some of these have been included amongst the universities selected for China's drive towards building world-class universities - Project 985, Project 212 and the Double First Class Universities Scheme (these impressive policy drives are discussed in more detail in ch. 10 dealing with China's deliberate attempts to establish world-class universities). Leading is the University of Minzu in Beijing (till 2008, its name was the Central Ethnic University). Just for clarification, it is mentioned that the universities for national minorities are not a system of universities for a specific minority group. As its mission, each of these universities has fulfilled the educational needs of all minority groups. Hence, the defining feature of a national minority university is not that the students admitted are exclusively from one particular minority group and the language of that minority group is the language of learning and teaching at that university; rather the defining features are that the probable overconcentration of students from the entire gamut of minorities at these universities, and that courses in minority languages (as subjects) and in the history and cultures of particular minority groups are more abundant at these universities than at the mainline universities.

\section{Hong Kong}

The history of Hong Kong shows policies (a lesser extent practice) regarding language of learning and teaching in schools having oscillated between English and Chinese (first Cantonese, later Mandarin), although especially before the introduction of compulsory schooling up to junior secondary level in 1978, it was for the elite only and dominated by English (see Tam 2011). During the period just before the handover in 1997, government followed a non-interventionist policy. Schools could choose their own policy regarding medium of learning and teaching, and over $90 \%$ of schools used English as a medium, no doubt the higher prestige of English was one reason for this (Lo \& Lo 2014:50). With the rejoining in mainland China, the policy turned towards Mandarin (see Tam 2011). However, this policy to change to Mandarin could not be enforced because of strong public opposition (see Lai 
2013; Lo \& Lo 2014:50-51). At present, about half of schools use English as medium and the other half Mandarin. The situation has developed where the more prestigious schools, better endowed and delivering better results in the HKDSE are English-medium schools. To complicate things, and to make it more problematic, in line with the Beijing government's view that Cantonese is no language in its own right but an impure or substandard variant of Mandarin (even though these two languages are mutually unintelligible; Loh, Tam \& Lau 2017:134), Cantonese is not taught in schools, the subject known as Chinese is Mandarin. But the de facto situation is that when teaching, teachers tend to use Cantonese comprehensibly with the learners. Thus, Hong Kong learners are having a substantial amount of their education through the medium they do not study as a subject.

Learners can write the HKDSE, the Hong Kong version of the mainland gaokao and a highly competitive and high stakes examination, either in English or Mandarin. At university level both English and Cantonese as languages of learning and teaching are encountered. Most universities, especially those with their roots abroad, use English; probably the best known example of this is the University of Hong Kong, the oldest university founded in 1911. In 1964, the second university was established in Hong Kong - the Chinese University of Hong Kong. This was established as a Cantonese-medium university. Hence, all courses are taught in Cantonese, except where the lecturer does not have a sufficient command over Cantonese, in which case English is used.

\section{Comparison}

As explained above, in contrast to a strong global trend visible in China too, the public discourse on the issue of language of learning and teaching from a perspective of multilingual education in South Africa has got stuck on either English or vernacular language as a medium of learning and teaching. Regular monotonous statements with lofty promises are made by policy makers regarding the empowerment and development of 
indigenous languages as languages of learning and teaching; such statements and promises made are totally unrealistic and/ or eventually bring nothing. An example of this is the announcement made in January 2020 by the Eastern Cape Provincial Education Department that learners can henceforth write their matric examinations either in isiXhosa or Sotho (Slatter 2020:8). This was announced despite the fact that no provision was made for using these languages as medium of teaching beyond the third year of school. Therefore, it would take at least 9 years to have the first cohort ready to write their matric examinations in these languages assuming textbooks could be produced, teachers and examiners with a sufficient command over these languages could be found, and the logistics of this could be worked out. It is not surprising that a Sunday newspaper reported that after a month of this announcement all role players were in dark and confused as to how this would work in practice (Slatter 2020:8).

As explained in Chapter 2, a meaningful comparison between education systems is taking into account similarities and differences between the societal and educational contexts of the two systems. Both China and South Africa are multilingual societies (in the sense that there are more than one first language in both countries); both live in a globalised world where English is the lingua franca, and where considerable cultural capital is attached to a command over English. Unlike South Africa, China has one clear dominant indigenous language and the strongest minority languages are geographically more concentrated than in the case of South Africa. An interesting parallel is that both have one strong language, namely Cantonese in China and Afrikaans in South Africa, which are not favoured by the ruling elite and deliberately downscaled and marginalised in terms of policy and political matters, despite having been developed as a medium of education right up to the university level. In China, the discourse and policy development are based on the reality of a multilingual world, whereas in South Africa - at variance with international developments and the reality and even the views of 
the citizenry - the public and scholarly discourse have become stuck in a discussion of vernacular versus English as a language of learning and teaching in education. In China, a number of trilingual education models, giving positive recognition to a minority language, majority language as well as English, have been developed according to a particular contextual ecology.

It is from this last development that South Africa can learn from China. Whilst South Africa does not have China's advantage of geographically concentrated minority languages (at least not to the extent as that in China), it has English which is neither a foreign nor an alien language but is one of the 11 official languages with a substantial number of first-language speakers. Furthermore, in at least six of the nine provinces there are three languages which are the first languages of the majority of population, and with many of the 11 languages being mutually intelligible, the policy of trilingual education, fine-tuned to the contextual ecology of a particular school, is not farfetched.

At the same time, a cautionary note also emanates from the track record of trilingual models of education in China. China could not equalise educational opportunities despite a commendable experiment carried out with trilingual education, signalling that even if trilingual education models can get off the ground, special attention still could be paid to the attainment of equal educational opportunities. Secondly, the models of China are not exemplary in the way that they made the majority Mandarin-speaking learner community acquainted with the minority languages.

\section{Conclusion}

From the track record of trilingual education in China, more so if buttressed with the record of immersion education in Canada (admittedly in a very favourable context, not identical to that of South Africa), it is an experiment well worth testing in South Africa, not as a carbon copy of one or more of the models of China but fine-tuned to the contextual ecology of South African schools and taking heed of the deficiencies of these models as 
they have been built in China. The (current) considerable autonomy that South African schools have in terms of law, gives individual schools much latitude to design and experiment with such models of trilingual or multilingual education, although such schools have to lobby to involve provincial education departments so as to extend opportunities to write the matric examinations in other languages than English and Afrikaans. Universities are also to come into action to promote multilingual education at their level, as without these two components, exercises of multilingual education at primary and secondary school level do not have much chance to succeed. Proponents of such experiments should also know (and be prepared for) that they will encounter considerable bureaucratic and political inertia regarding any efforts to develop any other language than English as a medium of instruction in education, and in the case of Afrikaans, they will probably be met with outright hostility. They will also come up against current plans to curtail the autonomy of schools in South Africa. However, none of these plans are insurmountable. In view of the role of language in determining ultimate educational success for learners, as explained in Chapter 4, the record of trilingual models in China, and immersion programmes in Canada and elsewhere, it is an experiment well worth trying. 


\section{Chapter 8}

\section{Violence and education in the BRICS countries: A comparative study}

Johan Botha

Subject Group Comparative and International Education, Education and Human Rights in Diversity Research Unit, Faculty of Education, North-West University, Potchefstroom, South Africa

Oliver Gore

Subject Group Comparative and International Education, Education and Human Rights in Diversity Research Unit, Faculty of Education, North-West University, Potchefstroom, South Africa

\section{Abstract}

Violence, be it violence in schools or in the society at large, adversely affects human right to education throughout the world. One way of addressing this issue is to gain an

How to cite: Botha, J. \& Gore, O., 2020, 'Violence and education in the BRICS countries: A comparative study', in C.C. Wolhuter (ed.), Critical Issues in South African Education: Illumination from international comparative perspectives from the BRICS countries (BRICS Education Volume 2), pp. 241-265, AOSIS, Cape Town. https://doi.org/10.4102/aosis.2020. BK207.08 
international perspective. The BRICS countries provide a more useful tertium comparationis for South Africa than the countries of the Global North, or the countries in the Global South that are not member of BRICS. This chapter compares the incidence, antecedent causes and attempts to address the deleterious effects of violence on education in the BRICS countries. The prime objective is to show that South Africa can benefit from the experience of other BRICS countries.

Keywords: Bullying; Learners; School-based violence; Schools; Violence.

\section{Introduction}

School violence is a global problem, which can have damaging physical and mental effects on learners' performance in class and their general wellbeing. The World Health Organisation (WHO 2019) found out that close to one billion young people are victims of physical, psychological or sexual violence and neglect, and a global survey conducted in 2019 shows that $40 \%$ of the learners reported to have been bullied within the past month, whilst $34 \%$ of the learners were involved in physical fighting within the past year (WHO 2019). Violence on children is exacerbated by teachers and family members who abuse the very children whom they are supposed to be protecting. Corporal punishment is widespread in schools and is not forbidden in many countries, with half of the school children being vulnerable to victimisation throughout the world (UNICEF 2017:37). It is a matter of considerable concern that children who are victims of violence play truant, perform poorly and are less likely to complete their schooling.

In this chapter, the term 'learners' is used to refer to pupils or scholars who are enrolled in schools or colleges, including those enrolled in technical and vocational colleges in China, and have not yet begun their tertiary education. One of the reasons for increase in violence is that learners are reluctant to report abuse 
as they often lack knowledge about the effects of abuse or are too shocked or frightened to do so.

The WHO (2002:5) highlights that violence involves the deliberate use of physical force and threats by perpetrators against other people who are vulnerable, causing physical and psychological damage or death to the victims. Underpinning this definition is the view that violence does immediate and longterm physical and psychological harm to learners. In schools, this can take the form of poor concentration in class, low school performance, early exit from school, depression, suicide, injuries, murder and illness (Burton \& Leoschut 2013:4). It is vital to address a very common form of violence in schools, that is, bullying, which threatens the safety and wellbeing of learners. Olweus (1993:9) highlights three key traits of bullying: aggression to victims, repeated acts of aggression perpetrated on the victim over time and the choice of victim who has little or no ability to defend themselves. Within the school setting, bullying could result in a pattern of victimisation, hurting others, damaging property, emotional assaults on learners, wielding control over victims, disruption in the proper functioning of school and creation of a school environment that is not favourable to learning (Botha 2007:4; Myburgh \& Poggenpoel 2009:456-457). What should be stressed upon is that bullying is not confined to the school settings only but can take place when a learner participates in school-organised activities or on their way to or back from school (Burton \& Leoschut 2013:3). Although this chapter is concerned with different forms of violence, particular attention is given to bullying because it is very common in schools worldwide. What makes it difficult to address is that it is not easy to detect and monitor because so much of it is indirect and comprises subtle verbal actions.

Besides the negative effects of school violence mentioned above, learners can experience secondary victimisation through fear when they witness violence not related to the victim. For example, children who have either witnessed or experienced 
violence are likely to develop negative feelings about others, which results in their aggression (Spillane-Grieco 2000:413). Learners who underperform or fail in school tend to become delinquent, suggesting a strong association between poor performance in schools and violence and conversely a strong association between good performance and a lack of violence. For instance, Mullis et al. (2016) revealed a significant association between bullying and academic achievement with learners who were performing well, whose grades were above 68\%, reporting not to have been involved in bullying (Reddy et al. 2015:13). Equally relevant is that unemployment in the youth and economic hardships as a result of dropping out of school indirectly feeds into violence in communities. Low-income neighbourhoods with high unemployment amongst the youth tend to experience high levels of school violence. Although school violence can have damaging effects on learners' success, and their present and the future wellbeing, it is a matter of concern that many schools do not provide safe spaces and a friendly environment for learning to happen. However, although they are the sites of violence, schools are also potential spaces for preventing it as they potentially constitute a significant element of learner socialisation, along with family, peer groups and the media (Prezenszky et al. 2018:03). A curriculum designed to raise learners' awareness of violence and to enhance their ability to diffuse it is an essential means of controlling school violence.

The high attrition of learners in South African schools is higher because of the escalating incidents of bullying compared to socio-economic deprivation and disproportionate access to resources in the country. This violates learners' constitutional and human rights to access education. Mitigating violence in the country would thus contribute to meeting the UN's SDG of providing quality education that is accessible to diverse children whilst giving all the children opportunities to pursue their aspirations throughout their lives (UNDP 2016:46).

The persistence of violence in South African schools suggests the need to explore alternative approaches to understand 
violence and bullying so that effective interventions could be designed and implemented. Various meta-analytical studies have discussed strategies to control bullying and violence in schools that have been successfully used in developed countries such as the UK, the United States of America (USA) and Norway (Ttofi \& Farrington 2011:43-48). These strategies include improving learner supervision at schools, enforcing the rules aimed at discouraging violence, encouraging cooperation within the school and ensuring that there is a sound discipline in the classroom. However, it is not necessarily true that these strategies apply to a developing country such as South Africa where there are limited resources and high incidences of violence in its schools (Baker-Henningham et al. 2012:101). The experiences of the BRIC (Brazil, Russia, India and China) countries may offer more relevant ways of preventing school violence.

Consequently, this chapter focuses on violence in the BRICS countries, namely, Brazil, Russia, India, China and South Africa, and compares the patterns and nature of school violence in these countries and their respective attempts to prevent it. The argument presented in this chapter is that violence in schools is complicated as it is influenced by an interplay of multiple factors that include family members, peers, community people, schools and the legislations. Various approaches have been employed to understand school violence in South Africa. Amongst them is the human rights-based approach which foregrounds the notion that all individuals are entitled to human rights. As such, there ought to be an environment in schools and communities that promote individuals' rights to be respected (Botha 2019:187-188). Another viewpoint is the systems' approach that sees the individual and the environment as independent but influencing each other. The individual, family, community and school systems together with the national policy are perceived as pivotal in understanding and addressing violence (SACE 2011:23). Lastly, the mental health approach stresses that individuals who are mentally healthy are integral in promoting safe school environments through positive intrapersonal, interpersonal and environmental relationships (Myburgh \& Poggenpoel 2009:446). Despite the adaptation of 
these approaches, the level of violence in South African schools points to a need to identify alternative approaches; for instance, to acquire international comparative perspectives from the BRICS countries. Because the BRICS countries are at the same stage of economic growth (middle-income or developing), they tend to have common challenges, which they can address collaboratively. Thus, a comparative international perspective amongst the BRICS countries presents alternative models to the frequently used traditional top-down approaches between the developed and developing countries (Rensburg, Motala \& David 2015:816). This means that the BRICS countries are likely to learn more from each other's experiences on preventing school violence than from the developed countries. Controlling violence is pivotal for the growth of the BRICS economies and the wellbeing of their societies in general. The research questions addressed in this chapter are as follows: What are the incidences, antecedent causes of violence and attempts to mitigate violence in schools within the BRICS countries? What lessons can South Africa draw from other BRICS countries? The chapter outlines the approach taken to the literature review before exploring violence in South Africa and case studies conducted in other BRICS countries. Finally, the insights gained are discussed.

\section{Approach to the literature review}

The study employed a document analysis research method to understand the incidence of, forms of and attempts to prevent violence in the BRICS countries. Corbin and Strauss (2008:156) explain that document analysis involves interpretation of data from secondary sources to create meaning with the aim of generating empirical knowledge. The research method is particularly useful for intensive qualitative research where the focus is a single phenomenon, which is school violence in this instance (Stake 1995:xi). We selected, appraised, synthesised and evaluated peer-reviewed documents and media reports on violence within the BRICS countries in this study. We adopted 
the document analysis method in this study because it enabled us to situate the findings within the contexts of each country, track the historical changes and compare the phenomenon across the BRICS countries (Yin 2004:1). We used Google scholar to select peer-reviewed articles, books, policy documents and media reports on school violence. The process involved typing keywords and phrases 'violence' AND 'school' AND 'prevention measures' AND '(country)'. Synonyms such as 'aggression' AND 'learner/students' AND 'mitigating strategies' or 'controlling strategies' AND '(country)' were also used to retrieve documents related to the topic. The dates were not delineated. After retrieving the documents, searching through them involved reading through abstracts and selecting documents that were related to violence for each of the BRICS countries. We also attempted to have a balanced overview of violence in schools through incorporating the perspectives of all of the selected documents when making a synthesis.

Following the selection process, we skimmed through the documents to allow preliminary examination before thorough reading (Bowen 2009:32). The authors then created a table to help organise data where each relevant study was summarised. Thematic analysis of the data followed and this was carried out by identifying the emerging themes from the data for each country, such as incidence of violence, forms of violence, perpetrators of violence, school location, socio-economic background, historical and cultural context, teachers' role, community role, school atmosphere, school and community interventions and legal framework. These emerging themes were then used as analytical units. The above selection and analytical steps allowed us to represent the research material fairly (objectivity) and derive subtle cues to meaning (sensitivity), which address the potential selection and analytical biases associated with the method. The research method was deemed suitable for this study because it allowed broad coverage of violence in schools over a long period of time and in various settings, in this case, the BRICS countries (Yin 2014:10). 
The strengths of the document review method that made us adopt it are: easy access to documents via Internet, less time needed, low cost and the document not being affected by the research process (Bowen 2009:31).

\section{Results from literature on violence in South Africa}

South Africa experiences high incidences of violence in its society. This manifests itself in the form of murders, sexual assaults and murders targeted at the youth, women and the general population. Overall, the number of killings rose from 20336 to 21022 between 2018 and 2019, which positions the number of killings at 58 per day (Africa Check 2019:n.p.). Whilst this indicates how serious the murder is in South African society, gender-based violence is also increasing. Rape, for instance, rose to 72.1 per 100000 in 2018-2019 from 70.5 per 100000 in 2017-2018 (Africa Check 2019:n.p.). Media reports have also highlighted escalating levels of violence that threaten citizens' safety and freedom. Children are also affected by the violence with 1014 of them being killed in 2017-2018 (Africa Check 2019:n.p.) and most of these victims were learners. This positions South Africa as one of the countries in the world with high incidences of violence. When positioned within the context of the BRICS nations, South Africa has the second-highest incidence of bullying after India for learners aged 13 to 15 years. It has the second-highest incidence of homicide after Brazil for adolescents aged 0-19 years, and the third, after China and India, of children aged 13-15 years involved in fighting (see Table 8.1) (Our World in Data 2019).

Seemingly, China has the lowest incidences of violence based on the figures presented in Table 8.1, but the actual prevalence of violence in the country could be higher than reported. Coid et al. (2017:1268) posit that there is underreporting of violence in the country, limited research on the phenomenon and fewer sources of recorded data from government departments to reflect the 
TABLE 8.1: A synopsis of violence in South Africa compared to Brazil, Russia, India and China for children in 2015.

\begin{tabular}{|c|c|c|c|c|c|}
\hline Prevalence of violence & $\begin{array}{l}\text { South } \\
\text { Africa }\end{array}$ & Brazil & Russia & India & China \\
\hline $\begin{array}{l}\text { Proportion of children (aged } \\
13-15 \text { years) who indicated to } \\
\text { have been bullied in the past } \\
\text { few months }\end{array}$ & $37.40 \%$ & $31.60 \%$ & $33 \%$ & $40.30 \%$ & $29 \%$ \\
\hline $\begin{array}{l}\text { Proportion of children (aged } \\
13-15 \text { years) who indicated to } \\
\text { have been involved in physical } \\
\text { fighting in the past } 12 \text { months }\end{array}$ & $33.50 \%$ & $28 \%$ & $37 \%$ & $33.80 \%$ & $19 \%$ \\
\hline $\begin{array}{l}\text { Homicide per } 100000 \text { for } \\
\text { adolescents aged 0-19 years }\end{array}$ & 8 & 17 & 2 & 2 & 1 \\
\hline
\end{tabular}

Source: Our World in Data (2019).

full extent of and factors contributing to violence in China. Turning back to the overall statistics of the BRICS countries, it is not surprising that safety and wellbeing of learners is of concern as these schools are part of the communities where violence thrives. The TIMSS in 2015 (Mullis et al. 2016) that investigated grade 9 learners in 38 counties shows that South Africa has the thirdhighest incidence of bullying (after Botswana and Thailand; Reddy et al. 2015:2). About half of the learners reported having been bullied in the past month, which is twice the TIMSS international average (Winnaar, Arends \& Beku 2019:n.p.).

The most frequent forms of school-based violence in South Africa are manifested physically, learner on learner and teacher on learner. Ncontsa and Shumba (2013:5) posit that smacking of children by teachers, group-related criminal activities, unfair exclusion of children by others or teachers in schools, verbal abuse, drug abuse and smoking are common in South African schools. Older learners, in most cases men, target younger learners. In most cases, the perpetrators are black from a poor economic background (Hlophe, Morojele \& Motsa 2017:6-7). Bullying is also expressed through discrimination against foreigners, touching the opposite sex without their permission, teasing based on physical 
appearance and beating other learners because they perform well in school (Hlophe et al. 2017:6). What can be emphasised is that in all these manifestations of bullying, perpetrators exercise their power to harm and force other learners to submit to them or surrender their possessions.

It is also crucial to mention that these forms of school violence cannot be perceived as isolated because they intersect with those in the family and community. Lamb and Warton (2017:n.p.) indicate that some of the learners are victims of multiple forms of violence at school, in extra-curricular activities, and when travelling to and from their schools or in their family situations. These learners are affected by violence, which could result in poor performance, depression or dropping out of schools. Worldwide, $20 \%$ of the learners do not only experience physical bullying but, more commonly, cyberbullying, which involves sending harmful messages or pictures online (Burton \& Leoschut 2013:xii). What makes cyberbullying especially significant is that it is a recent phenomenon, the perpetrators are often anonymous, and it can have devastating psychosocial effects on learners.

\section{Causes of school violence in South Africa}

Scholars have attempted to understand the nature and causes of violence in schools in the post-apartheid era in South Africa (Matthews, Griggs \& Caine 1999:4-20; Zwane 1997:6-11). Their findings attribute violence to the culture and history of schools where these institutions were previously sites for both statesponsored violence and resistance to apartheid. Learners and university students have been involved in active resistance to apartheid and violent protests in the post-1994 democratic South Africa.

A factor related to the history of the country is the aggression felt by white male teachers soon after apartheid. The white male teachers felt disempowered by the growing diversity in the former white schools as a result of post-1994 educational reforms (Botha, Myburg \& Poggenpoel 2013:7-8). The post-apartheid 
period saw a number of black students, especially those from middle-class families, enrolling into the former white schools. Many white male teachers found this difficult to accept and expressed their resentment through aggression (Botha et al. 2013:6-9). More importantly, school reform included the banning of corporal punishment. Teachers felt disempowered because they did not know how to discipline learners without violating their rights (Rossouw 2003:425). What can be stressed here is that the history of South Africa provided a fertile environment for school violence.

Inequality and high levels of poverty play a significant role in that they cause resentment amongst the low-income groups in schools and communities. South Africa remains one of the countries with the highest inequality. With a Gini coefficient of 0.67 that measures inequality in countries (where 0 shows an equal society and 1 reflecting a perfectly unequal society), South Africa has high levels of inequality with the majority of its population living in poverty (Institute of Race Relations 2018:460). In 2012, about $10.3 \%$ of the population (5.446 million) were poor and $17.1 \%$ of the population (9.04 million people) were close to multidimensional poverty in a population of 55 million (UNDP 2016:6). Youth unemployment is high. In the second quarter, the rate was 29\% (Statistics South Africa 2019:2). Unemployment as a whole tends to be concentrated in townships and informal settlements where poverty and violence are rife (Matthews et al. 1999:6). As mentioned in the previous section, poverty and unemployment are associated with violence, which manifests itself as increased family stress, domestic abuse, drug abuse, disproportionate discipline, bad parenting and neglect. Victimisation, low self-esteem, dysfunctional families, dysfunctional schools, limited access to resources and drug and alcohol abuse become central in such a society.

In this kind of environment, poverty-stricken communities struggle to give schools the support they need to deliver quality education. This usually results in learners from these schools performing poorly or dropping out. Failure to obtain academic 
qualifications in turn contributes to the cycle of violence as these young people struggle to find employment. For instance, youth who have not reached matriculation level have the highest level of unemployment of 34.5\% (Statistics South Africa 2019). Drug abuse, access to weapons such as guns, and theft are common (Ncontsa \& Shumba 2013:7). Bullying is also a common practice in the low-income schools as opposed to those in areas that are better-off (Winnaar et al. 2019:n.p.). Peer pressure and gangsterism exacerbate the problem through creating an ongoing atmosphere of violence.

Besides the factors mentioned above, learners' exposure to violence either as victims or witnesses in their families is a prime reason for violence in South African schools. This is problematic as experiencing or witnessing victimisation could lead to learners' becoming bullies (Strassberg, Dodge \& Pettit 1994:445). Another factor is single-parent households. It seems that most of the perpetrators of violence in schools are learners who are raised in single-parent households where they are abused, and neglected emotionally and physically. Thus, being raised by a single father or mother is a predictor of dropping out of school, and male learners who are abandoned by their fathers tend to perpetrate violence (Ramphele 1995:n.p.). An equally strong factor is the inadequate parental control that exposes learners to violence on the media, and the subsequent bullying that occurs when they imitate their television heroes from feature films or series and 'entertainment' such as wrestling (Hlophe et al. 2017:5).

There are also school-related factors that are partly responsible for the violence and bullying. These include absence of pastime facilities, the densely populated settlements in the communities where some of the learners live, absence of security measures to prevent intruders into school premises, disrespect of other learners, lack of discipline and frustration of school leavers in the surrounding communities as a result of joblessness (Ncontsa \& Shumba 2013:9). Yet another is the frustration caused by low achievements that trigger aggressive behaviour such as bullying (Botha 2007:104). 
It is also associated with a lack of understanding of diversity. This leads to other learners being discriminated against or assaulted verbally or physically purely because of their ethnicity, gender and race (Botha, Myburgh \& Poggenpoel 2012:5).

The above school-related factors are largely learner-centred but school management also plays a role. It needs to be sufficiently proactive in preventing and handling violence. At present, many schools do not adequately address the need to create a climate that supports learning and encourages learners to respect their peers and support one another. Research has shown that bullying is less common in schools where learners feel a sense of belonging, are constantly engaged and where teachers emphasise high achievement than in unhealthy schools (Winnaar et al. 2019:n.p.). Although they are supposed to be protecting the learners, some teachers are perpetrators of sexual abuse, corporal punishment and verbal abuse. Of the 561 cases of teacher misconduct that have been reported in South Africa, corporal punishment (253) constituted the highest percentage. Verbal abuse, victimisation, defamation and intimidation (87), sexual misconduct (sexual and love relations with learners) (78) and racism (9) also featured (SACE 2018:19). It is noteworthy that the incidence of corporal punishment is high despite its being illegal.

\section{Attempts to prevent violence in South Africa}

Although it experiences high incidences of school violence, South Africa is one of the countries with a sound legal framework to combat school violence. The Constitution of the Republic of South Africa 1996 guarantees the protection of human rights for all citizens, including learners, through safeguarding individuals against violence, torture and inhuman treatment (South Africa 1996a). A legislative framework was developed to ensure that learners are not harmed and that their freedom to access 
education and participate effectively in schools is maintained. The legislation includes the South African Schools Act 84 of 1996 (South Africa 1996b), Children's Act 38 of 2005 (South Africa 2005) and Protection from Harassment Act 17 of 2011 (South Africa 2011). The South African Schools Act 84 of 1996 (South Africa 1996b) emphasises that schools should adopt a code of conduct which provides guidelines on how discipline should be upheld in schools. The legal provision stresses that roles of the relevant stakeholders, including the disciplinary committee, teachers, the schools' governing body, parents, the DoE and learners' representative council, should be spelled in the code of conduct that schools should adopt (Rossouw 2007:82). The need to communicate with learners openly, discipline learners, have a strict daily school programme and promoting a sense of belonging to the school through the formation of groups should also be included as part of the schools' code of conduct. However, there is no clarity on bullying in the legislative framework of South African Schools Act 84 of 1996 (South Africa 1996b). Whereas most elements of bullying are prohibited in the South African Schools Act 84 of 1996 (South Africa 1996b), for example, causing physical and psychological damage and failure to respect other people's rights and dignity as outlined in the Bill of Rights (Laas \& Boezaart 2014:2680), bullying and how it relates to other forms of indiscipline is not mentioned explicitly (Laas \& Boezaart 2014). This is a major gap in the legal framework aimed to combat bullying in schools.

The Children's Act 38 of 2005 (South Africa 2005) gives rights to children, including protecting them against maltreatment, neglect and abuse. The legal instrument specifically protects children against physical and emotional harm. Another pertinent piece of legislation is the Child Justice Act 75 of 2008 (South Africa 2008) that provides restorative justice through guaranteeing that child offenders are held responsible and accountable for their wrong doings. This act emphasises the rehabilitation of the offender as opposed to punitive justice. The Protection from Harassment Act 17 of 2011 (South Africa 2011), related to this, can 
be used to protect children against bullying and harassment. For instance, a child can apply for a protection order against a perpetrator. As bullying involves physical and emotional violence, this means that the different aspects of the above-mentioned legislation can be adopted for each of these. However, there is no regulation to make these pieces of legislation work together to make it easier for schools and families to operationalise them, that is, the Children's Act 38 of 2005 (South Africa 2005), the Child Justice Act 75 of 2008 (South Africa 2008) and the Protection from Harassment Act 17 of 2011 (South Africa 2011).

\section{Evidence from Brazil, Russia, India and China on school violence}

To have an understanding of violence in each of these countries, the prevalence, causes and respective mitigation strategies are presented separately for each one of them.

\section{Brazilian schools}

Brazil is one of the 10 countries in the world with the highest level of violence. In 2015, the country registered 59080 homicides and this amounts to 28.9 per 100000 , which was four times the global rate in 2015 (Muggah 2017:2). For adolescents aged between 10 and 15 years, the country had a rate of 59 deaths per 100000 in 2015 (UNICEF 2017). Brazil homicide rate is double that of South Africa for the age group of 0-19 years, which is 17 per 100000 and 8 per 100000, respectively (Our World in Data 2019). The extent of the problem within its schools reflects the high frequency of violence in Brazilian society. A survey in schools revealed that $83.4 \%$ of the learners and $87.3 \%$ of the teachers were either perpetrators, victims or witnesses of violence in schools (Nesello et al. 2014:123). The nature of violence takes the form of thefts (19\%), other learners (12\%), teachers (7\%), threats (12\%), cyberbullying (7\%) and other forms constituting the remaining 5\% (Abramovay, Luciano \& Cerqueira 2016:33). A study 
that investigated the incidence of violence amongst teachers in middle-class schools in the Brazilian state of Londrinam Paraná showed that of the 789 teachers who participated, $8.4 \%$ were victims (Melanda et al. 2018:1). These findings highlight the extent of the scourge in Brazilian schools.

Apart from murder, learners experience violence such as gender-based violence. Brazil is rated fifth worldwide on the gender-based violence index and female learners constitute the most affected group (Prezenszky et al. 2018:1). In response to gender-based violence, the country adopted the Mari de Penha Law in 2015 as a means of creating safe spaces for women and children (Prezenszky et al. 2018:6). Despite the adoption of the legal framework, gender-based violence remains high in schools as the victims are less likely to report because of absence of supporting structures. These trends appear to be the same as those in South Africa where the increase in femicide and genderbased violence has attracted public attention.

As in South Africa, the prevalence of violence in Brazilian schools is partly attributed to the high level of inequality in the country and the authorities' failure to address the socio-economic needs of some parts of the population. Poverty and limited access to education that some disadvantaged populations experience have created feelings of exclusion and resentment as well as aggression. The Afro-Brazilian poor youth make up the largest group of the victims of killings as $23 \%$ of the Afro-Brazilian youth are likely to be victims of murders (Muggah 2017:03). Data from student questionnaires, teachers and police reports corroborate that there is a higher incidence of violence in schools located in the poorest areas than in those in middle- and higher-income areas. Learners from low-income neighbourhoods are likely to be perpetrators of physical violence, users of drugs and guns, and members of gangs (Pereira \& De Albuquerque 2013:66). Because the level of violence is so high in Brazil, most learners there experience anxiety, fear and lack of discipline, which diminish their ability to perform well in class. 
An unhealthy school climate seems to promote bullying in the Brazilian schools. In their study, Mehta et al. (2013:45) reveal that learners who were involved in bullying were unlikely to be committed to their school work but were mostly involved in extra-curricular activities. Furthermore, the hierarchical nature of relationships amongst learners in public middle-class schools encourages aggression in schools. Learners who were seen as popular were good in physical activities but were amongst the worst in academic subjects, and these were regarded as bullies (Crochí 2016:312). However, those whose performance in physical education was poor were frequently victims of bullying. This literature corroborates the findings from the review of the South African schools that an unhealthy school climate promotes bullying.

Besides the legislation to reduce gender-based violence, Brazil adopted the Statute of Children and Adolescents in 1990 to protect children's rights. The legislation outlines the responsibilities of guardians, families and caregivers (Muggah 2017:12). The legislation in Brazil opened the way for school- and community-based interventions to control aspects such as drug abuse, sexual abuse and murders. Evaluations of these school interventions demonstrate varying levels of success in reducing violence in schools. An evaluation of the bo/sa familia [family grant] intervention designed to empower learners significantly reduced the level of violence in schools (Chioda, De Mello \& Soares 2013:22). The same evaluation demonstrates that when the programme was expanded into the community, it lowered the incidence of crime in the neighbouring communities. Additionally, the bolsa familia intervention (Soares 2012:1-40) that aimed at increasing the access of young people into schools also contributed to improving the safety of communities as youth who were previously out of school and engaging in high-risk behaviours were now enrolled in schools where they were monitored (Chioda et al. 2013:19). However, the \#Tamojunto drug prevention programme (Júlia et al. 2018:116), a programme meant to reduce violence amongst learners, improve learners' performance and teachers' wellbeing (Stelko- 
Pereira \& Williams 2016:73) had little success in controlling violence in schools and communities. This shows that Brazil has developed models of partnerships between the government and school- and community-based organisation designed to quell violence. These models have had varying successes. South Africa should adopt those that are effective at improving safety at schools.

\section{Russian schools}

Russia has a lower homicide rate for the adolescents aged 0-19 years which stands at 2 per 1000000 (Our World in Data 2019). The Russian government does not see school violence as a huge problem that needs urgent attention despite a large proportion of learners being victimised in schools. For example, the HSE University's (2019:n.p.) study found that approximately $27.5 \%$ of the learners are bullied and a total of 130 children committed suicide in 2016 as a result of online games. This means that using the Internet increases the likelihood that Russian learners will perpetrate violence. Furthermore, media reports have shown an upsurge in the use of weapons by learners in schools (The Moscow Times 2019). In his study, Sizova (2014:28) raises concerns over the prevalence of physical violence against teachers and the poor relationships between the learners and teachers in most public schools. Almost every student surveyed in the same study reported to have participated in violence, although learners from gymnasia (low-income) were much more involved than those from lycees (high-income schools). From the authority's viewpoint, the teacher is expected to take responsibility for controlling violence. However, teachers perceive reporting violence as an admission of their failure to keep good order. This results in only $30 \%$ of the violence being reported to school authorities (Sizova 2014:36) and school violence being downplayed.

Another significant cause of violence is the access to social media and television. This seems to be a common problem throughout the world, including South Africa, because of the increasing use of technology and communication systems. 
Most of the learners in Russia have unlimited access to violent films on television. For example, three incidents occurred in 1 week in 2018 after the learners joined community Internet groups that promote violence in schools (Sinelschikova 2018:n.p.). The Russian community blamed the neglect of the children on parents, schools and social institutions as the perpetrators of the violence asked on social media where they could access weapons, yet nothing was affected to stop these murders. Because of the single-parent families, child-headed families and poor monitoring of children in most households in South Africa, learners are exposed to violence through social media. This plays a vital role in influencing them to perpetrate violence.

Russia is similar in some ways to South Africa. One is that school violence features strongly in the history of the country. Russia attributes the violence in schools to the vacuum left after the collapse of the Soviet Union in 1991. Russia transformed its education system during this period, and this resulted in the weakening of social contact between the teachers and the parents. The new system also saw responsibility for taking care of children shifting from teachers to families, who are not sufficiently skilled to do that on their own (Sizova 2014:37). The decrease in budget in most of the public schools has left the schools understaffed with some running without psychologists and social workers. The Russian government also blames the lack of cultural education in the curriculum as contributing to school violence. What also appears to delay reforms in the prevention of violence in schools is the absence of a clear communication system where parents can request action from the school authorities.

Terrorism is another cause of violence. For example, during the Beslan tragedy in 2004, 330 people were killed by suspected Islamic groups (Bateson \& Tsvetkova 2014). Because the violent incidents are infrequent, no intervention programmes are in place to mitigate them. However, schools tightened their security after the Beslan tragedy. In South Africa, terrorism in schools has not yet become a threat. 
Unlike South Africa, Russia does not have laws that specifically prohibit violence in schools. Because the Russian government downplays school violence, bullying and other forms of violence have not received public attention in the country (Vavilova \& Matveev 2012:171). At present, school violence is regulated by the general laws that protect the population against violence. There is no criminal liability for perpetrators of violence in schools, such as teachers who physically or mentally abuse learners, as their actions are not illegal.

\section{Indian schools}

India is amongst the countries with a low homicide rate which is at two per 100000 in the age group of 0-19 years (Our World in Data 2019). However, India has high levels of bullying in its schools: $17.7 \%$ of its learners are likely to experience bullying (Sharma \& Marimuthu 2014:3). A study conducted by Dutt et al. (2013:9) obtained similar findings: Whereas physical aggression was at $66.5 \%$ for male learners, verbal indirect aggression was common amongst female learners. In classes VII and IX, 56.7\% reported having verbally attacked others in the past month. Furthermore, in their cross-sectional study of 550 learners, Sharma, Grover and Chaturvedi (2008:85) found that 65 (11.85\%) learners carried weapons to school, whilst 74 (13.5\%) had threatened or injured others in the previous 12 months. These levels and forms of bullying appear similar to those ones identified in the previous sections, including those in South African schools. What appears to be different, however, is the learners' attitudes to violence and associated supporting beliefs as contributory factors that lead to the active expression of aggression and violence. A study conducted by Anand et al. (2019:695) found that a significant proportion of learners did not view violence negatively and believed that it was an acceptable way of addressing their differences.

Unlike in South Africa, India's education system supports the use corporal punishment on learners. Teachers are viewed as 
occupying positions of power which make it possible for them to use corporal punishment on learners. Sridhar (2019:n.p.) explains that Section 89 of the Indian Penal Code (Republic of India 2019) protects the guardian by giving them permission to use corporal punishment on children aged less than 12 years. Because teachers have quasi-parental authority, they are empowered by this legal provision to use corporal punishment (Sridhar 2019:n.p.). However, the use of corporal punishment violates the rights enshrined in the Convention of Child Rights where it stresses, humiliates and terrorises learners in the name of disciplining them. This suggests that the Indian government should consider introducing a legal framework to completely prohibit harmful forms of discipline in schools and at home, such as corporal punishment and forms of mental punishment that cause distress to learners.

\section{Chinese schools}

Although China has the lowest homicide rate amongst the BRICS countries for children aged 0-19 years, which is one per 100000 (Our World in Data 2019), other forms of school violence are prevalent in the country. School violence manifests itself in the form of physical and mental attacks; for instance, 40\% learners aged between 13 and 16 years from the middle schools in the poor provinces in China self-reported physical victimisation (Adams \& Hannum 2017:21). Although the level of violence declines in later grades, the prevalence of bullying ranges from $25 \%$ to $34 \%$ in Main Land China and $19 \%$ to $56 \%$ in Hong Kong (Chan \& Wong 2016:34). Forms of bullying in Chinese schools include the use of brooms, tooth brushes, leather belts, cold water, punching and kicking, slapping, hair pulling and using hot cigarette butts (Huang 2016:20). Although uncommon, other forms of violence are burning nipples, burning hair or forcing someone to shave his or her hair. This demonstrates the severe forms of violence that do not only physically harm the victims but also traumatise them (Wang, Veloo \& Gurnam 2018:4-5). 
Learners are vulnerable for a number of reasons. One such is that the social media makes a pernicious form of anonymous bullying possible. Another is that the emphasis on certain teaching subjects at the expense of moral education leaves learners with little knowledge of how to become socially responsible citizens. Along with this, a new curriculum is being implemented in Chinese schools, which changes the approach from a teacher-centred approach to a learner-centred one. Teachers are facing new challenges such as implementing the new curriculum at the same time as supervising the learners' complex group activities (Adams \& Hannum 2017:19). As yet, teachers are uncertain how to create a relaxed environment and at the same time maintain discipline. Ideally, teachers should be knowledgeable about their subjects and about how best to interest learners, able to detect violence, and supportive but firm in managing their classes to prevent bullying and learner on teacher violence (Roland \& Midthassel 2012:37).

Strategies to control violence in Chinese schools depend on the age of the perpetrators and whether they are enrolled in school. There are legal provisions to prevent violence in schools, and learners below the age of 14 years are dealt with by the school. However, the public security organ is responsible if an out of school youth is involved. Youths over the age of 16 years are prosecuted and punished through detention when they are found to be perpetrators of violence (Huang 2016:24). It looks as if these legal interventions are not fully effective in reducing violence in schools, as learners, aged 14 years, for example, are not held accountable for their actions that harm others. Violence therefore persists because some of the perpetrators go unpunished because of their age, even those who have murdered, raped or caused serious physical injuries to other learners. More importantly, it is crucial to improve the legal framework so that it focuses more on preventing violence in schools than on punishing perpetrators. Attention should also be given to raising awareness of the negative effects of violence. 


\section{Lessons from the above review}

The previous sections reviewed the literature on the nature of violence, contributory factors and the respective strategies used in each of the BRICS countries. What is clear is that causes of violence are multifaceted and intertwined as they appear at family, peer group, school and community levels. This implies that an integrated approach that addresses all these spheres and levels is needed (Prezenszky et al. 2018:2). Evidence in China has shown that minimal contact and cooperation between teachers and parents on ways of disciplining learners encourages violence in its schools. This suggests that South Africa should strengthen cooperation between community-based organisations, schools and learners to raise awareness of the need to prevent violence and empower learners to do so. Additionally, lessons can be drawn from Brazil where school- and community-based interventions are used to prevent violence in its schools. This implies that civic organisation could complement and supplement government efforts to implement interventions. This means strengthening the link between schools and communities, improving the learners' socio-economic status through appropriate schooling, and promoting functional family institutions in South Africa.

Evidence from literature on Brazil, Russia, India, China and South Africa strongly suggests that a negative school climate encourages violence in schools. This review has shown that having more control measures such as enforcing rules within the school premises, involving teachers and learners' representatives on adherence to school rules and promoting discipline in classes can mitigate victimisation and prevent transgressors from further acts of bullying (Stelko-Pereira \& Williams 2016:66). This means that South Africa should promote a culture of learning and selfdiscipline, and emphasise achievement in its schools to discourage learners from perpetrating violence. Further training for teachers that would enable them to detect, report and deal with bullying; workshops on how to improve the safety of schools are essential to create safe spaces in schools (Hlophe et al. 2017:9). 
This review also revealed that violence in Russia and China can partly be attributed to the prioritisation of teaching academic subjects at the expense of citizenship education. Although the South African school curriculum already emphasises values such as human rights, respect, cultural diversity, religion and spirituality (DBE 2011), more must be exercised. It is vital to develop inter-curriculum models where schools are given the support they need to cultivate these values in learners. Nussbaum (2010:37-38) argues that education should not only prepare learners to participate in the economy but also to become responsible social citizens who are able to respect the dignity of their peers and contribute to their communities. This corresponds with Walker's (2006:99) observation that the role of education is to help learners become humane individuals by instilling respect for human rights and diversity education that promote ethics and moral values as well as respect for the dignity of other individuals. These values can also be mainstreamed in teacher education to ensure that teachers believe in and practise them, which would make it more likely that learners will also do soothe same. Teachers should thus be role models that learners can identify with and emulate. Combined with that, more attention should be given to religion education that inculcates moral values in learners. Schools should become key players in raising awareness of violence and developing learners' agency on how to prevent, deal with and report bullying.

An important point that emerges from the above review is that having a legal framework is key in the extent to which a country can control violence in its schools and the wider society. South Africa has made good progress in designing legislation to ensure the safety of children, for example South Africa Schools Act 841996 (South Africa 1996b), Children's Act 38 of 2005 (South Africa 2005) and Protection from Harassment Act 17 of 2011 (South Africa 2011). These pieces of legislation can, however, be improved through developing regulations that help to operationalise them so that they combine to improve the safety and wellbeing of children. More relevantly, bullying should be 
explicitly mentioned in the legislation to make the need for action against it unequivocal. It is also essential to empower schools to design their own measures to address bullying within the historical and cultural context of their locations as a way of complementing South African legislation. At the time of writing, parliament was set to debate a 'Prevention and Combating of Hate Crimes and Hate Speech Bill' (South Africa 2018). This addresses issues to do with hate speech based on race, colour, sex, gender, albinism, ethnic and social origin. If it is passed into law, it could be a significant milestone on the road to combating aggression such as bullying in schools.

\section{Conclusion}

The review in this chapter has demonstrated that the BRICS countries have high incidences of violence in their schools, although the level of violence varies. The strengths and weaknesses of each country's strategies used to mitigate violence have also been discussed. The review has demonstrated that through the international comparative perspective of the BRICS countries, South Africa can draw on the research carried out in other countries to improve its violence prevention mechanisms. What is necessary is an integrated approach that recognises the different learners' identities which include ethnicity, race, gender, location (rural and urban), socio-economic background, historical and cultural context and how these intersect with school and community factors to increase violence in schools. These identities, schools and environmental factors can be used to design points of interventions to mitigate school violence. Each school should develop suitable strategies for its particular cultural context to complement the legislation. It is important to realise that focusing on a single factor, for instance the legal framework, will not provide an adequate way of addressing violence in South Africa. There is a need to change the local community's perceptions of and beliefs on violence and to improve the school atmosphere. 



\section{Chapter 9}

\section{The objectives of the BRICS organisation in correlation with the objectives of the Organisation for Economic Cooperation and Development}

Deon Vos

Subject Group Comparative and International Education, Education and Human Rights in Diversity Research Unit, Faculty of Education, North-West University, Potchefstroom, South Africa

Z.L. (Louw) De Beer Subject Group Comparative and International Education, Education and Human Rights in Diversity Research Unit,

Faculty of Education, North-West University, Potchefstroom, South Africa

How to cite: Vos, D. \& De Beer, Z.L., 2020, 'The objectives of the BRICS organisation in correlation with the objectives of the Organisation for Economic Cooperation and Development', in C.C. Wolhuter (ed.), Critical Issues in South African Education: Illumination from international comparative perspectives from the BRICS countries (BRICS Education Volume 2), pp. 267-304, AOSIS, Cape Town. https://doi.org/10.4102/aosis.2020.BK207.09 


\section{Abstract}

This qualitative research analyses relevant documents regarding the OECD and the BRICS organisation with the aim to enhance the functioning of the BRICS organisation regarding economic and educational signposts. The OECD is an example of an international organisation with far-reaching accomplishments. The OECD was established on the 30th September 1961 and consists of 37 member states. They pride themselves and highlight the following successes. The OECD (2019c) sets forth an outlet for administrations of various nations to cooperate and explore and discover answers to common pressing issues and incorporates working with jurisprudence countries that share a pledge to improve their local economies and the prosperity of every person. Other accomplishments include the promotion of European recovery, integration of developing comparable statistics and indicators measuring economic and policy performance, and to forge international consensus through peer pressure. The OECD's pioneering approach to cooperation is now becoming more mainstream. It is therefore important for the relatively new BRICS organisation to embrace the OECD methods to cooperate and peer-assess themselves against the giants in the international cooperation sphere.

Keywords: BRICS objectives; OECD objectives; Socio-economic trends; BRICS history; BRICS educational aims.

\section{Introduction}

This qualitative study aims to present the OECD as an external reference point to demonstrate that the BRICS's (Brazil, Russia, India, China and South Africa) intention for the collaboration of education has an international counterpart with a successful track record. The main objective of the OECD is to find solutions for socio-economic and educational problems in the member states. Monitoring economic trends in terms of trade, technological development, taxation and agricultural development are also 
part of the objectives of the OECD. The OECD focuses especially on the socio-economic development within the member countries. The OECD Education and Skills Development Directorate prioritise the development of education, training and skills to ensure better employment opportunities for the population and to combat poverty. The member states are encouraged to identify and implement best practices within the respective education systems and to set and implement achievable goals. The OECD emphasises the fact that effective education is the way to prosperity for each country. The OECD aims to ensure the optimal effectiveness of education by providing support programmes for parents, learners, teachers and policy makers. The presence of economic, social and environmental challenges has been identified by the OECD and is therefore provided for especially by policy makers to address these challenges. Young learners entering the education system in 2018 will be young adults in 2030, and the OECD aims to ensure that schools equip these learners to enter the labour market successfully. In order to successfully achieve the latter ideal, schools in the teaching and learning process must ensure that learners are equipped with inquisitiveness, curiosity, adaptability and self-directedness. They should regard and welcome the thoughts, points of view and estimations of others; they should adapt to disappointments and dismissals and to push ahead even in difficulty situations. Learners' motivation should not be only to have a good job and a decent income, but they will also have to look after the wellbeing of their friends and families, their communities and the planet. The OECD has launched The Future of Education and Skills 2030 project. The project aims to help countries find best practices to successfully measure the above ideals within the respective education systems as follows:

- What information, aptitudes, perspectives and qualities will the present understudies need to grow and shape their reality?

- By what method can instructional frameworks build up this information, aptitudes, perspectives and qualities successfully? 
The above-mentioned aims of the OECD correlate with the main objectives of the BRICS organisation. The focus of BRICS is also to develop the socio-economic status of the member states through an effective education system.

\section{Methodology}

This qualitative research was conducted through the lens of the interpreter. Interpretive studies are, as a research paradigm, based on the assumption that social reality is not singular or objective but is rather shaped by human experiences and social contexts (Lumen Learning 2020). Content analyses were applied to scrutinise relevant documents (journals, policy documents, laws, websites and library resources, etc.) and identify applicable themes. These were organised, and similarities and differences were identified. The main aim was to suggest best practices for the BRICS organisation regarding economic policy development and to advance their economies through effective education. The OECD was utilised as an example of experiences' cooperation between 37 countries.

\section{The history of BRICS}

The BRICS association comprises the following states: Brazil, Russia, India, China and South Africa. Brazil is situated in the north-eastern part of the South American mainland. Brazil is the biggest nation in Latin America. As the greatest financial force in Latin America, Brazil has a created agrarian industry, a sound modern premise and an effective service industry. Russia has abundant natural resources and is also the biggest country in the world by landmass. More than $50 \%$ of the land is covered in natural forests. Russia is ranked first in the world regarding natural gas reserves. Russia's natural gas reserves amount to 48 trillion cubic metres. India has the second-largest economy amongst developing countries. According to the International Monetary 
Fund (IMF), its economic growth rate was $7.2 \%$ in 2018 . The average global growth rate was $3.7 \%$. China is the world's largest developing country and only the United States of America (USA) has a bigger economy. China is a strong catalyser of world economic growth. South Africa is situated in the most southern part of Africa. South Africa has copious natural resources such as gold, coal and iron. The BRICS stems from their members' economic and strategic presence in the world.

Collaboration between Brazil, Russia, India and China (BRIC) started in 2006, with a working gathering of the foreign ministers of these four nations. They met informally during the UN General Assembly meeting. Since then, the acronym, created by O'Neill (2001) in his publication Building better global economic BR/Cs no longer confined itself to identifying four emerging economies. From 2009, the heads of state and government of the group meet annually. In 2011, at the Sanya Summit, South Africa became part of the grouping, adding the ' $S$ ' to the acronym, which now is BRICS (Brazil 2019). The BRICS member states together represent about $44 \%$ of the world's population (over 3 billion people in 2017), $23 \%$ of the world's GDP; more than $\$ 27 \mathrm{bn}$ ), $30 \%$ of its territory ( 38.4 million $\mathrm{km}^{2}$ ) and $23 \%$ of the global trade (RSA 2019). Ten summit meetings have taken place since 2009. Figure 9.1 represents BRICS and its global presence.

The following list includes the venue and dates of the 10 summits (Brazil 2019):

- 1st Summit: Yekaterinburg, Russia, June 2009

- 2nd Summit: Brasília, Brazil, April 2010

- 3rd Summit: Sanya, China, April 2011

- 4th Summit: New Delhi, India, March 2012

- 5th Summit: Durban, South Africa, March 2013

- 6th Summit: Fortaleza, Brazil, July 2014

- 7th Summit: Ufa, Russia, July 2015

- 8th Summit: Benaulim (Goa), India, October 2016 


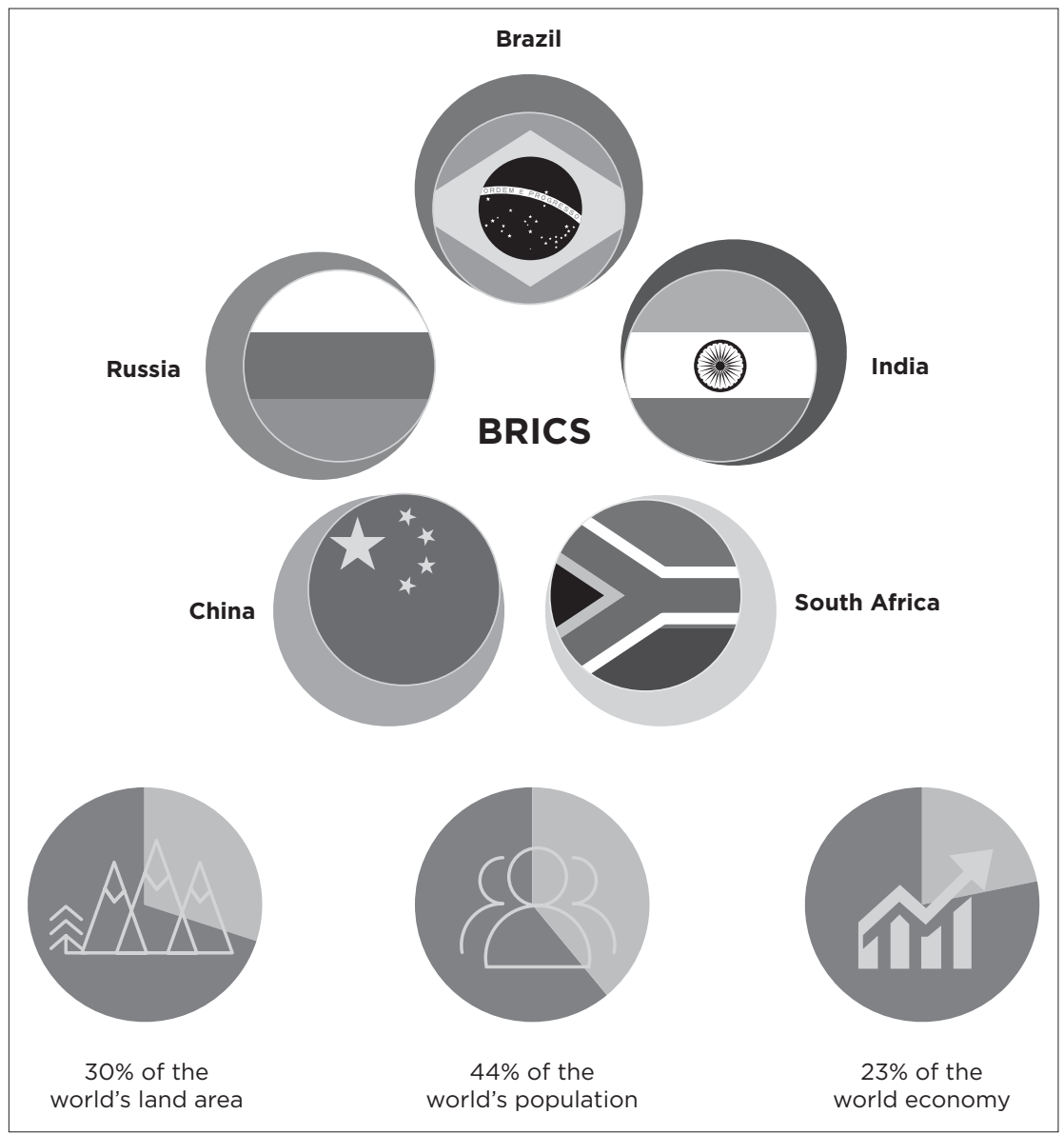

Source: Xinhuanet (2017).

FIGURE 9.1: BRICS and its global presence.

- 9th Summit: Xiamen, China, September 2017

- 10th Summit: Johannesburg, South Africa, July 2018

- 11th Summit: Brasília, Brazil, November 2019 


\section{BRIC Summit 1: Yekaterinburg, Russia, June 2009}

The initial BRIC summit in Yekaterinburg focused on the global economy and important issues regarding global development. The following issues were identified for action (Russian Federation 2009).

Firstly, the central role of the G20 (The Group of 20 is an international forum for the governments and central bank governors from 19 countries and the EU; G2O 2019) member states regarding the handling of financial crises was highlighted. Secondly, all the resolutions of the G2O summit held in 2009 to be implemented. BRIC also accentuated the reform of the international financial institution to represent all nations. Poorest countries of the world are most affected by financial crises. The international community must supply liquid financial resources to those affected countries. The implementation of SDGs must be prioritised to guide the paradigm shift in economic development. Cooperation regarding various areas such as energy, humanitarian relief during disasters and famine, science and education, democracy, international law, terrorism and reforms of the UN were also discussed (De Beer 2017:52).

\section{BRIC Summit 2: Brasília, Brazil, April 2010}

The second BRIC summit was organised by the Brazilians. South Africa attended as a visitant. During this summit, the BRIC aims were further refined into 32 aims and categorised into the following categories (BRICS5 2013a; De Beer 2017:58)

\section{$\square$ Category 1: Shared vision on global governance}

BRIC shared the perception of rapid and phenomenal change in the world. These changes imply the transformation of governance in all areas. The Group of 20 (G 20) must be more inclusive and 
diverse and must be representative and democratic. Diverse global governances also imply reform of the UN, and BRIC accentuates the importance of India and Brazil in the international sphere.

\section{$\square$ Category 2: International and financial business}

BRIC underlines the importance of economic development in which developing countries play an important role. The status of the major reserve currencies is highlighted in the role they play to stabilise economies. BRIC also supports the idea of a regional monetary currency.

\section{$\square$ Category 3: International trade}

The World Trade Organization (WTO) must deliver an open, fair and non-discriminative environment for international trade. BRIC puts accented focus on a multilateral trade system like the WTO. BRIC is also against any form of trade protectionism.

\section{$\square$ Category 4: Agriculture}

The importance of cooperation regarding farming, in general, and family and subsistence farming, in particular, was prioritised. Food security and food production were high on the agenda. Strategies must be developed to supply and secure food to the poor and venerable.

\section{$\square$ Category 5: Poverty relief}

All forms of poverty, social exclusion and inequity must be eradicated. Special attention must be given to vulnerable groups such as people with disabilities, women, the youth, the poorest and immigrants.

\section{$\square$ Category 6: Energy}

Energy is an important resource that can improve living standards. The importance of new eco-friendly energy technology is recognised. 
BRIC member states accelerate their cooperation regarding the energy sector.

\section{$\square$ Category 7: Climate change}

The negative impact of climate change is recognised. BRIC member states must urgently intervene.

\section{$\square$ Category 8: Terrorism}

Terrorism in any form is strongly condemned.

\section{$\square$ Category 9: Cooperation}

BRIC initiated the following sectoral initiatives aimed at cooperation. It consists of ministerial meetings regarding agriculture, science, culture, sports, finance, statistics, competition authorities, the development bank and the BRICS think tank.

\section{BRICS Summit 3: Sanya, China, April 2011}

South Africa attended this summit as a full-fledged member for the first time. BRICS summit 3 confirmed the BRIC 2 aims. The Sanya declaration focused on global financial reforms, the international economic and financial situation, multi-polar global systems and cooperation between BRICS member states. Financial reforms of the UN, WTO and international financial organisations were a priority. BRICS challenged the status quo regarding representative membership in international bodies such as the G-20 (CNTV 2011; De Beer 2017:60).

\section{BRICS Summit 4: New Delhi, India, March 2012}

The fourth BRICS summit's theme was 'BRICS partnership for global stability, security and progress'. This summit further refined the BRIC 2 and BRICS statements into 50 categories. 
It also let to the development of the Delhi action plan (BRICS5 2013b; De Beer 2017:62). The most significant point of agenda was the creation of the New Development Bank (NDB). The main aim of the BRICS bank was to provide funding for development and infrastructure projects in developing countries. It would also provide long-term loans during financial crises. The development bank is a powerful financial tool that is used to improve trade opportunities. BRICS 4 indicated the magnitude and scope of cooperation within BRICS member states.

\section{BRICS Summit 5: Durban, South Africa, March 2013}

The theme of BRICS 5 was 'BRICS and Africa: Partnership for development, integration and industrialisation' (BRICS 2013a). It highlighted the important role and development opportunities in Africa. This was also the first summit where education-specific aims were defined. These educational aims were condensed into four ideals for BRICS. They were the exchange of knowledge and the reinforcement of cooperation between BRICS universities and vocational colleges, the transferability of educational qualifications and the acceleration of UNESCO's EFA aims (De Beer 2017:63).

\section{BRICS Summit 6: Fortaleza, Brazil, July 2014}

The sixth BRICS summit led to the Fortaleza statement and action plan. The summit theme was 'Inclusive growth: Sustainable solutions'. During this summit, the following were lamented. Firstly, an agreement was reached about the functions and duties of the NDB. The convention about the establishing of the BRICS emergency relief fund and the agreement about export credit agencies were also discussed and agreed upon (BRICS6 2014). The importance of education for sustainable development is put under the spotlight. 'Education for All' and education-relevant MDGs were also deemed important by BRICS 5 . The BRICS University Network also form part of the Fortaleza action plan. 
The BRICS member states also agreed upon the start-up funding of the NDB. The initial capital fund was agreed to be $\$ 50 b n$ funded by the BRICS countries. Eventually, the bank would have $\$ 100$ bn available for development, et cetera. The BRICS member states also agreed to a $\$ 100 \mathrm{bn}$ emergency fund to stabilise economies of member states during periods of financial volatility and crises (De Beer 2017:69).

The Fortaleza action plan displayed the exponential growth and magnitude of BRICS cooperation with 72 different statements. It included areas such as global financial crisis, peace, security, development, health, education, unemployment, cybercrime, information communication technology, corruption and EFA goals.

\section{BRICS Summit 7: Ufa, Russia, July 2015}

During the seventh BRICS summit, the Russian government identified five priorities to order the statements and agreements of the first six BRICS summits (BRICS 2015). The first priority focused on the strengthening of international peace and security and the promotion of BRICS interests in the international sphere. Priority two states that multilateral facilitation must be applied to reform international financial systems and organisations such as the IMF. The third priority identified by the Russian delegation was about continued advancement regarding trade and economic cooperation. Social cooperation, for example, the consideration of children, old and differently able individuals and the joining of jobless individuals into the workforce should likewise be extended. The final priority focused on the deepening of humanitarian cooperation between BRICS member states (De Beer 2017:73)

\section{BRICS Summit 8: Benaulim (Goa), India, October 2016}

The eighth BRICS summit was held in Goa, India and led to the New Gao declaration. The theme of the summit was 'Building responsive, inclusive and collective solutions'. Under India's chairpersonship, the 8th BRICS summit adopted the five- 
pronged approach. This approach aimed to structure all the different declarations and action plans so that it can be implemented. The adopted five-pronged approach consisted of the BRICS organisation working to additionally extend, support and standardise BRICS participation; execution of the declarations from past summits; coordinating the current collaboration systems; advancement, that is, new collaboration components; and progression, that is, the continuation of the commonly agreed outputs on existing BRICS participation initiatives (BRICS 2016). This approach is known as the Institute-building, Implementation, Integration, Innovation and Continuity (IIIIC or the I4C).

The following condensed version of the new Goa declaration highlights the important issues: The BRICS nations denounce all forms of terrorism and emphasise the fact that there can be no justification for such acts. Terrorism groups, such as the Islamic State, are an unparalleled threat to international security and peace. There is an urgent need for the adaptation of the Comprehensive Convention on International Terrorism (CCIT) at the UN. The urgent reforming of the UN is once again on the agenda. The resolution of civil war in Syria to stabilise the region. All nations must fight radicalism and block financing and monitor the abuse of the Internet. BRICS also appreciated the progress in the implementation of the strategy for BRICS economic partnership and emphasised the importance of BRICS roadmap for trade, economic and investment cooperation until 2020. BRICS also welcomed the adoption of the 2030 agenda for sustainable development and its SDGs. The BRICS (2016) member states reiterated the use of all policy tools to achieve SDGs and inclusive growth.

\section{BRICS Summit 9: Xiamen, China, September 2017}

The ninth annual BRICS summit themed 'Stronger partnership for a brighter future', came after President Donald Trump decided to withdraw from trade deals such as the Trans-Pacific Partnership 
trade deal and climate agreements such as the Paris Climate Agreement (Suokes 2017; Xinhuanet 2017). Figure 9.2 depicts the cooperation rationale and the scope of cooperation in BRICS.

China as the host of BRICS 9 summit wanted to use this summit to evaluate successes in BRICS cooperation (Figure 9.2), plan a vision regarding the future developments, set a road map for the BRICS mechanisms and increase cooperation between BRICS member states and mould a manifesto for South-South cooperation with international influence (WTO 2017). One of the topics for discussion was the economic recovery of BRICS member states. China

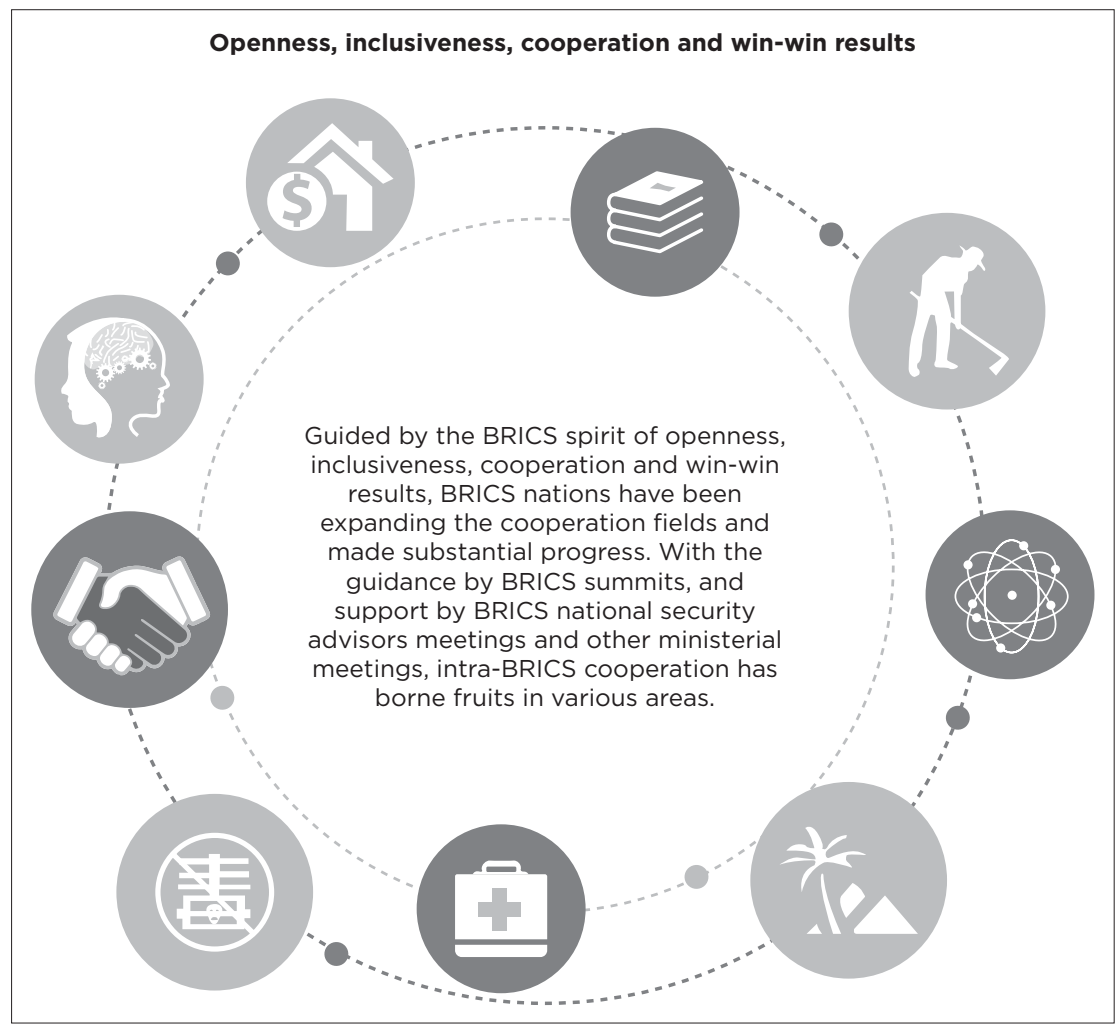

Source: Xinhuanet (2017).

FIGURE 9.2: Cooperation between the BRICS member states. 
particularly continued the push for a greater global presence in the international financial organisations such as the IMF and the WTO. BRICS also decided to increase their voice in global issues (Suokes 2017). BRICS sees itself as an alternative to the Group of Seven (the Group of Seven is an international intergovernmental economic organisation made up of the seven largest IMF-described advanced economies in the world: Canada, France, Germany, Italy, Japan, the UK and the USA) which voice the developing countries' concerns and interests.

\section{BRICS Summit 10: Johannesburg, South Africa, July 2018}

South Africa hosted its second BRICS conference with the theme: 'BRICS in Africa: Collaboration for inclusive growth and shared prosperity in the 4th Industrial Revolution'. The 10th BRICS summit's Johannesburg declaration had 102 different declarations categorised under four groups. The following is a condensed version of the content of each group (RSA 2018):

Reinforcing multilateralism, changing worldwide administration and tending to normal common challenges:

- Commitment to the UN, as the all-inclusive multilateral association endowed with the mandate to uphold universal international security and peace.

- Reaffirm the requirement for a far-reaching change in the UN, including its Security Council, with the end goal of making it progressively more inclusive.

- Support for continued participation of the BRICS individuals in zones of common interests.

- Commitment to complete the actualising of the 2030 Sustainable Development Plan and the SDGs.

- Finalising the work programme under the Paris Climate Agreement and express the eagerness to keep working collectively with different role players.

- Fortify BRICS collaboration in energy, especially in transitioning to more environmentally sustainable energy systems. 
- Reaffirm and bolster the foundation of the BRICS Agricultural Research Plan (ARP) initiated by India in 2016.

- Commitment to improving participation in the field of waterdependency for economic advancement in an incorporated manner.

- Establish a really wide universal counter-psychological warfare alliance and bolster the UN's focal organising job.

Strengthening and merging BRICS participation in universal worldwide harmony and security:

- Responsibility to aggregate endeavours for settlement of questions through political and strategic methods.

- Perturbing over the continuous conflict and increased strains in the Middle East.

- Highlight our help for the UN's relief and work agency for Palestine crisis.

- The Republic of Yemen humanitarian crises are a course for concern.

- Political emergency in the Gulf and welcoming the endeavours of Kuwait in the crisis.

- Reaffirm our help for the procedure of an 'Afghan-drove, Afghan-claimed' national harmony and compromise process.

- We call upon all stakeholders to comply with their commitments and guarantee the full and successful implementation of Joint Comprehensive Plan of Action (JCPOA).

BRICS organisation for worldwide monetary recuperation, reform of worldwide financial and administration establishments, and the fourth industrial revolution:

- The worldwide economy has kept on improving, but at the same time taking note of non-synchronised worldwide growth, the economic risk remains.

- Advocate ongoing utilisation of financial, fiscal and auxiliary arrangements in concert to produce solid, reasonable, adjusted and economically all-inclusive growth development.

- Commend the foundation of the BRICS Partnership on New Industrial Revolution (PartNIR). 
- Recognise the extensive and critical role the Internet web plays globally in advancing financial, social and cultural development.

- Reaffirm the centrality of the guidelines based on straightforward, non-prejudicial, open and comprehensive multilateral exchanging framework as epitomised in the WTO.

\section{Explicit person-to-person cooperation:}

- Underscore the centrality of individuals in BRICS and its projects.

- Reaffirm our responsibility for a people-focused perspective to deal with the advancement that is comprehensive of all sectors of interest.

- Perceive the significance of culture as one of the drivers of the fourth industrial revolution.

- Accentuate the directing role of the activity plan for the execution of the understanding between the governments of the BRICS states on cooperation in the field of culture.

The BRICS member states have sought to establish fair international governance to suit their sustainable national interests. This goal can be achieved through the reform of the IMF quota system, which must include, for the first time, Brazil, Russia, India and China amongst the top 10 largest shareholders. During the first 12 years of existence, BRICS has developed sectoral cooperation in different areas such as energy, health, science and technology, trade promotion, innovation, education and fight against transnational crime. Presently, cooperation covers more than 30 different areas and brings relevant real-life benefits to the populations of the five countries. The example of the tuberculosis (TB) research network, which aims to introduce quality medicines and diagnoses with affordable prices, is the evidence of the cooperation (Brazil 2019).

At the sixth BRICS in Fortaleza, Brazil, important institutions were initiated such as the Contingent Reserve Arrangement (CRA) and the NDB. The CRA is operational and is an important 
financial stability mechanism for the countries affected by financial crises. The NDB has approved more than \$8bn in infrastructure and renewable energy financing projects for the BRICS member states. In addition to presidential meetings, BRICS has organised, through its rotating chairpersonship, about 121 annual meetings, including about 15 ministerial meetings and dozens of gatherings with senior officials, technical events as well as meetings in the areas of culture, education and sports (Brazil 2019).

\section{The objectives of the Organisation for Economic Cooperation and Development}

\section{The Organisation for Economic} Cooperation and Development explains its existence in the policy-making sphere by answering the 'who, where, what and how questions'

- Who is the OECD? - The OECD is an international organisation that works to build better policies for better lives. Our goal is to shape policies that foster prosperity, equality, opportunity and wellbeing for all. We draw on almost 60 years of experience and insights to better prepare the world of tomorrow. (OECD 2019c:n.p.)

- Where does the OECD operate? - In 36 member countries spanning the globe, from North and South America to Europe and Asia Pacific. Ambassadors of the 36 countries are part of the OECD Council, which oversees and advises on our work. (OECD 2019c:n.p.)

- What does the OECD do? - The OECD help[s] countries forge a path towards better lives whilst saving billions of dollars for 
taxpayers and boosting prospects for stronger, fairer and cleaner economies and societies. (OECD 2019c:n.p.)

- How does the OECD do it? - The OECD brings policy creators together to share and exchange ideas and forge progress across a range of policy areas. (OECD 2019c:n.p.)

\section{The Organisation for Economic Cooperation and Development education and skills}

The OECD Directorate for Education and Skills helps individuals and nations identify and develop the knowledge and skills that drive better lives and better jobs, generate prosperity and promote social inclusion. We encourage countries to compare their experiences and learn from each other, and we accompany them in the difficult process of policy implementation (OECD 2019d:n.p.).

This OECD (2019d) educational gaol is further defined into the following three aims:

Firstly, the OECD directorate aid[s] OECD economies in planning and managing their education systems, and in implementing reforms, so that their citizens can develop the knowledge, skills, attitudes, and values they need throughout life. Secondly, the OECD directorate for education and skills wants to make sure that learners understand their own learning needs and have the opportunity and means to choose paths that help them develop. Lastly, the directorate wants to make sure that educators have the skills and knowledge and values to improve their teaching practices. (n.p.)

The OECD wants member states and other countries through better policies to enhance the level and quality of education so that learners and citizens can have a better life. BRICS also focuses on the quality of education through partnership and declaration set out at every BRICS summit. The BRICS education aims to focus on similar viewpoints. Firstly, BRICS must invest cooperatively in education to promote economic growth and human resource development. 


\section{The educational aims of the BRICS member states regarding socio- economic development}

\section{BRICS educational aims}

The third meeting of the BRICS education ministers held in Moscow on 18 November 2015 (BRICS7 2015:1) outlined the BRICS educational objectives as follows.

\section{$\square$ Higher education}

- Higher education in BRICS should move towards increased collaboration in teaching and research on common knowledge fields.

- Establishing teaching and research centres of excellence at the foremost universities of the BRICS member countries.

- Supporting collaborative research projects and promoting joint publishing in scientific journals.

- The BRICS education ministers also want to improve cooperation in the recognition of degrees and diplomas amongst themselves.

- The BRICS education ministers also support the establishment of the BRICS university league.

- Finally, BRICS must now be constituted as prescribed by the collaboration agreement mentioned above (BRICS7 2015:1).

\section{$\square$ Technical vocational education}

- The BRICS education ministers emphasised the important impact of technical VE in the labour market.

- The development and sharing of ideas, concepts, methods and tools that can determine supply and demand of labour.

- Vocational education must be enhanced by initiatives that enhance skills development so that best practices can be used by BRICS. 
- Collaboration on specific projects instituted by the BRICS skills development working group of the BRICS business council (BRICS7 2015:1).

\section{$\square$ General education}

- BRICS encourages comparative research on the quality of education so that norms between the BRICS member states could be established.

- Promote lifelong learning and encourage self-education through formal and informal education.

- Provide possibilities for learning other languages to fortify business and professional communication (BRICS7 2015:2).

\section{$\square$ Instruction strategy procedures}

- Official delegates from each BRICS nation ought to be selected to arrange and coordinate projects and tasks.

- Member nations need to explicitly fund training to advance monetary development and to improve human resources.

- The BRICS nations must share measurable information and create procedures to create general training indicators.

- Guarantee the sharing of data regarding national evaluation frameworks of the BRICS nations (BRICS7 2015:2).

From the above, four goals were set for education, that is, strengthening collaboration between the BRICS universities for partnerships and the exchange of knowledge; the conclusion of partnerships and the exchange of knowledge on technical VE and training; to promote the transferability of educational qualifications between the BRICS countries and to accelerate the importance of collaboration with UNESCO for the sake of EFA objectives. At BRICS 7, this was further refined and grouped under four divisions, that is, Higher Education, Vocational Education, General Education and Education Policy. 
One of the first direct consequences of BRICSology in education is the constitution of the BRICS Network University. Another direct consequence for South Africa was the announcement by the minister of education that Mandarin would be presented as an additional language at various schools as a pilot project. From the above historical description, the scope and influence of the BRICS organisation become clear.

\section{The status of socio-economic trends in the BRICS member states}

The socio-economic status of a country is largely determined by the effectiveness of the country's education system. One of the main educational objectives of the BRICS organisation is that education must be available for all (EFA) and there should be an opportunity for lifelong education (World Bank Group 2018). It was also found in the previous source that poverty is one of the main reasons for inadequate learning. One of the main factors that combat unemployment is effective and targeted education and training (Mizne 2019). In the report of the World Bank Group (2018), it is clearly stated that through adequate education, the following characteristics will be visible in a country: minimising of poverty, a high form of productivity, minimising of unemployment, adequate income per household, better health, better resilience and adoptability, make better choices, better life satisfaction, better economic growth, creating of lifelong economic development, better socialisation in the community, better service delivery, positive civic engagement and social cohesion. Low learning outcomes in Mathematics and reading skills can be linked to poverty and unemployment (World Bank Group 2018). The principle of 'poorer children learn the least' is not only the reason for poverty and unemployment, but is also a cruel reality (OECD 2019a; World Bank Group 2018). It is also found that poverty has a negative impact on the health of a human being as well as development of human brain (World Bank Group 2018). Poverty also has a negative impact on the level of motivation and preparedness of a child. Vocational 
education and training is one of the effective ways to maximise the effectiveness of education and training programme of a country. It not only empowers the workforce of a country but also reduces poverty and contributes to the social development of its inhabitants. More examples of socio-economic trends that are affected by a weak economy are, amongst others, low level of literacy, insufficient workplace skills, high mortality rates, increase in corruption and crime, and child neglect. Even lower mortality rates are found in countries where education and socio-economic trends are favourable (OECD 2019c; World Bank Group 2018). Examples of economic progress and stability can be found in countries where economic needs are addressed in the curricula of its education system (Lim 2019; OECD 2019a; World Bank Group 2018).

It is visible in the above-mentioned findings that better and effective education can be directly linked to the stronger socioeconomic development of a country. The so-called secondchance programme aims at the minimising of poverty through feeding schemes and re-teaching programmes for children (World Bank Group 2018). According to the World Bank Group's (2018) report, better salaries for teachers will attract better quality teachers to the profession and in-service training courses will also be in favour for better educational outcomes. The principle of spending more and wisely on education should be a strong consideration in every country.

It is important to compare the averages of socio-economic indicators given in Table 9.1 with each indicator of individual BRICS member states in order to realise what is reflected by the socio-economic and educational factors of each country.

Next, the socio-economic status of the BRICS member countries are considered in more detail.

\section{Brazil}

Brazil's economic freedom (51.6 economic freedom index) is significantly lower than the world economic freedom index 
TABLE 9.1: Average socio-economic indicators.

\begin{tabular}{ll}
\hline Socio-economic indicators & Average of indicators \\
\hline Economic freedom index & 61 index points \\
Unemployment & $7.22 \%$ \\
Economy growth & $3.31 \%$ \\
Life expectancy in years & 72.41 \\
Poverty & $23.88 \%$ \\
Expenditure on education of the GDP & $4.53 \%$ \\
Inflation & $3.50 \%$ \\
\hline
\end{tabular}

Source: Global Economy.com (2018).

(60.8 economic freedom index). This middle-income country, with a population of 207.7 million, has an unemployment rate of $13.3 \%$ and an inflation rate of $3.4 \%$ (The Heritage Foundation 2019). The percentage of the total expenditure on education in 2015 was $6.24 \%$ of the GDP. Poverty occurs in $26.50 \%$ of the population and the economy has a growth rate of $1.12 \%$ (Global Economy.com 2018). From 2016 to 2017, poverty increased by 2 million inhabitants, which means that 54.8 million people were declared as poor, with 18.2 million of whom were under the age of 14 years (Mizne 2019; Statlink 2019). Of the 4 million babies born annually, only $15 \%$ will be enrolled in colleges by the age of 21 (Mizne 2019). The life expectancy in Brazil is 75.46 years (Global Economy.com 2018). The Brazilian education authorities are trying their best to accommodate learners in schools and make education more accessible to learners, yet the dropout rate of school-going learners remains very high. The education and training that learners receive are simply not good enough to make them successful citizens, and even graduates are experiencing this problem (Mizne 2019). Approximately $70 \%$ of learners in Brazil attend public schools, but the curricula differ from school to school, which significantly impairs the education process. Poor teaching and training means that the young workforce does not have the necessary skills to make a positive economic contribution. Homeless and hungry learners receive substandard education and training from education authorities and the poor socio-economic situation of these learners further 
aggravates the negative impact of this situation on Brazil's economic progress. During the OECD PISA investigation, it was found that the level of knowledge and education in 15-year-old learners of private schools was 3 years ahead of learners in public schools. In some cases, it was found that some of the learners in private schools are 4 years ahead in academic progress than learners in public schools. With the vast majority of learners in public schools, there is a significant discrepancy in the socio-economic situation of the population (Mizne 2019). Only $2.1 \%$ of poor learners make a positive contribution to this country's socio-economic prosperity.

As of 2017, the Brazilian education authorities are reversing this trend by implementing the first ever national learning standards (Mizne 2019). The implementation of the Lemann Foundation ensures that all Brazilian learners have the right to education and training (Mizne 2019). The latter initiative aims to have the new curriculum implemented in all schools by 2024 . Since 2017, this initiative has benefited approximately 7 million learners in accessing education and training with a better education standard (Mizne 2019). Equal education opportunities that provide quality education and training reduce unemployment, minimise poverty, ensure social justice, and improve health and public safety (Mizne 2019; Statlink 2019).

According to the 2017 educational reform programme, schools have given more flexibility to determine the educational needs of their learners and the curricula should be adapted accordingly. The need for vocational training has been also expanded, especially for low-skilled workers. Scholarships are now available for tertiary education. Vocational training programmes also focus on professional training programmes in order to address skill shortages and reduce dropout rates in schools. The programme also focuses on better teacher salaries, in-service training and even incentives for better teacher performance. Full-day schooling and the upgrading of infrastructure and building of new schools are also part of this initiative (Statlink 2019). 


\section{Russia}

Russia has a total population of 144435 000, of which 25735000 are aged between $O$ and 14 years (World Bank Group 2018). According to the Worldwide Educating for the Future Index (WEFFI), produced by the Economist Intelligence Unit and presented by the Yidan Prize Foundation, an entity created by Tencent co-founder Chen Yidan to promote international education, Russia is ranked 26th worldwide in ensuring that its youth is future-ready. The result marks an improvement of one position compared to the Index produced in 2017 (Frolovskiy 2018). The expansion of private schools is an outcome of the state's efforts to impose a unified but inflexible curriculum. As a result of this trend, these learners are 'exposed to a western-style curriculum' with an 'emphasis on mastering English' (Frolovskiy 2018). The Russian education system still relies on science and traditional skills, whilst learning resources only partly cover the skills needed by the broader society for economic growth. The salaries of teachers are low and the socio-economic environment is also not as expected (cf. Frolovskiy 2018).

Russia has an unemployment figure of $4.8 \%$ and an inflation rate of $3.9 \%$. Poverty rate is $12.9 \%$. People living in poverty are defined according to their income: An income of less than 10287 rubbles per month is seen as poverty (World Bank Group 2019a). The spending on education (3.82\% of the GDP) and health lacks far behind economically advanced OECD countries (World Bank Group 2019a). The economic freedom index is 30 index points. The life expectancy in Russia is 72.12 years. Its economic growth of $2.25 \%$ is expected to slow down because of higher oil price, poverty and non-energy commodity values (Global Economy.com 2018).

Informal employment is increasing in Russia. In 2001, the informal employment was $12.5 \%$ of the labour force, and in 2016 , it increased to 21.2\% (World Bank Group 2019a). Informal employment is defined as persons working without a formal contract or in a short-term contract in a company. Self-employed persons are also seen as an example of informal employment. 
Compared with other middle-income countries such as Kazakhstan and Turkey, Russia does not have a significantly higher informal employment rate. The research conducted by the World Bank Group (2019a) showed that the number of citizens with tertiary education has increased rapidly over the last 10 years, which shows that Russia has a high level of quality education. It was also found that informal employment occurs more within the labour force with only basic education. People with higher qualifications and better educational level were more formally employed (World Bank Group 2019a). If informal employment also occurs in the population with higher education, then Russia would have a significantly higher informal employment ranking compared to the rest of the world. In order to address growth in informal employment, better training skills are needed at the workplace so that the expansion of vocational education and training can take place (World Bank Group 2019a).

Russia is implementing extra-curricular activities (ECA) to address the development of both intra- and interpersonal skills. With robots and artificial intelligence taking on an ever-greater scale in the society, the delivery of effective education should emphasise the delivery of knowledge and basic skills (World Bank Group 2019b). Extra-curricular activities can be a 'disruptive innovation' that can change the status quo of the traditional form of delivery of education (World Bank Group 2019b). More participative activities in all spheres of education are needed to achieve the goal of developing intra- and interpersonal skills. Following are the examples of activities set by ECA to reach their goals in developing intrapersonal skills: Collaboration in group work activities with children, art activities and recognition of the importance of theatre and sport development programmes and activities where concentration and discipline are stressed (World Bank Group 2019b). Russia is one of the best countries with regard to basic skills in the early years (Progress in International Reading Literacy Study [PIRLS]) and scores average amongst OECD countries for grade 9 learners (PISA), but it scores below average in Collaboration Problem-Solving Skills (CPLS). 


\section{India}

India's population is 1370182 940, with a median age of 27 years. The life expectancy in India is 70 years. The infant mortality of 26.6 per 1000 births is shocking, and the death figure of 32.9 per 1000 births (less than 5 years of age) is also disturbing. The total dependency ratio is also a shocking $32.73 \%$ of the population (Worldometer 2019). The economic freedom index is 40 index points and the country has an unemployment rate of $5.36 \%$ of its population. The economic growth is $6.98 \%$ and the Inflation rate is $3.21 \%$. The poverty rate is $21.90 \%$ of the population. The expenditure on education is $3.84 \%$ of the GDP (Global Economy.com 2018).

India focuses on an inclusive and high-quality education to fulfil its dream of prosperity for all. India has one of the biggest youth populace on the planet with 600 million youngsters aged less than 25 years. The estimation for India's population to grow by 2030 is 1.5 billion, which will be the largest population in the world (Trines 2018).

India has the fastest-growing economy in the world, outpacing the economy of China. Indians in the middle-income group are expected to multiply by nearly 10 times within just 20 years, from 50 million in 2010 to 475 million in 2030. Experts predict that India will become the second-largest economy in the world by 2050 (Trines 2018).

India, although seen as a developing country, still has socioeconomic challenges. India has the largest number of poor people next to Nigeria in the world. Unpaved roads (40\% of roads), the spreading of TB infection (kills more than 435000 people each year), the highest mortality rate in the world amongst children aged less than five years, and the worst sanitation systems in the world (in 2017, 524 million Indians did not have access to public toilet facilities) are some of the challenges the country is facing. Poverty is declining in India but still despite this decline India still has about one-fourth of the world's extremely poor population with great social imbalances (Trines 2018). 
Owing to the demographic changes in India, the growth and development of its economy is rapidly thriving. India will have to modernise and expand its education system, raise instructive accomplishment levels and provide relevant 21st-century skills to its growing youth population to be significantly competitive with countries such as China. India's noteworthy affinity for pioneering development and its young, gifted and quickly growing Englishspeaking workforce are to the advantage of its economic growth and prosperity (Trines 2018).

India is facing a challenge regarding physical access to secondary schooling. In some cases, certain communities are located more than $5 \mathrm{~km}$ away from lower secondary schools. In primary education, $99 \%$ of the learners are enrolled in nearby primary schools but only $50 \%$ are enrolled in secondary schools. Owing to the lack of infrastructure in secondary schools, it is found that in several cases, the classrooms are overcrowded and this situation has a severe and negative effect on the quality of education. The result of this is low learning outcomes (World Bank Group 2019c). Owing to this challenge, in 2009, the government of India launched an initiative called the Rashtriya Madhyamik Shiksha Abhiyan (RMSA) framework (World Bank Group 2019c). The RMSA was aimed to provide universal access to secondary education by 2017, with universal retention/ completion by 2020. The RMSA's objective is to increase and improve equitable secondary education as well as enhance its quality. This programme is supported by the World Bank Group (2019c). The following were the achievements of the programme at the end of 2017: Learner enrolment increased from 50\% to $64.5 \%$, there was also a significant improvement in gender parity (the number of girls per 100 boys completing Grade 10 improved from 79.0\% to 91.2\%; World Bank Group 2019c). The government approved the establishing of 12000 new secondary schools with an enrolment of 1.47 million learners. The programme also provided funding for the construction of 50000 additional classrooms in 31000 existing government schools to improve the student-classroom ratio (World Bank Group 2019c). The 
upgrading of science labs, computer rooms, library rooms and activities for the enhancement of art/craft/culture also contributed to a more functional and effective delivery of education. The upgrading of toilet and drinking water facilities also contributed to the enhancement of the socio-economic background of learners. The result of this initiative was that the studentclassroom ratio decreased from 56 students per class in 2011 to 46 students per class in 2016 (World Bank Group 2019c).

\section{China}

The economy of China has transformed from a centrally planned socialist economy to a more market-based economy and the country is experiencing rapid economic and social development. With a population of 1.4 billion people, more than 850 million people have lifted themselves from poverty over the last decade, which is an extraordinary achievement (World Bank Group 2019d). China has the second-largest economy in the world and has contributed around $30 \%$ of global growth in the past 8 years. With China's impressive economic and social development, the country's reforms are still incomplete, and its per capita income remains that of a developing country, with only about a quarter of the average of high-income countries. It is estimated that poverty will be absolutely eliminated by 2020 (World Bank Group 2019d).

The economic freedom index is 20 points and the economic growth is $6.6 \%$. The unemployment rate is $3.61 \%$ of the population, with a poverty rate of $3.10 \%$ and an inflation rate of $2.51 \%$. The total expenditure on education is $1.89 \%$ of the GDP. The average life expectancy in China is 76.47 years (Global Economy.com 2018).

Following are the challenges that China is facing: Rapid economic ascendance, inequality between urban and rural areas, environmental sustainability and external imbalances. Demographic pressure related to an ageing population and internal labour migration are also part of these challenges. Rapid economic growth exceeded the pace of institutional development. 
Important institutional and reform gaps need to be addressed by significant policy adjustments in order to ensure a sustainable growth path. Instances of these policy changes are to advance administrations and measures to address ecological and social inequities, setting focuses to diminish contamination, to build energy productivity, to improve access to training and medicinal services, and to extend social assurance (World Bank Group 2019d). The 13th Five-Year Plan's yearly growth aim is $6.5 \%$. It focuses on both the rebalancing of economy and the quality of growth whilst maintaining the objective of achieving a 'moderately prosperous society' by 2020 (doubling GDP for 2010-2020; World Bank Group 2019d).

According to the 2015 PISA results, the following observations were made regarding the socio-economic status and education equity of China (OECD 2016):

- The science results outperformed most of the countries that have participated.

- Disadvantaged learners outperformed advantaged learners in 20 of the OECD countries.

- There was greater socio-economic diversity in China measured against the average socio-economic status of the OECD countries.

- There was a great discrepancy in the distribution of resources between the advantaged and disadvantaged socio-economic groups.

- Better academic results were found where improvement of student resilience took place.

\section{South Africa}

The economic freedom index in South Africa is 50 points, with economic growth of $0.62 \%$. The unemployment rate is $27.20 \%$ of the total population and the poverty rate is an astonishing $55.50 \%$ of the population. A low life expectancy of 63.54 years is not a good indicator for South Africa. A high expenditure on education 
occurs with $6.13 \%$ of the total GDP. South Africa's basic education department receives about $17.1 \%$ of the total budget allocation. South Africa has an inflation rate of $4.34 \%$ (Global Economy.com 2018).

The above-mentioned indicators reflect that South Africa is not in a good and healthy economic position compared with the rest of the world indicators and even not in a good position compared with the indicators of the BRICS member states. The unemployment indicator for South Africa (27.20\%) is the worst of all the member states and way above the average world indicator (7.22\%). The economic growth indicator of $0.62 \%$ is also way lower than the average world indicator of $3.31 \%$. The life expectancy of South Africans (63.54 years) is also not a good and economically attractive figure, compare with the world life expectancy indicator of 72.41 years. The South African poverty rate of $55.50 \%$ compared with the world indicator of $23.88 \%$ is a further pattern of distraction. The only indicator that is better than world indicators is the expenditure on education (6.13\% of the total GDP compared with $4.53 \%$ of the world GDP). This is also a worrying factor because according to the TALIS results in 2018, South Africa was one of the worst educationally performing countries, on various levels, in the world (OECD 2019b).

It is the desire of each parent that their child must grow and settle as a citizen to work independently and successfully in modern society where there is a long-term economic growth. To achieve this goal or objective, there should be a sound primary and secondary education system to build on for future tertiary education. The democratisation of South Africa triggered significantly vicissitudes the funding of non-discriminatory education, education governance, education management, curriculum redesign and curriculum restructuring. Some of the main aims and objectives of the transformation of the South African education system were to accumulate knowledge, enhance higher-order critical thinking and problem-solving, and to refocus the racially segregated public spending on education 
to targeting disadvantaged families with poor children. These aims have improved the education systems of most of the countries and added value to the prosperity of the economy and educational development of the people. In South Africa, it has realised a rapid expansion of education system and increase in the enrolment of learners throughout the system, although the quality of education has remained substandard and is characterised by inequality. Various international researches highlight the poor quality of the South African education system. This trend was proven by international assessments of educational achievements. According to the measure of the National School Effectiveness Study, South Africa had a mean score of numeracy and literacy of $19 \%$ and $27 \%$, respectively, in grade 4 compared with the score of $28 \%$ and $35 \%$, respectively, for other middleincome countries ( $\mathrm{Ngozo} \&$ Mtantato 2018). The results of the TIMSS showed that South Africa ranked almost last in its various rankings. The outcome of TIMSS shows that $27 \%$ of South African pupils who have attended school for 6 years cannot read. This compares unfavourable with 4\% in Tanzania and 19\% in Zimbabwe. Amongst other factors that have a negative impact on the delivery of effective education in South Africa is the questionable content knowledge of educators. It was also found that after 5 years of schooling, only $50 \%$ of learners could do basic mathematical calculations, and $60 \%$ of grades 1 to 6 educators failed to pass tests for mathematics of the grade level they were teaching. South Africa was rated 126th amongst 138 countries in the World Economic Forum's Global Competitiveness Report for 2016-2017 (Ngozo \& Mtantato 2018).

The economic stagnation in South Africa is directly linked to the poor performance of the education system. Because of the poor education system, the reality of poor labour skills, low labour productivity and low labour income exist in the self-employed informal sector (Ngozo \& Mtantato 2018).

There are wide-ranging policy options with which the government could improve the education system (Ngozo \& Mtantato 2018). These include the following: 
- Enhancing the equity, effectiveness and efficiency of resource use across the education system.

- Increasing the managerial, administrative and technical capacity of the national and provincial bureaucracy.

- Increasing teacher content knowledge and teaching skills.

- Introducing entrepreneurship learning within the education system.

- Developing an education system for the fourth industrial revolution that actively applies knowledge to collaborative problem-solving.

\section{Dossible best practices regarding the development of the socio-economic status in the BRICS member states}

The following best practices have been identified in the fivemember states of BRICS. However, it is not given that these best practices will be relevant for all the countries. For this research, only the best practices that are successfully implemented in each country are discussed.

\section{Brazil}

The expansion of private schools resulted in better access to proper and quality education. This initiative also resulted in a better teacher-learner ratio where quality education can be provided. However, this is an expensive way of delivery of curriculum and not all learners are in the financial position to access these schools. The constitution of Brazil is also clear on the fact that education must be provided for all learners according to the educational needs of each individual. Equal opportunities to education and quality education resulted in the reduction of unemployment, minimisation of poverty, insurance of social justice, improvement of health and insurance of public safety. The individual educational needs of learners can now be more effectively addressed because of a more flexible 
management approach in schools. The expansion of vocational education and training programmes resulted in various successful realities: Training is provided for low-skill workers, resulting in a better-equipped labour force, the shortage of certain skills is addressed, and it also effectively addressed the dropout estimates. Better salaries, in-service training programmes and performance incentives not only attracted better teachers but also the quality of their performance became significantly better. Full-day schooling and the sensitivity towards teaching time also increased the quality of teaching and better results have become a reality.

\section{Russia}

The expansion of private schools imposed a more unified and inflexible curriculum. This resulted in the enhancement of English as a language that can be used in schools as well as in the business sector. Informal employment is reduced, introducing training programmes for the enhancement of labour skills. Vocational training and teaching programmes are also introduced to address the issue of reducing informal employment. Extra-curricular activities are used to better intra- and interpersonal skills, as the era of using high-technology sources has oppressed these kinds of skills.

\section{India}

The principle of prosperity for all in India put the focus on highquality EFA. This also results in the focus on programmes of economic growth. Entrepreneurship innovation programmes are also used to assure economic growth. The advantages that India is entertaining for the enhancement of education system and successful growth of their economy are the relatively large young labour force, highly skilled in the use of technology and the growth of English as a language to be used in the schools as well as the business sector. The building of a large number of 
secondary schools, upgrading libraries, science laboratories, computer rooms, and enhancement of cultural, art and craft activities are some of the best practices of India that can be adopted by other countries. The upgrading of sanitation and water drinking facilities are also contributing to the socioeconomic enhancement of people in India.

\section{China}

China has moved from a centrally planned economy to a more market-based economy. This has resulted in a very affirmative growth of its economy and the advancement of social development. A priority for Chinese development is services and measures to address environmental and social imbalances. Other priorities are to set targets to reduce pollution, increase energy efficiency, expansion of education, healthcare and social protection. Disadvantaged learners enjoy more attention and the needs of these learners are taken care of. More efficient distribution of resources in all sectors of education system is also a priority.

\section{South Africa}

Several transformation programmes have been launched in South Africa in order to address past inequalities. These transformation programmes include the following: Accumulation of knowledge of teachers in their respective fields of study, enhancement of critical thinking, enhancement of problem-solving skills and expansion of expenditure on poor or disadvantaged children.

Following are the other programmes that have been introduced in the education sector to address the poor quality of education:

- QLTC: Quality of Teaching and Learning Campaign

The Quality of Teaching and Learning Campaign is introduced to develop structures at all levels in the South African education system to ensure the quality of education and to monitor these measures regarding the enhancement of 
education system. The campaign also emphasises the importance of taking ownership and accepting responsibility for what we are responsible for.

- IQMS: Integrated Quality Management System

This initiative is to measure and manage the work output of all educators. The main focus of this initiative is on the improvement of education in general. This initiative also emphasises the accountability and responsibility of all stakeholders in the education sector. It also provides feedback and interventions to stakeholders in order to deliver education and training of an expectable level.

- WSE: Whole School Evaluation

Whole School Evaluation also emphasises the importance of effective education management in South African schools. This initiative measures the effectiveness of education management of all stakeholders in schools. It also provides feedback and intervention or action plans in order to improve education management in schools. Effective education management by different stakeholders in schools is the heart and backbone of effective teaching and learning in institutions.

- Unions

Different unions in the DoE play a very important role in the effective delivery of the curriculum. These structures have certain departments that build up teachers in the effective delivery of the curriculum. Workshops and other training opportunities presented by the unions are to the advantage of both the teachers and DoE.

- Subject advisory services

The DoE has appointed competent and skillful officials to assist teachers to deliver the curriculum effectively. The subject advisory services visit teachers at the schools, monitor their work, give feedback and advice, and re-train them if necessary. These structures are also responsible to ensure the accumulation of knowledge of teachers and that the teaching skills are to the benefit of learners. 


\section{The BRICS economy synopsis 2020 and COVID-19}

The current status and threats for the BRICS countries are summarised by Silk Road Briefing (2020). Brazil was slow in its reaction and will show a decline in the capacity for its economy to bounce back. There is a potential for COVID-19 to become unmanageable. The Brazilian currency and markets are at a historic low. Russia will endure the economic threat of COVID-19 as it has enough reserves to fight the disease. The state is presently supporting the industry and people but could do more. India likewise seems to have enough resources to brave the financial effect of the disease. Racial conflict may persist in India but the COVID-19 will affect maximum the poorest of poor. China has weathered the first wave of virus but it's not yet in the clear state because a new wave of infection is reported in Beijing. In South Africa, underlying medical problems with sanitation, access to clean water, lack of healthy sustenance and high instances of TB and HIV are issues that have a significant effect on economic development. Poor frameworks and medicinal services could demolish its economy. The prediction is that the BRICS economies will retract between $6 \%$ and $10 \%$ after COVID-19.

\section{Conclusion}

The BRICS member states are characterised by their socioeconomic development to improve the lifestyle of their residents. The BRICS organisation should adapt their cooperation methods to the OECD example to enhance economic and educational outcomes as declared by BRICS. These priorities include cooperation from the BRICS administrators to cooperate, explore and discover answers for common pressing issues and to share economic statistics and knowledge to improve their economies and advance the prosperity of citizens. The promotion of the BRICS economies and the sharing of comparable statistics 
and indicators measuring economic and policy performance can enhance these countries. The best practices from the OECD can help the BRICS organisation to work together more effectively. The importance of education and training is prioritised and serves as a means of improving the living standards of all residents in these developing economies. It is the characteristic of these member states that the working conditions of teachers receive attention and that remuneration packages are constantly reviewed. Furthermore, it is also noticeable that there is a concern in these countries regarding the social status of teachers. The attractiveness of education as a profession should receive attention to ensure good quality teachers. 


\section{Chapter 10}

\section{The creation of world- class universities in China as an object lesson for South Africa}

Charl C. Wolhuter Subject Group Comparative and International Education, Education and Human Rights in Diversity Research Unit, Faculty of Education, North-West University, Potchefstroom, South Africa

\section{Abstract}

For producing education research guiding South Africa towards meeting the education challenges it faces, world-class universities is a sin qua non. From a time not very long ago, when university education came to a standstill in China (1966-1976), it has managed to establish a cluster of world-class universities, with its Project 985, Project 211 and the current 'Double First

How to cite: Wolhuter, C.C., 2020, 'The creation of world-class universities in China as an object lesson for South Africa', in C.C. Wolhuter (ed.), Critical Issues in South African Education: Illumination from international comparative perspectives from the BRICS countries (BRICS Education Volume 2), pp. 305-332, AOSIS, Cape Town. https://doi. org/10.4102/aosis.2020.BK207.10 
Class University Scheme'. The aim of this chapter is to chart China's successful creation of world-class universities and to spell out the implications of that exercise for South Africa, which has set itself on that trajectory too. The chapter commences with a portrayal of the pivotal place that universities have come to assume in the present world, followed by the clarification of the concept of a 'world-class university' and how that has become the much coveted prize in the higher education sector of every nation. Subsequently, the history of higher education in China is surveyed, and the creation of world-class universities in China in the past few decades is reconstructed. The focus then shifts to the history and present state of higher education in South Africa, and in conclusion lessons for South Africa from the experience of China are extracted. Whilst it is tempting to recommend the concentrated and intense investment China has made in the construction of world-class universities, the present economic realities in South Africa make the emulation of China's experiment impossible. It is finally recommended that South African universities seize the opportunity of China's 'belt and road' outreach to the world, to plug into the world-class universities of China, as a way to give impetus to the development of worldclass universities in South Africa.

Keywords: 'Belt and road' initiative; China; Comparative and international education; Doctoral education; Fourth industrial revolution; Initiative; Knowledge society; South Africa; Worldclass universities.

\section{Introduction}

One of the striking features of the contemporary world is a global higher education revolution taking place (see Altbach, Reisberg \& Rumbley 2009). Whilst the most salient feature of this revolution certainly is the massification of higher education, another very important feature is the race to the top, that is, in the nomenclature of the sector, the drive to become a world-class university (Wolhuter 2011). This clamour has not bypassed South Africa 
either, as South African universities, for example, have joined the game of university rankings and those who do make it to the top, boast their achievements through web pages and media. One country where the higher education sector has seen a meteoric rise in recent decades, from nowhere to massification and to filling the list of top universities worldwide, is China. The drive to create world-class universities in China was the outcome of a deliberate policy, worthy of being studied and emulated by other nations pursuing the same ideal of having world-class universities.

Developments in higher education in China are noteworthy for a number of reasons. China has become the second most popular destination for African students studying abroad after France. Most of those heading to Chinese universities hail from Tanzania, Kenya, Zimbabwe, Ethiopia, Morocco, Eritrea and Cameroon (Nakkazi 2018). On top of this, China is by all indications intending to strengthen its outreach to students from Africa: At the 2018 Beijing Summit of the Forum on China-Africa Cooperation (FOCAC), the Chinese government declared to honour its pledge after some time, and increase opportunities for Africa's young people - and pledged to allocate to Africa 50000 government scholarships and 50000 training opportunities in the form of seminars and workshops (cf. Anthony 2017; Nakkazi 2018).

The aim of this chapter is to chart out China's successful creation of world-class universities and to spell out the implications of that exercise for South Africa, which has set itself on that trajectory. The chapter commences with a portrayal of the pivotal place which universities have come to assume in the present world, followed by the clarification of the concept of a 'world-class university' and how that has become the much coveted prize in the higher education sector of every nation. Subsequently, the history of higher education in China is surveyed, and the creation of world-class universities in China since past few decades reconstructed. The focus then shifts to the historical evolution and present situation of higher education in South Africa, and in conclusion, the lessons for South Africa from the experience of China are extracted. 
This chapter limits its scope to mainland China, that is, omitting Hong Kong, which has a history and societal and higher educational context different from that of mainland China. Moreover, Hong Kong is also not included in project 985 and project 211, which China has instituted in order to build worldclass universities.

\section{The pivotal place of university in the 21st-century society}

\section{What is a university?}

The lexical definition of a university is 'an advanced autonomous educational institution for the promotion (teaching and research) of various branches of science' (cf. Merriam-Webster Dictionary 2020). It (almost invariably) finds itself at the pinnacle of any national education system, and in current times of globalisation, also at the pinnacle of the global education project. Over the course of history, the contention has also taken root that one of the features of a university is autonomy, that is, freedom to engage in its own activities of teaching, research and in other capacities (to be enumerated and discussed later in this chapter) without interference of government or civil society.

\section{The beginnings of the university}

It is a very difficult question to answer as to where and when the first university was started. Historians of education writing from a western or Eurocentric perspective usually accord the honour of the world's first university to the University of Paris and denote 1080 as the year of its establishment (when it obtained its charter from the Pope). On the other hand, many Islamic or African historians regard the University of Karouine in Fez, Morocco, founded in 859, as the oldest existing university in the world. The answer to the question as to the oldest university in the world does depend on scholar's exact definition of a university, how much value is accorded to the autonomous nature of that 
university, and how much autonomy the scholars find in universities such as the University of Fez and the University of Paris.

\section{The long, unimpressive history of universities in the society}

Despite its origins fairly long ago, for much of its history, the university was but on peripheral in the society. To illustrate this point, reference can be made of the seismic changes that took place in the 17th and 18th centuries - changes which laid the basis upon which the modern-day political dispensation of the world is based: the Glorious Revolution and the adoption of Bill of (Human) Rights in England in 1689, the American Independence (formation of a republic and adoption of constitution and bill of human rights as part thereof) and the French Revolution of 1789. Neither those who drafted any of these bills of human rights nor the founding fathers of the American republic and constitution (Thomas Jefferson and Thomas Paine) and those who intellectually prepared the way for the French Revolution (Montesquie, JeanJacques Rousseau and Voltaire) were attached with any university or even had any university education.

Even in 1950, worldwide higher education enrolments were 6.134 million and the gross higher education enrolment ratio of global aggregate was only 5\% (Wolhuter Forthcoming).

\section{The take-off since the mid-20th century}

Changes started occurring in the mid-20th century. Higher education enrolments grew by more than 15-fold during the second half of the 20th century. Whilst in 1950, there were 6.1 million students in HEls worldwide, this figure reached to 99.5 million in 2000 (UNESCO 1971, 2020). This acceleration in development of higher education was part of a global education expansion project which took off in the mid-20th century growth in enrolments at primary and secondary levels, and also at pre-primary and post-secondary levels, of education during 
this period was no less impressive (see Wolhuter Forthcoming). The forces behind this massive education expansion drive worldwide were not only the rise of the creed of human rights and the view of education as a human right (see Wolhuter \& Van der Walt 2019) but also a belief that took hold that education is a solution to every problem faced by the society. Education was amongst others seen as:

- an economic production factor and no longer as an item of consumption. Here, Nobel laureate Theodore Schultz's Human Capital Theory was decisive (see Reay, Crozier \& Clayton 2009; Schultz 1961; Sobel 1982)

- an instrument to effect modernisation of what was regarded as underdeveloped countries (see Fägerlind \& Saha 1984:49)

- a way to entrench democracy by inculcating democratic values and a way to mould national unity (see Wolhuter et al. 2020)

- a ladder for upward social mobility for individuals as well as group mobility (see OECD 2018; Parelius \& Parelius 1987).

Whilst this growth in higher education since 1950 is nothing less than impressive, it dwarfs against what has begun since about 1990, when a global higher education revolution took off, which placed development in higher education in yet higher gear.

\section{The global higher education revolution}

Since 1990, higher education got in motion worldwide and is still picking up momentum. This global higher education revolution can be summarised in one word, namely massification (see Altbach et al. 2009). A number of societal drivers have been driving this global higher education revolution (see Wolhuter et al. 2010). These include the growing global affluence, the democratisation movement in the world and revolution in international communications and transport technology. Since 1990, one of the most powerful and enduring economic upswings has taken place in history. This upswing has made higher 
education affordable to an ever bigger sector of society, whilst the democratisation of large parts of the world since 1990 has resulted in more people feeling that they can afford higher education. As stated, the one signature feature of this global higher education revolution has been the massification of higher education. In a short span of 18 years, the total global higher education enrolment of 99.5 million in the year 2000 quoted above has more than doubled to reach 223671873 in 2018 (UNESCO 2020), whilst gross higher education enrolment ratio of global aggregate has almost doubled from $19.08 \%$ in 2000 to $38.04 \%$ in 2018 (UNESCO 2020).

Two current developments or societal (or economic) trends lending further value to higher education are the rise in knowledge economies and the fourth industrial revolution.

\section{The nascent knowledge society and the fourth industrial revolution}

Economic historians distinguish between phases in the development of national economies. The first and the most primitive stage is that of hunting and gathering economies, that is, when hunting and gathering were the sole economic activities. Then came agricultural economies after the agricultural revolution, which commenced in the 'fertile crescent' of the Middle East about 10000 to 12000 years ago, when agriculture and/or other extractive industries, such as mining, fishing and forestry, for trade and profit became the main economic activity. Subsequently, the Industrial Revolution occurred for the first time in England in about 1760, when industrial economies emerged and manufacturing industries (factories) became the economic basis. Next, an era of service economies dawned, when services made up the majority of economic activities, appearing for the first time in North America and Western Europe in the 20th century (see a 'macro-sociological' description of the paradigm shifts which commenced in the so-called simple and advanced agrarian societies, preceded by the hunting and gathering, and the 
horticultural phases, finally resulting in market economies; Lenski, Nolan \& Lenski 1995:84-85, 196). Currently, in the most advanced economies, a phase of knowledge economies is nascent, that is, economies where the production and consumption of new knowledge has become the axial principle of economic development. This obviously lends new, enhanced value to education, higher education in particular.

The 'fourth industrial revolution' is a term introduced by Schwab (2016), describing its quintessential feature of blurring or fusion of physical, biological and digital/technological worlds; to contrast it with previous waves of industrialisation, namely the first industrial revolution (based on steam, in 1750), the second one (based on electricity, in 1850) and the third one (based on computers and digitalisation, in 1960). This revolution has offered at once the frightening and exciting possibilities around developments such as the development of artificial intelligence, robotics, autonomous vehicles, biotechnology, nanotechnology and much other technological advancement. As such, the development of these technologies, as well as the pivotal discourse of making sure that their development and application takes place within an acceptable ethical framework, has given higher education an enhanced importance.

\section{The purpose or mission of a university}

The mission or purpose of a university in the society can be summarised under six rubrics (Habermas 1968; Maassen 2011; cf. Pauw 1975).

In the first place, the university is a place of teaching and learning. Mindful of the definition of a university supplied above, that is, 'an advanced educational institution for the promotion (teaching and research) of various branches of science', this means that various branches of learning should be taught and studied at their most advanced levels. At least from the time of the medieval university, this teaching-learning activity has recognisably displayed two facets or levels: Firstly, the teaching 
and learning of basic or foundational disciplines, with the intention to cultivate both mind and character (in a later historical context this came to be called a liberal education), and secondly, the teaching and learning of fields of learning with a clear and specific vocational or professional preparation or grounding in mind. For example, all students who entered the medieval university firstly studied the seven liberal arts in the Faculty of Arts before proceeding to study at one of the three faculties, that is, faculty of theology or medicine or law (Duggan 1916).

The second function of a university is that of research. This role came forcefully to the fore with the creation of Humboldt University in Berlin in 1810, and from there it spread to the rest of the world. A notable impetus in that process was the adoption of the Humboldt model by private university with the inception of Johns Hopkins University in 1876, which gave this model a foothold in the United States of America (USA). Paralleling the learning and teaching function, research has two sides: basic research (or 'blue sky' research, aiming at pushing back the frontiers of knowledge), and applied research (i.e. research aiming to address problems in praxis, problems experienced by the society).

The third purpose of the university is that of service. Of all the purposes, service is probably the vaguest and the most difficult to define. Some scholars contend that faculty service is an 'engagement', whilst others take it as an 'outreach'. One comprehensive exposition of this function of the university is given by Ward (2003), where he enumerates the full gamut of activities which could be classified as the service activities of the university. Ward (2003) divides these functional activities as internal and external service activities. Internal services could, in turn, be sub-divided into on-campus and off-campus (discipline/ scholarly field-oriented) service activities. On-campus service includes institutional governance and institutional support, student advising or counselling (on matters outside the narrow scope of the curriculum) and academic oversight. Off-campus services in which faculty occupy themselves include service 
activities to disciplines or scholarly fields by means of membership and commitments to different associations, for example, professional/scientific societies or publication-related activities (such as serving on editorial boards or acting as reviewers of papers). External services refer to the way HEls put their expertise for the benefit of different external stakeholders and include consulting, learning services, community action-based research, community upliftment projects, participation in cultural activities and civic services. Such service activities could be paid or unpaid; however, the common factor amongst all service activities is that these are based on the expertise of faculty.

The fourth purpose of the university is to be the conscience of society, that is, to critique on society (cf. Habermas 1968:3-4). This purpose takes on particular importance at present when societies and governments are pledging subservience to the creed of human rights, and where humankind is encountering challenges and critical issues such as the threat of ecological destruction and the possibilities created by the fourth industrial revolution. The university can serve this purpose as an autonomous institution, free from influence of or prescription from government or any lobby sector of society. In order to be free to speak as the conscience of the society, the university should not fear any menace from those who are the target of social criticism of the university (Wolhuter \& Mushaandja 2015:215). The fifth function of the university is that of preserving the finest products of culture bestowed by and for humankind (Wolhuter 2011). This is the most obvious function but not limited to the objects of art, such as literature (books), languages and painting.

The sixth and final assignment of the university is with respect to innovation. This refers to innovation flowing from the high levels of expertise of knowledge of scholarly type, and in a knowledge economy (as described above) this purpose of the university comes very strongly to the fore. Universities' role in this regard can be seen in the number of patents emanating from researches conducted therein. 


\section{World-class university}

Whilst massification can be taken as the signature feature of the current global higher education revolution, this revolution shows a number of other features as well. One is the paradoxical feature that whilst the proliferation of HEls gave rise to a differentiation of HEls, where various institutions search for their own niche, virtually every university wants to become a 'world-class university' (Altbach 2010). Whilst this concept is widely used in public and scholarly discourses of higher education sector, looking for a definition, much more of a robust interrogation or explication is likely to end in frustration (cf. Altbach 2010; Wolhuter 2011). Wolhuter (2011), however, has constructed a model for explicating the concept of a world-class university, departing from the three sections of the term. Accordingly, the word 'university', as explained above, refers to an institution with a mission to advance various branches of advanced learning; the word 'class' refers to a category in a hierarchy or a rank-order and the word 'world' would then mean the best in the world, that is, the highest quality in the world. Therefore, a world-class university would be a university offering the highest quality of education in the world. Education quality is similarly a term defying an easy definition, but Wolhuter (2014), adapting the model of Bergman (1996:581), distinguishes between the following components of quality: input quality (comprising, for example, financial investment and physical infrastructure), process quality (which includes, for example, quality of teaching, quality of learning and curricula), output quality (in the case of a university, this is the function of the university, that is, the amount and quality of learning that took place, research output, service delivery, cultural preservation and development, innovation and social critique) and product quality (i.e. the effect of education on the individual life of alumnus and benefits the society eventually gains from the education given to alumnus).

Whilst there has not been impressively much scholarly attention given to the definition of the term 'world-class 
university', university rankings (as a measure or indicator of universities in the global course of universities) have emerged and gained currency in the past 30 years (see eds. Shin, Toutkoushian \& Teichler 2011). Whilst university rankings have a long history reaching back to the 19th century (see Wolhuter 2011), these have rapidly gained prominence in this age of globalisation. In 2003, the Shanghai Academic Ranking of World Universities (carried out by the Institute of Higher Education at Shanghai Jaiotong University) appeared (the name of this ranking was subsequently changed to Academic Ranking of World Universities [ARWU]). The next, a year later, was the university ranking system of the Times Higher Education Supplement (THES). In 2010, the Quacquarelli Symonds (QS) developed from the THES to become the third major ranking system in the world. Whilst there are many other ranking systems in circulation (see Liu \& Cheng 2011:147-149), the above-mentioned three are the most often used systems.

The criteria whereby various ranking agencies do ranking vary (although invariably research output is given heavy weight in the ranking formula). The Shanghai Jiao Tong University ranking index is made up of the following six components (ARWU 2020:n.p.):

- Quality of education (number of alumni who earned a Nobel Prize or a Fields Medal, the latter in mathematics [10 percent]).

- Quality of staff (number of researchers who earned a Nobel Prize in physics, chemistry, medicine or economics and/or the Fields Medal in mathematics [20 percent]).

- Number of highly cited researchers in the fields of life science, medicine, physics, engineering and social sciences (20 percent).

- Research output (number of articles published in Nature and Science) (20 percent).

- Research output (number of articles listed in Thomson Scientific's Science Citation Index Expanded and its Social Sciences Citation Index [20 percent]). 
- Size of the institution (the weighted score of the above five indicators divided by the number of full-time equivalent academic staff [10 percent]).

The THES ranking methodology unashamedly privileges research activity. It uses 13 performance indicators, grouped into the following five areas (THES 2020):

- Teaching (the learning environment) (30\%).

- Research (volume, income and reputation) (30\%).

- Citations (research influence) (30\%).

- International outlook (staff, students and research) (7.5\%).

- Industry income (knowledge transfer) (2.5\%). (n.p.)

The QS system of ranking uses the following formula: Academic peer review: $40 \%$, faculty/student ratio: $20 \%$, citations per faculty: 20\%, employer reputation: $20 \%$, international student ratio: $5 \%$ and international staff ratio: 5\% (QS 2018).

Whilst the ranking of universities and the methods used by ranking agencies have drawn their share of criticism (see Wolhuter 2011), they remain the best available and the most often used yardsticks to measure the university status, including the worldclass status of universities.

\section{Higher education in China}

Education in China, and higher education in particular, has had a long, slow and uneven history till the mid-20th century, whence it flowed and ebbed dramatically. Firstly, during the convulsion of the Cultural Revolution, c. 1966-1976, the existing, rather small higher education sector came to all but a standstill. Then, because of the implementation of reforms and Open Door Policy in 1978, China became open and has become one of the fastest-growing and the most influential economies of the world. In tandem with this economic rise, the education system of China, including the higher education system, has grown spectacularly. The Decision on the reform of the educational structure issued by the 
Communist Party's Central Committee in 1985 was the pioneer policy document symbolising the beginning of significant educational reforms after China's Open Door Policy (Hui, Yue \& Pi Symanco 2020). This document spelled out the principles, missions and measures to reform the administrative system and to adjust the educational structure so as to effectively strengthen basic education, promote extensive development of vocational and technical education, and give full play to the potential and vitality of HEls (Hui et al. 2020). The following year, in 1986, the 'Compulsory education law of the People's Republic of China', promulgated by the National People's Congress, laid a firm legal basis for the development of basic education system: A system of 9 years of compulsory education started from there only. This 9-year compulsory schooling was largely rolled throughout the country in ensuing years. However, it was not only the 9-year of basic schooling which marked the education miracle of post-1978 China. In fact, the 9-year of basic schooling has laid the basis for the extension of senior secondary school enrolments and thereafter for the rebuilding and growth of higher education system.

Consequently, a massive higher education expansion effort took off in China in 1978, and in sync with the global higher education since 1990 as explained above. This expansion of higher education in China has been in an even faster mode since 1990. The gross higher education enrolment ratio rose from $0.71 \%$ in 1978 to 50.60\% in 2018 (UNESCO 2020). According to 2018 estimates, China has 44935169 higher education students (these are the latest available figures at the time of writing; UNESCO 2020). In 2010, in terms of enrolments, China overtook the USA to become the largest higher education system in the world. Currently, China has $2631 \mathrm{HEls}$ amongst which 1243 are regular colleges and universities (including 265 independent colleges) and 1388 are higher vocational colleges (Hui et al. 2020). China has introduced the three-cycle academic degree system which encompasses bachelor's, master's and doctoral programmes. In China, almost all the students have to write the senior secondary 
school termination examination (gaokao) as a high-stake qualifier for selection to higher education. In 2015, China overtook the USA yet again to become the country with maximum doctorates: 71000 against the just under 50000 in the USA.

Online and distance education has been an expanding part of the higher education system in recent times. In 2018, the ministry of education announced a national development plan with the intention to become world leader in massive open online courses (MOOCs) and planned to increase the number of national-level courses of this kind from 490 in 2018 to 3000 by 2020 (Lei 2018).

In 2017, the research and development (R\&D) expenditure in China was estimated to be 1750 billion Yuan, which equals to $2.12 \%$ of GDP, an increase of $11.6 \%$ than the previous year (Hui et al. 2020). Funding of R\&D in HEls has risen over the years, reaching 107.22 billion Yuan by 2016 (European Organisation for Nuclear Research [CERN] 2019). Under the 'Made in China 2025' strategy, China aims to increase its competitiveness globally in terms of advanced and innovative manufacturing (Hui et al. 2020). Mindful of what has been written earlier in this chapter on the nascent knowledge economy and the dawning fourth industrial revolution, the importance of higher education in the future of China is once more highlighted.

China has made extensive provisions of higher education for adult students. In fact, Guan and Plower (2020) describe how China actually has two parallel higher education systems: the first regular higher education system for students who proceed after finishing with senior secondary school and qualifying the gaokao examination to university, and the second system for adult students, especially aiming at the senior generation who were denied opportunity for higher education during the cultural revolution. Leading universities, such as Peking, Shanghai Jiaotong, Tsinghua and Fudan, have developed MOOCs and distance education arms. Li, Wang and Hu (2017) have reported that China already had more than 10 million distance education students in 2017. In 1979, the erstwhile China Central Radio and 
TV University (which operated by means of radio and television) was revamped and modelled on the UK's Open University to become the National Open University, which now operates by means of distance contact and blended learning modes through a network of almost 1000 centres throughout China.

\section{China's quest to build world-class universities}

In its expansion drive of higher education, the global race to build world-class universities has not bypassed China. In fact, China has devised a number of deliberate policies and programmes to pursue this dream vigorously. These include project 985, project 211, the 1000 talents programme and the double first class university scheme.

In 1995, the ministry of education launched the '211 Higher Education Institute Project'. The intention of this project was to build 100 world-class universities by means of concentrated investment in leading promising universities in selected fields or disciplines. Leading universities in China, such as Tsinghau University and Peking University, were harnessed according to this scheme.

In 1998, Project 211 was followed by the ' 985 World First Class University Project'. Under the '1000 talents' programme, top Chinese and foreign scholars are lured to China with princely salaries; preference is accorded to scholars from top international universities. This programme was originally launched in 2008. Ryan (2019:61) notes that how much this programme is driven by the global ranking race is evident in an advertisement of a university where it was stated that Nobel Prize winners are encouraged to apply. The Chinese Scholarship Council is awarding scholarships to postgraduate students from China to pursue their studies abroad. The aim of this programme is to attract 'leading talents', then '10 000' talents, that means to attract high-calibre individuals, and '1000 young talents' to lure back to China those young talents who have emigrated to foreign universities. 
These schemes involve not only very high salaries but also attractive benefits and promotion prospects.

After Project 211 and Project 985, the next major initiative, launched in 2015, was the 'Double World-Class Project' (referring to both world-class universities and world-class disciplines). This project comprises an even more intense investment in infrastructure and human resources of identified top universities. Government has targeted 42 universities as well as 465 disciplines from 140 universities for additional, substantial financial support. This funding is aimed at increased research output, 'talent cultivation' (i.e. staff development), social service, international exchange and preservation of cultural heritage.

The investment made in universities registered its impact on the global research output forum. Wolhuter (2017) did an analysis of authorship of all 18523 articles published in all the 2012 issues of Web of Science-indexed (Thomsons Reuters) scholarly journals in the field of education, and found that China contributed the 10th largest number of authors of all countries of the world. The first 10 countries and their authors and percentage of total authorship in the pool are as follows:

1. USA: $5974(35.72 \%)$

2. UK: 1915 (10.34\%)

3. Australia: 1490 (8.04\%)

4. Taiwan: 755 (4.08\%)

5. Canada: 709 (3.82\%)

6. The Netherlands: 688 (3.71\%)

7. Turkey: $614(3.31 \%)$

8. Spain: $600(3.23 \%)$

9. Germany: $546(2.95 \%)$

10. China: 455 (2.46\%) (Wolhuter 2017).

This stands in contrast to the analysis of authorship of articles published in Comparative Education Review, a top comparative and international education journal, since its inception in 1957 till 2006, when there were no authors from China despite it constituting a strong focal point of research in the field (see Wolhuter 2008). 
By 2016, the breakthrough came when China made to the top 100 universities in ARWU, with Tsinghua University attaining 45th rank, Peking University was ranked 57th and Zhejiang University's rank was 67.

The QS (2020) rankings include the following 42 universities from China in its top 1000 universities of the world:

1. Tshinghua University (16)

2. Peking University (22)

3. Fudan University (40)

4. Zhejiang University (54)

5. Shanghai Jiao Tong University (60)

6. University of Science and Technology of China (89)

7. Nanjing University (120)

8. Wuhan University (257)

9. Tongji University (265)

10. Beijing Normal University (277)

11. Harbin University of Technology (277)

12. Sun Yat Sen University (287)

13. Xi'an Jiantong University (307)

14. Nankai University (368)

15. Huazong University of Science and Technology (400)

16. Shanghai University (412)

17. Tianjin University (429)

18. Beijing University of Technology (436)

19. Xiamen University (451)

20. Beihang University (462)

20. University of Science and Technology Beijing (462)

21. Shandong University (468)

22. South China University of Technology (480)

23. Jilin University (484)

24. Southeast University (501-510 category)

25. East China Normal University (531-540 category)

26. Remnin (People's) University of China (531-540 category)

27. East China University of Science and Technology (551-560 category) 
28. Dalian Institute of Technology (571-580 category)

29. Sichuan University (601-650 category)

30. China Agricultural University (651-700 category)

31. Beijing Jiaotong University (701-750 category)

32. Beijing University of Technology (701-750 category)

33. Central South University (701-750 category)

34. Hunan University (701-750 category)

35. Shenzhen University (701-750 category)

36. Shongqing University (751-800 category)

37. Lanzhou University (751-800 category)

38. Beijing Foreign Studies University (801-1000 category)

39. Shanghai International Studies University (801-1000 category)

40. Wuhan University of Technology (801-1000 category)

41. Xi'an Jiaotong Liverpool University (801-1000 category).

China has 42 universities in the top 1000 world universities, according to QS (2020) rankings, surpassed by the USA (157 universities), the UK (84 universities) and Germany (46 universities). China has increased its number by two more universities in this top 1000 than it had in the 2019 rankings; however, here this is to be kept in mind that China had commenced the project of building universities, and world-class universities in particular, only in 1978. This clearly shows that China is on an upward trajectory in the global race for world-class universities.

\section{The South African higher education sector and the ideal of a world-class university}

By far, in most parts of the world today, the university has commenced as an imported institution, that is, it is being imported from Europe with its historically evolved features as evident in the universities of Europe which have remained unchanged. South Africa is no exception to this pattern; on the contrary, it 
represents a rather extreme example. Formal education in South Africa began relatively (compared with the rest of the world) recently in 1652 after the Dutch East Indian Company established a refreshment station in the Cape. Higher education appeared at an even later date, a few decades after the Cape Colony was taken over from the Dutch by the British in 1806. Higher education in South African became visible only in 1873, with the University of the Cape of Good Hope; its name was changed in 1919 to the University of South Africa. As is common in a colonial context, education developed along the lines of segregation, and eventually, legislation steered higher education in that direction. According to law, the population of South Africa was classified into four groups, namely, white people (people from European descent), black people (people from African descent), Asians (people from Asian, mainly Indian descent) and mixed race people (a very controversial term, referred to people of mixedracial descent). Thus by 1994, the year in which white rule in South Africa ended, there were separate universities for white, black, mixed race and Asian people.

The system of segregated education gave rise to much grievance and resistance amongst black South Africans (cf. Christie 1991). This resistance revolved around a number of objections. The first was the inequality in the system of segregated education (cf. Wolhuter 1998). Other objections included the elitistic and Eurocentric nature of education: Curricula mainly comprised European natural and cultural heritage and neglected the African natural and cultural heritage (cf. Mphahlele \& Mmninele 1997:104-119). During the socio-economic turmoil in South Africa in the run-up to 1994, schools and universities became a rallying point of unrest, civil disobedience and boycotts (cf. Booyse et al. 2011).

Thus, when the ANC took over the government in 1994, they designed a new education system based - at least in terms of stated objectives as these appeared in white papers, legal acts and other policy documents - on the principles of desegregation, equal education opportunities, democratisation and multiculturalism 
(cf. Wolhuter 1999). The attempted reconstruction of higher education based on these principles was commenced. Higher education enrolments grew impressively (although not out of proportion to global trends) from 495355 to 1116017 in 2017 (latest available figures). The South African higher education gross enrolment ratio increased from 14\% in 1994 to $22.37 \%$ in 2018 (UNESCO 2020). However, South Africa is still trailing behind other upper middle-income countries: in Argentina, Brazil and Malaysia, the corresponding figures are $89.96 \%, 51.34 \%$ and $45.13 \%$ (UNESCO 020).

Equalisation proceeded as observed in Table 10.1.

As is evident in Table 10.1, since 1994, the composition of student corps at South African public universities demonstrates a strong trend of equalisation, the composition coming closer, although still congruent to the demographic profile. However, this lack of participation corresponding to the composition of national population is not the only or even the smallest of the problems facing South African universities on the equalisation front. Coming from differential secondary school systems (black students from historically black schools entering universities are woefully underprepared academically for the demands of university studies), together with a lack of cultural capital, results in high failure and drop out rates for black students entering universities where the European heritage as building blocks still

TABLE 10.1: Student composition in South African public universities as per population group.

\begin{tabular}{lccccc}
\hline $\begin{array}{l}\text { Population } \\
\text { group/Year }\end{array}$ & Black (\%) & $\begin{array}{c}\text { Mixed race } \\
\text { (\%) }\end{array}$ & Indian (\%) & White (\%) & Total (\%) \\
\hline 1994 & 43 & 5 & 7 & 45 & 100 \\
\hline 2005 & 61 & 6 & 6 & 25 & 100 \\
\hline 2016 & 73 & 6 & 5 & 16 & 100 \\
$\begin{array}{l}\text { Population group } \\
\text { percentage of } \\
\text { total South African } \\
\text { population }\end{array}$ & 74.6 & 8.9 & 2.5 & 9.1 & 100 \\
\hline
\end{tabular}

Source: DHET (2018) and Wolhuter (2009, 2014). 
stand strong. One very visible facet of this is the difficulty South African universities experience in the Africanising of faculty, especially the professoriate.

Although the call for decolonisation has recently risen to the highest volume (see Mlamlo 2020), this is by far not the only other challenge faced by South African higher education. To return to the functions of a university as outlined above, and to use these as analytical devices, South African universities face pressing challenges on each of these five functions. On teaching and learning front, the need to increase access and decolonise curricula and to make the professoriate more representative, is already outlined. Furthermore, increasing participation and equalisation at the access point is rather meaningless if it is cancelled out by high attrition (drop out and failure) rates, more so by differential attrition rates, two stark problems besetting the South African higher education scene. A recent analysis, based on the 2010 student intake, revealed that merely $22 \%$ of students in South African universities completed their 3-year degree course in stipulated 3 years; just 39\% had completed their degrees by the fourth year, whilst 56\% completed their 3-year degree in 6 years (Businesstech 2019). For 4-year degrees, the dropout rate as per population group was $21.5 \%$ for black students, $17.8 \%$ for mixed race students, $12.2 \%$ for Indian students and $10.3 \%$ in the case of white students (Businesstech 2019). A recent survey amongst black students reported that they felt severely alienated in South African campuses (Swartz et al. 2018). White students according to the proportion of their population constitute the highest percentage of students who obtain a bachelor's degree, with $25 \%$ of them obtaining a bachelor's degree after matric (Businesstech 2019). The comparable figures of Indian, mixed race and black people are, respectively, around 15\%, 5\% and 5\% (Businesstech 2019).

The above amounts to spectacular progress made in South African higher education during the past quarter of the century, with equally formidable challenges facing the higher education sector. 
On the research front, South African universities face serious challenges regarding research output as well as research capacity. Whilst there are indications that South African universities have at least pockets of excellence regarding research. For example, in an analysis of the articles published in all Web of Science-indexed journals in the field of education in 2012, Wolhuter (2017) found that in the total global author pool of 18523 authors, South Africa occupied the 14th position in the rank-order of countries, a notable achievement in view of the small size of South African academic profession. These pockets of excellence of scholars have made their mark on international research fora; still on aggregate, the South African academic profession does not excel when it comes to area of research. For example, in the international Changing Academic Profession (CAP) survey of academics, it was found that of the 23 participating countries, South African academics have the lowest research output (Wolhuter et al. 2011, 2014). Mouton et al. (2019:3) have carried out monumental research regarding the research output of South African scholars and the international standing thereof. South Africa's total output of articles published in Web of Science-indexed journals rose from 3668 publications in 2000 to 15550 in 2016. This increase represents an average annual growth rate of $2.9 \%$. This also means that South Africa's share of world output more than doubled from $0.4 \%$ in 2000 to $0.91 \%$ in 2016 . As far as country rank is concerned, South Africa has improved its world ranking: From rank 34 in 2000 to 28 in 2016 (Mouton et al. 2019:3).

Huge challenges are present on the front of doctoral education too. South Africa produces 46 doctorates per million population per year, placing it at 64th rank-order position in the world (Mouton et al. 2019:36). For comparison, the corresponding figures for Switzerland and Slovenia (currently the world leaders) are 485 each, for the UK 409, the USA 166 and China 31. The number of doctoral degrees awarded has increased impressively from 972 in 2000 to 2525 in 2012 (Mouton et al. 2019:36). However, there is still quite some way to cover to attain the $2030 \mathrm{goal}$ of 100 doctoral graduates per million population per year set by the 
National Development Plan (see Auf der Heyde 2015). On the equalisation front, although much progress has been made, the inclination is even steeper than in the case of the aggregate university enrolments cited above. The percentage of black students in the doctorate cohort has risen from 25\% in 2000 to $47 \%$ in 2015 (latest available figures at the time of writing; Mouton et al. 2019:36). Whilst it has been empirically shown that the attainment of a doctorate makes a significant difference in the research output of South African academics (at least at aggregate level; see Wolhuter et al. 2004), research has also indicated a very low rate of transpiration of doctoral research into scholarly output, especially impact-making scholarly articles and book chapters (see Wolhuter 2015).

On the service function, South African universities, or at least academics, as measured by the results of the CAP survey, do not excel. As far as innovation is concerned, South African universities are not known as fountain heads of patents or technological innovations. Regarding the function of the preservation and development of cultural heritage, the failure to protect, let alone develop and empower the indigenous languages of the country as languages and learning and teaching at university level (as explained in ch. 4 and ch. 7 of this book) is a serious indictment on South African universities.

As explained above, by nature of its unique place in the society, university as an autonomous institution promoting the advancement of various branches of higher learning is the conscience of society, delivering social critique (see Wolhuter 2012). Whilst especially the historically white English universities as well as (in another way) black universities have performed this role of social critique actively in the years up to 1994, since 1994 this critical voice has become mute (see Gumede \& Dikeni 2009; Weeks et al. 2006). Although it is true that South African university campuses - particularly in 2015 and some time immediately thereafter - were places of student activism hitting the front pages of newspapers, two provisionary notes should be made before these could be judged as being part of the university's 
societal critique function. The first is that protests revolve around student grievances (i.e. students' personal grievances), rather than national, much less international, issues (issues such as student financing, student housing and students' sense of belonging they were experiencing on campuses; see Habib 2019; Wolhuter \& Van der Walt Forthcoming). Global issues such as global warming or global refugee problem were totally absent. The second problem is that the violent and destructive behaviours that accompany such protest actions makes it hard to declare these as places where societal critique can take place in a secure atmosphere of free speech. In the bout of activism on South African campuses in 2015, damage to the extent of South African Rand 150 million (roughly $\$ 10 \mathrm{~m}$ ) was incurred. Even very progressive South African social commentators, such as Makhanya (2020) - who in no way is regarded as reactionary - have expressed their unreserved objection to this kind of activism.

It is not only with respect to each of the five functions of the university that the university sector in South Africa is facing considerable challenges. Challenges of similar magnitude are present on institutional and systemic levels too. Managerialism, for a variety of reasons, has become a global problem in the university sector to the effect that it hampers the academic profession in carrying out its work and the university to fulfil its mission in the society (see Wolhuter et al. 2011). In the post-1994 context of the restructuring of higher education in South Africa, consonant to the new socio-political dispensation, managerialism suddenly came down upon the South African academic profession from a double barrel, that is, from national government as well as institutional governance, with grave consequences. According to the results of the CAP survey, the South African academic profession is experiencing more severe and more dispiriting consequences than any of the other 22 countries in which the survey was carried out (Wolhuter et al. 2011).

However, at the same time, the desire to grow into world-class universities is present as strongly as anywhere else in the world. This can be read (even though the precise term world-class 
university may not always be used) in the policy statements and acts of government as well as mission statements of individual universities. South African universities take part in world rankings, and when they make it to the top echelons, they proudly boast their status on their web pages. In the QS (2020) rankings, eight South African universities made their mark in the list of top 1000 world universities, although this is one down from the QS (2019) rankings. This indicates a downward trajectory. Commenting on the performance of South African universities in global rankings in recent years, compared to previous years, commentators have observed and expressed their concerns on this drop in ranking (e.g. see Businesstech 2018a, 2018b).

\section{Conclusion}

In the global history, the university as an institution has been present for more than a millennium. For a long time, the university existed as an institution at the fringe of society. It is only in the past century that it began to move to the centre of the society and societal dynamics. The global higher education revolution, which began in around 1990 and is still continuing, with no signs of decreasing momentum, has given the university new prominence in the society. Moreover, the nascent knowledge economy and the approaching fourth industrial revolution have bode well for an even more pivotal role of university in the society. In a globalised 'flat' world (to use Friedman's [2006] expression for the 21st-century world, where technology has obliterated any advantage which geography may have endowed on nations, and where expertise is becoming the pivotal factor to determine national power), the competition or race to develop world-class universities has inevitably hit every nation. This dream of having world-class universities has also - rightfully and commendably come home to South African society as a collective, visibly in its politically organised form, as well to each university, and surely must be treasured by alumni of every university too. At present, however, it seems that not only a few South African universities 
have made to the top echelon of world universities but in the conventional academic rankings, they are sliding downwards. Mindful of what was explained in Chapter 2 of this volume, regarding the use of comparative international perspectives in elucidating domestic educational issues - it brings to the fore the following question: What can South Africa learn from the experience of China?

The first and obvious lesson, speaking out of the experience of China, is the value of a concerted, concentrated and financially muscular effort to build world-class universities. Certainly, that would be well worth emulating by South Africa. However, as explained in Chapter 2, the use of comparative method in a valid manner requires the factoring-in of contextual similarities and differences of the two societal and education systems. Whilst the imperative to build world-class universities in South Africa is as strong as in China, that is, a contextual similarity, there is hardly any free-flowing cash in either the DHET or the fiscus of national government to make such an exercise a realistic option.

The second and more realistic suggestion that can be tabled from this chapter is to utilise the 'belt and road' outward drive of China, which is also evident in its higher education sector (see Steyn et al. 2018). This drive, more so within the frame of the BRICS supranational grouping and its facilitating structures, creates opportunities for collaborations between the universities of China and that of South Africa. Through this way, South African universities and scholars can plug into China's initiatives of building world-class universities and have benefits accordingly. It should be cautioned that the imperative to build world-class universities is by far not the only (it can even, arguably, be stated as not the most pressing or most important) challenge facing South African universities. A single-minded focus on this task of building world-class universities can easily render South African universities irrelevant on the South African societal landscape, and thus even make such an exercise contra-productive or selfdefeating. The assignment of building world-class universities in 
South Africa should be carried out in harmony and in sync, in symbiosis with a host of other tasks such as expanding and equalising access to higher education, building research capacity and decolonising higher education. Conversely, it should also be mentioned that collaboration in the higher education sector with China has recently come under criticism from scholars of many countries (e.g. see Altbach 2019; Bennett 2019; UK Parliament 2019). These criticisms should be given heed too when pursuing the interests of South Africa and South African universities in building world-class universities and looking to China for support.

Receiving the 'belt and road' outreach from China's worldclass universities and crafting it in such a way that it serves the South African higher education sector on a broad front, with its culmination in the building of world-class universities should be the vision. 


\section{References}

\section{Chapter 1}

Africa Check, 2018, Fact sheet: South Africa's crime statistics for 2016/17, viewed 07 January 2018, from https://africacheck.org/factsheets/south-africascrime-statistics-201617/.

Ananga, E.D., 2011, 'Typology of school dropout: The dimensions and dynamics of dropout in Ghana', International Journal of Educational Development 4, 374-381. https://doi.org/10.1016/j.ijedudev.2011.01.006

Battin-Pearson, S., Newcomb, M.D., Abbott, R.D., Hill, K.G., Catalano, R.F. \& Hawkins, J.D., 2000, 'Predictors of early high school dropout: A test of five theories', Journal of Educational Psychology 92(3), 568-582. https://doi. org/10.1037/0022-0663.92.3.568

Berry, L., Almeleh, C., Giese, S., Hall, K., Masitery, K. \& Sanke, W., 2017, South African early childhood review 2017, viewed 12 August 2019, from http://ilifalabantwana. co.za/wp-content/uploads/2017/10/SA-ECR_2017_WEB-new.pdf.

Booyse, J.J., 2011, 'Education provisioning during the period of National Party Rule', in J.J. Booyse, C.S. Le Roux, J. Seroto \& C.C. Wolhuter (eds.), A history of schooling in South Africa: Method and context, pp. 215-265, Van Schaik, Pretoria.

Bowles, S. \& Gintis, H.A., 1976, Schooling in capitalist America: Educational reform and the contradictions of economic life, Haymarket Books, Chicago, IL.

Bray, M. \& Thomas, R.M., 1995, 'Levels of comparison in educational studies: Different insights from different literatures and the value of multilevel analyses', Harvard Educational Review 65(3), 472-490. https://doi. org/10.17763/haer.65.3.g3228437224v4877

Businesstech, 2018, 'South African universities drop down global ranking', Businesstech, 15 August, viewed 27 August 2019, from https://businesstech. co.za/news/government/264989/south-african-universities-drop-downglobal-ranking/.

Carruthers, J., 1992, 'South African universities: A historical perspective', in J. Carruthers (ed.), Universities in South Africa 1873 to 1918 and the Royal Society of South Africa, pp. 59-75, Royal Society of South Africa, s.I.

Centre for Early Childhood Development, 2018, Annual report 2017/18, viewed 12 August 2019, viewed 23 December 2019, from https://www.hst.org. za/publications/NonHST\%2OPublications/Centre\%2Ofor\%20Early\%20 Childhood\%2ODevelopment\%20Annual\%20Report\%202017\%202018.pdf.

Centre for World University Rankings (CWUR), 2019, World University Rankings 2019: Results announced, viewed 24 August 2020, from https://www. timeshighereducation.com/news/world-university-rankings-2019-resultsannounced. 
Christie, P., 1991, The right to learn: The struggle for education in South Africa, 2nd edn., Ravan Press, Braamfontein.

Council for Higher Education (CHE), 2017, CHE briefly speaking, vol. 2, viewed 05 August 2019, from https://www.che.ac.za/sites/default/files/publications/ BrieflySpeaking\%20(2)\%20Educational\%20pathways.pdf.

Department of Education (DoE), 2001, Manifesto on values, education and democracy, viewed 12 December 2018, from https://www.gov.za/sites/ default/files/manifesto_O.pdf.

Department of Higher Education and Training (DHET), 2018, Statistics on post-school education and training in South Africa, 2016, viewed 27 August 2019, from http://www.dhet.gov.za/Research\%20Coordination\%20 Monitoring\%20and\%20Evaluation/6_DHET\%20Stats\%20Report_04\%20 April\%202018.pdf.

De Wet, C. \& Wolhuter, C., 2009, 'A transitiological study of some South African educational issues', South African Journal of Education 29(3), 359-376.

Farrell, J.P., 1982, 'Educational expansion and the drive for social equality', in P.G. Altbach, R.F. Arnove \& G.P. Kelly (eds.), Comparative education, pp. 52-60, Macmillan, New York, NY.

Farrell, J.P., 2013, 'Equality of education: Six decades of comparative evidence seen from a new millennium', in R.F. Arnove, C.A. Torres \& S. Franz (eds.), Comparative education: The dialectic of the global and the local, pp. 149-174, Littlefield and Rowman, Lanham, MD.

Fourie, J., 2019, 'Prioriteit nommer een: Skep werk', Rapport, Sake-Rapport, 18 August 2019, p. 2.

Friedman, T.L., 2006, The world is flat: The globalized world in the twenty-first century, Penguin, London.

Fukuyama, F., 1999, The great disruption: Human nature and the restoration of social order, Profile Books, London.

Giliomee, H., 2019, The rise and demise of the Afrikaner, Tafelberg, Cape Town.

Irvin, K.G., Siddiqi, A. \& Hertgrun, C., 2007, Early childhood development: The great equalizer, Report for the World Health Organization, viewed 12 August 2019, from https://www.hst.org.za/publications/NonHST\%2OPublications/ Centre\%20for\%20Early\%20Childhood\%20Development\%20Annual\%20 Report\%202017\%202018.pdf.

Karis, T. \& Gerhart, G.M., 1977, From protest to challenge: A documentary history of African politics in South Africa: 1882-1964, Volume 3: 1953-1964, Stanford University, Hoover Institution Press, Stanford, CA.

Kuper, S., 2019, 'How Oxbridge distorts British life', Financial Times, O1 August, viewed 05 August 2019, from https://www.ft.com/content/15da8c42-b32511e9-bec9-fdcab53d6959.

Lazenby, H., 2016, 'What is equality in education?', Theory and Research in Education 14(1), 65-76. https://doi.org/10.1177/1477878515619788 
Li, Y., 2017, 'International education comparison: An intellectual tradition and its contemporary considerations', Discourse: Studies in the Cultural Politics of Education 38(6), 955-963. https://doi.org/10.1080/01596306.2016.1187873

Locke, W., Cummings, W.K. \& Fisher, D. (eds.), 2011, Changing governance and management in higher education: The perspectives of the academy, Springer, Dordrecht.

Morrow, S. \& Gxabalashe, K., 2000, 'The records of the University of Fort Hare', History in Africa 27, 481-497 (Cambridge University Press). https://doi. org/10.2307/3172130

Manzon, M., 2014, 'Comparing places', in M. Bray, B. Adamson \& M. Mason (eds.), Comparative education research: Approaches and methods, pp. 97-138, Springer, Dordrecht.

Mentz, E., Bailey, R., Verster, M. \& Breed, B., 2018, 'Incorporating active teaching - Learning strategies to enhance self-directed learning within the curriculum as praxis: An imperative for the 21st century', in C.C. Wolhuter (ed.), Raising the impact of education research in Africa, pp. 151-180, AOSIS, Cape Town. https://doi.org/10.4102/aosis.2018.BK53.08

Montacute, R. \& Nightingale, R., 2019, Sutton trust cabinet analysis 2019, viewed 05 August 2019, from https://www.suttontrust.com/research-paper/suttontrust-cabinet-analysis-2019/.

Mupunga, V., 2019, 'Investing in education: The case for independent schools in South Africa', Mail \& Guardian, viewed 25 August 2020, from https://mg.co. za/article/2019-08-02-00-investing-in-education-the-case-for-independentschools-in-sa/.

Nel, C.-A., 2016, 'Getal Afrikaanse Skole Krimp Erg Sedert 2010', Beeld, 18 February, p. 1.

Nkomo, M. (ed.), 1990, Pedagogy of domination: Towards a democratic education in South Africa, Africa World Press, Trenton, NJ.

Ogude, N.A., Netswera, F.G. \& Mavundla, T.R., 2003, 'Status and evolution of research within South African technikons: A critical analysis', Higher Education Policy 16(3), 283-299. https://doi.org/10.1057/palgrave.hep.8300022

Organisation for Economic Cooperation and Development (OECD), 2018, A broken social elevator? How to promote social mobility, viewed 05 August 2019, from https://read.oecd-ilibrary.org/social-issues-migration-health/ broken-elevator-how-to-promote-social-mobility_9789264301085-en\#page1.

Republic of South Africa (RSA), 1996, South African Schools Act, Act 84 of 1996, viewed 13 August 2019, from https://www.gov.za/sites/default/files/gcis_ document/201409/act84of1996.pdf.

Republic of South Africa (RSA), 2005, Education statistics at a glance in 2004, Government Printer, Pretoria.

Republic of South Africa (RSA), 2018, 2011 Census in brief, viewed 08 January 2018, from http://www.statssa.gov.za/census/census_2011/census_products/ Census_2011_Census_in_brief.pdf. 
Republic of South Africa (RSA), 2019a, Quarterly labour force statistics: Quarter 2: 2019, viewed 18 August 2019, from http://www.statssa.gov.za/publications/ P0211/P02112ndQuarter2019.pdf.

Republic of South Africa (RSA), 2019b, South African education statistics, viewed 17 August 2019, from https://www.southafricanmi.com/educationstatistics.html.

Rubagumya, C.M., Afitska, O., Clegg, J. \& Kiliku, P., 2011, 'A three-tier citizenship: Can the state in Tanzania guarantee linguistic human rights?', International Journal of Educational Development 31, 78-85. https://doi.org/10.1016/j. ijedudev.2010.06.007

Schiavone, G., 2005, International organizations: A dictionary and directory, 6th edn., Palgrave Macmillan, New York, NY.

Segalo, L. \& Rambuda, A.M., 2018, 'South African public school teachers' views on right to discipline learners', South African Journal of Education 38(2), 1-11.

Skosana, I., 2018, Women teach and men lead? Gender inequality in South African schools examined, viewed 17 August 2019, from https://africacheck. org/reports/women-teach-and-men-lead-gender-inequality-in-south-africanschools-examined/.

Sobe, N. \& Kowalzyk, J.A., 2014, 'Exploring the cube: Revisioning context in the field of comparative education', Current Issues in Comparative Education 16(1), 6-12.

Steiner-Khamsi, G. (ed.), 2004, The global politics of educational borrowing and lending, Teachers College Press, New York, NY.

Steyn, H.J. \& Wolhuter, C.C., 2008, 'The education system and probable societal trends of the twenty-first century', in H.J. Steyn \& C.C. Wolhuter (eds.), Education systems: Challenges of the 21st century, pp. 35-100, Keurkopie, Noordbrug.

Stiglitz, J., 2019, People, power and profits: Progressive capitalism for an age of discontent, Allen Layne, London.

Strassburg, S., Meny-Gibert, S. \& Russell, B., 2010, Left unfinished: Temporary absence and drop-out from South African schools. Findings from the access to education study, vol. 2, Social Surveys Africa, Johannesburg.

Sutherland, L. \& Wolhuter, C., 2002, 'Do good researchers make good teachers', Perspectives in Education 20(3), 77-83.

Tabata, J.G., 1960, Education for barbarism, Unity Movement of South Africa, London.

Tandwa, L., 2016, 'South Africa: \#Fees must fall costs country R150 million Nzimande', News24, 16 January, viewed 14 April 2016, from http://allafrica. com/stories/201601201489.html.

Thomson Reuters, 2019, World's most innovative universities 2018, viewed 11 August 2019, from https://www.reuters.com/innovative-universities-2018/ profile?uid=1. 
Townsend, L., Flisher, A.J. \& King, G., 2007, 'A systematic review of the relationship between high school dropout and substance use', Clinical Child and Family Psychology Review 10(4), 295-317. https://doi.org/10.1007/s10567007-0023-7

Trends in International Mathematics and Science Study (TIMSS), 2019, TIMSS 2015 international mathematics achievement, viewed 16 August 2019, from http://timssandpirls.bc.edu/timss2015/international-results/wp-content/ uploads/filebase/mathematics/1.-student-achievement/1_0_8_math-studentachievement-infographic-grade-8.pdf.

United Nations Educational Scientific and Cultural Organization (UNESCO), 1972, Apartheid: Its effects on education, sciences, culture and information, UNESCO, Paris.

United Nations Educational Scientific and Cultural Organization (UNESCO), 2018, Statistics, viewed 23 August 2019, from http://data.uis.unesco.org/.

United Nations Educational Scientific and Cultural Organization (UNESCO), 2019, Statistics, viewed 13 August 2019, from http://data.uis.unesco.org/.

Van der Walt, J.L. \& Wolhuter, C.C., 2016, 'Eerste Taal as Onderrig medium in Hoër Onderwys: 'n internasionale perspektief [First Language as a Teaching Medium in Higher Education: An International Perspective]', Tydskrif vir Geesteswetenskappe 56(4-1), 1016-1033. https://doi.org/10.17159/22247912/2016/v56n4-1a9

Ward, K., 2003, Faculty service roles and the scholarship of engagement, viewed 11 August 2019, from https://files.eric.ed.gov/fulltext/ED476222.pdf.

Weybright, E.H., Caldwell, L.L., Xie, H., Wegner, L. \& Smith, E.A., 2017, 'Predicting secondary school dropout among South African adolescents: A survival analysis approach', South African Journal of Education 37(2), a1353. https:// doi.org/10.15700/saje.v37n2a1353

Wolhuter, C.C., 1993, 'Gelyke Onderwysgeleenthede met besondere verwysing na die implikasies daarvan vir onderwysvoorsiening in die RSA [Equal education opportunities and the implications thereof for education supply in the RSA]', D.Ed thesis, University of Stellenbosch.

Wolhuter, C.C., 1994, 'Vergelykende perspektief op Vergelykende Opvoedkunde in Suid-Afrika [Comparative Perspective on Comparative Education in South Africa]', Suid-Afrikaanse Tydskrif vir Opvoedkunde 14(3), 155-158.

Wolhuter, C.C., 1997a, 'Classification of national education systems: A multivariate approach', Comparative Education Review 41(2), 161-177. https:// doi.org/10.1086/447428

Wolhuter, C.C., 1997b, 'Desiderata in South African higher education studies' window on the outside world', South African Journal of Higher Education 11(1), 35-40.

Wolhuter, C.C., 1998, 'Spektroskopie van die Suid-Afrikaanse onderwysstelsel binne die internasionale ry van onderwysstelsels [Spectroscopy of the South African education system within the international line of education systems]', Suid-Afrikaanse Tydskrif vir Opvoedkunde 18(1), 9-19. 
Wolhuter, C.C., 1999, 'Sociaal-wetenschappelijke literatuur over onderwijs in Zuid-Afrika: van verzuilen tot eensgezindheid vanuit verscheidenheid [Social science literature on education in South Africa: from pollarization to unity based on diversity]', Pedagogische Studiën (the Netherlands) 76, 361-370.

Wolhuter, C.C., 2008, 'Review of the review: Constructing the identity of comparative education', Research in Comparative and International Education 3(4), 323-344. https://doi.org/10.2304/rcie.2008.3.4.323

Wolhuter, C.C., 2011, 'The spectrum of international educational development', Journal of Educational Planning and Administration 25(3), 235-247.

Wolhuter, C.C., 2012, "n Wêreldklasuniversiteit in Suid-Afrika: Ideaal, wenslik, haalbaar, werklikheid, hersenskim? [A world-class university in South Africa: Ideal, desirable, achievable, reality, brain teaser?]', Lit Net Akademies 9(2), 284-308.

Wolhuter, C.C., 2014a, 'Research on higher education in South Africa: Stock taking and assessment from international comparative perspectives', South African Journal of Higher Education 28(1), 275-291. https://doi. org/10.20853/28-1-323

Wolhuter, C.C., 2014b, 'Weaknesses of South African education in the mirror image of international educational development', South African Journal of Education 34(2), 1-9. https://doi.org/10.15700/201412071120

Wolhuter, C.C., 2015, 'The case of the education system of South Africa on the world map: Inspiring case or call for guidance from abroad?', in C.C. Wolhuter, L. Jacobs \& H.J. Steyn (eds.), Thinking about education systems, pp. 57-77, Keurkopie, Noordbrug.

Wolhuter, C.C., 2020, 'The scholarly field of comparative and international education and its promise in the global south', in J. Seroto, C.C. Wolhuter \& D. Noor (eds.), History of education and comparative education: Decolonising education in the Global South, pp. 21-39, Pearson, Pretoria.

Wolhuter, C.C. \& Mushaandja, J., 2015, 'Contesting ideas of a university:

The case of South Africa', Humanities 4, 212-223. https://doi.org/10.3390/ h4020212

Wolhuter, C.C., Thomas, M., Mashau, T.S. \& Steyn, H.J., 2018, 'Comparative and international education: A tool for powerful global impact available to South African scholars', in C.C. Wolhuter (ed.), Raising the impact of education research in Africa, pp. 253-284, AOSIS, Cape Town. https://doi.org/10.4102/ aosis.2018.BK53.12

Wolhuter, C.C. \& Van der Walt, J.L., 2018, 'Wat is Fout met Suid-Afrikaanse Skole: Geheelbeeld van, en leemte in die navorsing oor skoolleierskap as sleutelfaktor [What is Wrong with South African Schools: Overall picture of, and gap in, research over-school leadership as a key factor]', Lit net Akademies (Opvoedkunde) 15(2), 463-485.

Wiseman, A.W. \& Wolhuter, C.C., 2013, 'The incalculable promise of the African continent in higher education rising to the occasion', in A.W. Wiseman \& 
C.C. Wolhuter (eds.), Development of higher education in Africa: Prospects and challenges (International Perspectives on Education and Society 21), pp. 3-20, Emerald, Bingley.

\section{Chapter 2}

Agarwal, P., 2017, 'India's growth of postsecondary education: Scale, speed and fault lines', in P.G. Altbach, L. Reisberg \& H. De Wit (eds.), Responding to massification: Differentiation in postsecondary education worldwide, pp. 71-81, Boston College, Boston, NY.

Altbach, P.G., Reisberg, L. \& Rumbley, L.E., 2009, Trends in global higher education: Tracking an academic revolution, United Nations Educational Scientific and Cultural Organisation, Paris.

Baxi, U. \& Parekh, B. (eds.), 1995, Crisis and change in contemporary India, The Book Review Literary Trust, New Delhi.

Bereday, G.Z.F., 1964, Comparative method in education, McGraw-Hill, New York, NY.

Biraimah, K., 2006, 'Knowing others and knowing self: Patterns of differential publishing in education journals from the north and self', Southern African Review of Education 12(2), 81-92.

Bray, M., 2014, 'Comparative education: Actors and purposes', in M. Bray, B. Adamson \& M. Mason (eds.), Comparative education: Approaches and methods, pp. 19-46, Comparative Education Research Centre, the University of Hong Kong, Hong Kong.

Brock, C., 2013, Education around the world: A comparative introduction, Bloomsbury, London.

Central Intelligence Agency (CIA), 2019, World fact book, viewed 24 August 2020, from https://www.cia.gov/library/publications/the-world-factbook/ rankorder/2172rank.html.

Cherry, M., 2011, 'Education and training need the involvement of all levels of government, editorial comment', South African Journal of Science 107(7/8), 1.

De Wet, C. \& Wolhuter, C., 2007, 'From "borrowing" to "learning" in international comparative study: A critical reflection', South African Journal of Education 27(2), 317-328.

Earth Overshoot Day, 2019, Country overshoot days, viewed 23 December 2019, from https://www.overshootday.org/newsroom/country-overshoot-days/.

Epstein, E., 1992, 'The problematic meaning of "comparison" in comparative education', in J. Schriewer \& B. Holmes (eds.), Theories and methods in comparative education, pp. 3-23, Peter Lang, Frankfurt.

Forestier, K. \& Crossley, M., 2014, 'International education policy transfer Borrowing both ways: The Hong Kong and England experience', Compare: 
A Journal of Comparative and International Education 45(5), 664-685. https://doi.org/10.1080/03057925.2014.928508

Frankopan, P., 2018, The new silk roads: The present and future of the world, Bloomsbury, London.

Harbison, F. \& Myers, C.A., 1964, Education, manpower and economic growth: Strategies of human resource development, Macmillan, New York, NY.

Jakhar, P., 2019, 'Confucius institutes: The growth of China's controversial cultural branch', BBC Monitoring, 07 September, viewed 24 December 2019, from https://www.bbc.com/news/world-asia-china-49511231.

Johnson, R.W., 2015, How long will South Africa survive? The looming crisis, Jonathan Ball, Johannesburg.

Kotze, K., 2019, 'Use BRICS to help build a better country', Mail \& Guardian, 15-21 November, p. 31, viewed 25 August 2020, from https://mg.co.za/article/201911-15-00-use-brics-to-help-build-a-better-country/.

Li, Y., 2017, 'International education comparison: An intellectual tradition and its contemporary considerations', Discourse: Studies in the Cultural Politics of Education 38(6), 955-963. https://doi.org/10.1080/01596306.2016.1187873

Lo, V.I., Hiscock, M. \& Edward Elgar, P., 2014, The rise of the BRICS in the global political economy: Changing paradigms?, Edward Elgar, Cheltenham.

Manzon, M., 2011, Comparative education: The construction of a field, Comparative Education Research Centre, the University of Hong Kong, Hong Kong.

Morgan Stanley Capital International (MSCI), 2019, MSCl emerging markets, viewed 25 December 2019, from https://www.msci.com/emerging-markets.

Online Etymological Dictionary, 2019, Comparison, viewed 25 December 2019, from https://www.etymonline.com/word/comparison.

Organisation for Economic Cooperation and Development (OECD), 2011, Education at a glance: Highlights, Organisation for Economic Cooperation and Development Publishing, Paris.

Pedrosa, R.H.L., 2011, 'Assessing higher education outcomes in Brazil', International Higher Education 63 (March), 24-26.

Planel, C., 2008, 'The rise and fall of comparative education in teacher training; should it rise again as comparative pedagogy?', Compare 38(4), 381-383. https://doi.org/10.1080/03057920701467867

Pounds, N.J.G., 1972, Political geography, McGraw-Hill, New York, NY.

Ryan, J., 2019, Education in China, Polity, Cambridge.

Sahlberg, P., 2010, Finnish lessons: What can the world learn from educational change in Finland?, Teachers College Press, Amsterdam.

Statistics Times, 2019, List of countries in the world as per capita income, viewed 25 December 2019, from http://statisticstimes.com/economy/countries-bygdp-capita.php. 
Steyn, H., Van der Walt, H. \& Wolhuter, C., 2015, 'A generic model of "the" education system for the purposes of making critical comparisons of policy', Croatian Journal of Education 17(4), 1131-1158. https://doi.org/10.15516/cje. v17i4.1739

Stone, H.J.S., 1983, The common and the diverse: A profile of comparative education, McGraw-Hill, Johannesburg.

Ulich, R., 1961, The education of nations: A comparison in historical perspective, Harvard University Press, Boston, MA.

Thut, I.N. \& Adams, D.K., 1964, Educational patterns in contemporary societies, McGraw-Hill, New York.

Trace, A., 1961, What Ivan knows that Johnny doesn't, Random House, New York, NY.

United Nations Educational Scientific and Cultural Organization (UNESCO), 2019, Statistics, viewed 22 December 2019, from http://data.uis.unesco.org/.

Vadra, R., 2017, 'Knowledge economy in BRICS: A case of South Africa', Journal of Knowledge Economy 8(4), 1229-1240. https://doi.org/10.1007/s13132-0170512-y.

Vadra, R., 2018, 'After BRICS, CIVETS as emerging markets', Journal of International Economics 9(2), n.p.

Van Noort, C., 2018, 'Study of strategic narratives: The case of BRICS', Politics \& Governance 5(3), 121-129. https://doi.org/10.17645/pag.v5i3.961

Watson, K., 2012, 'South-east Asia and comparative studies', Journal of International and Comparative Education 1(1), 31-39. https://doi. org/10.14425/00.36.42

Wiseman, A.W., 2012, 'A framework for understanding international perspectives in education', in N. Popov, C. Wolhuter, B. Leutwyler, G. Hilton, J. Ogunleye \& P.A. Almeida (eds.), International perspectives on education, pp. 1-21, Bulgarian Comparative Education Society, Sofia.

Wiseman, A.W. \& Wolhuter, C.C. (eds.), 2019, Comparative and international education: Survey of an infinite field, Emerald, Bingley.

Wolhuter, C.C., 1995., 'Education in Latin America: Lessons for South Africa from a sister continent', UNISA Latin American Report 11(1), 21-30.

Wolhuter, C.C., 1996, 'Whatever happened to education in the erstwhile Union of the Socialist Soviet Republics', Paidonomia 19(1), 21-33.

Wolhuter, C.C., 2008, 'Review of the review: Constructing the identity of comparative education', Research in Comparative and International Education 3(4), 323-344. https://doi.org/10.2304/rcie.2008.3.4.323

Wolhuter, C.C., 2011, 'The spectrum of international educational development', Journal of Educational Planning and Administration 25(3), 235-247.

Wolhuter, C.C., 2015, 'Comparative and international education: Conceptual clarification and significance', in C.C. Wolhuter, L. Jacobs \& H.J. Steyn (eds.), Thinking about education systems, pp. 13-32, Keurkopie, Noordbrug. 
Wolhuter, C.C., 2017, 'The geography of authorship regarding research in education', Croatian Journal of Education 19(3), 981-1000. https://doi. org/10.15516/cje.v19i3.2207

Wolhuter, C.C., 2018, 'The salience of African scholars in education research', Africa Education Review 16(1),142-157. https://doi.org/10.1080/18146627.2016.1241669

Wolhuter, C.C. \& Barbieri, N., 2017, 'Is the ideal of universal adult literacy in the world by the year 2030 statistically attainable?', Revista Internazionale Scienze Sociali 2017(1), 87-102.

Wolhuter, C.C. \& Chigisheva, O., 2020, 'The BRICS countries grouping: Promise of a new thematic and methodological research focus in the Social Sciences and the Humanities', Journal of Space and Culture, India 7(5), 3-13.

Wolhuter, C.C., O’Sullivan, M., Anderson, E., Wood, L., Karras, K.G., Mihova, M. et al., 2011, 'Students' expectations of and motivations for studying comparative education: A comparative study across nine countries in North America, Europe, Asia, Africa and Latin America', Educational Research 2(8), 1341-1355.

Wolhuter, C. \& Van der Walt, H., 2018, 'Wat is Fout met Suid-Afrikaanse Skole: Geheelbeeld van, en leemte in die navorsing oor skoolleierskap as sleutelfaktor [What is Wrong with South African Schools: Overall picture of, and gap in, research on school leadership as a key factor]', Litnet Akademies (Opvoedkunde) 15(2), 463-485.

Wolhuter, C., Van Jaarsveld, L. \& Challens, B., 2018, 'Die oorkoming van kontekstuele Beperkinge in Leierskap aan Toppresterende Skole [Overcoming Contextual Restrictions in Leadership at Top-Performing Schools]', Litnet Akademies 15(3), 866-892.

Word Finder, 2019, Tertium comparationis, viewed 26 December 2019, from https://findwords.info/term/tertium\%20comparationis.

World Bank, 2019, World Bank indicators, viewed 26 December 2019, from https://data.worldbank.org/indicator/ny.gdp.mktp.kd.zg.

Worldometers, 2019, Population, viewed n.d., from https://www.worldometers. info/population/most-populous-countries/\#future.

\section{Chapter 3}

Atmoree, E., 2013, 'Early childhood development in South Africa - Progress since the end of apartheid', International Journal of Early Years Education 21(2-3), 152-162. https://doi.org/10.1080/09669760.2013.832941

Azevedo de Aguiar, G., Barker, G., Nascimento, M. \& Segundo, M., 2007, 'Early childhood in Brazil: General overview and current issues', Working Paper 44, Bernard van Leer Foundation, The Hague, The Netherlands.

Center for Early Childhood Education and Development (CECED), 2012a, Exploring impact of early learning, socialization and school readiness experiences in pre-school settings on educational and behavioral outcomes along the primary stage, Ambedkar University, Delhi and Assessment Survey Evaluation Research (ASER), New Delhi. 
Center for Early Childhood Education and Development (CECED), 2012b, Report on preparing teachers for early childhood education, Centre for Early Childhood Education and Development, Ambedkar University, Delhi and National Council of Teacher Education, New Delhi.

Choi, S., 2007, Policy review report on early childhood and care in Brazil, UNESCO, Paris.

Department of Basic Education (DBE), 2009, National early learning and development standards for children birth to four years (NELDS), pp. 1-38, Department of Basic Education, Pretoria.

Department of Basic Education (DBE), 2015, The South African national curriculum framework for children from birth to four (NCF), pp. 1-81, Department of Basic Education, Pretoria.

Department of Education (DoE), 2001, Education white paper 5 on early childhood education, meeting the challenge of early childhood development in South Africa, Department of Education, Pretoria.

Department of Education, 2010, Annual report: 2009-2010, viewed 22 October 2019, from https://www.education.gov.za/Portals/O/ Documents/Reports/DoE\%20Annual\%20Report\%202009-10\%20web. pdf?ver=2010-10-21-090504-097.

Education Promotion Society for India, 2019, National education policy (NEP), Government of India, New Delhi.

Evans, D.K. \& Kosec, K., 2012, Early child education: Making programs work for Brazil's most important generation, Report No. 69307, World Bank, Washington, DC.

Fernandes, S., 2014, 'The World Bank's position on early childhood education in Brazil: A critical assessment of contributions and shortcomings', Journal of Education Policy 29(2), 263-279. https://doi.org/10.1080/02680939.2013. 825328

Goncalves, T.R., Duku, E. \& Janus, M., 2019, Developmental health in the context of an early childhood programme in Brazil: The Primeira Infancia Melhor experience, Cadernos De Saude, Rio de Janeiro.

Haddad, L., 2016, 'An integrated approach to early childhood education and care and integration within education: The Brazilian experience', Creative Education 7, 278-286. https://doi.org/10.4236/ce.2016.72026

Heckman, L., 2012a, Invest in early childhood development: Reduce deficits, strengthen the economy, viewed 30 October 2019, from https:// heckmanequation.org/resource/invest-in-early-childhood-developmentreduce-deficits-strengthen-the-economy/.

Heckman, J., 2012b, The Heckman equation, viewed 03 October 2019, from https://heckmanequation.org/www/assets/2013/07/F_ HeckmanDeficitPieceCUSTOM-Generic_052714-3-1.pdf.

Hu, B.Y., Roberts, S.K., Leng leong, S.S. \& Guo, H., 2015, 'Challenges to early childhood education in rural China: Lessons from the Hebei province', Early Child Development and Care 186(5), 815-831. https://doi.org/10.1080/030044 30.2015.1062984 
Johnson, C., 2013, Preschool education in Brazil, viewed 03 October 2019, from https://pennstatebrazil.wordpress.com/2013/04/12preschool-education-inbrazil/.

Kamerman, S.B., 2006, A global history of early childhood education and care, viewed 04 June 2020, from https://olc.worldbank.org/sites/default/files/3A_ global_history_of_early_childhood_care_and_education_Background_ paper_EFAGlobalMonitoringReport2007UNESCO_O.pdf.

MacEwan, A., 2013, Early childhood education as an essential component of economic development: With reference to the New England States, Political Economy Research Institute, University of Massachusetts, Amherst, MA.

Mami, Y.A., 2013, Early childhood education in Brazil, viewed 04 November 2019, from https://www.childresearch.net/projects/ecec/2013_10.html.

Ministry of Human Resource and Development (MHRD), 2007-2008, Selected educational statistics (SES), Government of India, New Delhi.

Ministry of Social Welfare, 1974, National policy for children, Government of India, New Delhi.

Ministry of Women and Child Development (MWCD), 2007, Report of working group on development of children for the eleventh five year plan (20072012), Government of India, New Delhi.

Ministry of Women and Child Development (MWCD), 2010, Annual report, Government of India, New Delhi.

Ministry of Women and Child Development (MWCD), 2012, Integrated child development scheme (ICDS), Government of India, New Delhi.

National Council of Educational Research and Training (NCERT), 2005, National curriculum framework (NCF), Government of India, New Delhi.

National Council of Educational Research and Training (NCERT), 2006a, National focus group on early childhood education, NCERT, New Delhi.

National Council of Educational Research and Training (NCERT), 2006b, Position paper national focus group on early childhood education, viewed 07 September 2019, from http://goo.gl/TWY93.

Nayyar, D., 2008, 'The rise of China and India: Implications for developing countries', in P. Arestis \& J. Eatwell (eds.), Issues in economic development and globalization, pp. 73-94, Palgrave Macmillan, London.

Nayyar, D., 2016, 'BRICS, emerging markets and the world economy', in P. Anand, F. Comim, S. Fennell \& R. Weiss (eds.), Oxford handbook on BR/CS, pp. 576-591, Oxford University Press, Oxford.

Povell, P., 2017, 'Maria Montessori, yesterday, today and tomorrow', in L.E. Cohen \& S. Waite-Stupiansky (eds.), Theories of early childhood education, developmental, behaviourist and critical, pp. 18-30, Routledge, London.

Qi, X. \& Melhuish, E.C., 2017, 'Early childhood education and care in China: History, current trends and challenges', Early Years 37(3), 268-284. https:// doi.org/10.1090/09575146.2016.1236780. 
Rajawat, P., 2016, 'Effects of pedagogical approaches \& practices for sustainable development in early childhood education: A research review', Scholar Research Journal for Humanity Science \& English Language 6(25), 7312-7320. https://doi.org/10.21922/srjhsel.v6i26.11437

Saracho, O.N., 2019, Research in young children's literacy and language development: Language and literacy development for different populations, Routledge, London.

Statistics South Africa, 2015, Millennium development goals: Country report, Department of Statistics South Africa, Pretoria.

Stellenbosch Municipality, 2017, Early childhood development policy, viewed 23 October 2019, from Stellenbosch.gov.za/documents/municipal-policy/5479draft-ecd-policy-2017-2018/file.

Storbeck, C. \& Moodley, S., 2011, 'ECD policies in South Africa - What about children with disabilities?', Journal of African Studies and Development 3(1), 1-8.

Systems Approach for Better Education Results (SABER), 2016, Country report. China: Early childhood development, pp. 1-46, viewed 24 October 2019, from https://www.google.com/search?client=firefoxab\&ei=Bo6xXdbMBrWf1fAP09 uaoAE\&q=china+stats+early+childhood+education.

Tunyogi, R. \& Schuurman, M., n.d., Training tool on engaging children in advocacy work on their right to participate in decision-making, viewed 22 June 2020, from www.eurochild.org > public > 05_Child_Participatione.

United Nations Children's Fund (UNICEF), 2010, Advocacy toolkit: A guide to influencing decisions that improve children's lives, UNICEF, New York, NY.

United Nations Educational, Scientific and Cultural Organization (UNESCO), 2003, Early childhood services in Brazil, viewed 06 October 2019, from http://www.unesco.org/new/en/brasilia/education/educational-quality/earlychildhood-education/.

United Nations Educational, Scientific and Cultural Organization (UNESCO), 2006, Policy review report: Early childhood care and education in Brazil, viewed 04 October 2019, from https://unesdoc.unesco.org/ark:/48223/ pfO00015127.

United Nations Educational, Scientific and Cultural Organization (UNESCO), 2015, Policies on early childhood care and education: Their evolution and some aspects, viewed 05 June 2020, from http://oro.open.ac.uk/41552/1/ Woodhead\%20et\%2Oal\%202014\%20Early-Childhood-Development-TopicGuide.pdf.

Vagh, S.B., Nag, S. \& Banerji, R., 2017, 'India: The policy and practice of early literary acquisition in the akshara languages', in N. Kucirkova, C.E. Snow, V. Grøver \& C. McBride (eds.), The Routledge international handbook of early literacy education: A contemporary guide to literacy teaching and interventions in a global context, pp. 419-433, Routledge, London. 
Vong, K.P. \& Li, M.Y., 2016, 'Challenges in establishing kindergarten education system in villages of Guizhou, China: A preliminary study', South African Journal of Childhood Education 6(2), a445. https://doi.org/10.4102/sajce.v6i2.445.

Worcester Polytechnic Institute, 2015, Challenges of early childhood development in South Africa, viewed 30 October 2019, from https://wp.wpi. edu/capetown/projects/p2014/flamingo/background-research/challengesof-early-childhood-development-in-south-africa/.

Yu, Y., 2017, 'Early childhood curriculum development in China', in N. Rao, J. Zhou \& J. Sun (eds.), Early childhood education in Chinese societies: International perspectives on early childhood education and development, vol. 19, pp. 101-110, Springer, Dordrecht.

Zhou, X., 2011, 'Early childhood education policy development in China', International Journal of Child Care and Education Policy 5(1), 29-39. https:// doi.org/10.1007/2288-6729-5-1-29

Zhou, C., Sylvia, S., Linxiu, Z., Luo, R., Yi, H., Liu, Y. et al., 2015, 'Project HOPE The People-to-People Health Foundation, Inc.', Health Affairs 34(11), 1964-1971. https://doi.org/10.1377/hlthaff.2015.0150

Zhu, J., 2009, 'Early childhood education and relative policies in China', International Journal of Child Care and Education Policy 3(1), 51-60. https:// doi.org/10.1007/2288-6729-3-1-51

\section{Chapter 4}

Acharya, P., 1978, 'Indigenous vernacular education in pre-British era: Traditions and problems', Economic and Political Weekly 48(2), 1981-1988.

Barzalo, Y.R., 2020, Linguistic independence hypothesis: Definition and application, viewed 23 December 2019, from https://study.com/academy/ lesson/linguistic-interdependence-hypothesis-definition-application.html.

Bourdieu, P., 1986, 'The forms of capital', in J. Richardson (ed.), Handbook of theory and research for the sociology of education, pp. 241-258, Greenwood, New York, NY.

Christie, P., 1991, The right to learn: The struggle for education in South Africa, 2nd edn., Ravan Press, Braamfontein.

Dalvit, L., Murray, S. \& Terzoli, A., 2009, 'Deconstructing language myths: Which languages of learning and teaching in South Africa?', Journal of Education 46, 33-56.

Devy, G., 2020, India is becoming a graveyard of languages, viewed 24 August 2020, from https://www.livemint.com/Opinion/vlbx7ZUHxvTQMbwboNYHPI/ India-is-becoming-a-graveyard-of-languages.html.

Eloff, T., 2020, 'Hou dié vyf tendense dop', Die Burger, 08 January, p. 11.

Fishman, J.A., 1991, Reversing language shift: Theoretical and empirical foundations of assistance to threatened language, Multilanguage Matters, Clevedon. 
Gasa, V., Mafora, P. \& Maphalala, M., 2015, 'The literature review', in C. Okeke \& M. Van Wyk (eds.), Educational research: An African approach, pp. 132-147, Oxford University Press Southern Africa, Cape Town.

Giliomee, H., 2019, The rise and demise of the Afrikaners, NB Publishers, Cape Town.

Hyslop, J., 1999, The classroom struggle: Policy and resistance in South Africa 1940-1990, University of Natal Press, Pietermaritzburg.

Joubert, J., 2019, Gaan Suid-Afrika Okei Wees?, Tafelberg, Cape Town.

Macaulay, T.B., 1835, 'Minute by the hon’ble T. B. Macaulay', 02 February, viewed 18 December 2019, from http://www.columbia.edu/itc/mealac/ pritchett/OOgenerallinks/macaulay/txt_minute_education_1835.html.

MacDonald, C. \& Burroughs, E., 1990, Eager to talk and learn to think bilingual primary education in South Africa, Maskew Miller Longman, Cape Town.

Mgqwashu, E.M., 2013, 'On developing academic literacy in the mother tongue for epistemological access: The role of isiZulu as the LoLT in a South African University', Current Issues in Language Planning 2013, 1-14. https://doi.org/10. 1080/14664208.2014.857577

Mphahlele, M.C.J. \& Mminele, S.P.P., 1997, Education through the ages, part 3, Kagiso, Pretoria.

Republic of South Africa (RSA), 1996, The constitution of the Republic of South Africa, Act 108 of 1996, viewed 19 December 2019, from https://www.justice. gov.za/legislation/constitution/SAConstitution-web-eng.pdf.

Republic of South Africa (RSA), 2018, 2011 census in brief - Statistics South Africa, viewed 23 June 2020, from http://www.statssa.gov.za/census/ census_2011/census_products/Census_2011_Census_in_brief.pdf.

Robson, C., 2011, Real world research: A resource for users of social science research methods in applied settings, John Wiley, Chichester, West Sussex.

Santhakumar, V., 2014, The roots of ill governance and corruption, Sage, New Delhi.

Santhakumar, V., 2016, An intervention into the debates on 'work-in-education' and skill development in India, APU working paper No. 3, Azim Premji University, Bengaluru.

Santhakumar, V. \& Das, A., 2018, Schooling of the scheduled tribes in India. Lessons from the education of indigenous people in Brazil, viewed 24 December 2019, from https://practiceconnect.azimpremjiuniversity.edu.in/ schooling-of-scheduled-tribes-in-india/.

Santhakumar, V., Gupta, N. \& Sripada, R., 2016, Schooling for all in India: Can we neglect the demand?, Oxford University Press, New Delhi.

Setati, M., Chitera, N. \& Essien, A., 2009, 'Research on multilingualism in mathematics education in South Africa: 2000-2007', African Journal of Research in MST Education 2009, 65-80. https://doi.org/10.1080/10288457.2 009.10740662 
Suid-Afrikaanse Akademie vir Wetenskap en Kuns, 2019, 'SA Academy condemns remarks by Minister of Higher Education and Training regarding the Afrikaans language community', Media release, SA Academy for Science and Arts, Arcadia, Pretoria.

United Nations Educational Scientific and Cultural Organization (UNESCO), 1953, The use of vernacular languages in education: Monographs on fundamental education, vol. 8, p. 154, UNESCO, Paris.

Wilkinson, K., 2018, 'New York Times \& others STILL wrong on number of immigrants in S. Africa', Africa Check, 20 February, viewed 24 December 2019, from https://africacheck.org/reports/new-york-times-use-plagiarisedarticle-to-back-up-sa-immigrant-number/.

Wolhuter, C.C., 1999, 'Sociaal-wetenschappelijke literatuur over onderwijs in Zuid-Afrika: Van verzuiling tot eensgezindheid vanuit verscheidenheid [Social-scientific literature on education in South Africa: From compartmentalization to unity from diversity]', Pedagogische Studiën (the Netherlands) 76(6), 361-370.

Wolhuter, C.C., 2020, 'The South African education system: Poignancy in the global education project and in the domestic societal reconstruction', in C.C. Wolhuter, L. Jacobs \& H.J. Steyn (eds.), Reflecting about education systems, n.p., Keurkopie, Noordbrug.

World Bank, 2005, In their own language: Education for all, viewed 21 September 2014, from http://siteresources.worldbank.org/EDUCATION/ Resources/Education-Notes/EdNotes_Lang_of_Instruct.pdf.

\section{Chapter 5}

Adegbesan, S.O., 2010, 'Establishing quality assurance in Nigerian education system: Implication for educational managers', Educational Research and Review 5(7), n.p.

Afeti, G., 2006, Technical and vocational education and training for industrialization, Commonwealth Association of Polytechnics in Africa (CAPA), Addis Ababa.

African Union, 2007, Developing an African higher education quality rating system, viewed 28 October 2013, from http://www.africa-union-org.

Agrawal, T., 2012, 'Vocational education and training in India: Challenges, status and labour market outcomes', Journal of Vocational Education \& Training 64(4), 453-474. https://doi.org/10.1080/13636820.2012.727851

Alam, G.M., Hoque, K.E., Ismail, L. \& Mishra, P.K., 2010, 'Do developing countries need education laws to manage its system or are ethics and a market-driven approach sufficient?', African Journal of Business Management 4(15), 3406-3416.

Ayonmike, C.S., Okwelle, P.C. \& Okeke, B.C., 2015, 'Towards quality technical vocational education and training (TVET) programmes in Nigeria: Challenges and improvement strategies', Journal of Education and Learning 4(1), n.p. https://doi.org/10.5539/jel.v4n1p25 
Boslaugh, S., 2007, Secondary analysis for public health: A practical guide, Cambridge University Press, New York, NY. https://doi.org/10.1017/ CBO9780511618802

Billett, S. \& Boud, D., 2001, 'Participation in and guided engagement at work: Workplace pedagogic practices', paper presented at Second international conference on learning and work, Calgary, Alberta, 26-28th July.

Buthelezi, Z.G., 2016, 'At the policy-practice interface: Exploring TVET lecturers' post-apartheid educational reform experiences', Unpublished PhD thesis, University of KwaZulu-Natal.

European Centre for the Development of Vocational Training (CEDEFOP), 2011, Glossary: Quality in education and training, Publications Office of the European Union, Luxembourg.

European Centre for the Development of Vocational Training (CEDEFOP), 2014, Briefing note - Skill mismatch: More than meets the eye, Publications Office of the European Union, Luxemburg.

Cresswell, J.W., 2009, Research design: Qualitative, quantitative and mixed method approaches, 3rd edn., Sage, Los Angeles, CA.

Darvas, P. \& Palmer, R., 2014, Demand and supply of skills in Ghana: How can training programs improve employment and productivity?, World Bank Studies, Washington, DC.

Department of Higher Education and Training (DHET), 2012, Further Education and Training (FET) Amendment Bill 2012, Department of Higher Education and Training, Pretoria.

Department of Higher Education and Training (DHET), 2013, White paper for post-school education and training: Building an expanded, effective and integrated post-school system. Department of Higher Education and Training, Pretoria.

Department of Higher Education and Training (DHET), 2016, Statistics on postschool education and training in South Africa: 2014, Department of Higher Education and Training, Pretoria.

Department of Higher Education and Training (DHET), 2018, Department of Higher Education and Training: Republic of South Africa, viewed 01 June 2018, from http://www.dhet.gov.za/SitePages/HRDPlanning New.aspx.

DNA Economics, 2015, Performance and expenditure review: TVET, final report, National Treasury, Pretoria.

Edglossary, 2017, Competency based learning, viewed 02 December 2017, from http://edglossary.org/competency-based-learning.

Government of India, 2015, Draft national policy for skill development and entrepreneurship 2015, Ministry of Skills Development \& Entrepreneurship, New Delhi.

Hager, P., 2004, 'Conceptions of learning and understanding learning at work', Studies in Continuing Education 26(1), 3-17. https://doi.org/10.1080/ 158037042000199434 
Johanson, R., 2009, A review of national training funds, SP discussion paper No. 0922, World Bank, Washington, DC.

Kulkarni, P.P., 2013, 'A literature review on training and development and quality of work life', Journal of Arts, Science \& Commerce IV(2), 136-143.

Kotsikis, V., 2007, Educational administration and policy, Ellin, Athens.

Mehrotra, S., Gandhi, A., Sahoo B., \& Saha, P., 2012, 'Organised and unorganised employment in the non-agricultural sectors in the 2000s', IAMR occasional paper no. 6/2012, viewed from www.iamrindia.gov.in.

Mehrotra, S., Gandhi, A., \& Sahoo, B.K., 2013, 'Estimating India's skills gap on realistic basis for 2022', Economic and Political Weekly XLVIII(13), 30th March.

Organisation for Economic Cooperation and Development (OECD), 2014, Skills beyond school, synthesis report, Organisation for Economic Cooperation and Development Publishing, Paris. https://doi. org/10.1787/9789264214682-en.

Pilz, M., 2012, 'Modularisation of vocational training in Germany, Austria and Switzerland: Parallels and disparities in a modernisation process', Journal of Vocational Education and Training 64(2), 169-183.

Safety and Security Sector Education and Training Authority (SASSETA), 2018, Sasseta research report, viewed 26 June 2018, from http://sasseta.org.za/ index.php?page=about.

Schmitter, P., 2004, 'Neo-functionalism', in A. Wiener \& T. Diez (eds.), European integration theory, pp. 45-74, Oxford University Press, Oxford.

Smith, E., 2008, Using secondary data in educational and social research, McGraw-Hill, New York, NY.

Tikly, L., 2013, 'Reconceptualizing TVET and development: A human capability and social justice approach', in K. Ananiadou (ed.), Revisiting global trends in TVET: Reflections on theory and practice, UNESCOUNEVOC, Bonn.

United Nations Educational Scientific and Cultural Organization (UNESCO), 2017, Towards quality assurance of technical and vocational education and training: Trends and challenges in the Asia-Pacific region, UNESCO, Bangkok.

Venkatram R., 2012, 'Vocational education and training system (VET) in India', in M. Pilz (ed.), The future of vocational education and training in a changing world, Springer VS, Wiesbaden.

Usman, A. \& Abdullahi, T., 2013, 'Revitalizing technical and vocational education (TVET) for youth empowerment and sustainable development', Journal of Educational and Social Research 3(4), 149-154.

World Bank, 2006, Skill development in India: The vocational education and training system. Human Development Unit, South Asia Region, World Bank, Washington, DC. 


\section{Chapter 6}

World Bank, 2012, World development report 2013: Jobs, The World Bank, Washington, DC.

World Bank, 2009, Doing business 2010, World Bank, Washington, DC.

Anderson, J. \& Boyle, B., 2015, 'Inclusive education in Australia: Rhetoric, reality and the road ahead', Support for Learning 30(1), 4-22. https://doi.org/10.1111/14679604.12074

Bhandari, S., 2014, 'From external to the internal application of the right to selfdetermination: The case of Nepal', International Journal on Minority and Group Rights 21(2014), 330-370. https://doi.org/10.1163/15718115-02103002

Census India, 2011, Census of India, viewed 24 February 2020, from http://www. censusindia.gov.in/2011census/c-01.html.

Charter of Paris Vide European Community Civicus, 2019, Brazil: Discrimination and hate speech are becoming normalised, viewed 04 February 2020, from https://www.civicus.org/index.php/media-resources/news/interviews/4030brazil-discrimination-and-hate-speech-are-becoming-normalised.

Claassen, J.C., 1996, Die voorsiening van onderwys aan minderheidsgroepe: 'n teore/tiese agtergrond, University of South Africa, Pretoria.

Cresswell, J.W., 2009, Research design: Qualitative, quantitative and mixed method approaches, 3rd edn., Sage, Los Angeles, CA.

Davey, G., De Lian, C., \& Higgins, L., 2007, 'The university entrance examination system in China', Journal of Further and Higher Education 31: 385-96.

Detrick, S., 1992, The United Nations conventions on the rights of the child, Martinus Nijhoff, Dordrect.

De Witte, B., 1993, 'The European communities and its minorities', in C. Brölmann, R. Lefeber \& M. Zieck (eds.), Peoples and minorities in international law, Martinus Nijhoff, Dordrecht.

Doliwa-Klepacka, A., 2019, 'Linguistic rights in the education system in light of the framework convention for the protection of national minorities (by the example of Poland and Lithuania)', Studies in Logic, Grammar and Rhetoric 58(71), 59-76. https://doi.org/10.2478/slgr-2019-0017.

Dombrowskia, L.M., Danson, E., Danson, M., Chalmers, D. \& Neil, P., 2014, 'Initial teacher education for minority medium-of-instruction teaching: The case study of Scottish Gaelic in Scotland', Current Issues in Language Planning 15(2), 119-132. https://doi.org/10.1080/14664208.2013.811006.

Du Buisson, T., 2018, 'Die ekonomiese belang van die beskerming van minderheidsgroepe vir die staat [The economic importance of the protection of minority groups for the state]', Tydskrif vir Geesteswetenskappe 58(3), a12. https://doi.org/10.17159/2224-7912/2018/v58n3a12.

European Community, 1990, Charter of Paris of a new Europe, HMSO, London.

Federal Republic of Russia, 1991, Law of the Russian Federation of October 25, 1991 No. 1807-1, About languages of the people of the Russian Federation (as amended on 31 July 2020), viewed 08 March 2019, from https://cis-legislation. com/document.fwX?rgn=1466. 
Federal Republic of Russia, 1993, Russian constitution, viewed 11 February 2020, from http://www.constitution.ru/en/10003000-03.htm.

Federal Republic of Russia, 2010, Russian census, viewed 01 February 2020, from https://www.gks.ru/free_doc/new_site/perepis2010/croc/perepis_itogi1612.htm.

Framework Convention for the Protection of National Minorities (FNCM), 2018, Четвертое заключение по Российской Федерации Принято 20 февраля 2018 г, viewed 10 February 2020, from https://rm.coe.int/4th-advisory-committeeopinion-on-the-russian-federation-russian-langu/1680908bOd.

Grant, C.A. \& Gillette, M., 1987, 'The Holmes report on minorities in education', Social Education November/December, 517-521.

Instituto Brasileiro de Geografia e Estatística (IBGE), 2010, Censo 2010, viewed 06 February 2020, from https://censo2010.ibge.gov.br/en/noticias-censo. html?id=3\&idnoticia=1669\&t=census-2010-enumerators-start-final-trainingphase\&view=noticia.

Klausky, M., 1995, Small schools: The numbers tell a story, Illinois University, Chicago, IL.

Laerskool Middelburg en 'n ander v Departmentshoof: Mpumalanga Department van Onderwys en andere, 2002, 4 All SA 745 (T).

Lang W., 2010, 'Entrance exam admission policies on ethnic minorities and equal educational rights for minorities in China', Chinese Education \& Society 43(4), 41-48. https://doi.org/10.2753/CED1061-1932430404

Larorest, G., 1993, 'Introduction', in C. Taylor (ed.), Reconciling the solitudes, McGill-Queens University Press, Montreal.

Lerner, N., 1993, 'The evolution of minority rights in international law', in C. Brölmann, R. Lefeber \& M. Zieck (eds.), Peoples and minorities in international law, Martinus Nijhoff, Dordrecht.

MacQuarrie, S. \& Lyon, F., 2018, Defying expectations: Valuing the engagement and participation of practitioners with research: Insights from minority language education in Scotland, viewed 01 February 2020, from https://doiorg.nwulib.nwu.ac.za/10.1080/01434632.2017.1417414.

Matukane and Others v. Laerskool Potgietersrus, 1996, 3 SA 215 (T).

Minority Right Group International (MRGI), 2020, Home, viewed 14 May 2020, from https://minorityrights.org/.

Mochwanaesi, D., Steyn, H. \& Van der Walt, J., 2005, 'Education for minority groups: A case study', South African Journal of Education 25(4), 287-291.

National Department of Education, 1997, Language-in-education policy, Government Notice No. 383, Vol. 17997, Government Printers, Pretoria.

Parnell-Berry, B. \& Lawton, A., 2019, 'Citizenship for all? Mobility and the "right" way to live', Administrative Theory \& Praxis 41, 35-59. https://doi.org/10.1080/ 10841806.2018.1512335

Pretorius, S.G. 1996. "Hervormingstendense in die onderwys: " $n$ " internasionale ondersoek [Reform trends in education: an international inquiry]',. SuidAfrikaanse Tydskrif vir Opvoedkunde 16(3), 134-143. 
Qureshi, Y.F. \& Janmaat, J.G., 2015, 'Diverging or converging trends: An investigation of education policies concerning the incorporation of ethnic minority children in England, France and Germany', Compare 44(5), 710-731. https://doi.org/10.1080/03057925.2013.800782.

Republic of Brazil, 1988, Brazilian constitution, viewed 21 February 2020, from https://www.google.com/url?sa=t\&rct=j\&q=\&esrc=s\&source=web\&cd=25\&ved =2ahUKEwjS66Gjj-LnAhXrx4UKHSI1DFMQFjAYegQIChAB\&url=https\%3A\%2F \%2F www.constituteproject.org\%2Fconstitution\%2FBrazil_2017.pdf\%3Flang\% 3Den\&usg=AOvVawOIvspvG3ILDXzqauxQGi6t.

Republic of Brazil, 1989, Brazil: Law 7.716/89, viewed 22 February 2020, from https://www.equalrightstrust.org/content/brazil-law-no-771689.

Republic of India, 1950, The Constitution of India. 1950, viewed 18 February 2020, from https://www.refworld.org/docid/3ae6b5e20.html.

Republic of India, 2009, Ministry of minority affairs. Prime Minister's new 15-point programme for the welfare of minorities, viewed 06 February 2020, from http://www.minoritywelfare.bih.nic.in/15PP.htm.

Republic of India, 2020, Ministry of minority affairs, viewed 12 February 2020, from http://www.minorityaffairs.gov.in/.

Republic of South Africa (RSA), 1996a, Constitution of the Republic of South Africa, Act No. 108 of 1996, Government Printer, Pretoria.

Republic of South Africa (RSA), 1996b, South African Schools Act, Act No. 84 of 1996, Government Printer, Pretoria.

Republic of South Africa (RSA), 2011, Statistics South Africa: Census 2011, viewed 14 February 2020, from http://www.statssa.gov.za/?page_id=3839.

Ross, H. \& Wang, Y., 2010, 'The college entrance examination in China: An overview of its social-cultural foundations, existing problems, and consequences', Chinese Education \& Society 43(4), 3-10. https://doi. org/10.2753/CED1061-1932430400

Sautman, B., 1999, 'Ethnic law and minority rights in China: Progress and constraints', Law \& Policy 21, 283-314. https://doi.org/10.1111/14679930.00074

Southiram, R., 1995, 'The education of minorities: Typologies, issues and effects', paper presented at international conference: Education and change, UNISA, South Africa, 18-22nd September.

Steyn, H.J., 1998, The perceptions of the national education system by minority groups, Keurkopie, Potchefstroom.

Steyn, H.J., Alkan, M., Tupan, M. \& Oeyen, S., 2007, “'Unity in diversity” in South African education: Inciting ideas from Europe', SA-eDUC Journal 4(1), 1-13.

Steyn, H., 2009, 'The national education system and the education rights of minority groups', SA-eDUC Journal 6(2), 65-80.

Steyn, H.J. \& Wolhuter, C.C, 2014, The education system: A Comparative Education perspective, Keurkopie, Potchefstroom. 
Taylor, C., 1993, Reconciling the solitudes, McGill-Queens University Press, Montreal.

Thornberry, P., 1991, International law and the rights of minorities, Claredon, Oxford.

Tomlinson, S., 2016, 'Discourse: Studies in the cultural politics of education', Discourse: studies in the cultural politics of education 37(4), 513-528. https:// doi.org/10.1080/01596306.2015.1073013

United Nations (UN), 1948, 'International bill of human rights', in United Nations (ed.), Human rights: A compilation of international instruments, United Nations, New York, NY.

United Nations (UN), 1966, 'International covenant on civil and political rights', in United Nations (ed.), Human rights: A compilation of international instruments, United Nations, New York, NY.

United Nations (UN), 1988, Human rights: A compilation of international instruments, United Nations, New York, NY.

United Nations (UN), 1990, 'The United Nations convention on the rights of the child', in S. Detrick (ed.), The United Nations conventions on the rights of the child, Martinus Nijhoff, Dordrecht.

United Nations Educational, Scientific and Cultural Organization (UNESCO), 1960, 'Convention against discrimination in education', in United Nations (ed.), Human rights: A compilation of international instruments, United Nations, New York, NY.

Unterhalter, E., Wolpe, H., Botha, T., Badat, S., Dlamini, T. \& Khotseng, B., 1991, Apartheid education and popular struggles, Ravan, Johannesburg.

Wang, F., 2013, 'Educational equity in the access to post-secondary education: A comparison of ethnic minorities in China with aboriginals in Canada', Interchange 44, 45-62. https://doi.org/10.1007/s10780-013-9196-9

Western Cape Minister of Education and others $v$ Governing Body of Mikro Primary School and another, 2005, 3 All SA 436 (SCA).

Yang, R., 2008, 'Transnational higher education in China: Contexts, characteristics and concerns', Australian Journal of Education 52(3), 272-286. https://doi.org/10.1177/000494410805200305

Zhu, Z., 2010, 'Higher education access and equality among ethnic minorities in China', Chinese Education \& Society 43(1), 12-23. https://doi.org/10.2753/ CED1061-1932430101

\section{Chapter 7}

Adamson, B. \& Feng, A., 2014, 'Models for trilingual education in the People's Republic of China', in D. Gorter, V. Zenotz \& J. Cenoz (eds.), Minority languages and multilingual education, pp. 29-44, Springer, Dordrecht. 
Adamson, B. \& Feng, A., 2015, 'Trilingualism in education: Models and challenges', in A. Feng \& B. Adamson (eds.), Trilingualism in education in China: Models and challenges, pp. 243-258, Springer, Dordrecht.

Anderson, L.W., Krathwohl, D.R., Airasian, P.W., Cruikshank, K.A., Mayer, R.E., Pintrich, P.R., et al., 2001, A taxonomy for learning, teaching, and assessing: $A$ revision of Bloom's taxonomy of educational objectives, Longman, New York, NY.

Arnaut, K., Blommaert, J., Rampton, B. \& Spotti, M. (eds.), 2015, Language and super diversity, Routledge, New York, NY.

Barzalo, Y.R., 2020, Linguistic independence hypothesis: Definition and application, viewed 23 December 2019, from https://study.com/academy/ lesson/linguistic-interdependence-hypothesis-definition-application.html.

Blommaert, J., 2010, The sociolinguistics of globalisation, Cambridge University Press, Cambridge.

Bloom, B.S., Engelhart, M.D., Furst, E.J., Hill, W.H. \& Krathwohl, D.R., 1956, Taxonomy of educational objectives: The classification of educational goals. Handbook l: Cognitive domain, David McKay, New York, NY.

Bourdieu, P., 1986, 'The forms of capital', in K. Richardson (ed.), Handbook of theory and research for the sociology of education, pp. 241-258, Greenwood, New York, NY.

Chomsky, N., 1959, 'Review of verbal behaviour', Language 35, 26-58. https://doi. org/10.2307/411334

Feng, A. \& Adamson, B. (eds.), 2014, Trilingualism in education in China: Models and challenges, Springer, Dordrecht.

Giliomee, H., 2019, The rise and demise of the Afrikaners, Tafelberg, Cape Town.

Heugh, H., 2013, 'Multilingual education policy in South Africa constrained by theoretical and historical and historical disconnections', Annual Review of Applied Linguistics 33, 215-237. https://doi.org/10.1017/S0267190513000135

Joubert, J., 2019, Gaan Suid-Afrika okei wees?: 17 Sleutelvrae, Tafelberg, Cape Town.

Keeling, A., 2017, 'English-medium schools in China now leading the world', ISC News, 18 December, viewed 20 December 2019, from https://www. iscresearch.com/news-and-events/isc-news/isc-news-details/ post/englishmedium-schools-in-china-now-leading-the-world-20171204.

King, L., 2018, The impact of multilingualism on global education and language learning, University of Cambridge Local Examinations Syndicate, Cambridge.

Krashen, S., 1982, Principles and practice in second language acquisition, Prentice-Hall, New York, NY.

Lai, M.L., 2013, 'Impacts of medium of instruction on language attitudes: A case of Hong Kong', Asia Pacific Journal of Education 22, 61-68. https://doi. org/10.1007/s40299-012-0025-1

Lambert, W.E. \& Peal, E., 1962, 'The relation of bilingualism to intelligence', Psychological Monographs: General and Applied 27(3), 1-23. https://doi. org/10.1037/h0093840 
Lambert, W.E. \& Tucker, G.R., 1972, Bilingual education of children: The St. Lambert experiment, Newbury House, Rowley, MA.

Lo, Y.Y. \& Lo, E.S.C., 2014, 'A meta-analysis of the effectiveness of English medium education in Hong Kong', Review of Educational Research 84(1), 47-73. https://doi.org/10.3102/0034654313499615

Loh, E.K.Y., Tam, L.C.W. \& Lau, K., 2017, 'Moving between language frontiers: The challenges of the medium of instruction policy for Chinese as a second language', Language Policy 18, 131-153. https://doi.org/10.1007/s10993-018-9465-7

Lu, M., Cui, M., Shi, Y., Fang, C., Mo, D. \& Scott, R., 2016, 'Who drops out from primary schools in China? Evidence from minority-concentrated rural areas', Asia Pacific Education Review 17(2), 235-252. https://doi.org/10.1007/s12564016-9421-1

Manitoba Bureau de l'éducation Française, 2007, French immersion in Manitoba: A handbook for school leaders, Bureau de l'éducation Française Division, Winnipeg, Manitoba.

May, S. (ed.), 2014, The multilingual turn implications for SLA, TESOL and bilingual education, Routledge, New York, NY.

Melikoff, O., 2018, The St. Lambert experiment in French immersion revisited: Fifty years later, viewed 23 June 2020, from olgamelikoff.com > the-stlambert-experiment-in-french-immersion.

Mingyuan, G., 2014, Cultural foundations of Chinese education, Brill, Leiden.

Rubagumya, C.M., 1991, 'Language promotion for educational purposes: The example of Tanzania', International Review of Education 37(1), 67-85. https:// doi.org/10.1007/BF00598168

Ryan, J., 2019, Education in China, Polity, Cambridge.

Slatter, L., 2020, 'Xhosa, Sotho in matriek "kan lol”', Rapport, 09 February, p. 8, viewed 24 August 2020, from https://www.netwerk24.com/Nuus/Onderwys/ xhosa-sotho-in-matriek-kan-lol-20200208.

Spaull, N., 2013, Language(s) of learning in South Africa, viewed 24 December 2019, from https://nicspaull.com/2013/10/27/languages-of-learning-in-southafrica/.

Tam, A.C.F., 2011, 'Does the switch of medium of instruction facilitate the language learning of students? A case study of Hong Kong from teachers' perspective', Language and Education 25(5), 399-417. https://doi.org/10.1080 /09500782.2011.573076

Tang, W., Hu, Y. \& Jin, S., 2016, 'Affirmative inaction: Education, language proficiency and the socio-economic attainment among China's Uyghur minority', Chinese Sociological Review 48(4), 346-366. https://doi.org/10.108 O/21620555.2016.1202753

Wang, Q., 2007, 'The national curriculum changes and their effects on English language teaching in the People's Republic of China', International Handbook of English Language Teaching 15(1), 87-105. https://doi.org/10.1007/978-0387-46301-8_8 
Wolhuter, C.C., 2015, 'Comparative and international education: Conceptual clarification and significance', in C.C. Wolhuter, L. Jacobs \& H.J. Steyn (eds.), Thinking about education systems, pp. 13-32, Keurkopie, Noordbrug.

Wolhuter, C.C., 2018, 'Education and cultural crises of the early twenty-first century', Iranian Journal of Comparative Education 1(2), 10-29.

Wolhuter, C.C., 2020, 'Chinese educational aims', in L. De Beer, E. Niemczyk \& D. Vos (eds.), A New Dawn, pp. 251-269, AOSIS Cape Town. https://doi. org/10.4102/aosis.2020.BK146.09

Wolhuter, C.C. \& Van der Walt, H., 2018, 'Wat is Fout met Suid-Afrikaanse Skole: Geheelbeeld van, en leemte in die navorsing oor skoolleierskap as sleutelfaktor [What is Wrong with South African Schools: Overall picture of, and gap in, research on school leadership as a key factor]', Litnet Akademies (Opvoedkunde) 15(2), 463-485.

Zhang, W., 2012, A brief introduction to foreign languages education policy in China, viewed 25 December 2019, from https://files.eric.ed.gov/fulltext/ED530281.pdf.

\section{Chapter 8}

Abramovay, M.G.C., Luciano, A.P.S., \& Cerqueira, M., 2016, Diagnóstico participativo das violências nas escolas: Falam Os jovens [Participatory diagnosis of violence in schools: Young people speak], Flacso, Rio de Janeiro.

Adams, J. \& Hannum, E.C., 2017, 'School violence in China: A multi-level analysis of student victimisation in rural middle schools', in Gansu survey of children and families papers, viewed 30 September 2019, from http://repository. upenn.edu/gansu_papers/56.

Africa Check, 2019, Factsheet South Africa's crime statistics for 2018/19, viewed 21 January 2020, from https://africacheck.org/factsheets/factsheet-southafricas-crime-statistics-for-2018-19/.

Anand, T., Kishore J, Grover, S., Bhave, S. \& Yadav, S., 2019, 'Beliefs supporting violence, attitudes and aggressive behavior among school adolescents in rural Delhi', Community Mental Health Journal 55(4), 693-701. https://doi. org/10.1007/s10597-018-0315

Baker-Henningham, H., Scott, S., Jones, K. \& Walker, S., 2012, 'Reducing child conduct problems and promoting social skills in a middle-income country: Cluster randomised controlled trial', The British Journal of Psychiatry 201(2), 101-108. https://doi.org/10.1192/bjp.bp.111.096834

Bateson, I. \& Tsvetkova, M., 2014, Mosco teen kills two in rare Russian school shooting, viewed 03 February 2019, from https://www.reuters.com/article/ us-russia-shooting-school/moscow-teen-kills-two-in-rare-russian-schoolshooting-idUSBREA120C920140203.

Botha, A.J., 2007, 'The facilitation of aggression management in secondary schools in Mpumalanga', Unpublished DEd thesis, University of Johannesburg. 
Botha, J., 2019, 'In search of ways of curtailing aggression and violence in schools: A human rights-based approach', in J.P. Rossouw \& E. De Waal (eds.), Human rights in diverse education contexts (NWU education and human rights in diversity series Volume 1), pp. 173-193, AOSIS, Cape Town. https://doi.org/10.4102/aosis.2019.BK158.06

Botha, J., Myburgh, C. \& Poggenpoel, M., 2012, 'Peer aggression by secondary school learners in a South African school setting: Effects of race, ethnicity, and gender', Journal of Psychology in Africa 22(3), 409-414. https://doi. org/10.4102/curations.v3811.1233

Botha, J., Myburgh, C. \& Poggenpoel, M., 2013, 'Male teachers' experiences of own aggression', South African Journal of Education 33(3), 1-15.

Bowen, G.A., 2009, 'Document analysis as a qualitative research method', Qualitative Research Journa/ 9(2), 27-40. https://doi.org/10.3316/ QRJ0902027

Burton, P. \& Leoschut, L., 2013, School violence in South Africa: Results of the 2012 national school violence study, Centre for Justice and Crime Prevention, viewed 14 September 2019, from http://www.cjcp.org.za/ uploads/2/7/8/4/27845461/monograph12-school-violence-in-south_africa.pdf.

Chan, H.C.O. \& Wong, D.S.W., 2016, 'Traditional school bullying and cyber bullying perpetration: Examining the psychosocial characteristics of Hong Kong male and female adolescents', Youth and Society 51(1), 3-29.

Chioda, L., De Mello, J. \& Soares, R., 2013, Spillovers from conditional cash transfer programs: Bolsa familia and crime in urban Brazil draft, viewed 03 October 2019, from http://siteresources.worldbank.org/INTRES/ Resources/4692321380041323304/Chioda_deMello_Soares_BolsaFamilia_ April242013.pdf.

Coid, J., Hu, J., Kallis, C., Ping, Y., Zhang, J., Hu, Y. et al., 2017, 'A cross-national comparison of violence among young men in China and the UK: Psychiatric and cultural explanations', Social Psychiatry Epidemiology 52, 1267-1279. https://doi.org/10.1007/s00127-017-1420-y

Corbin, J. \& Strauss, A., 2008, Basics of qualitative research: Techniques and procedures for developing grounded theory, 3rd edn., Sage, Newbury Park, CA. https://doi.org/10.4135/9781452230153

Crochí, J.L., 2016, 'Hierarchy, violence and bullying among students of public middle schools', Paidéia 26(65), 307-315. https://doi.org/10.1590/198243272665201608

Department of Basic Education (DBE), 2011, Values and action: A manual in constitutional values and school governance for school governing bodies and representative councils of learners in South African public schools, Government Printers, Pretoria.

Dutt, D., Pandey, G.K., Pal, D., Hazra, S. \& Dey, T.K., 2013, 'Magnitude, types and sex differentials of aggressive behaviour among school children in a rural area of West Bengal', Indian Journal of Community Medicine 38(2), 109-113. 
Hlophe, Z.L., Morojele, P.J. \& Motsa, N.D., 2017, 'Learners constructions of bullying in a South African school context', The Journal for Transdisciplinary Research in Southern Africa 13(1), 1-9. https://doi.org/10.4102/td.v13i1.391

HSE University, 2019, The campaign against bullying: How to effectively reduce bullying, Institute of Education study, HSE University, Moscow.

Huang, Q., 2016, Phenomenon of the attribution of school violence in China and the law to prevent normative research, International conference of humanity, education and social science (ICHESS), Atlantis Press, Paris.

Institute of Race Relations, 2018, South African survey 2017, Institute of Race Relations, Johannesburg.

Júlia, D.S.P., Gusmões, J.D.S.P., Sañudo, A., Valente, J.Y. \& Sanchez, Z.M., 2018, 'Violence in Brazilian schools: Analysis of the effect of the \#Tamojunto prevention program for bullying and physical violence', Journal of Adolescence 63, 107-111. https://doi.org/10.1016/j.adolescence.2017.12.003

Laas, A. \& Boezaart, T., 2014, 'The legislative framework regarding bullying in South African schools', PER: Potchefstroomse Elektroniese Regsblad 17, 2667-2702. https://doi.org/10.4314/pelj.v17i6.12

Lamb, G. \& Warton, G., 2017, The determinants, pathways and prevention of physical violence against children in the Western Cape: The current state of knowledge, Safety and Violence Initiative, Children's Institute, and Centre for Social Science Research, University of Cape Town, Cape Town.

Matthews, I., Griggs, R. \& Caine, G., 1999, The experience review of interventions and programmes dealing with youth violence in urban schools in South Africa, Independent Projects Trust, viewed 23 August 2019, from https:// www.ipt.co.za.

Mehta, S.B., Cornell, D., Fan, X. \& Gregory, A., 2013, 'Bullying climate and school engagement in ninth-grade students', Wiley Online Library 83(1), 45-52. https://doi.org/10.1111/j.1746-1561.2012.00746.x

Melanda, F.N., Dos Santos, D.A., Salvagioni, D.A.J., Mesas, A.E., González, A.D. \& De Andrade, S.M., 2018, 'Violence against schoolteachers: An analysis using structural equation models', Cadernos de Saúde Pública 34(5), 1-11. https:// doi.org/10.1590/0102-311x00079017

Muggah, R., 2017, Youth, security and peace: Brazil revisited, viewed 11 September 2019, from https://www.youth4peace.info/system/ files/2018-4/2.\%20CFR_Brazil_Robert\%20Muggah_0.pdf.

Mullis, I.V.S., Martin, M.O., Foy, P. \& Hooper, M., 2016, TIMSS 2015 international results in mathematics, TIMSS \& PIRLS International Study Center, Boston College, Chestnut Hill, MA.

Myburgh, C. \& Poggenpoel, M., 2009, 'Meta-synthesis on learners' experience of aggression in secondary schools in South Africa', South African Journal of Higher Education 29, 445-460.

Ncontsa, V.N. \& Shumba, A., 2013, 'The nature, causes and effects of school violence in South African high schools', South Africa Journal of Education 33(3), 1-15. 
Nesello, F., Sant'Anna, F.L., Dos Santos, H.G., De Andrade, S.M., Mesas, A.E. \& González, A.D., 2014, 'Características da violência escolar no Brasil: Revisão sistemática de estudos quantitativos [Characteristics of school violence in Brazil: A systematic review of quantitative studies]', Revista Brasileira de Saúde Materno Infantil 14(2), 119-136. https://doi.org/10.1590/S151938292014000200002

Nussbaum, M., 2010, Not for profit: Why democracy needs humanities, Princeton Press, Cambridge.

Olweus, D., 1993, Bullying at school: What we know and what we can do, Blackwell, Oxford.

Our World in Data, 2019, Latest research, viewed 22 November 2019, from https://ourworldindata.org/blog.

Pereira, A.C. \& De Albuquerque, W., 2013, 'School violence with income and neighbourhood safety in Brazil', Children, Violence, Community and Physical Environment 23(1), 105-123. https://doi.org/10.11144/Javerianacali.PPSI14-1.ebsv

Prezenszky, B.C., Galli, E.F., Bachega, D. \& De Mello, R.R., 2018, 'School actions to prevent gender-based violence: A (quasi-)systematic review of the Brazilian and the international scientific literature', Frontiers in Education: Educational Psychology 3(89), 1-16. https://doi.org/10.3389/feduc.2018.00089

Ramphele, M., 1995, 'How sweet is home? Family dynamics in new crossroads', in L.E Glan \& A.D. Spiegel (eds.), Violence and family life in a contemporary South Africa: Research and policy issues, pp. 43-59, Human Sciences Research Council, Pretoria.

Reddy, V., Visser, M., Winnaar, L., Arends, F., Juan, A., Prinsloo, C. et al., 2015, TIMSS 2015 highlights of mathematics and science achievement of grade 9 South African learners: Nurturing green shoots, Human Sciences Research Council, Cape Town.

Rensburg, I., Motala, S. \& David, S.A., 2015, 'Opportunities and challenges for research collaboration among the BRICS nations', Compare: A Journal of Comparative and International Education 45(5), 814-818. https://doi.org/10.10 80/03057925.2015.1074823

Republic of India, 2019, Act No. 45 of 1860, Government of India, New Delhi.

Roland, E. \& Midthassel, U.V., 2012, 'The zero program', special issue: Evidencebased bullying prevention programs for children and youth', New Directions for Youth Development 133(Spring) 29-39. https://doi.org/10.1002/yd.20005

Rossouw, J.P., 2003, 'Learner discipline in South African public schools - A qualitative study', Koers 68(4), 413-435.

Rossouw, J.P., 2007, 'The role of the governing body in school discipline', in R. Joubert \& E. Bray (eds.), Public school governance in South Africa, pp. 79-92, Centre for Education Law, Leadership and Policy, Pretoria.

Sharma, R., Grover, V.L. \& Chaturvedi, S., 2008, 'Risk behaviors related to interpersonal violence among school and college-going adolescents in South Delhi', Indian Journal of Community Medicine 33(2), 85-88. https://doi. org/10.4103/0970-0218.40874 
Sharma, M. \& Marimuthu, P., 2014, 'Prevalence and psychosocial factors of aggression among youth', Indian Journal of Psychological Education 36(1), 48-53. https://doi.org/10.4103/0253-7176.127249

Sinelschikova, S., 2018, Russia beyond: Attacks on Russian schools: Are they similar to the Columbine massacre?, viewed 05 February 2018, from https:// www.rbth.com/lifestyle/327494-attacks-russian-schools-columbine.

Sizova, I.L., 2014, 'The risk of prevalence of violence at Russian schools: Sociological analysis', Social Work 13(1), 28-39. https://doi.org/10.13165/SD-14-13-1-03

Soares, S., 2012, 'Bolsa família, its design, its impacts and possibilities for the future', Institute for Applied Economic Research (IPEA) 89, 1-40.

South Africa, 1996a, The constitution of the Republic of South Africa of 1996, Government Printer, Pretoria.

South Africa, 1996b, South African Schools Act 84 of 1996, Government Printer, Pretoria.

South Africa, 2005, Children's Act 38 of 2005, in Government Gazette 33076, Government Printer, Pretoria.

South Africa, 2008, Child Justice Act 75 of 2008, Government Printer, Pretoria.

South Africa, 2011, Protection from Harassment Act 17 of 2011, in Government Gazette 36357 April 2013, Government Printer, Pretoria.

South Africa, 2018, Prevention and Combating of Hate Crimes and Hate Speech Bill, Government Gazette No. 41543 of 29 March 2018, viewed 14 January 2020, from https://justice.gov.za/legislation/hcbill/B9-2018-HateCrimesBill.pdf.

South African Council for Educators (SACE), 2011, School-based violence report, SACE Policy and Research Division, Pretoria.

South African Council for Educators (SACE), 2018, Annual report 2017/18, viewed 22 August 2019, from https://www.sace.org.za/assets/documents/ uploads/sace_63207-2018-10-15-SACE\%20-\%20Annual\%20Report.pdf.

Spillane-Grieco, E., 2000, 'From parent verbal abuse to teenage physical aggression', Child and Adolescent Social Work Journal 17(6), 411-430.

Sridhar, M., 2019, Corporal punishment: Violation of child rights in schools, Laws in India, viewed 13 September 2019, from https://www.parentcircle.com/ article/corporal-punishment-violation-of-child-rights-in-schools.

Stake, R.E., 1995, The art of case study research, Sage, London.

Statistics South Africa, 2019, Quarterly labour force statistics quarter 2: 2019, viewed 18 August 2019, from http://www.statssa.gov.za/publications/P0211/ P02112ndQuarter2019.pdf.

Stelko-Pereira, A.C. \& Williams, L.C.A., 2016, 'Evaluation of a Brazilian school violence prevention program (Violência Nota Zero Pensamiento Psicológico)', Pensamiento Psicológico 14(1), 63-76. https://doi.org/10.11144 Javerianacali. PPSI14-1.ebsv publicación

Strassberg, Z., Dodge, K.A. \& Pettit, G.S., 1994, 'Spanking in the home and children's subsequent aggression toward kindergarten peers', Development and Psychopathology 6, 445-461. https://doi.org/10.1017/S0954579400006040 
The Moscow Times, 2019, 'Students open fire in school in Siberia, detained by police', 05 February, viewed 16 September 2019, from https://www. themoscowtimes.com/2019/01/25/student-opens-fire-school-siberiadetained-police-a64285.

Ttofi, M.M. \& Farrington, D.P., 2011, 'Effectiveness of school-based programs to reduce bullying: A systemic and meta-analytic review', Journal of Experimental Criminology 7(1), 27-56. https://doi.org/10.1007/s11292-010-9109-1

United Nations Children's Fund (UNICEF), 2017, A familiar face. UNICEF: Monitoring the situation of children and women, viewed 26 November 2019, from https://www.unicef.org/publications/files/Violence_in_the_lives_of_ children_and_adolescents.pdf.

United Nations Development Programme (UNDP), 2016, Human development for everyone: Briefing note for countries on the 2016 human development report, UNDP, viewed 19 September 2019, from http://hdr.undp.org/sites/ default/files/2016_human_development_report.pdf.

Vavilova, A. \& Matveev, V., 2012, 'Violence in schools in the Russian Federation', International Journal for Education Law and Policy (IJELP) 8(2), 171-172.

Walker, M., 2006, Higher education pedagogies: A capabilities approach, Open University Press, Berkshire, viewed 11 November 2019, from https:// philpapers.org/rec/WALHEP.

Wang, H., Veloo, P.K. \& Gurnam, G.S., 2018, 'The incidence of bullying in Beijing middle school', The Turkish Online Journal of Design, Art and Communication Special Edition, 2146-5193.

Winnaar, L., Arends, F. \& Beku, U., 2019, 'Reducing bullying in schools by focussing on school climate and school socio-economic status', South African Journal of Education 38(S1), S1-S10.

World Health Organization (WHO), 2002, World report on violence and health, WHO, Geneva.

World Health Organization (WHO), 2019, Violence and injury prevention: New handbook promotes schools as an ideal setting for violence prevention, viewed 13 November 2019, from https://www.who.int/violence_injury_ prevention/violence/school-based-violence-handbook/en/.

Yin, R.K., 2004, The case study anthology research, Sage, London.

Yin, R.K., 2014, Case study research: Design and methods, Sage, London.

Zwane, W., 1997, 'Restoring the social fabric', Recovery 2(12), 6-12.

\section{Chapter 9}

Brazil, 2019, 'BRICS - Brazil, Russia, India, China, South Africa: What does BRICS do?', viewed 21 October 2019, from http://www.itamaraty.gov.br/en/politicaexterna/mecanismos-inter-regionais/7505-brics-brazil-russia-india-chinasouth-africa. 
BRICS, 2015, Priorities from president of the Russian Federation, viewed 15 April 2018, from http://en.brics2015.ru/.

BRICS, 2016, India 2016, viewed 22 October 2019, from http://brics2016.gov.in/ content/innerpage/8th-summit.php.

BRICS5, 2013a, Fifth BRICS summit, Durban, South Africa, viewed 17 May 2019, from http://www.brics5.co.za.

BRICS5, 2013b, Summit declaration, viewed 12 June 2019, from http://www. brics5.co.za/about-brics/summit-declaration/second-summit/.

BRICS6, 2014, BRICS, viewed 14 June 2019, from http://brics.itamarary.gov.br/.

BRICS7, 2015, Third meeting of the BRICS education ministers: Moscow declaration, 18 November 2015, viewed 28 October 2018, from http:// en.brics2015.ru/documents/.

CNTV, 2011, Full text of the Sanya declaration of the BRICS leaders meeting, viewed 15 May 2019, from http://english.cntv.cn/20110415/103829.shtml.

De Beer, Z.L., 2017, 'The BRICS organisation: Meaning for education provision in the member states', PhD thesis, North-West University.

Frolovskiy, D., 2018, Russian education improves in ranking, but gets more politicked, viewed 07 October 2019, from https://www.thenewfederalist.eu/ russian-education-improves-in-rankings-but-gets-more-politicised.

Global Economy.com, 2018, Education spending percentage of GDP, viewed 15 October 2019, from https://www.theglobaleconomy.com/rankings/ Education_spending/.

G20, 2019, Group of twenty, viewed 18 October 2019, from https://g20.org/en/.

Heritage Foundation, 2019, Brazil: Index of economic freedom, viewed 30 September 2019, from https://www.heritage.org/index/country/brazil.

Lim, S., 2019, Investopedia: Social economics, viewed 30 September 2019, from https://www.investopedia.com/terms/s/social-economics.asp.

Lumen Learning, 2020, Chapter 12: Interpretive research, viewed 13 June 2020, from https://courses.lumenlearning.com/atd-herkimerresearchmethodsforsocialscience/chapter/chapter-12-interpretive-research/.

Mizne, D., 2019, 'Poverty, inequity and the potential of Brazil's public schools', Financial Times, viewed 01 October 2019, from https://www.ft.com/ content/62dfe12a-32e9-11e9-bbOc-42459962a812.

Ngozo, T. \& Mtantato, S., 2018, 'Basic education is failing the economy', The Mail \& Guardian, 23 November, viewed 15 October 2019, from https://mg.co.za/ article/2018-11-23-00-basic-education-is-failing-the-economy/.

O'Neill, J., 2001, Building better global BRICS, viewed 21 October 2019, from http://www.goldmansachs.com/our-thinking/archive/archive-pdfs/buildbetter-brics.pdf.

Organisation for Economic Cooperation and Development (OECD), 2016, PISA results 2015: Excellence and equity in education. Socioeconomic status, student performance and students' attitudes towards 
science, viewed 14 October 2019, from https://www.oecd-ilibrary.org/ docserver/9789264266490-10-en.pdf?expires=1571060556\&id=id\&accname= guest\&checksum=683311477557EC5B51D47943DFOB883F.

Organisation for Economic Cooperation and Development (OECD), 2019a, TALIS 2018 results (volume I): Teachers and school leaders as lifelong learners, TALIS, OECD Publishing, Paris.

Organisation for Economic Cooperation and Development (OECD), 2019b, Education GPS: South Africa, viewed 15 October 2019, from http:// gpseducation.oecd.org/CountryProfile?plotter=h5\&primaryCountry=ZAF\&tre shold $=5$ \&topic $=$ EO.

Organisation for Economic Cooperation and Development (OECD), 2019c, Together, we create better policies for better lives, viewed 05 September 2019, from https://www.oecd.org/about/.

Organisation for Economic Cooperation and Development (OECD), 2019d, Education and skills at the OECD, viewed 12 April 2019, from https://www. oecd.org/education/OECD-Education-and-Skills-Brochure-2019.pdf.

Republic of South Africa (RSA), 2018, The presidency of South Africa. 10th BRICS summit: Johannesburg declaration, viewed 12 May 2019, from http:// www.thepresidency.gov.za/press-statements/10th-brics-summit\%3Ajohannesburg-declaration.

Republic of South Africa (RSA), 2019, Statistics South Africa, viewed 21 October 2019, from http://www.statssa.gov.za/?p=11355.

Russian Federation, 2009, Joint statement of the BRIC countries' leaders, viewed from 22 October 2018, from http://archive.kremlin.ru/eng/text/ docs/2009/06/217963.shtml.

Statlink, 2019, Economic policy reforms: Going for growth country note, viewed 03 October 2019, from https://doi.org/10.1787/888933956434.

Suokes, J., 2017, BRICS revival hangs on economic recovery, viewed 15 February 2019, from https://gbtimes.com/brics-revival-hangs-economic-recovery.

Trines, S., 2018, World education news and review: Education in India, viewed 14 October 2019, from https://wenr.wes.org/2018/09/education-in-india.

World Bank Group, 2018, Learning to realize education's promise, viewed 03 October 2019, from https://openknowledge.worldbank.org/ handle/10986/28340.

World Bank Group, 2019a, Modest growth: Focus on informality. Russian economic report 41, viewed 04 October 2019, from http://documents. worldbank.org/curated/en/332081560895493011/Russia-Economic-ReportModest-Growth-Focus-on-Informality.

World Bank Group, 2019b, Russian Federation: Doing extra-curricular education: Blending traditional and digital activities for equitable learning, viewed 08 October 2019, from http://documents.worldbank.org/curated/ en/341991561976813788/pdf/Russian-Federation-Doing-Extra-CurricularEducation-Blending-Traditional-and-Digital-Activities-for-EquitableLearning.pdf. 
World Bank Group, 2019c, India, viewed 10 October 2019, from http:// documents.worldbank.org/curated/en/243191569332247421/pdf/The-WorldBank-in-India-Newsletter-Vol-18-No-2.pdf.

World Bank Group, 2019d, World Bank in China, viewed 14 October 2019, from https://www.worldbank.org/en/country/china/overview.

Worldometer, 2019, India population, viewed 10 October 2019, from https://www. worldometers.info/world-population/india-population/.

World Trade Organization (WTO), 2017, 9th BRICS summit, viewed 15 June 2019, from https://www.who.int/life-course/news/events/9-brics-summits/en/.

Xinhuanet, 2017, BR/CS 9th summit, viewed 09 May 2019, from http://www. xinhuanet.com/english/special/brics2017/index.htm.

\section{Chapter 10}

Academic Ranking of World Universities (ARWU), 2020, Academic ranking of world universities, viewed 23 August 2020, from http://www.shanghairanking. com/ARWU-Methodology-2019.html.

Altbach, P.G., 2010, 'Global higher education futures: The UNESCO trend report', unpublished paper presented at the 2010 conference of the comparative and international education society, Palmer House Hilton, Chicago, 28th February-5th March.

Altbach, P.G., 2019, 'The coming "China crisis” in global higher education 2019', University World News, 03 April, viewed 22 December 2019, from https:// www.universityworldnews.com/post.php?story=20190403104242366.

Altbach, P.G., Reisberg, L. \& Rumbley, L.E., 2009, Trends in global higher education: Tracking an academic revolution, United Nations Educational, Cultural and Scientific Organization, UNESCO, Paris.

Anthony, R., 2017, 'Is China the new lodestar for African students?', University World News, 07 April, viewed 24 December 2019, from https://www. universityworldnews.com/post.php?story=20170403173146423.

Auf der Heyde, T., 2015, 'PhDs hold key to SA's development', Mail \& Guardian, 09 February, viewed 24 December 2019, from https://mg.co.za/article/201502-09-phds-hold-key-to-sas-development/.

Bennett, R., 2019, 'China tries to gag UK universities: Beijing targets critics on campuses, MPs warn', The Times, 06 November, viewed 24 December 2019, from https://www.thetimes.co.uk/article/academic-freedom-in-uk-at-riskfrom-chinese-interference-say-mps-gzlrp6mrg.

Bergman, H., 1996, 'Quality of education and the demand for education: Evidence from developing countries', International Review of Education 42(6), 581-604. https://doi.org/10.1007/BF00601404

Booyse, J.J., Le Roux, C.S., Seroto, J. \& Wolhuter, C.C., 2011, A history of schooling in South Africa, JL van Schaik, Pretoria. 
Businesstech, 2018a, 'Only one South African university climbed the latest global rankings', Businesstech, 07 June, viewed 24 August 2020, from https:// businesstech.co.za/news/lifestyle/250131/only-one-south-african-universityclimbed-the-latest-global-rankings/.

Businesstech, 2018b, 'South African universities drop down global ranking', Businesstech 15 August, viewed on 24 Augsut 2019, from https:// businesstech.co.za/news/government/264989/south-african-universitiesdrop-down-global-ranking/.

Businesstech, 2019, 'South Africa's university pass rate shocker', Businesstech 13 November, viewed 24 December 2019, from https://businesstech.co.za/news/ government/353575/south-africas-university-pass-rate-shocker/.

Christie, P., 1991, The Right to learn: The struggle for education in South Africa, Ravan, Braamfontein.

Department of Higher Education and Training (DHET), 2018, Statistics on postsecondary education and training in South Africa 2016, Government Printer, Pretoria.

Duggan, S.P., 1916, A student's textbook of history of education, Appleton, New York, NY.

European Organization for Nuclear Research (CERN), 2019, 2017 China R\&D expenditure totalled 1.75 trillion yuan, viewed 25 December 2019, from http:// www.edu.cn/rd/zui_jin_geng_xin/201802/t20180214_1585999.shtml.

Fägerlind, I. \& Saha, L.J., 1984, Education and national development: Comparative perspectives, Pergamon, Oxford.

Friedman, T.L., 2006, The world is flat: A brief history of the twenty-first century, Penguin, Harmondsworth.

Guan, S. \& Ploner, J., 2020, 'The influence of cultural capital and mianzi (face) on mature students' orientation towards higher education in China', Compare: $A$ Journal of Comparative and International Education 50(1), 1-17. https://doi.org /10.1080/03057925.2018.1490999

Gumede, W. \& Dikeni, L., 2009, The poverty of ideas: South African democracy and the retreat of intellectuals, Jacana, Pretoria.

Habermas, J., 1968, Toward a rational society: Student protest, science and politics, Beacon Press, Boston, MA.

Habib, A., 2019, Rebels and rage: Reflecting on \#fees must fall, Jonathan Ball, Jeppestown.

Hui, M.W., Yue, K. \& Pe Symanco, L., 2020, 'Education in China', in H.J. Steyn \& C.C. Wolhuter (eds.), World education systems entering the twenty-first century, Keurkopie, Noordbrug, Forthcoming.

Lenski, G., Nolan, P. \& Lenski, J., 1995, Human societies: An introduction to macrosociology, 7th edn., McGraw-Hill, New York, NY.

Li, F., Wnag, N. \& Hu, X., 2017, 'Distance education and lifelong learning', in W. Morgan, Q. Gu \& F. Li (eds.), Handbook of education in China, pp. 111-123, Edward Elgar, Cheltenham. 
Lei, L., 2018, 'College courses online proving popular: China takes leading role', China Daily 23 April, p. 4.

Liu, N.C. \& Cheng, Y., 2011, 'Global university rankings and their impact', in P.G. Altbach (ed.), pp. 140-155 Leadership for world-class universities: Challenges for developing countries, Routledge, New York, NY.

Maassen, P., 2011, 'Global university reform pressures and diverse national responses', unpublished paper presented at the Conference on higher education reform, East London, 22-24 November.

Makhanya, M., 2020, 'War on education: Glorification of hooliganism is damaging the value and reputation of our tertiary sector', The Natal Witness O3 February, p. 6.

Merriam-Webster Dictionary, 2020, University, viewed 25 December 2019, from https://www.merriam-webster.com/dictionary/university.

Mlamlo, S., 2020, 'Stellies forges ahead with its decolonization drive: University implements 18 academic programmes to keep curricula Afrocentric', Cape Argus 20 February, p. 3.

Mouton, J., Basson, I., Blanckenberg, J., Boshoff, N., Prozesky, H., Redelinghuys, $\mathrm{H}$. et al., 2019, The state of the South African research enterprise, DSTNRF, Centre for Excellence in Scienceomterics and Science, Innovation and Technology Policy, Stellenbosch, viewed 25 December 2019, from http:// wwwO.sun.ac.za/crest/wp-content/uploads/2019/08/state-of-the-SouthAfrican-research-enterprise.pdf.

Mphahlele, M.C.J. \& Mminele, S.P.P., 1997, Education through the ages, part 3, Kagiso, Pretoria.

Nakkazi, E., 2018, 'China ramps up support for African higher education', University World News, 07 September, viewed 25 December 2019, from https://www.universityworldnews.com/post.php?story=20180907083412817.

Organisation of Economic Cooperation and Development (OECD), 2018, A broken elevator? How to promote social mobility, viewed 25 December 2019, from http://www.oecd.org/social/broken-elevator-how-to-promote-socialmobility-9789264301085-en.htm.

Parelius, R.J. \& Parelius, A.P., 1987, The sociology of education, Prentice-Hall, Englewood Cliffs, NJ.

Pauw, J.R., 1975, Die westerse universiteit: Sy ontstaan, aard en toekoms, De Jong, Johannesburg.

Quacquarelli Symonds (QS), 2018, QS university rankings methodology, viewed 25 December 2019, from https://www.topuniversities.com/qs-worlduniversity-rankings/methodology.

Quacquarelli Symonds (QS), 2020, 2020 university rankings, viewed 25 December 2019, from https://www.topuniversities.com/university-rankings/ world-university-rankings/2020.

Reay, D., Crozier, G. \& Clayton, R., 2009, 'Strangers in paradise'? Workingclass students in elite universities', Sociology 43(6), 1103-1121. https://doi. org/10.1177/0038038509345700 
Ryan, J., 2019, Education in China, Polity, Cambridge.

Schultz, T., 1961, 'Investing in human capital', American Economic Review 4(1), $1-20$.

Schwab, K., 2016, The fourth industrial revolution, Penguin, London.

Shin, J.C.D., Toutkoushian, R.K. \& Teichler, U. (eds.), 2011, University rankings: Theoretical basis, methodology and impacts on global higher education, Springer, Dordrecht.

Sobel, I., 1982, 'The human capital revolution in economic thinking', in P.G. Altbach, R.F. Arnove \& G.P. Kelly (eds.), Comparative education, pp. 54-77, McGraw-Hill, New York, NY.

Steyn, H.J., Wolhuter, C.C., Vos, D., De Beer, L. \& Caanen-Ivanicki, A., 2018, 'A "road and belt" for South African researchers in education to be involved in impact-making research', in C. Wolhuter (ed.), Raising the impact of education research in Africa, pp. 285-308, AOSIS, Cape Town.

Swartz, S., Mahali, A., Moletsane, R., Arogundade, E., Khalema, N.E., Cooper, A. et al., 2018, Studying while black: Race, education and emancipation in South African universities, Human Sciences Research Council, Pretoria.

Times Higher Education (THE), 2020, Times higher education university rankings methodology, viewed 20 August 2020, from https://www. timeshighereducation.com/world-university-rankings/world-universityrankings-2020-methodology.

UK Parliament, 2019, Defending democracy in an age of autocracies, viewed 25 December 2019, from https://publications.parliament.uk/pa/cm201919/ cmselect/cmfaff/109/10902.htm.

United Nations Educational Scientific and Cultural Organization (UNESCO), 1971, UNESCO statistical yearbook 1971, UNESCO, Paris.

United Nations Educational Scientific and Cultural Organization (UNESCO), 2020, Statistics, viewed 25 August 2020, from http://data.uis.unesco.org/.

Ward, K., 2003, Faculty service roles and the scholarship of engagement, ASHEERIC Higher Education Report, vol. 29, Jossey Bass, San Francisco, CA.

Weeks, S., Herman, H., Maarman, R. \& Wolhuter, C., 2006, 'SACHES and comparative, international and development education in Southern Africa: The challenges and future prospects', Southern African Review of Education 12(2), 5-20.

Wolhuter, C.C., 1998, 'Spektroskopie van die Suid-Afrikaanse onderwysstelsel binne die internasionale ry van onderwysstelsels [Spectroscopy of the South African education system within the international line of education systems]', Suid-Afrikaanse Tydskrif vir Opvoedkunde 18(1), 9-19.

Wolhuter, C.C., 1999, 'Sociaal-wetenschappelijke literatuur over onderwijs in Zuid-Afrika: van verzuilen tot eensgezindheid vanuit verscheidenheid [Social science literature on education in South Africa: from pillarization to unity based on diversity]', Pedagogische Studiën (the Netherlands) 76, 361-370. 
Wolhuter, C.C., 2008, 'Review of the review: Constructing the identity of comparative education', Research in Comparative and International Education 3(4), 323-344. https://doi.org/10.2304/rcie.2008.3.4.323

Wolhuter, C.C., 2009, 'The transformation of higher education in South Africa since 1994: Achievements and challenges', Higher Education Forum (Japan) 6, 59-72.

Wolhuter, C.C., 2011, 'Die wêreldrevolusie in die hoër onderwys en die verrekening daarvan binne die Suid-Afrikaanse konteks [The global revolution in higher education and its set-off within the South African context]', Litnet Akademies 8(3), 95-121.

Wolhuter, C.C., 2014, 'Weaknesses of South African education in the mirror image of international educational development', South African Journal of Education 34(2), 1-9. https://doi.org/10.15700/201412071120

Wolhuter, C.C., 2015, 'The scholarly impact of doctoral research conducted in the field of education in South Africa', South African Journal of Education 35(3), 1-13. https://doi.org/10.15700/saje.v35n3a1090

Wolhuter, C.C., 2017, 'The geography of authorship regarding research in education', Croatian Journal of Education 19(3), 981-1000. https://doi. org/10.15516/cje.v19i3.2207

Wolhuter, C.C., (Forthcoming), 'The stellar rise of the international education expansion project taking shape in the early twenty-first century', in H.J. Steyn \& C.C. Wolhuter (eds.), World education systems entering the twenty-first century, Keurkopie, Noordbrug.

Wolhuter, C.C., Higgs, P., Higgs, L.G. \& Ntshoe, I., 2010, 'How affluent is the South African higher education sector and how strong is the academic profession in the changing international academic landscape?', South African Journal of Higher Education 24(1), 196-213. https://doi.org/10.4314/ sajhe.v24i1.63437

Wolhuter, C., Higgs, P., Higgs, L. \& Ntshoe, I., 2011, 'South Africa: Recklessly incapacitated by a fifth column - The academic profession facing institutional governance', in W. Locke, W.K. Cummings \& D. Fisher (eds.), Changing governance and management in higher education: The perspectives of the academy, pp. 107-125, Springer, Dordrecht.

Wolhuter, C.C., Janmaat, G-J., Van der Walt, J.L. \& Potgieter, F.J., (Forthcoming), 'The role of the school in inculcating citizenship values in South Africa: Theoretical and international comparative perspectives', South African Journal of Education 40(4), forthcoming.

Wolhuter, C.C. \& Mushaandja, J., 2015, 'Contesting ideas of a university: The case of South Africa', Humanities 2015(4), 212-223. https://doi.org/10.3390/ h4020212

Wolhuter, C.C., Naidoo, K., Sutherland, L. \& Peckham, G., 2004, 'Description of a course in research management at a university in New Zealand: A model for the South Afrian scene', Southern African Review of Education 9/10, 2003/2004, 69-76. 
Wolhuter, C.C. \& Van der Walt, J.L., 2019, 'Neo-liberalism and the human rights creed: Conflicting forces vying for control of the global education agenda', South African Journal of Education 39(4), 1-9. https://doi.org/10.15700/saje. v39n4a1834

Wolhuter, C.C. \& Van der Walt, J.L., (Forthcoming), 'Student activism in South Africa (2015-2016) and the status of Afrikaans as a university language medium: A preliminary analysis and explanation', in V. Stead (ed.), Toward abolishing white supremacy in higher education, Peter Lang, New York, NY. 


\section{Index}

A

accept, 106, 251

acceptance, 164, 177, 205

Africa, 1-4, 11-21, 24-31, 37-46, 48, 50, 52-57, 59-61, 65, 88-105, 109-120, 122, 124, 126, 128, 130, 132, 134-137, 139-141, 151, 160-173, 175-177, 180, 194-197, 202, 210, 213-216, 220-223, 237-242, 245-246, 248-256, 258-260, 263-265, 267-268, 270-273, 275-276, 280, 287, 296-298, 301, 303, 305-308, 310, 312, 314, 316, $318,320,322-332$

African, 1-4, 6, 8, 10-24, 26-32, 37, $43,45-46,48,53,56,59,61$, 89-90, 94, 97, 101, 104, 109-111, 116-117, 119-121, 137, 139, 145, 151, 163-164, 175, 183, 194, 196-198, 213-215, 222, 239-241, 244, 246, 248-249, 252, 254, 257, 260, 264-265, 267-268, 297-298, 301-302, 305-308, 323-332 age, $6,8,10,12-14,16-17,21,61-65$, 72-73, 76-86, 95, 97-98, 103, $143,178,229,255,260,262$, 289, 293, 316

Asia, 131, 283

attitude, 105, 121, 143, 147, 199

awareness, 74, 151, 156, 159, 172-173, 244, 262-264

\section{B}

belt and road, 306, 331-332

Brazil, 3, 30-31, 40-47, 50, 52, 54-56, 60-61, 65, 82-88, 98-104, 176-177, 202, 209-210, 214, 242, 245, 248-249, 255-258, 263, 268, 270-274, 276, 282-283, 288-290, 299, 303, 325
BRICS countries, 1-3, 28-32, 34, 36, $38,40-46,48,50,52,54-57$, 59-60, 109, 139, 141, 175-176, 210, 213, 223, 241-242, 244-250, 252, 254, 256, 258, 260-265, 267, 277, 286, 303, 305

BRICS educational aims, 268, 285 BRICS, 1-3, 28-32, 34, 36, 38-46, 48-50, 52-57, 59-60, 109, 111, 139, 141, 175-177, 193, 210-211, 213-215, 223, 241-242, 244-250, 252, 254, 256, 258, 260-265, 267-268, 270-272, 274-288, 290, 292, 294, 296-300, 302-305, 331

bullying, 242-245, 248-250, 252-255, 257, 260-265

business, 23, 55, 114, 120, 221, 226 , 274, 286, 300

C

care, 2, 11, 31, 61-65, 70, 74, 77-78, 83, 85, 87-89, 93-96, 98, 104-106, $128,259,301$

challenges, 2-3, 18, 25, 27-28, 30-32, 46, 60-61, 66, 70, 72-73, 86-88, 91, 98-99, 103, 106-107, 125, 127, 141, 150-152, 156-158, 164, 167-173, 176, 188, 191-192, 194, 198, 200, 203, 209-210, 246, 262, 269, 280, 293, 295, 305, 314, 326-327, 329

change, 38, 44, 110, 116-117, 130, 133, $183,204,222,224,228,234$, 236, 265, 273, 275, 280, 292

character, 5, 313

characteristics, 140, 144, 177-178, $180-181,185,187,192,287$

child, 11-12, 61-62, 64, 72-79, 81, 83-85, 88-90, 97, 99-100, 102, 105-107, 183-185, 224, 254-255, 259, 261, 287-288, 297 
children, 11-12, 15-16, 50, 60, 62-66, 68-79, 81-89, 91-101, 103-106, 115-116, 127, 133-134, 183-185, 188, 191, 196-197, 218-219, 224, 228-229, 231, 234, 242-244, 248-249, 254-259, 261, 264, 277, 287-288, 292-293, 298, 301

China, 2-3, 30-31, 40-45, 51-56, 60-61, 65-74, 98-105, 111, 124, 131-132, 137, 176-177, 202-208, 213-216, 218-220, 222-240, 242, 245, 248-249, 255, 261, 263-264, 268, 270-272, 275, 278-279, 282, 293-296, 301, 303, 305-308, 310, 312, 314, $316-324,326-328,330-332$ collaboration, 94, 100, 140, 145, 166, 172-174, 268, 271, 278, 280, 285-286, 292, 332

community, 6, 10, 43, 48-49, 95-96, 99, 104, 115-117, 141, 155, 168, 172, 176-177, 180, 183, 186-190, 194, 203-204, 219, 226, 232, 235, 239, 245, 247, 250, 257-259, 263, 265, 273, 287, 314

Comparative and International

Education, 1-2, 6, 13, 29-30, 41, 54-55, 109, 112, 139, 175, 213-214, 223, 241, 267, 305-306, 321

comparative education, 31-39, 49, 111, 321

concept, 4-6, 93, 144, 150, 178-179, 195, 306-307, 315

context, 3, 6, 13, 21, 30, 34-35, 38-40, $43,48,56,71,74,81,85,90,96$, 99, 110-111, 121, 132, 134, 137, 160, 184, 191-192, 205, 210, 214-215, $218,223,232,239,247-248$, $265,308,313,324,329$

contextual, 3, 7-8, 11, 16-18, 23, 30, 32-33, 35, 37-39, 46, 112-113, $137,223,230-231,239,331$

court, 197, 199, 222, 224

create, 2, 7, 44, 56, 60, 119, 131-132, 199, 201, 246, 253, 262-263, 286, 307

creating, $5,14,20,64,68,87,103,166$, 252, 256, 287 culture, 2, 4-5, 14, 17, 24-25, 45, 50, 71, 116, 176, 179-180, 185-186, 189-190, 192, 195-200, 203, 207, 209-211, 226, 231, 250, 263, 275, 282-283, 295, 314

\section{D}

defined, 33, 84, 99, 102, 142, 178, 181, 187, 195, 276, 284, 291

democracy, 2, 5, 14, 25, 45, 118, $125-126,129,194,273,310$

design, 36, 240, 265

develop, 71, 94, 98, 110, 118-119, 124, 129-130, 136, 159, 161, 168, 177-178, 181, 183, 194, 207, 222, 240, 244, 264-265, 270, 284 , $301,328,330$

developing, 39, 56, 60-61, 66, 90, 94, 145, 150-152, 157, 160, 208, 245-246, 264, 268, 270-271, 274, 276, 280, 292-293, 295, 299, 304 development, 2, 4, 6-7, 9-11, 21, 24, 39-40, 47, 50-51, 59-71, 74-79, 81, 84-95, 97-106, 109-110, 114, 118-119, 123, 130, 132, 140-143, 146-148, 151-156, 158-161, 164, 167-168, 172-174, 181-182, 184-186, 199, 201, 204-208, 216, 220, 222-223, 235, 237-239, 267, 269-270, 273-278, 280-288, 292, 294-295, 298-299, 301, 303, 306, 309-312, 315, 318-319, 321, 328

dignity, 25, 177, 200, 254, 264 diversity, 1-2, 28-30, 43, 52, 60-61, 103, 109-111, 113, 136, 139, 175, 197-198, 203, 213-214, 217, 241, 250, 253, 264, 267, 296, 305 doctoral education, 51, 306, 327

E economic growth, 7, 18, 21-22, 34-35, 44, 46, 55, 131, 224, 246, 271, 284, 287, 291, 293-297, 300 economic, 5-7, 14-16, 18, 21-24, 26, 30, $33-35,39,41,44,46-48,53,55$, 57, 60, 62, 64-66, 69, 75-76, 
78-79, 82, 87, 89, 98, 106-107, $114-115,118,121,123,131,136$, 140-141, 173, 179, 201, 204-205, 217, 221, 224, 228, 233-234, 244, 246-247, 249, 256, 263, 265, 267-271, 273-275, 277-281, 283-284, 287-291, 293-300, 303-304, 306, 310-312, 317, 324 educate, 70, 85, 195 education quality, 1-2, 4, 18, 315 education, 1-41, 44, 46-57, 59-106, 109-137, 139-146, 148-172, 174-178, 182-211, 213-232, 234-242, 244, 246, 248, 250-252, 254, 256-260, 262, 264, 267-270, 273, 276-277, 282-302, 304-313, 315-321, 323-327, 329-332

emerging countries, 30, 55-57 environment, 4, 42, 64, 147, 156, 162-163, 167, 201, 243-245, 251, 262, 274, 291, 317

ethical, 64, 99, 227, 312

ethics, 227, 264

Europe, 39, 49, 51, 116, 132, 181, 283, 311, 323

exclusion, 116, 184, 196, 249, 256, 274

\section{$\mathbf{F}$}

families, 7, 11, 15-16, 50, 60-61, 64-65, 74, 84, 87, 95-96, 104-105, 203, 251-252, 255, 257, 259, 269, 298 family, 4, 12, 57, 64, 69, 71-72, 83, 89, 100-101, 103, 224, 242, 244-245, 250-251, 257, 263, 274

father, 16, 252

fear, 26, 70, 124, 243, 256, 314 formation, 9, 30, 89, 123, 254, 309 formulation, 8, 51, 79, 144, 154, 162 fourth industrial revolution, 281-282, 299, 306, 311-312, 314, 319, 330

\section{G}

generation, 23, 226, 319

globalisation, 21, 204, 217, 308, 316 goods, 76, 131-132

governance, 10, 143-144, 154, 161, 167-169, 190, 227, 273, 282, 297, 313,329 government, $2,10,13,15,20,27,48$, $50,53,61-64,68,71,73-74$, 76-80, 82-97, 99, 101-102, 104, 106, 110, 116-117, 119-120, 123-124, 132-134, 136-137, 140-141, 146-149, 153-156, 158-162, 164, 167, 169-170, 182, 187-188, 199, 202, 204, 208-209, 222-227, 229, 231, 236-237, 248, 258-261, 263, 271, 277, 294, 298, 307$308,314,321,324,329-331$ growth, 6-7, 12, 18, 21-22, 25, 34-35, 41-44, 46, 55, 63, 66, 68, 76-77, 79, 124, 131-134, 159-160, 164, 223-224, 246, 271, 276-278, 280-281, 284, 287, 289, 291-297, 300-301, 309-310, 318, 327

H

holistic, 62-64, 78, 81, 86, 88, 93, 98, 102

human rights, $1-2,8,10,14,29,45$, $48,51,109,115,118,139,175-177$, 182, 184-185, 198, 209-210, 213, $216,221,241,244-245,253,264$, 267, 305, 309-310, 314

human, 1-2, 6, 8-10, 14, 25, 29, 45, 48, $51,62,76,78-79,98,109,115$, $118,121,139,154-156,175-177$, 182, 184-185, 198, 209-210, 213, 216, 221, 241, 244-245, 253, 264, 267, 270, 284, 286-287, 305, 309-310, 314, 321

humanity, 6, 9, 116, 194

\section{I}

identity, 32, 125, 134, 181-184, 188, 235 immersion programmes, 214, 219, 240 implementation, 69, 88, 90-91, 98, 104-105, 119, 144, 147, 154-155, $162,167,169-170,173,188,195$, 204, 206, 273, 278, 281, 284 , 290, 317

implications of, 181, 186, 306-307 importance, 11, 23, 51, 60, 62, 75, 77, $90,93,98,111,173,193,200-201$, 205, 215, 228, 274, 276, 278, 286, 292, 302, 304, 312, 314, 319 
inclusion, 79, 90, 284

inclusive, 55, 92-93, 197, 201, 273, 276-278, 280-281, 293

independence, 46, 49, 75, 77, 110-111, 117, 122-123, 126, 128, 136, 147, 309

India, 3, 30-31, 40-45, 49-52, 54-56, 60-61, 64-65, 74-82, 98-104, 109-114, 116, 118, 120-128, 130-137, 139-141, 152-159, 168-173, 176-177, 200-203, $210,214,216,220,222,242$, 245, 248-249, 255, 260-261, 263, 268, 270-272, 274-275, 277, 281-282, 293-294, 300-301, 303

inequality, 6, 14-16, 20, 24, 43-44, 48, 204, 251, 256, 295, 298, 324

influence, 7-8, 66, 99, 128, 173, 226-227, 279, 287, 314, 317

initiative, 93, 160, 290, 294-295, 299, 302, 306, 321

instruction, 13, 119-121, 123, 125-128, 130-131, 133-136, 150, 199, 221-223, 233-234, 240, 286

interests, 53, 64, 76, 128, 174, 179, 201, $277,280,282,332$

international education, 1-2, 6, 13, 29-30, 41, 54-55, 109, 112, 139, 175-176, 213-214, 223, 241, 267, 291, 305-306, 321

interpretation, 112, 246

investigation, 54, 72, 140-141, 290

\section{J}

justice, 25, 75, 92-93, 118, 182-183, 200, 254-255, 290, 299

\section{K}

knowledge society, 21, 306, 311

\section{$\mathbf{L}$}

language and education, 2, 124 Language of Learning and Teaching, 2, 109-124, 126, 128-130, 132-137, 192, 197, 213-218, 220-223, 232, 234, 236-237, 239 language, 2, 7, 10, 13, 16-17, 26, 43, 45, 50, 57, 64, 85, 98, 103, 109-137, 179-180, 182, 184, 186, 188, 190, 192-193, 195-200, 202-203, 208, 213-227, 230-240, 287, 300

laws, 32-34, 66-67, 76-77, 90, 92, 99-100, 105, 119, 194-195, 260, 270

leadership, 4, 84

learners, 2, 4-5, 7-8, 12-13, 15, 22, 39, 47, 50, 109, 120-121, 137, 142-143, 147, 152, 157, 161, 168, 174, 185-186, 188-193, 197 , 219, 231-235, 237-238, 240, 242-244, 248-265, 269, 284, 289-292, 294-296, 298-299, 301-302

legislation, 68, 77, 88, 119, 176, 194-195, 198-199, 209-210, 229, 254-255, 257, 264-265, 324

liberal, 19, 21-23, 45-47, 50, 123, 136, 313

M

marginalisation, 115, 120, 190

media, 191, 198, 244, 246-248, 252, 258-259, 262, 307

minority groups, 175-178, 180, 182-194, 196-200, 202-206, 208, 210, 225, 230, 235-236

minority rights, 176, 181-182, 193, 198, 202, 210-211

mission, 8, 160, 201, 235-236, 312, 315, 329-330

moral, 25, 185, 262, 264

motivation, 79, 111, 269, 287

multilingual education, 214, 237, 240

N

National Development Plan, 51, 104, $160,319,328$

need, 30, 61, 72, 85, 87, 103, 106-107, $119,130-132,147,149,161-162$, 195, 211, 244, 246, 251, 253-254, 263-265, 269, 278, 284, 286, 290, 296, 326 
needs, 18, 31, 35, 62-63, 71, 74, 76, 78, $80,87,98,101,103,105-106,122$, $125,134,142-143,146,151,153$, 156, 165, 174-178, 180, 182-192, 194, 196, 198, 200, 202, 204, 206-208, 210, 236, 253, 256, 258, 284, 288, 290, 299, 301 network, 167, 276, 282, 287, 320

o

objectives, $8,14,24-25,117,130$, 194, 216, 267-270, 272, 274, 276, 278, 280, 282-288, 290, 292, 294, 296-298, 300, 302, 304,324

\section{$\mathbf{P}$}

paradigm, 99, 106, 220, 270, 273, 311 parent, 74, 98, 196, 252, 259, 297 parents, 69, 72, 78, 87, 96-97, 106, $133-135,173,184-185,190,196$, 213, 219, 232, 254, 259, 263, 269

participation, 4, 10, 15, 46, 132, 143, 146, 173, 204-205, 278, 280-281, 314, 325-326

peace, 25, 118, 194, 277-278, 280 people, 6-8, 14, 16-21, 24-25, 33, 42-43, 51-52, 71-73, 76, 78, 85, 116-118, 122-128, 130-133, 136, 142, 149-151, 153, 160, 178-180, 182-183, 185, 198-199, 203, 208, 210, 217-218, 220, 225, 232, 242-243, 245, 251-252, 254, 257, 259, 271, 274, 282, 289, 291-293, 295, 298, 301, 303, 307, 311, 318, 322, 324, 326

philosophy, 42, 45-46, 75, 80, 179 politics, 6, 24, 44, 55, 115, 179, 221 poor, 13, 16, 42, 64, 70, 75, 79, 83, 87, 89, 101, 105, 116, 151-152, $166,218,243-244,249-251$, 256-259, 261, 274, 289-290, 293, 298, 301, 303

poverty, 11-12, 24, 46-47, 50, 60-61, 64-65, 73, 118, 161, 204-205, 251, 256, 269, 274, 287-291, 293, 295-297, 299 power, 10, 19, 40-41, 52, 103, 114-115, $117,178,195,217,221,250,261$, 330

process, 4, 8, 48-49, 54, 77, 87-88, 99, 103-104, 106, 126-127, 129, 145-147, 149, 188, 209, 216, 247-248, 269, 281, 284, 289, 313,315

protection, 11, 62-63, 75-77, 79, 83, 87-88, 93, 95-96, 100, 105-106, 181, 184-185, 194, 198, 201, 209, 253-255, 264, 301

purpose, 35, 52, 81, 93-94, 110, 116, 121, $145,312-314$

\section{$\mathbf{R}$}

recognition, 80, 83, 177, 180-181, 186, 188, 192-194, 230, 239, 285, 292 relation, 204, 233

relationship, 63, 218, 227

research, 1, 9-10, 12-13, 15-16, 22, 26-27, 29-30, 33, 35-37, 54, 56-57, 64, 72, 106, 109, 111-112, 120-121, 139-141, 147, 175-178, 195, 211, 213-214, 216, 218, 222, 233, 241, 246-248, 253, 265, 267-268, 270, 281-282, 285-286, 292, 299, 305, 308, 312-317, 319, 321, 327-328, 332

resources, 23, 42, 46, 54, 76, 79, 89, $93,96,105,116,121,145,161,192$, 202, 209, 217, 221, 228, 235 , 244-245, 251, 270-271, 273, 286, 291, 296, 301, 303, 321 responsibilities, 71, 76-77, 87, 97, 99, 103-104, 161, 167, 170, 257

responsibility, $25,65,75,84,88$, 144-145, 155, 166-167, 186, 206, 258-259, 281-282, 302

rights, $1-2,8,10,14,29,45,48,51$, 75-77, 79, 89, 93, 100, 109, 115, 118-119, 125, 139, 175-177, 180-186, 192-196, 198-202, 204-205, 208-211, 213, 216, 221, 241, 244-245, 251, 253-254, 257, 261, 264, 267, 305, 309-310, 314 risk, 12, 257, 281 
Russia, 3, 13, 30-31, 38, 40-45, 48-49, $51-53,55-56,60,176-177$, 198-200, 202, 214, 242, 245, 249, 255, 258-260, 263-264, 268, 270-273, 277, 282, 291-292, 300, 303

\section{S}

school, 3-5, 8, 11-12, 15-17, 20, 39, 46-47, 49, 52, 59-60, 63-64, 70-73, 75, 77, 81-82, 84-87, 96-97, 103-105, 109, 114, 116-117, 119, 121, 123, 125 , 128-131, 133, 139, 149, 153, 157, 162-166, 168, 171, 189-190, 192, 194, 196-197, 202, 207, 218-219, 221, 227-235, 238-240, 242-247, 249-255, 257-265, 289, 298, 302, 318-319, 325

schools, 4, 8, 12-17, 20, 50, 52, 63, 66, 74-75, 81, 89, 96, 99, 101, 115-117, $119-122,126,129,133-135,148$, 154-155, 176, 184-185, 189, 192, 196, 202, 207-208, 210, 218, 226-237, 239-247, 249-265, 269, 287, 289-291, 294, 299-302, 324-325

services, 7, 10-11, 60, 64, 68-74, 76-78, 81-83, 86-89, 91, 93-97, 99-106, 131-132, 147, 191-193, 224, 296, 301-303, 311, 313-314

societies, $8,21,30-31,44,64,152$, 187-188, 193, 198, 205, 217, 222, 238, 246, 284, 311, 314

society, 1-2, 7-8, 10, 14-17, 19, 21, 24-25, 30-31, 33-35, 39, 43-44, 50, 63-64, 79-82, 85, 115, 118, 123, 130, 136, 151, 153, 168, 171, 178-180, 182-188, 191-192, 198, 207, 209, 217, 226-227, 231, 241, 248, 251, 255, 264, 291-292, 296-297, 306, 308-315, 328-330

socio-economic, 6, 14-16, 60, 65, 75, 82, 87, 89, 107, 115, 140-141, $217,224,233,244,247,256$, 263, 265, 268-270, 287-291, 295-296, 299, 324 solidarity, 48, 178

South Africa, 1-4, 11-21, 24-31, 37-46, 48, 50, 52-57, 59-61, 65, 88-105, 109-120, 122, 124, 126, 128, 130, 132, 134-137, 139-141, 160-173, 175-177, 180, 194-197, 202, 210, 213-216, 220, 222-223, 237-242, 245-246, 248-256, 258-260, 263-265, 267-268, 270-273, 275-276, 280, 287, 296-298, 301, 303, 305-308, 310, 312, $314,316,318,320,322-33$

space, 48, 60, 114, 129, 177, 221 spaces, 244, 256, 263 status, 14, 16, 70, 115, 118-119, 155, 157, 159, 169, 171-172, 199-201, 204, 229, 233, 263, 270, 274-275, 287-288, 292, 296, 299, 303-304, 317, 330

\section{T}

teach, 129-130, 234

tertium comparationis, 2, 30, 35, 37, $111,214,223,242$

transformation, 21-22, 173, 273, 297, 301 trust, 55, 155

V

value, $10,21,25,30,36,39,65,110,118$, $128,135,140-141,169,174,205$, 207, 214, 235, 298, 308, 311-312, 331

values, 5, 7-8, 14, 25, 43, 45, 53, 71, 140-143, 145, 152, 178-179, 183, 190-191, 264, 284, 291, 310

violence, 17, 82, 181, 241-265 vocational education, 139-146, 148-155, 157, 159-163, 165, 168-172, 285-286, 292, 300

\footnotetext{
W

workplace, 141, 147, 150, 159-160, 162-163, 168, 288, 292

written, 114, 203, 207, 220-221, 224 , 232, 319
} 
The book is a significant contribution to the scientific discourse on education. It provides rich information and data that researchers, academics and professionals, education planners and policy makers will find beneficial in their different areas of work. More important, the book provides a springboard for researchers in Comparative Education to identify areas that need further research development.

\section{Prof. Dr Ntlantla Sebele, Open Distance Learning, University of the Free State, Bloemfontein, South Africa}

This is a very brilliant book topic. The book researches different aspects of education, including the way in which it is offered or provided from Early Childhood Development to tertiary education by all BRICS member states and the usage of medium(s) of instruction. Most chapters gave a number of population per BRICS member state. There are also percentages of economic trends and variations. Studying the provision of education from early childhood to tertiary education and medium (language) of instruction gives lessons learnt from different countries covers all BRICS countries. The number of publications in Comparative and International Education in BRICS member states have roused considerable interest. How much work has been done and how far research should go is a challenge to all Comparative and International scholars.

\section{Prof. Dr Takalani S. Mashau, Educational Management, University of Venda, Makhado, Limpopo, South Africa}

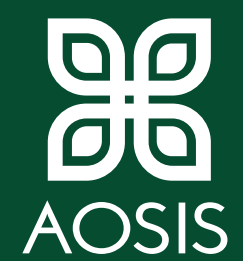

aosis.co.za

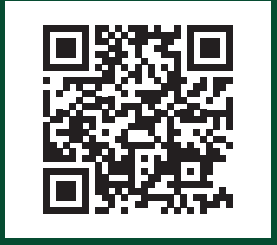

Open access at https://doi.org/10.4102/ aosis.2020.BK207

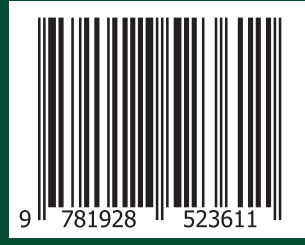

ISBN: 978-1-928523-61-1 